\title{
EFFECTS OF PCM THERMAL PROPERTIES AND THERMODIODE PANEL (TDP) ON BUILDINGS' ENERGY DEMAND AND INDOOR TEMPERATURE
}

by

\begin{abstract}
Mohammad Ebrahim Poulad
Bachelor of Applied Science (Materials Sciences Engineering), Shiraz University (Iran), 1988

Master of Applied Science (Mechanical Engineering), Ryerson University (Canada), 2009
\end{abstract}

\author{
Dissertation \\ presented to Ryerson University \\ in partial fulfillment of the degree of \\ Doctor of Philosophy \\ In the program of \\ Mechanical Engineering
}

Toronto, Ontario, Canada, 2014

CM.E. Poulad 2014 


\section{AUTHOR'S DECLARATION}

I hereby declare that I am the sole author of this dissertation. This is a true copy of the dissertation, including any required final revisions, as accepted by my examiners.

I authorize Ryerson University to lend this thesis to other institutions or individuals for the purpose of scholarly research.

I further authorize Ryerson University to reproduce this thesis by photocopying or by other means, at the request of other institutions or individuals for the purpose of scholarly research.

I understand that my dissertation may be made electronically available to the public. 


\title{
EFFECTS OF PCM THERMAL PROPERTIES AND THERMODIODE PANEL (TDP) ON BUILDINGS' ENERGY DEMAND AND INDOOR TEMPERATURE
}

\author{
Mohammad Ebrahim Poulad \\ Doctor of Philosophy \\ Department of Mechanical \& Industrial Engineering \\ Ryerson University, Toronto, Ontario, Canada, 2014
}

\begin{abstract}
The performance of a thermodiode panel (TDP) is investigated thoroughly. A phase change material (PCM) layer is integrated into the TDP. A TDP can transfer solar thermal energy into the building. Adding a PCM layer to the TDP adds capacity of storing solar energy into the TDP, and releases the stored energy when the sun goes down. The TDP is composed of dense foam, which is sandwiched between two aluminium sheets, and a thermosyphon passes through the foam layer. PCM layer is added to the condenser section of the TDP that is connected into the building envelope.

PCM thermal properties and their effects on energy demand and indoor temperature are investigated on a typical building. The best melting point for the PCM was found to be a temperature in the middle of the set points (upper and lower). Quantitative indices are introduced to evaluate the effects of PCM on indoor air temperature fluctuations. PCM reduces the indoor air temperature fluctuations. Increasing thermal conductivity of PCM by an order of magnitude reduces about $2 \%$ annual energy demand of a building. Regarding convention heat transfer coefficient, by increasing the convective heat transfer coefficient at interior wall surface, the cooling demand slightly increases in summer. In winter, energy demand is sensitive to h-value with a positive correlation.

Matlab codes developed using genetic algorithm to optimize the TDP sizes, i.e., thicknesses of three aluminium sheets, copper tube diameter and its thickness that makes the structure of thermosyphon. The
\end{abstract}


optimum sizes found to be: plate thicknesses of $1.5 \mathrm{~mm}, 2.5 \mathrm{~mm}$, and $2 \mathrm{~mm}$ and thermosyphon diameter and thickness of $32 \mathrm{~mm}$ and $9 \mathrm{~mm}$, respectively, provide the maximum objective function (the best performance of the TDP). Thermal bridging of a TDP can be reduced 76 times by adding a piece of Teflon in the thermosyphon assembly. The integration can do both store and collect/gain solar thermal energy, which makes this panel a novel alternative for south walls. It is also shown that thermosyphon angle from the horizon shall be between 30 and 45 degree to have the best performance of the TDP. 


\section{ACKNOWLEDGEMENTS}

I would like to thank Drs. Alan Fung, David Naylor, and Wey Leong for their directions and invaluable advice throughout this project. Without their guidance and technical help, it was impossible to finish this dissertation successfully.

I would also like to thank technical officers Roy Churaman, Alan Machin, Devin Ostrum, Andrew Heim, and Joseph Amankrah for their help to make all tools and help setup/provide all experimental equipment.

I would also like to thank the Smart Net-Zero Energy Buildings Research Network (SNEBRN) under the Strategic Network Grants Program of the Natural Sciences and Engineering Research Council (NSERC) of Canada for funding this project.

I would like to thank my friends for their support of my studying. Special thanks to students who worked on this project during summer times: Saman Shaban-Nejad, Meijian Lee, Sylvain Lefrene, Yannick Lidove, and Adrien Gillot. 
This work is dedicated to my sons and my mom. 


\section{TABLE OF CONTENTS}

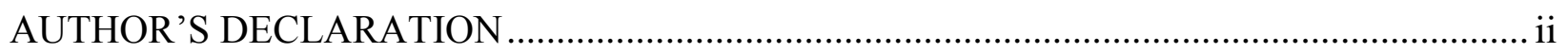

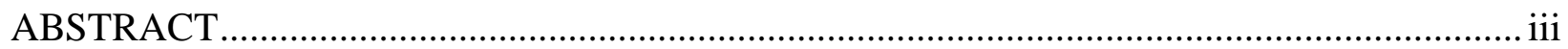

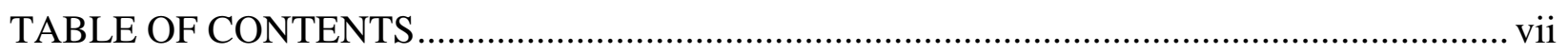

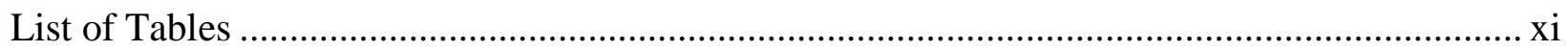

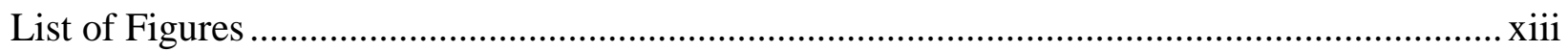

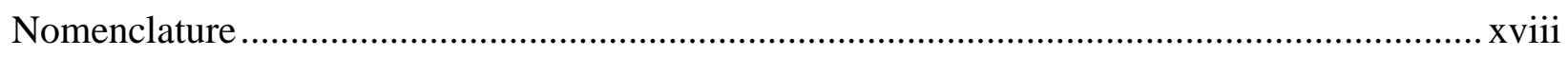

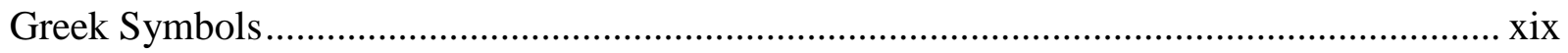

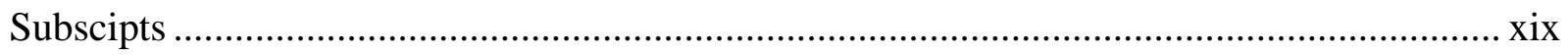

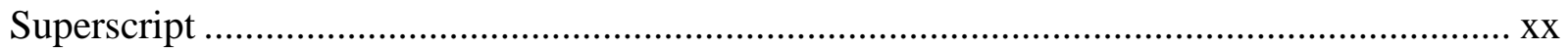

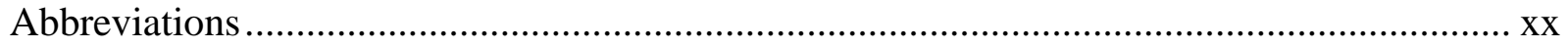

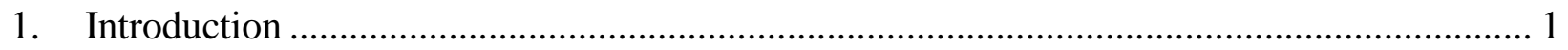

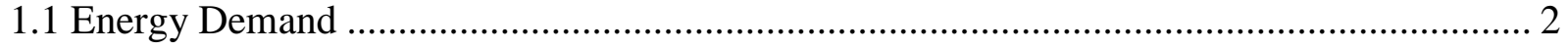

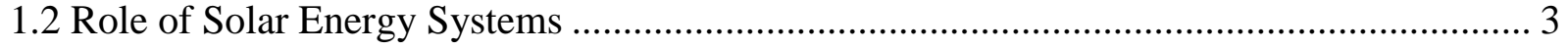

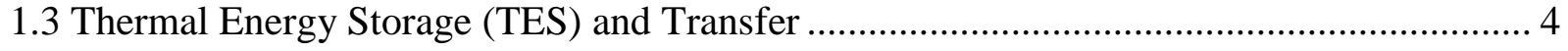

1.3.1 Phase Change Material (PCM) Storage ……............................................................... 5

1.3.2 Mathematical Modeling of PCM ............................................................................... 7

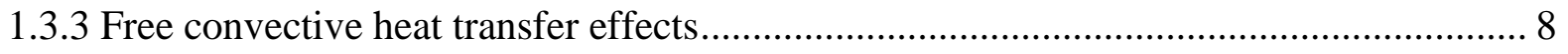

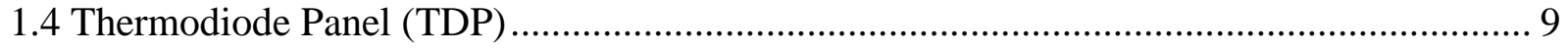

1.4.1 Specification for a solar thermodiode ………......................................................... 11

1.4.2 Specification for a night cooling thermodiode........................................................... 12

1.6.3 Specification for a heat pipe/thermosyphon ……....................................................... 12

1.4.4 How does a thermosyphon work?....................................................................... 13

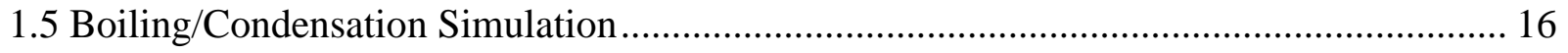

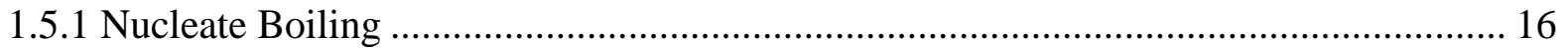

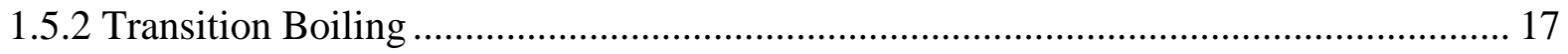

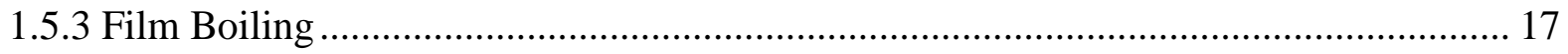

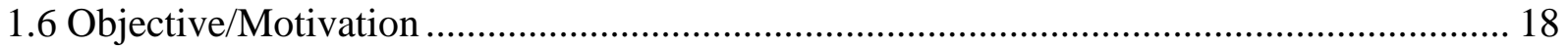

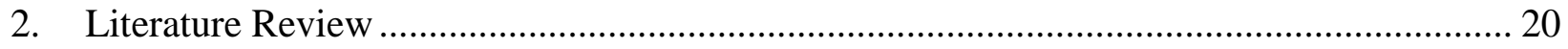

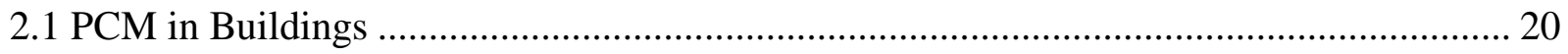

2.1.1 Phase Change Material (PCM) Modelling ................................................................ 23 


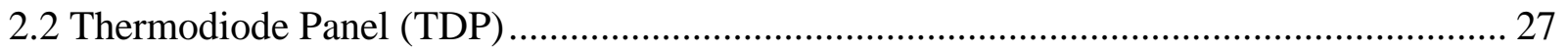

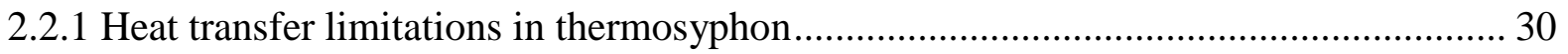

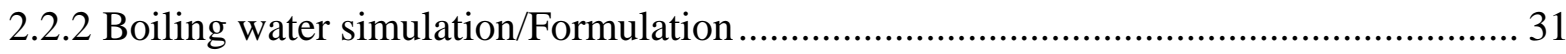

2.2.3 Steady/Transient two-dimensional analysis of thermosyphon ...................................... 34

2.2.4 Effect of inclination on a thermosyphon performance …………................................. 37

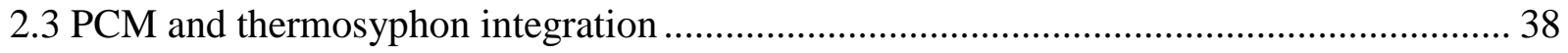

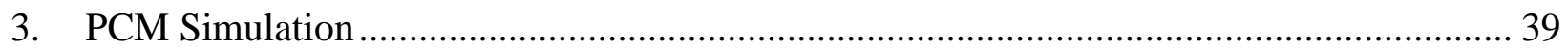

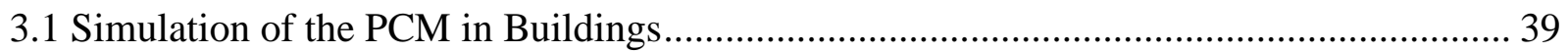

3.1.1 Net Zero Energy Building (NZEB) Simulation in Toronto ........................................... 40

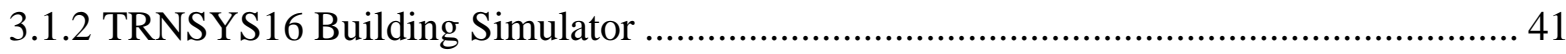

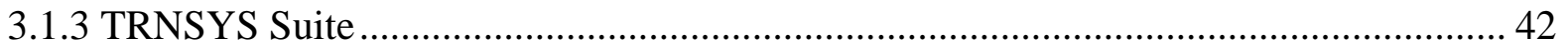

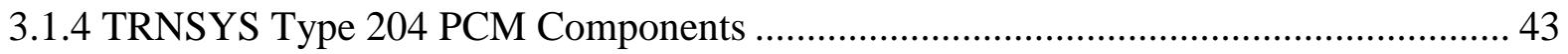

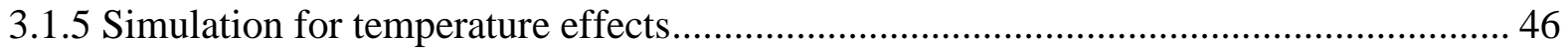

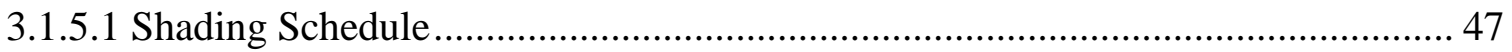

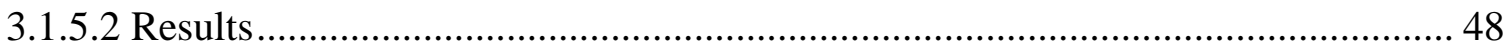

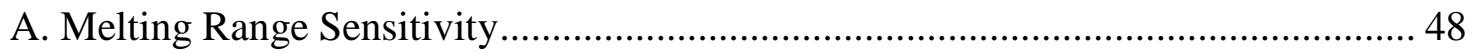

B. Effects of Thermal Conductivity on IAT …………............................................ 49

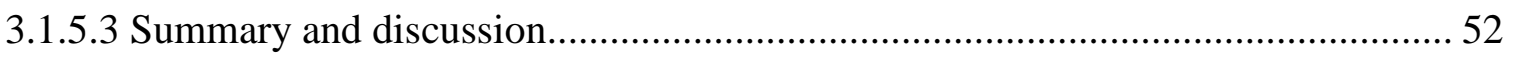

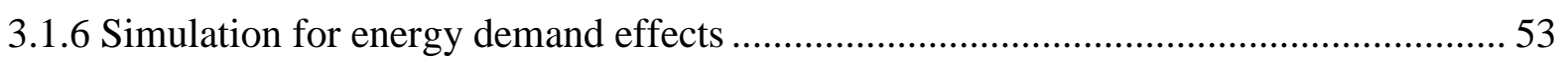

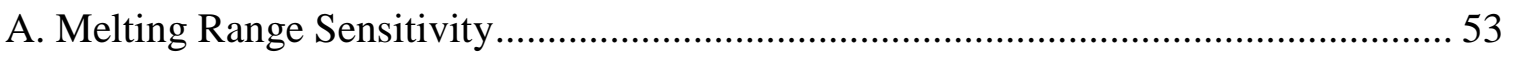

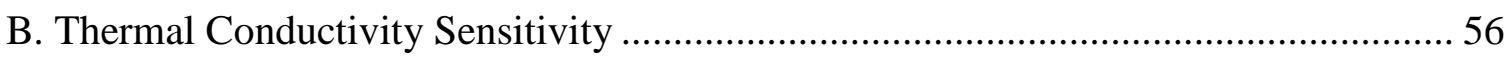

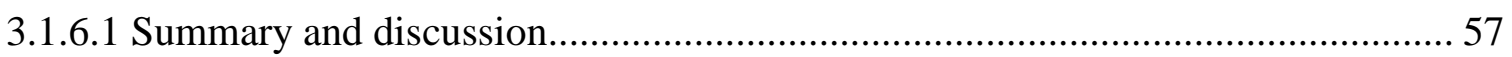

3.1.7 Simulation for effects of convective heat transfer coefficient on the ability of a PCM to

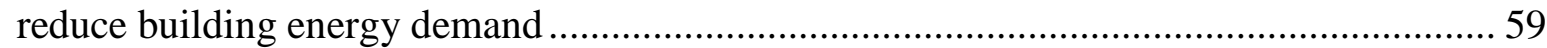

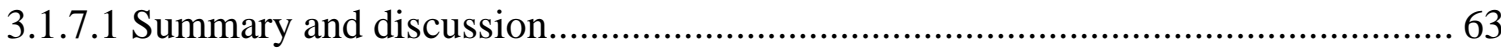

3.1.8 Simulation for effects of PCM on temperature fluctuation in set-point-controlled (21-

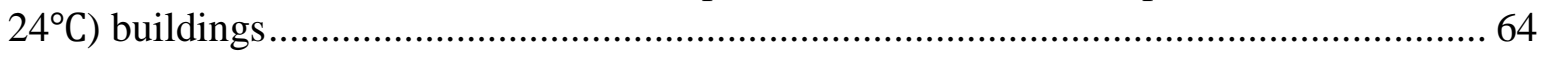

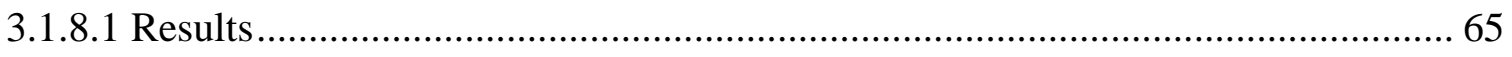

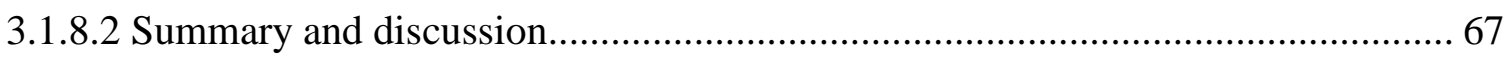

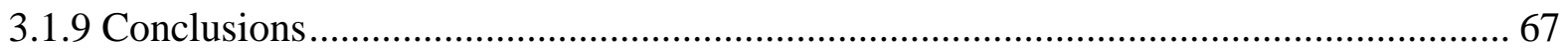

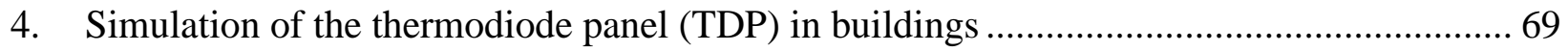

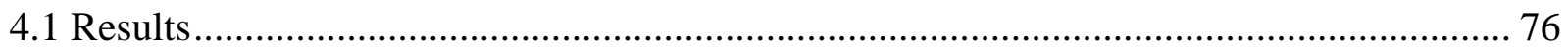

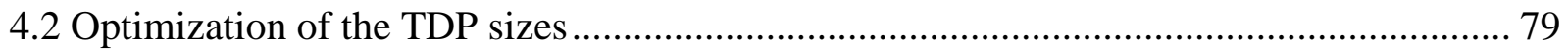

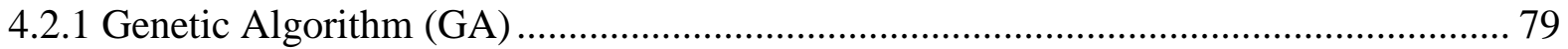




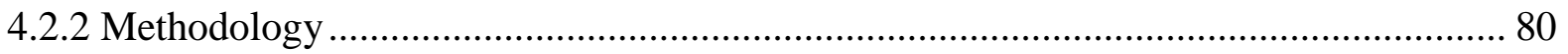

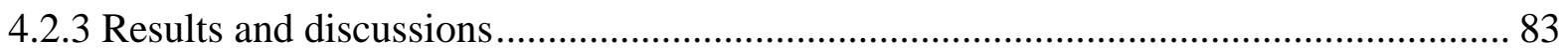

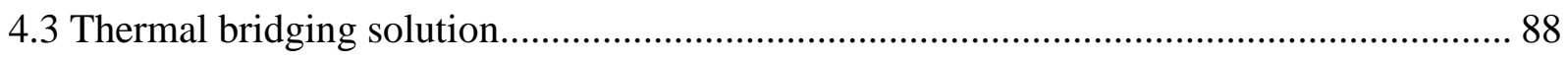

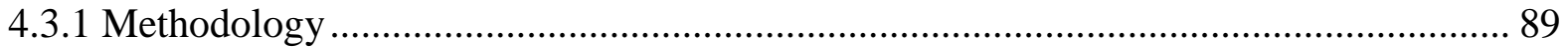

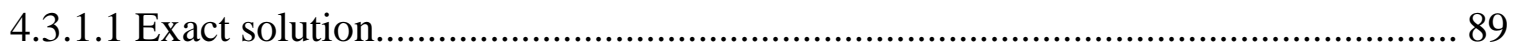

4.3.1.2 Thermal simulation results..................................................................... 92

4.3.1.3 Displacement/strain results of simulation......................................................... 93

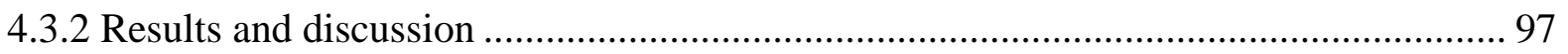

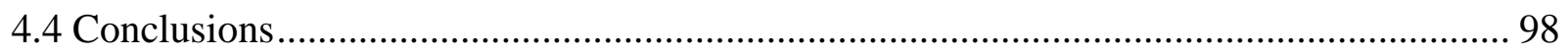

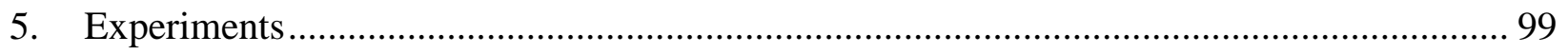

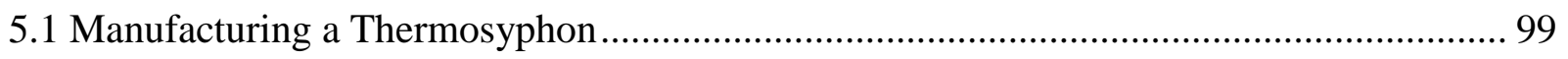

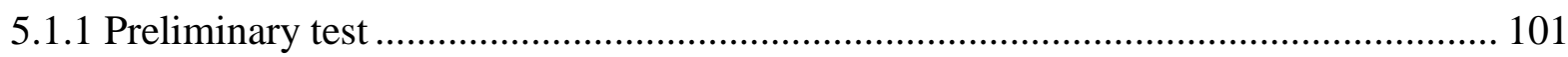

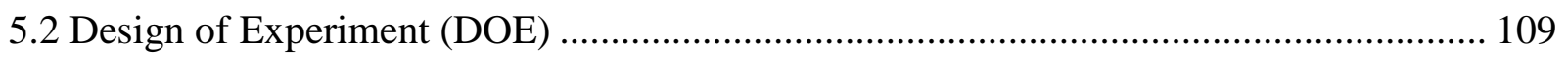

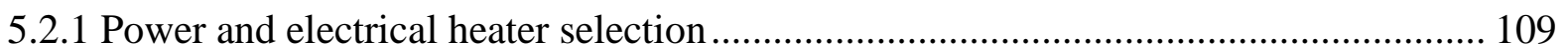

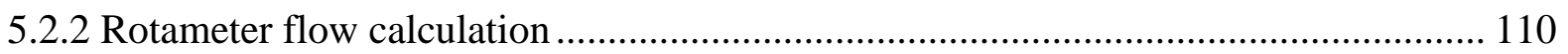

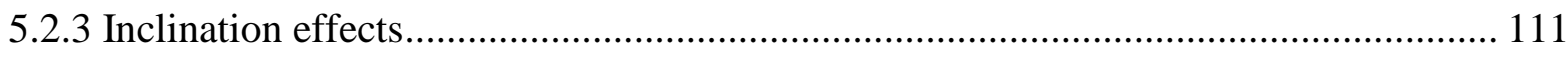

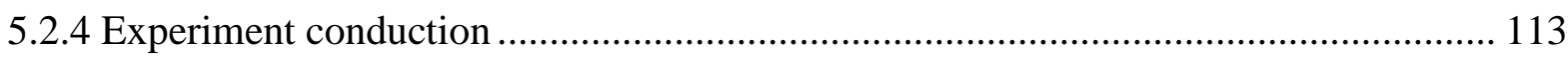

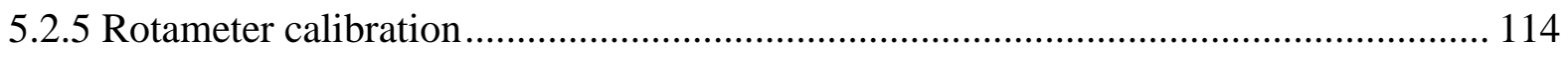

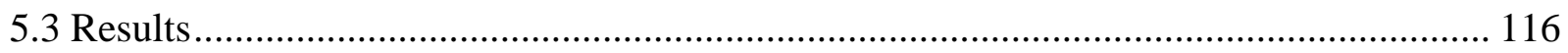

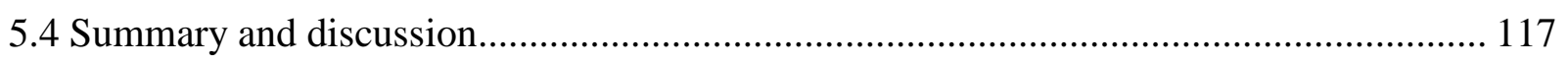

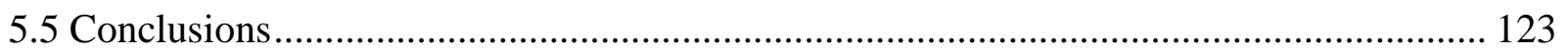

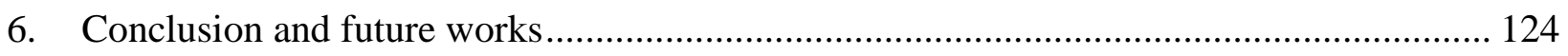

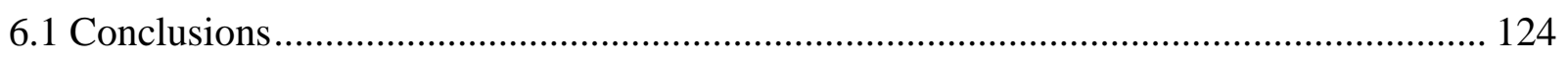

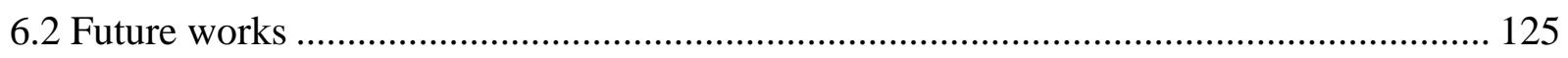

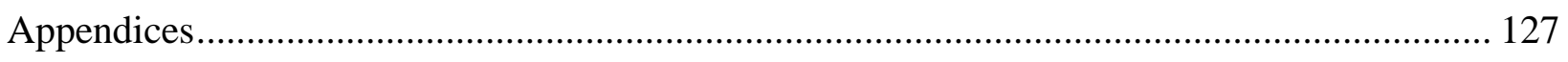

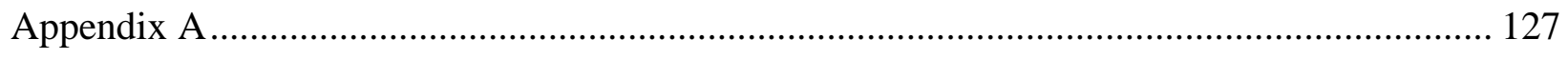

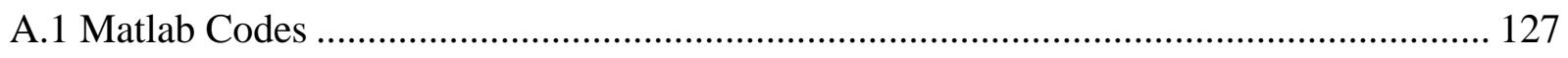

A.1.1 Surface temperature calculation ........................................................................ 127

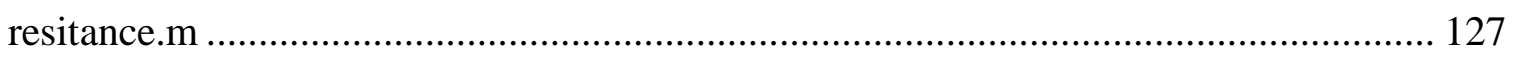

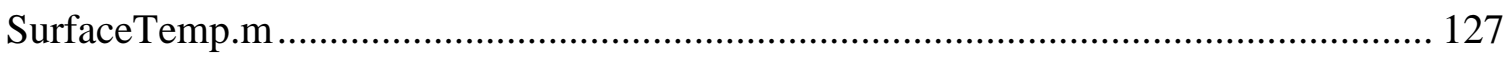

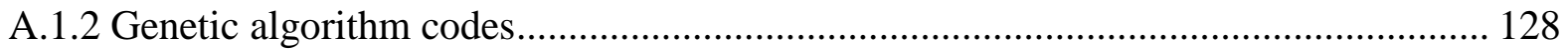

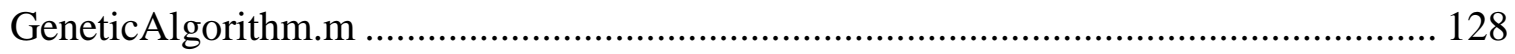

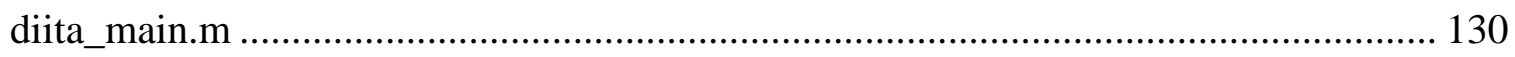

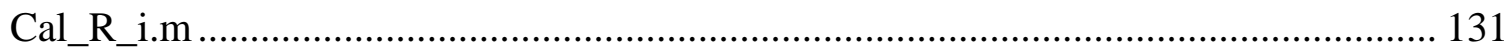




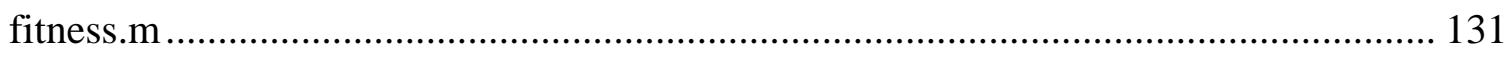

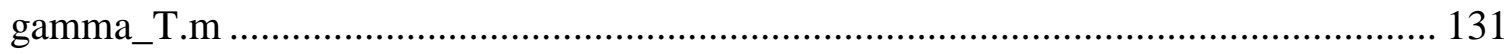

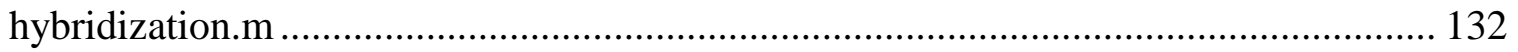

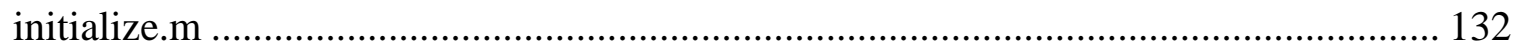

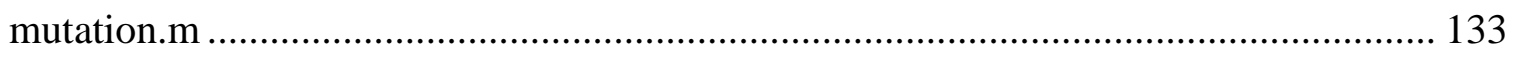

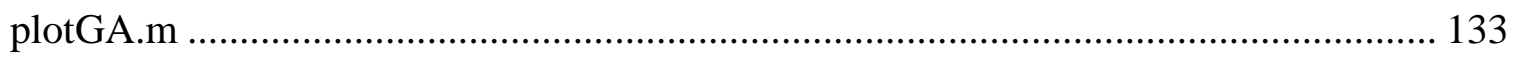

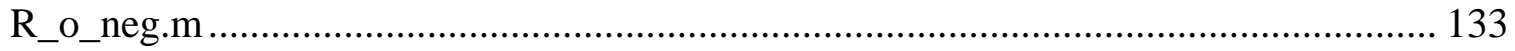

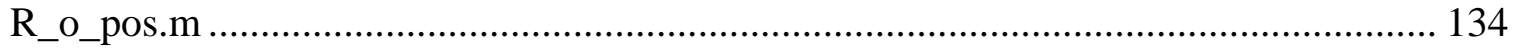

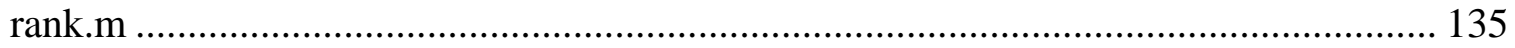

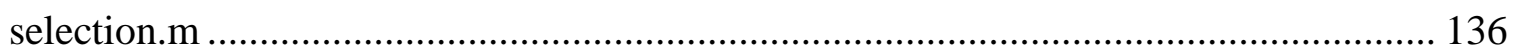

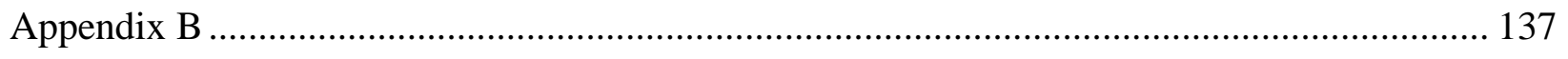

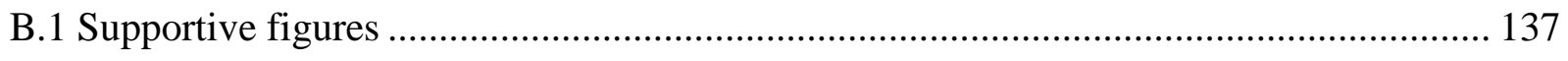

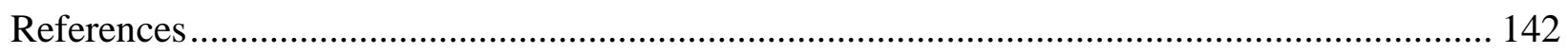




\section{List of Tables}

Table 1-1: Summary of the experimental results for forced convection tests [13].................... 8

Table 2-1: Thermal and physical Properties of some common PCMs [7]............................. 21

Table 3-1: The Layers of the NZEB Wall (Left) and Floor (Right) [69] ................................ 42

Table 3-2: The NZEB Zones Descriptions and the PCM Sizes ............................................. 47

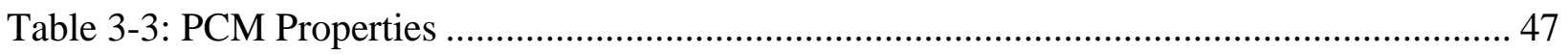

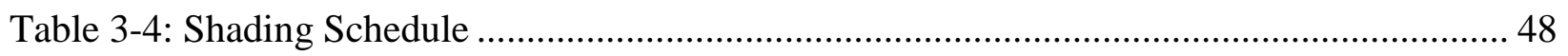

Table 3-5: AHTF of Different Zones and Ambient Temperature in the First Week of Jan. and

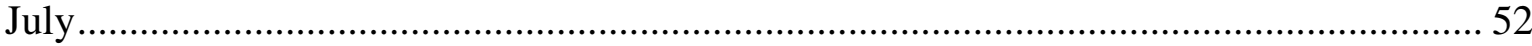

Table 3-6: Average temperature difference and RFI in different zones ................................ 67

Table 3-7: Temperature fluctuations in Mezzanine at the coldest and the warmest hours of the

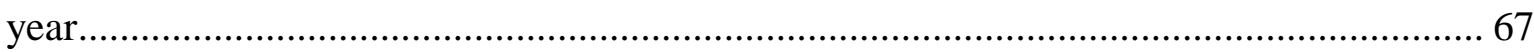

Table 4-1: Some thermal resistances (in K/W) in the TDP panel.......................................... 77

Table 4-2: Annual (8760 hours) solar radiation facts in Toronto (Meteotest, 2011).................. 78

Table 4-3: GA suggestions based on Of1 and Of0 (green/shaded rows) with different interactive

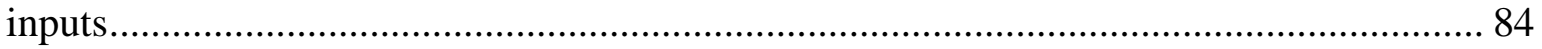

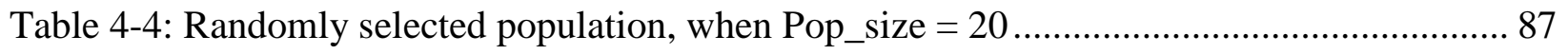

Table 4-5: Values of the parameters used in Equation (4-41). Lengths, areas and thermally conductivities are in $\mathrm{mm}, \mathrm{mm}^{2}$, and $\mathrm{W} / \mathrm{mK}$, respectively. Subscripts I and O refer to inside

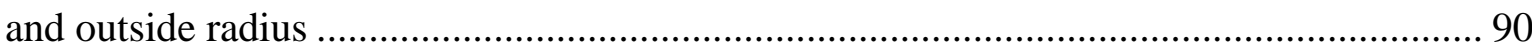

Table 4-6: Coupling material decision matrix ............................................................ 91

Table 4-7: Backward heat flux $\left(\mathrm{W} / \mathrm{m}^{2}\right)$ statistics for 12 nodes on each section ........................ 93

Table 5-1: Record of manufactured thermosyphons....................................................... 101

Table 5-2: Record of calibration of HH147U channels .................................................. 102

Table 5-3: The difference between evaporator and condenser temperatures .......................... 109 
Table 5-4: The best option for $d m$ is underlined ....................................................... 110

Table 5-5: The summary of rotameter calibration results.............................................. 115

Table 5-6: The summary of the values and uncertainty of the rotameter ............................. 115

Table 5-7: The record of flow and $\Delta T$ at different time ............................................... 120

Table 5-8: The summary of calculated power transferred and maximum temperature difference

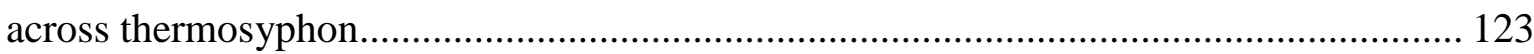




\section{List of Figures}

Figure 1-1: Classification of energy sources and storages. Arrow shows the direction of increase in energy density amongst Thermal, Sorption and TCM ............................................ 1

Figure 1-2: Annual energy use in residential buildings in Canada [3] .................................... 2

Figure 1-3: TDP components, evaporator is subjected to solar radiation and condenser is inside the home

Figure 1-4: A thermosyphon structure fitted inside the TDP 14

Figure 1-5: Thermal fluid model of condensation and evaporator [28].... 15

Figure 1-6: Boiling curve for water at atmospheric pressure (101,325 Pa). The same surface heat flux can result in different excess temperatures depending on the boiling regime [33] ...... 17

Figure 2-1: Energy density of high energy storage materials [1] ....................................... 22

Figure 2-2: Classification of energy storage materials [44].............................................. 23

Figure 2-3: TRNSYS flow chart of information for the building containing PCM [49]............ 26

Figure 2-4: TDP structure, thermosyphon is passing across the panel. Three aluminum plates are

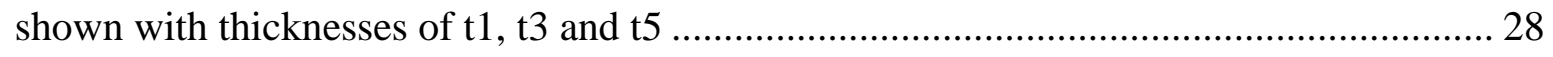

Figure 2-5: A section of thermosyphon inside the TDP structure, thermosyphon transfers heat across the TDP

Figure 2-6: A section of thermosyphon inside, a control volume of falling liquid flow is magnified 35

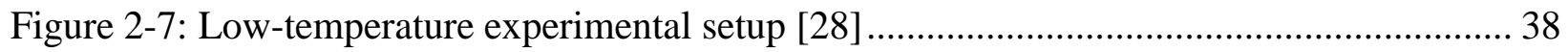

Figure 3-1: Three dimensional computer representation of the three identical NZEB [69]........ 41

Figure 3-2: Effect of increasing iteration on ASHRAE Standard 140-2001 (Case 600 BESTEST)

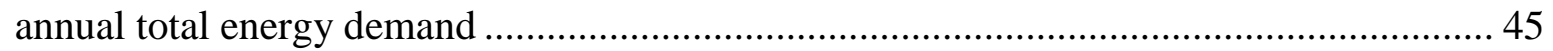

Figure 3-3: Sensitivity of IAT to the melting range in a typical summer (bottom), July 2nd, and winter (top), Jan. 2nd, day (both figures share the same legends) 50 
Figure 3-4: Temperature sensitivity on the PCM thermal conductivity (W/mK) in a typical winter, Jan. 2nd, (top) and summer, July 2nd, (bottom) day (both figures have the same legends)

Figure 3-5: Melting range sensitivity of the annual energy demand of the SUI house 54

Figure 3-6: Melting range sensitivity of the peak power demand of the SUI house 54

Figure 3-7: Sensitivity of hourly power demand to the melting range in typical summer days, July 1 st to 3 rd 55

Figure 3-8: Sensitivity of hourly power demand to the melting range in typical winter days, Jan. 2nd to 5 th 56

Figure 3-9: Sensitivity of peak power and energy demand to the PCM thermal conductivity..... 57

Figure 3-10: Annual energy demand (y) versus PCM thermal conductivity (x). The best fit regression equation is also shown 58

Figure 3-11: Effect of h-value on cooling energy demand at the warmest hour (4839) of the year

Figure 3-12: Effect of h on cooling energy demand in one of the warm month of the year, August

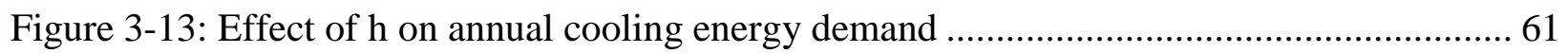

Figure 3-14: Effect of $h$ on heating energy demand at the coldest hour (289) of the year .......... 62

Figure 3-15: Effect of $\mathrm{h}$ on heating energy demand in the coldest month of the year, February . 62

Figure 3-16: Effect of $\mathrm{h}$ on annual heating energy demand 63

Figure 3-17: Temperature fluctuation inside the set points (21 to 24) in Mezzanine on July 21st 66

Figure 3-18: Temperature fluctuation inside the set points (21 to 24) in Mezzanine on January 13 th 66

Figure 4-1: PCM-thermosyphon combination in charging (left) and discharging (right) conditions

Figure 4-2: Energy balance for control volume on the evaporator surface 70 
Figure 4-3: TP panel (top) and its thermal resistance network (bottom), related surfaces are connected by arrows. $\mathrm{T}$ and $\mathrm{T} 3$ represent the average temperature of the surfaces 71

Figure 4-4: Energy balance on the element shown in Figure 4-5 ........................................ 72

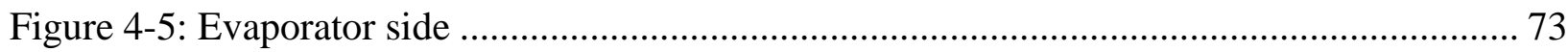

Figure 4-6: Energy balance on the element shown in Figure 4-7 ........................................ 74

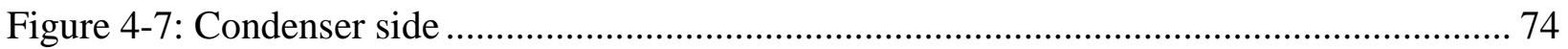

Figure 4-8: Maximum power that can be transferred (Q_in) per $\mathrm{m}^{2}$, radiation power, surface and ambient temperatures in Toronto in January ....................................................... 78

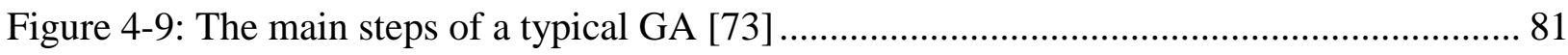

Figure 4-10: Flow chart for calculating objective function ............................................ 82

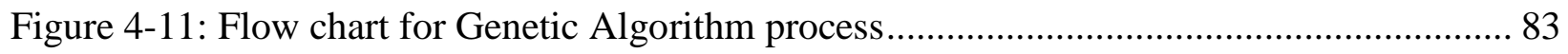

Figure 4-12: Generation size versus average fitness in two different conditions based on OJ1 .. 85

Figure 4-13: graphical results for the number of cases of 100 (20 populations times 5 generations), V5 (top) and $\mathrm{Q}_{\text {in }}$ (bottom) are shown on the secondary axes (based on OJ1) 86

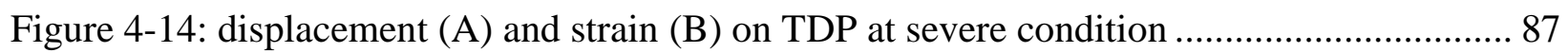

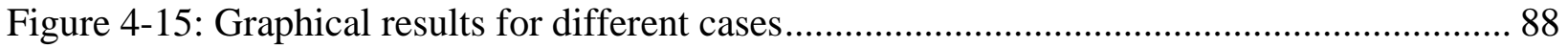

Figure 4-16: Sketch of the adiabatic section of the thermosyphon with its electric circuit network

Figure 4-17: Heat flux distribution at different length (Y-value) of the thermosyphon. The top sketch shows the location of the heat flux measurement, the middle graph represents the new design backward heat flux (BNTSS), and the bottom graph shows the current/old design backward heat flux (BOTSS). In the middle graph, PART 1-1 and 1-2 are the cupper pieces around the Teflon piece (MIXED PART) 94

Figure 4-18: Heat flux distribution at different points of the cross section (same Y-value) of the new/suggested design in backward direction. The pictures show the heat flux at $y=60 \mathrm{~mm}$

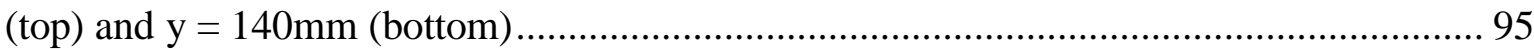


Figure 4-19: Heat flux distribution at different points of the cross section (same Y-value) of the current design in backward direction. The pictures show the heat flux at $\mathrm{y}=60 \mathrm{~mm}$ (top) and $\mathrm{y}=140 \mathrm{~mm}$ (bottom)

Figure 4-20: Displacement (left) and strain (right) distribution of the new design parts (Teflon and cupper parts attached to it) in the forward heat transfer condition. 97

Figure 5-1: The last step of connecting compressor to a fridge (not to scale)..... 99

Figure 5-2: the manufacturing process of the thermosyphon ..... 100

Figure 5-3: The manufactured thermosyphon, S (left) and I (right) shape 100

Figure 5-4: The measuring devices used for the experiment 103

Figure 5-5: The set-up for the copper tube test (vertical position) 104

Figure 5-6: Transient temperature of the surface points on the copper tube 104

Figure 5-7: Steady state temperature of the selected points on the surface of the Cu-tube 105

Figure 5-8: The setup for preliminary test 106

Figure 5-9: Transient temperature of the surface point $\mathrm{T} 1$ on the copper tube and thermosyphons at $40^{\circ} \mathrm{C}$ 107

Figure 5-10: Transient temperature of the surface point $\mathrm{T} 1$ on the copper tube and thermosyphons at $45^{\circ} \mathrm{C}$ 108

Figure 5-11: Transient temperature of the surface of the condenser (point T1) of the thermosyphon II at different heat bath temperature 108

Figure 5-12: the setup of thermosyphon at 30 degree. 111

Figure 5-13: the upper and lower surface temperature (at the point T1 on Figure 5-5) of the condenser of the thermosyphon $\mathrm{V}$ at 30 degree inclination in constant heat bath temperature of $50^{\circ} \mathrm{C}$ 112

Figure 5-14: the average surface temperature (at the point T1 on Figure 5-5) of the condenser of the thermosyphon $\mathrm{V}$ with different inclination in constant heat bath temperature of $50^{\circ} \mathrm{C}$ 
Figure 5-15: Experiment configuration, which shows electrical heat and data logger sensors (A to D) mounting. 114

Figure 5-16: Calibration curve for the rotameter. 116

Figure 5-17: Thermosyphon III after soldering a copper sheet $(10 \mathrm{~cm} \times 21 \mathrm{~cm} \times 1.55 \mathrm{~mm})$ on its evaporator. Electrical heater is attached evenly on this copper sheet to simulate solar radiation

Figure 5-18: Transient temperature of the thermosyphon III at point T1 with and without attaching/soldering copper sheet in constant heat bath temperature of $40^{\circ} \mathrm{C}$ 118

Figure 5-19: Transient temperatures of the points T1 to T4 (run 1, 45 degree) 118

Figure 5-20: Transient temperatures of the points T1 to T4 (run 2, 45 degree) 120

Figure 5-21: Transient temperatures of the points T1 to T4 (run 3, 45 degree) 121

Figure 5-22: Transient temperatures of the points T1 to T4 (run 3, 45 degree) before water flow starts

Figure 5-23: Transient temperatures of the point $\mathrm{T} 3$ at different angles and heat fluxes 122

Figure A-1: A low-temperature heat pipe filling rig [28] 137

Figure A-2: Leak test of the Plexi glass container. 138

Figure A-3: Testing thermosyphon performance in different angle 139

Figure A-4: Testing results at different runs, lower is the $3^{\text {rd }}$ run, middle is the $1^{\text {st }}$ run and upper is the $2^{\text {nd }}$ run ( 45 degree). 140

Figure A-5: Testing results at 35 degree (top), 60 degree (middle) and vertical (bottom). 141 


\section{Nomenclature}

A weighting factor between 0 and 1

Ar area/cross section

b body force

BNTSS backward, new/suggested design and steady state thermal analysis

Bo Bond number

BOTSS backward, old/current design and steady state thermal analysis

C constant

COV coefficient of variation, STDEV/average

$\mathrm{C}_{\mathrm{p}} \quad$ specific heat

$\mathrm{C}_{\mathrm{pe}} \quad$ effective specific heat

D diameter

E enthalpy

f fraction

FFEPLUS an iterative solver used by SolidWorks

FEA finite elemet analysis

g gravitational acceleration

G TDP width

h free convection heat transfer coefficient

$\mathrm{h}_{\mathrm{lv}} \quad$ latent heat of vaporization

$\mathrm{H} \quad$ TDP height

I electric current in Amper

1 Teflon part length

L length

$\mathrm{k}$ thermal conductivity

$M^{\prime} \quad$ merit number

$\mathrm{Nu} \quad$ Nusselt number

$\mathrm{P} \quad$ absolute pressure

q heat flux

Q instantaneous heat flow

r radius 


$\begin{array}{ll}\text { R } & \text { gas constant } \\ \text { Ra } & \text { Rayleigh number } \\ \text { Rt } & \text { thermal resistance } \\ \mathrm{S} & \text { surface tension } \\ \mathrm{Sr} & \text { strain-rate tensor } \\ \mathrm{t} & \text { time } \\ \mathrm{T} & \text { temperature } \\ \mathrm{x}, \mathrm{y}, \mathrm{z} & \text { cartesian coordinates } \\ \mathrm{u} & \text { velocity } \\ \mathrm{U}_{\mathrm{D}} & \text { uncertainty of the measurement } \\ \mathrm{v} & \text { vapour } \\ \mathrm{V} & \text { volume } \\ \text { w/w } & \text { weight percentage } \\ \text { Wt } & \text { weight } \\ \mathcal{R} & \text { electrical resistance in Ohm }\end{array}$

\section{Greek Symbols}

$\alpha$

$\beta$

$\Gamma$

$\delta$

$\Delta$

$\varepsilon$

$\mu$

$\eta$

$\vartheta$

$\rho$

$\tau$

$\Omega$ solar absorptivity

volumetric expansion coefficient

mass flow rate

condensed water thickness

change/difference

surface emissivity

dynamic/absolute viscosity

apparent/kinematic viscosity $(\mu / \rho)$

voltage in Volt

density

viscous shear stress

electrical resistance unit (ohm)

\section{Subscipts}




\begin{tabular}{ll}
0 & Teflon properties \\
1 & copper properties \\
a & adiabatic \\
B & backward direction \\
c & condenser \\
e & evaporator \\
f & fluid \\
i & inside/indoor \\
l & liquid \\
mrt & mean radiant \\
n & new/suggested design \\
o & outside/outdoor \\
ol & old/current design \\
op & operative \\
p & pool \\
Rf & reference condition \\
s & surface \\
sat & saturate \\
v & vapour \\
w & wall \\
$\infty$ & infinite/ambient \\
& liquid-vapour interface \\
\hline &
\end{tabular}

\section{Superscript}

$\begin{array}{ll}\text { ap } & \text { apparent } \\ * & \text { reference condition }\end{array}$

\section{Abbreviations}

AHTF average hourly temperature fluctuation

ASHRAE American Society of Heating, Refrigerating and Air-Conditioning Engineers CFD computational fluid dynamic 


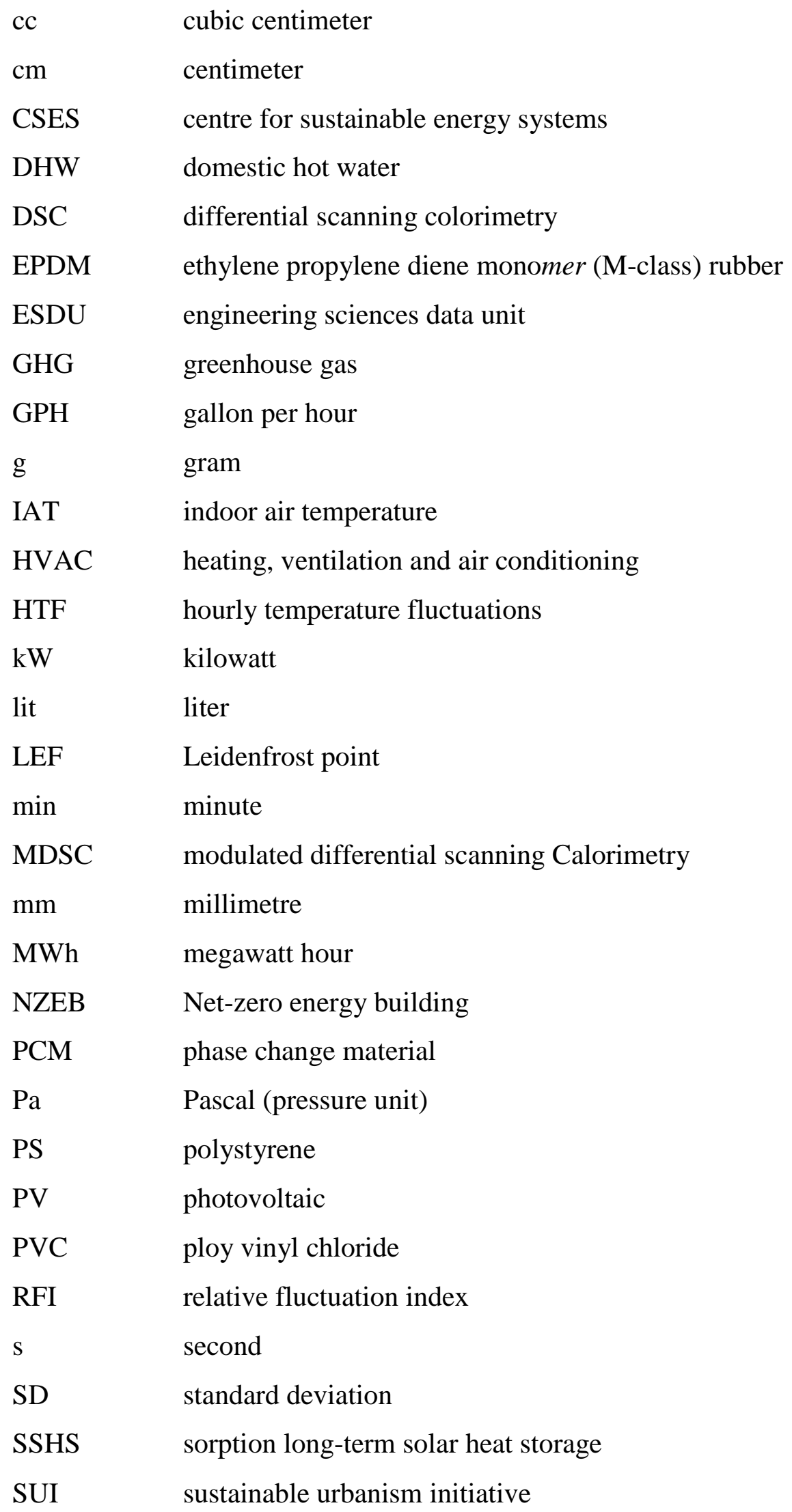


TB thermal bridging

TCM thermo-chemical material

TD temperature difference

TDP thermodiode panel

TES thermal energy storage

TMY typical meteorological year

TSI temperature swing index

ZT zone temperature 


\section{Introduction}

Utilization of exhaustible sources of energy (e.g., oil and gas) is the main reason many buildings can be habitable in the $20^{\text {th }}$ century; therefore, the dependency of comfort in buildings on fossil fuel is undeniable.

Figure 1-1 shows the different sources of energy and their classifications. This dissertation will research the examples displayed in the grey boxes. Both the density and energy storing capacity increase from thermal/sensible materials to thermo-chemical materials (TCM). As displayed, sensible materials have lower energy storage density than phase change materials (PCMs), and PCMs have lower energy density than sorption materials [1].

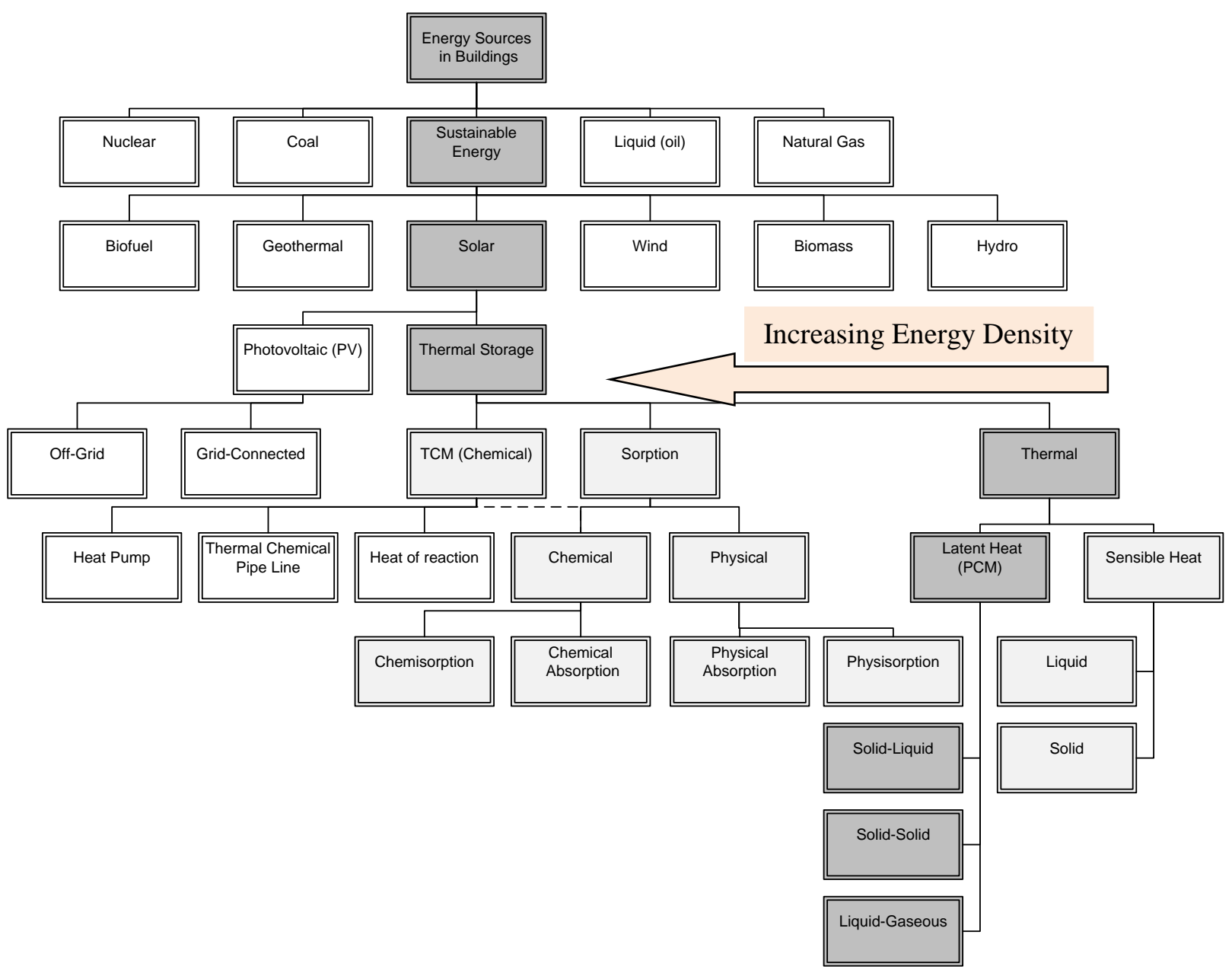

Figure 1-1: Classification of energy sources and storages. Arrow shows the direction of increase in energy density amongst Thermal, Sorption and TCM 
Recent advances in technology, computer simulation, artificial intelligence (AI) and material sciences provide an opportunity to make using sustainable sources of energy (e.g. sun) as easy as using fossil fuels. Therefore, there is no credible reason for not using sustainable sources of energy. In fact, the Sun provides us with the most abundant source of free energy on the Earth [2].

\subsection{Energy Demand}

Across Canada, buildings consume about 53\% of electricity production [3]. Thus, reduction of energy demand related to buildings improves the quality of the environment by reducing greenhouse gas (GHG) emission. Canada has been a pioneer in energy efficient housing. Innovations include the Saskatchewan Conservation House (1977), Equilibrium Houses and EcoTerra (2007) [3]. Figure 1-2 shows the annual energy use in all Canadian residential buildings. Considering a typical house, it receives solar radiation energy more than its total energy demand yearly. For example, the total annual solar radiation of each square meter is about one Mega Watt Hour (MWh) in Toronto [4]. This greatly exceeds the energy demand of a building.

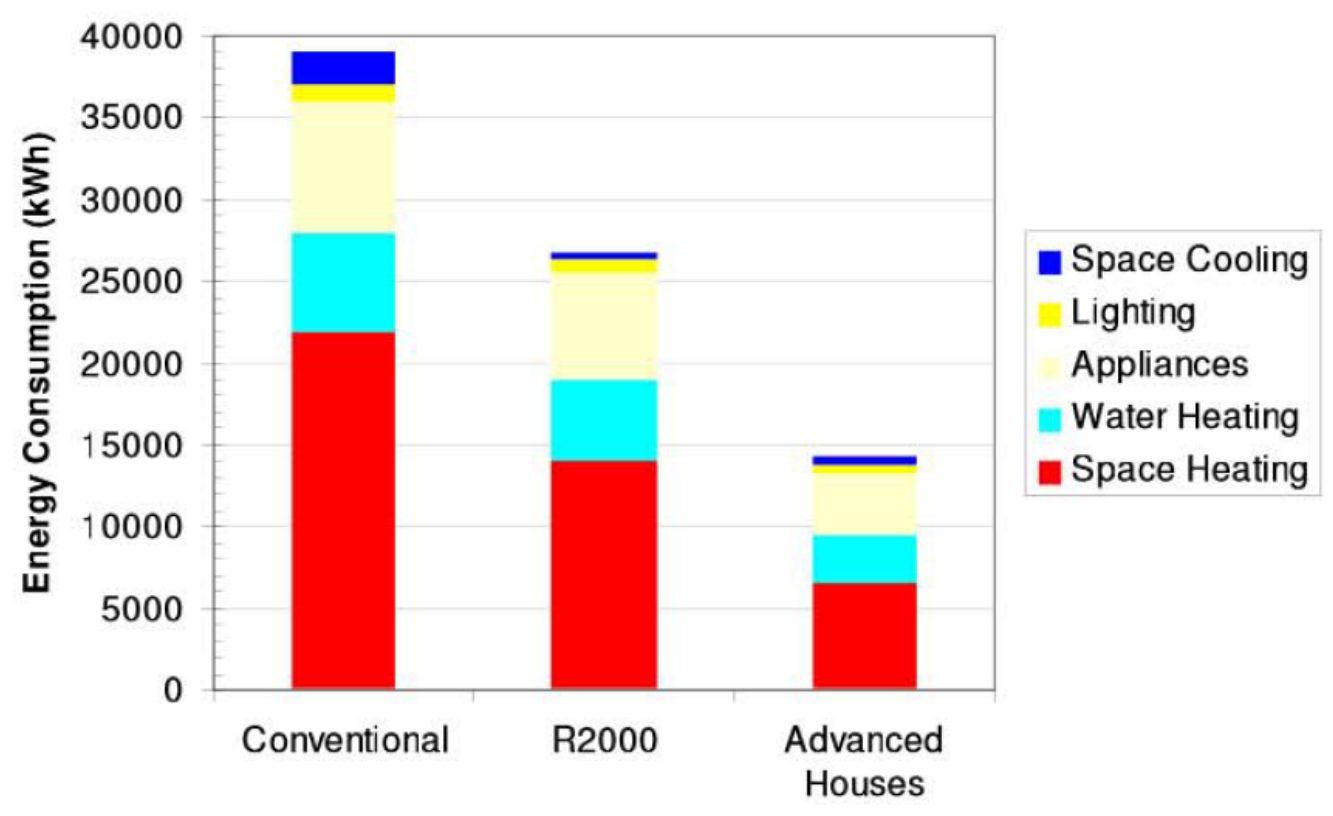

Figure 1-2: Annual energy consumption/houshold in residential buildings in Canada [3] 


\subsection{Role of Solar Energy Systems}

Physically, the Sun is spherical and composed of a very hot gaseous material with a radius of $6.95 \times 10^{8} \mathrm{~m}$. Radiation from the Sun travels 8 minutes and 20 seconds to reach our planet, which is $1.5 \times 10^{11} \mathrm{~m}$ away. The surface temperature of the Sun is estimated to be $5762 \mathrm{~K}$. Theoretically, fusion reaction occurs to produce helium from transformation of hydrogen in the Sun, continuously. The total energy output due to the fusion is $3.8 \times 10^{20} \mathrm{MW}$. This energy radiates equally around the sun sphere. Very small amounts of this radiation $\left(1.7 \times 10^{14} \mathrm{~kW}\right)$ reach the Earth surface. Interestingly, even with this little portion, 30 minutes of solar radiation falling on the Earth is almost enough to supply the annual world energy consumption in all sectors [5].

World energy demand is projected to increase substantially, while fossil fuel stocks are decreasing [6]. Consequently, it is becoming necessary to increase use of renewable energy sources and to invest in alternative energy sources. Due to the abundance of solar energy as well as its sustainability and environmental benefits, there is a potential for solar-based energy systems to meet increasing energy demands.

The Sun is a plentiful source of sustainable energy. Solar-assisted systems can provide heat and power. In order to make these systems more attractive, decision makers such as governments and policy advisors must start internalizing the costs associated with fossil fuel combustion. These costs include climate change and pollution. Internalizing such costs will result in a more realistic picture of the economics behind different energy systems and their associated costs. Second, an effort must be mounted to diversify the world's energy profile, utilizing renewable energy systems wherever feasible. These efforts can encourage a transition away from fossil fuel based systems towards renewable energy systems.

To direct the world's energy systems toward sustainability, attention must be paid to the applicability and appropriateness of various energy systems. For example, solar thermal systems are appropriate for providing domestic hot water, space heating, and space cooling, and thus should be used in these cases whenever feasible. Since nearly all people heat their building environments, and most rely on hot water, there is potential for solar thermal systems to contribute as energy sources. 
As the Sun is the most available source of sustainable energy, it is used widely to supply energy needs. The Sun is not always available when needed. Therefore, its energy should be stored and later used. Solar energy can be stored for a short term (nightly) and a long term (seasonally). Specifically, solar energy storage systems provide energy when it is demanded and there is no supply at the moment by sun (e.g., at night) [1].

Net-zero energy buildings (NZEBs) are now becoming technically possible. Center for Sustainable Energy Systems (CSES) Laboratory designed and built a HVAC system to participate in the 2009 international Solar Decathlon contest in Washington, DC. It was built by optimally combining energy efficiency measures with building-integrated solar systems and heat pumps. The sharp drop in prices of photovoltaic (PV) panels and recent advances in NZEB technologies provide the adaptation of the NZEB initiative both in residential and industrial buildings [3].

\subsection{Thermal Energy Storage (TES) and Transfer}

Energy storage systems play a key role in improving energy utilisation, as many energy sources including solar energy, are intermittent. Solar energy is available during the day, while a demand for domestic hot water exists, and space heating during times of low solar radiation. To guarantee the availability of energy when it is needed, use of efficient thermal energy storage such as collecting heat during sunshine hours for later use between sunset and sunrise is recommended [7].

Generally, four different materials are involved in TES:

i. Water (sensible): this is traditional and the most popular technology in existence.

ii. Phase Change Materials, PCM (latent): this technology is at the demonstration phase and requires new materials development and research.

iii. Sorption (physical): this technology is under development.

iv. Thermo-Chemical Materials or TCM (chemical): this technology is the most promising as it can be charged and discharged repeatedly. TCM are being researched to develop new materials.

While storing heat in materials (sensible) is the most common, there is much activity in the research of thermal storage for solar energy applications using PCM storage. PCM storage relies 
on the material's latent heat as the mode of heat transfer as opposed to sensible heat as the transfer mode. Latent heat storage is a new and developing technology that has attracted much attention due to its advantages over sensible heat storage, including smaller temperature fluctuations, smaller size and lower weight to volume ratio [8].

Besides the domestic hot water (DHW) tank, the following methods are employed to improve long-term, solar energy heat storage:

1) Thermal energy storage in the ground.

2) PCM-based storage techniques.

3) TCM storage methods.

Conveniently, PCM storage is preferred for heat sources with temperature lower than $100^{\circ} \mathrm{C}$, while ground storage is mostly applied for seasonal solar energy storage.

\subsubsection{Phase Change Material (PCM) Storage}

Phase change process either releases or absorbs heat. Using latent heat storage capacity is an efficient way of storing thermal energy due to two key factors. First, latent heat storage using PCMs has a much higher storage density (either per unit mass or volume) than sensible heat storage. Second, in using the latent heat storage method, there are less temperature fluctuations and temperature difference between storing and releasing heat can be lower compared to sensible heat storage [7]. A recent study reveals that using PCMs increase 2.59 - 3.45 times the storage time of hot water, the mass of hot water which is produced, and total heat stored in the solar water-heating system, compared to that of the conventional solar water-heating system without PCMs. This translates directly into a cost savings as a smaller tank with less insulation could be used in conjunction with PCM storage [8].

PCM storage relies on the material to store, absorb, and provide energy as it changes the state, utilizing the latent heat of fusion. Generally, PCMs with a large latent heat and a high thermal conductivity, have a melting temperature within the range of desired operating temperatures, low in cost, be chemically stable, non-corrosive and non-toxic are preferred [7].

In solar thermal applications, it is important to collect the required amount of solar energy during the day and it should be possible to recover this stored energy later. PCM storage is an attractive 
option for thermal storage in solar thermal applications because, given the proper PCM material, a large amount of the solar energy available during the day could be stored. As soon as the hot water storage tank temperature goes above the melting temperature of the PCM, the PCM melts as it absorbs heat. When the energy is not supplied, the PCM will release its energy as it solidifies [8].

Several materials have been investigated to discern their applicability to solar thermal applications. Such issues as degradation of thermal properties, phase segregation, and stability have been researched to ensure good systemic performance [7]. Current research indicates that paraffins (e.g., RT58), salt hydrates, and fatty acids are potential candidates for storing thermal energy in solar applications [8]. More specifically, capric, lauric, palmitic, and stearic acids (fatty acids), possess good thermal characteristics making them promising PCMs for solar applications [7]. Fatty acids, with a melting point ranging between 30 and $65{ }^{\circ} \mathrm{C}$ and latent heat of fusion varying from 153 to $180 \mathrm{~kJ} / \mathrm{kg}$, could potentially be used in space and domestic hot water applications as these have demonstrated stable thermal properties in terms of thermal cycling when used as latent heat of fusion/evaporation storage materials in solar thermal applications [9].

Thermal, physical, chemical and kinetic properties of PCM should be considered in selecting them [10]:

i. Thermal properties
a. Suitable phase-transformation temperature.
b. High thermal conductivity.
c. High latent heat of fusion.

ii. Physical properties
a. High density.
b. Favorable phase equilibrium.
c. Low vapour pressure.
d. Small volume change.

iii. Intermolecular properties
a. Long-term chemical stability.
b. Construction materials compatibility.
c. Non-toxic.
d. Nonflammable or fire hazard. 
iv. Kinetic properties

a. Sufficient crystallization rate.

b. No super cooling.

v. Also, economics is important in designing a PCM. It should be abundant, available and cost effective [10].

vi. With regard to storage density and the avoidance of large temperature fluctuations, latent heat energy storage is an efficient way to store thermal energy. In addition to increased efficiency, advantages to this method of thermal storage compared to sensible heat storage include a better energy storage density and lower temperature fluctuations. Soon after the PCM has reached its melting temperature, the energy added to the storage system is used in the melting process. This prevents large temperature fluctuations. There are, however, difficulties when using latent heat thermal storage. PCMs applicable to solar thermal applications, such as paraffin wax, have relatively low thermal conductivities and may need to be mixed with thermally conductive materials, such as any metallic powder, metal matrix structures, finned tubes and aluminum shaving to enhance the heat transfer characteristics. Also, PCMs may undergo density change, phase segregation, sub-cooling, and lose stability under extended thermal cycling [7].

\subsubsection{Mathematical Modeling of PCM}

Generally, governing equations to describe PCM heat transfer are mass, momentum (NavierStockes) and energy conservation equations. General equations can be found in the fluid mechanics and heat transfer textbooks [11].

Despite its solid-solid or solid-liquid PCM states, mass is conserved; therefore, there is no need to investigate mass conservation equation. Zalba et al. (2003) showed that momentum equation can be neglected in building application of PCM. Mass conservation (continuity) equation is:

$$
\dot{\rho}+\rho(\nabla \cdot \mathbf{u})=0
$$

N-S is basically Newton's second law of motion $\left(\sum \vec{F}=m \vec{a}\right)$. Using the Eulerian Frame of Reference in a Newtonian, incompressible fluid:

$$
-\nabla p+\mu\left(\nabla^{2} \boldsymbol{u}\right)+\rho \boldsymbol{b}=\rho(\dot{\boldsymbol{u}}+\boldsymbol{u} \cdot \nabla \boldsymbol{u})
$$

where: $\boldsymbol{b}$ is the body force in $\mathrm{N} / \mathrm{kg}$ (mainly due to gravity), $\boldsymbol{u}$ is velocity vector in $\mathrm{m} / \mathrm{s}, p$ is pressure in $\mathrm{N} / \mathrm{m}^{2}, \rho$ is density in $\mathrm{kg} / \mathrm{m}^{3}$, and $\mu$ is dynamic (coefficient of) viscosity in Pa's. 
Eventually, energy equation is the only governing equation for the PCM analysis in building applications. This equation can be written as [12]:

$$
\rho \frac{\partial E}{\partial t}=\rho C_{p} \frac{\partial T}{\partial t}=k \nabla^{2} T
$$

where: $\boldsymbol{E}$ is enthalpy (sensible plus latent heat) in Joule, $\boldsymbol{t}$ is time in s, $T$ is temperature in Kelvin, $\boldsymbol{k}$ is thermal conductivity in $\mathrm{W} / \mathrm{K} \cdot \mathrm{m}$, and $C_{p}$ is the heat capacity in $\mathrm{J} / \mathrm{kg} \cdot K$.

\subsubsection{Free convective heat transfer effects}

It is convenient, in building simulations, to assume that the room air is well-stirred so that a constant air temperature $\left(T_{\infty}\right)$ is used. The Newton's law predicts average convective heat flux (q) from the PCM surface as:

$$
q=h\left(T_{s}-T_{\infty}\right)
$$

where $T_{s}$ is the surface temperature and $h$ is the average convective heat transfer coefficient.

In order to calculate average convective heat flux (q), h-value shall be estimated because $\mathrm{T}_{\mathrm{s}}$ and $T_{\infty}$ are possible to measure. In the literature, several h-values and its equations are given between the interior building surfaces (PCM surface either heated or cooled) and the space (average indoor air temperature).

Reviews in literature and experimental findings help estimate the h-value by monitoring the air speed: $\mathrm{h}=5.34+3.27 \mathrm{u}=\mathrm{C} \Delta T^{n}$ ( $\mathrm{u}$ is the air speed in $\mathrm{m} / \mathrm{s}$ and $\Delta T$ is the temperature difference between air and the surface in K). The experimental results for forced convection tests are summarized in Table 1-1 [13]:

Table 1-1: Summary of the experimental results for forced convection tests [13]

\begin{tabular}{|c|c|c|}
\hline Air speed $(\mathrm{m} / \mathrm{s})$ & Experimental h-value $\left(\mathrm{J} / \mathrm{K} \cdot \mathrm{m}^{2}\right)$ & Range of h-value in the literature \\
\hline 0.6 & 7.52 & 2.3 to 10.1 \\
\hline 1.1 & 8.44 & 4.3 to 11.5 \\
\hline 1.5 & 10.52 & 5.9 to 12.4 \\
\hline
\end{tabular}

In defining comfort conditions in ASHRAE Standard 55, operative temperature $\left(\mathrm{T}_{\mathrm{op}}\right)$ is used. $\mathrm{T}_{\mathrm{op}}$ is the weighted average of the mean radiant $\left(\mathrm{T}_{\mathrm{mrt}}\right)$ and ambient air $\left(T_{\infty}\right)$ temperatures, weighted by 
their respective heat transfer coefficients [14]. In TRNSYS 16, the operative room temperature is a function of both the air and surface temperatures in the zone:

$$
\mathrm{T}_{\mathrm{op}}=\mathrm{A} T_{\infty}+(1-\mathrm{A}) \mathrm{T}_{\mathrm{s}}
$$

where $\mathrm{A}$ is a weighting factor between 0 and 1 .

\subsection{Thermodiode Panel (TDP)}

The performance of a building envelope could be enhanced by a well-designed thermodiode panel (TDP) [15]. Such a system could provide a means to achieve a cost effective NZEB in a cold climate like Canada. This overall investigation will address the fact that $63 \%$ of Canadian residential energy goes to space heating [16]. This section illustrates the conceptual design and simulation of a cladding material incorporated with thermosyphon and is suitable for use in new and existing buildings. Such a panel is capable of acting as a TDP, as it has a low thermal resistance in the forward direction and a low thermal conductivity in the reverse direction. TDP has potential application in buildings to transfer insolation heat and conduct it across the panel to the interior of buildings. It also acts same as thermal insulator in reverse mode. This help reduce heat loss when the indoor temperature is higher than the outdoor temperature. When such a panel was added to the sun-facing wall of a building in Los Alamos, New Mexico, $50 \%$ of the incident solar radiation was found being used for heating the envelope during the winter [15]. Other simulation results and experimentations revealed that at least $40 \%$ of solar radiation energy could be transferred to the building envelope [17].

In the region where average ambient temperature is high, the TDP may substitute the roofing material partly; therefore, the building can lose heat at night time. In this method, heat is conducted in the forward direction from the inner to the outer surface of the building. From the outer surface, dissipation of the heat occurs by radiating to the moderately cool sky/ambient at night. On the other hand, low thermal conductivity in the reverse mode stops solar radiation to pass into the building during daytime.

The main part of a TDP is the thermosyphon/heat pipe, which transfers heat by evaporation. Phase change of the liquid inside the heat pipe occurs continuously from liquid to gas at the hot end (evaporator). Thus, heat is absorbed from the radiation of the Sun. The reverse reaction (gas to liquid) occurs at the cold end (condenser) to transfer the condensation heat to indoor air (heat 
sink). A heat pipe/thermosyphon is a passive device that uses no energy. It is a simple but effective heat transfer device [18]; [19]; [20]; [21]; [22]. The thermosyphon is an evacuated closed pipe with a liquid pool in the lowest level (bottom) (Figure 1-3). It is composed of three sections: condenser with length of $L_{c}$, adiabatic with length of $L_{a}$, and evaporator with length of $\mathrm{L}_{\mathrm{e}}$. The liquid pool absorbs the heat in the evaporator section, turning the saturated working fluid into a vapour. Due to the lower density, the vapour rises and passes through the adiabatic section to the condenser. Since there is no heat transfer in adiabatic section, the vapour dissipates its latent heat of evaporation $\left(\mathrm{h}_{\mathrm{lv}}\right)$ and condenses in the condenser. Due to high density, the condensate drops back to the evaporator section by gravity. Usually, the evaporator is lower than the condenser. In this case, gravity brings the condensed fluid back to the evaporator, and there is no need for the wick to assist the process. This type of heat pipe, with no wick, is called thermosyphon.

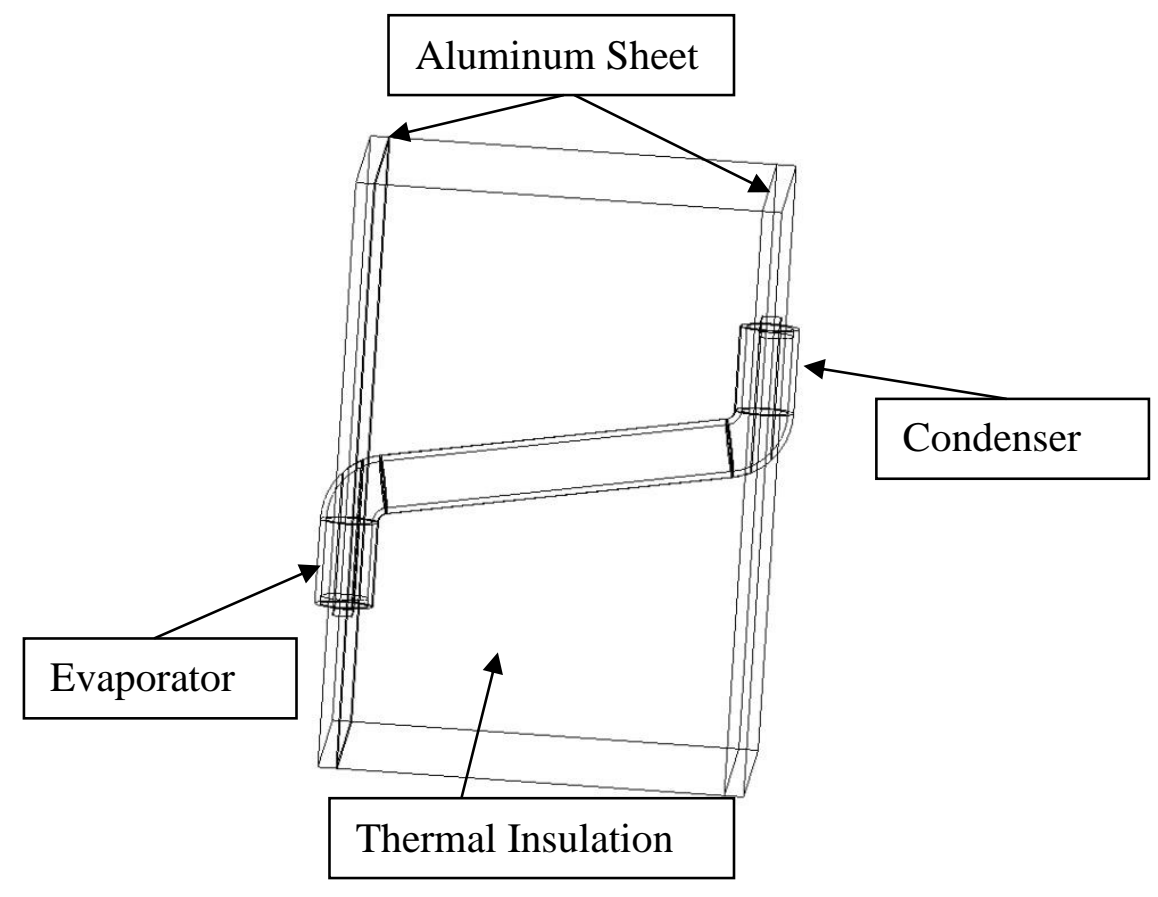

Figure 1-3: TDP components, evaporator is subjected to solar radiation and condenser is inside the home 


\subsubsection{Specification for a solar thermodiode}

In building applications, one-dimensional heat transfer is investigated mostly. Thermal diode or thermodiode is name to the component of a thermal system that controls heat transfer direction. It allows the heat to pass in the intended direction (forward) and blocks the passage of heat in the other (reverse) direction. The terms thermodiode and thermal diode were used to refer to the same identity. Recently, researchers decided to use thermal diode in cases where thermionic or thermoelectric devices are involved to generate electrical power directly from thermal energy [17]. Thus, the name thermodiode is used in this dissertation as well.

In the literature, the term "thermal rectification" is used as well. It describes thermal flow dependency along a defined direction upon the sign of the heat flow or temperature gradient [23]. Thermal rectification investigates thermal management improvement of electronics when sizes keep changing to smaller scale and new technologies emerge by identifying directions of spontaneous thermal flow. In phononic applications where materials with thermal rectification

properties could be of use, materials need to permit one-directional high thermal conductivity to allow for effective flow of heat from heat generating components to a sink and one-directional high thermal resistivity to block the temperature and heat flux sensitive components. The TDP works similarly to this phenomenon in macro scale. One-directional thermal flow can be applied to phononic devices because the diode is essential for electronic devices. Fourier's law predicts one-directional thermal flow in a sample composed of two dissimilar materials which have different temperature dependences of thermal properties [24]:

$$
q=-k \frac{d T(x)}{d x}
$$

where $q, k$ and $\mathrm{T}$ are heat flux, thermal conductivity (which is a function of $\mathrm{x}$ and temperature), and absolute temperature, respectively. All units are SI (international system or MKS).

TDPs are mounted to a mass wall. It is expected that they act both as a thermal insulator and external surface of the wall, which is subjected to weather. Generally, the diode panel characteristics should be [25]:

- Bondable to walls' materials using adhesives which are currently available on the shelf.

- Accessible in standard sizes, e.g. $1.2 \times 2.4 \mathrm{~m}$ in area.

- Possible to cut to suit individual locations. 
- Wear resistant, non-degradable due to exposure to ultra-violet light.

- Bondable to the outside of the thermodiode panel without impairing good heat transfer for the external weathering surface.

- High thermal resistant in backward direction, which reduces thermal bridging.

\subsubsection{Specification for a night cooling thermodiode}

For night cooling and cold regions, a panel performance specification is expected to have the following properties [25]:

- Possible to adhere to a masonry substrate using available adhesives for built-up roofing systems.

- Ductile enough to be cut to fit without impairing the integrity of the product structural stability.

- Enduring loads during installation, without permanent deformation.

- Weatherproofing outer layer (e.g. $\mathrm{EPDM}^{1}$, PVC) adhered to it.

- Being possible to fabricate in manageable sizes, e.g. $1.2 \times 2.4 \mathrm{~m}$, and in different thicknesses to provide appropriate R-values.

\subsubsection{Specification for a heat pipe/thermosyphon}

The two-phase closed thermosyphon/heat pipe is a simple but effective heat transfer device. Heat pipe/thermosyphon is the heart of a TDP. In the TDP sketch, in Figure 1-3, the inside components of the thermosyphon are not shown, i.e., fluid. Heat pipe includes an evaporator at one end and a condenser at the other. Capillary force in the wick sucks the liquid from the hot end to the cold end in heat pipes. This means that a heat pipe does not need gravity for operation. Basically, the heat pipe was intended to operate for space applications where there is no gravity. Thermal conductivity of a heat pipe is much higher than that of the metals. For example, effective thermal conductance of an $\mathrm{Al} / \mathrm{NH}_{3}$ heat pipe (container pipe is made of aluminum and fluid inside is $\mathrm{NH}_{3}$ ) is 260 times better than that of a solid aluminum rod of the same size [26]. The fluid inside the heat pipe should have the following properties [27]:

- Operates in capillary applications

- Boiling and condensation temperatures are close together

\footnotetext{
${ }^{1}$ Ethylene Propylene Diene Monomer (M-class) rubber
} 
- Good thermal stability

- Low liquid and vapour viscosities $(\mu)$

- Wettability of wall materials/wick

- High thermal conductivity $(\mathrm{k})$, surface tension and latent heat of vaporization $\left(\mathrm{h}_{\mathrm{lv}}\right)$

- Maintains high heat fluxes in the evaporator.

The installation of a heat pipe affects its performance. For best performance, the evaporator section should be located at the same height as the condenser section or below it. If the mentioned condition is not possible to satisfy, then a sintered powder wick structure will be necessary. Fortunately, heat pipes accommodate to the physical constraints of the system and can be deformed to any desired shape. Typically, the bend radius shall be 3 times the heat pipe diameter for a tubular heat pipe. There are risks of breaking or blocking the vapour flow if tighter bend radii are applied. Vapour flow blockage reduces the heat transfer capacity. The number of bends should be limited; otherwise, the heat pipe performance would be in jeopardy. Generally, $1^{\circ} \mathrm{C}$ temperature loss is considered for each $90^{\circ}$ bend. The heat pipe can also be flattened (a 3$\mathrm{mm}$ diameter heat pipe can be flattened to $2 \mathrm{~mm}$ ) as long as the vapour passage is not choked. There are some limitations for a thermosyphon in transferring heat [28]:

- Dry-out occurs when the fill volume of the fluid is very small

- Boiling occurs when the heat pipe wall temperature becomes excessively high

- Entrainment or flooding occurs when water vapour velocity is sufficiently high

- Sonic occurs when operating pressure is low

\subsubsection{How does a thermosyphon work?}

Thermosyphon is the core of a TDP. Figure 1-4 shows a typical thermosyphon structure which is used for the design of the TDP. Working fluid inside the thermosyphon has a key role in the evaporator performance. The thermal characteristics of the fluid, environmental factors, the desired lifetime of the thermosyphon, and compatibility with the material of the thermosyphon container shall be considered in selecting the working fluid for a thermosyphon.

There are several available working fluids to choose from. The working fluid selection is based on the widely used parameter called Merit number $\left(M^{\prime}\right)$. Basically, fluids that have high latent heat and surface tension tend to have a higher $M^{\prime}$. Conveniently, $M^{\prime}$ is defined as a criterion to 
select the working fluid; the higher $M^{\prime}$ means better quality. Water has the maximum $M^{\prime}$ amongst all candidates as potential fluid for heat pipe/thermosyphon manufacturing. $M^{\prime}$ is calculated as [28]:

$$
M^{\prime}=\left(\frac{h_{l v} k_{l}^{3} S_{l}}{\mu_{l}}\right)^{1 / 4}
$$

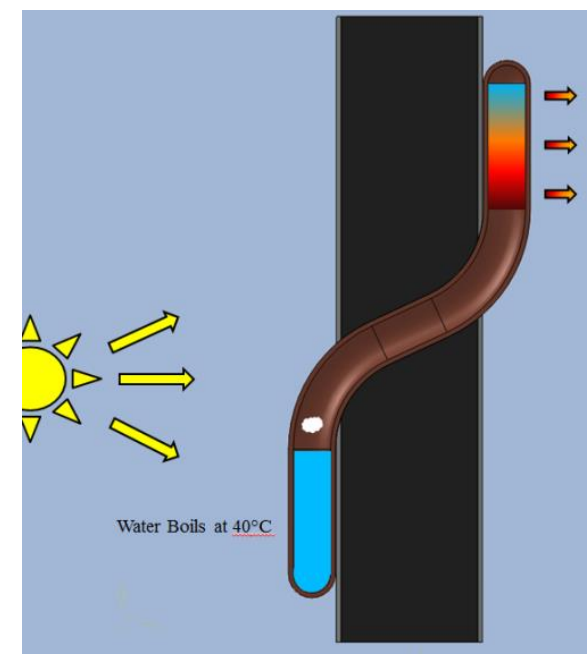

Figure 1-4: A thermosyphon structure fitted inside the TDP

where subscript 1 and $\mathrm{v}$ stand for liquid and gas/vapour, respectively, inside the thermosyphon, $\mathrm{h}_{\mathrm{lv}}$ is the latent heat of evaporation ( $l v$ represents liquid to vapour phase change), $\mathrm{k}, S$, and $\mu$ are thermal conductivity, surface tension, and dynamic/absolute viscosity of the liquid, respectively. As surface tension is not an issue in the thermosyphon (condensed fluid returns back to the evaporator by gravity not by capillary pressure), the above index is important for heat pipe design. Another index has yet to be specifically defined for the thermosyphon. The amount of fluid inside the thermosyphon should be experimentally optimised. Generally, from the classical Nusselt theory, the total volume of the liquid (V) was determined as Equations (1-6) to (1-9) [28]. It is assumed that the thermosyphon is in a steady state condition, i.e., a constant temperature difference between the wall and the saturated vapour in condenser, $T_{s a t}-T_{w, c}$, and a constant temperature difference between saturated vapour and the part of evaporator which is covered by the liquid film, $\left(T_{w, f}-T_{s a t}\right)$. Figure $1-5$ illustrates a wall section of the thermosyphon and all the parameters used in the following equations.

$$
\mathrm{V}=\mathrm{V}_{\mathrm{f}}+\mathrm{V}_{\mathrm{p}}
$$


$\mathrm{V}_{\mathrm{f}}$ is the fluid that was condensed and $\mathrm{V}_{\mathrm{p}}$ is the available liquid for boiling in the pool (Fig. 1-5).

$$
\begin{gathered}
V_{p}=\frac{\pi D^{2}}{4} L_{p} \\
V_{f}=\pi D\left(\frac{4 k \mu_{l}}{\rho_{l}^{2} g h_{l v}}\right)^{\frac{1}{4}}\left[\left(T_{s a t}-T_{w, c}\right)^{\frac{1}{4}}\left(\frac{4}{5} L_{c^{\frac{5}{4}}}+L_{a} L_{c} c^{\frac{1}{4}}\right)+\frac{4}{5}\left(T_{w, e}-T_{s a t}\right)^{1 / 4}\left(L_{f}{ }^{5 / 4}-L_{f p}{ }^{5 / 4}\right)\right] \\
L_{p}=L_{e}-L_{c}\left(\frac{T_{s a t}-T_{w, c}}{T_{w, e}-T_{s a t}}\right)+\left[\frac{1}{4 k\left(T_{w, e}-T_{p}\right)}\right]\left(\frac{\mu_{l}}{\rho_{l}^{2} g h_{l v}}\right)^{1 / 3}\left(\frac{3 Q_{p}}{\pi D}\right)^{4 / 3}
\end{gathered}
$$

In the above equations, $\mathrm{D}$ is the internal diameter, $h_{l v}$ is the latent heat of evaporation, subscript 1 refers to liquid phase property (this script is used for density, $\rho$, and dynamic viscosity, $\mu$ ), $\mathrm{k}$ is the thermal conductivity of the working fluid, and $g$ is the gravitational acceleration.

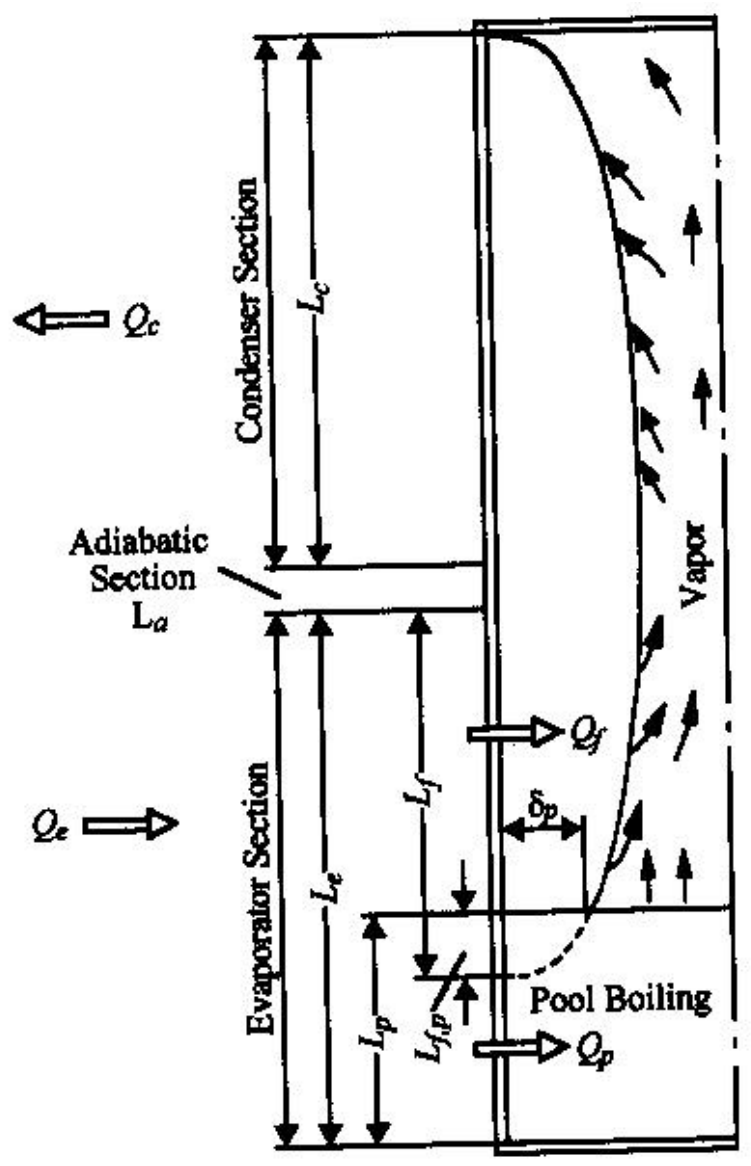

Figure 1-5: Thermal fluid model of condensation and evaporator [28]

It is interesting that the thermosyphon has no macro scale moving parts and is considered fully passive. In addition, PCM is well known as a sustainable source of thermal storage, because it 
barely degrades or reduces its capacity after so many times of charging and discharging. PCM can be charged and discharged without reducing its energy storage capacity [29]. The combination of these two identities provides a panel that can be integrated with the south facing wall to store the solar energy (charge). The storage comprises an energy storage container, full of PCM, and a two-phase closed thermosyphon loop. Cold water is heated during discharge by passing through the charged PCM. The thermosyphon loop is filled with an adequate amount of water as working fluid. The adequacy of the amount of fluid is discussed in some references ( [28], [30], [31], [32]).

Design criteria of a thermosyphon as part of the TDP is explained comprehensively in Chapter 5.

\subsection{Boiling/Condensation Simulation}

Fluid inside the thermosyphon boils when the temperature of a liquid rises above its saturation temperature. This can be accomplished in many ways: exposure of an external heat to the evaporator surface which is in contact with the liquid or by reducing the pressure inside the sealed environment. Three distinct regimes occur during the boiling while the evaporator surface is heated: nucleate, transition, and film. The surface temperature shall be higher than the saturation temperature of the liquid to keep boiling. The difference between the surface temperature and the equilibrium temperature of the liquid is defined as excess temperature. The boiling process depends on the applied heat flux magnitude and the excess temperature on the evaporator surface [33].

\subsubsection{Nucleate Boiling}

At atmospheric pressure, nucleate boiling occurs for water for an excess temperature between $5^{\circ} \mathrm{C}$ and $30^{\circ} \mathrm{C}$ [34]. It is estimated that the heat flux between $10^{4} \mathrm{~W} / \mathrm{m}^{2}$ and $10^{6} \mathrm{~W} / \mathrm{m}^{2}$ is required to sustain this surface temperature. Due to mass transfer from the liquid to the vapour phase, nucleation sites that form due to imperfections in the solid surface expand and separate. Buoyancy forces make bubbles rise, and these may merge from isolated bubbles to form a column. The effective thermal conductivity of the fluid layer close to the surface is high as the detaching bubbles are quickly replaced by liquid. This means that despite applying very high heat flux, the excess temperature remains low. Nucleate boiling is most efficient at the critical 
heat flux (point 2 on Figure 1-6). At this point, liquid can still rapidly replace the vapour produced, and continuously wets the surface. This results in a heat transfer coefficient of more than $10^{4} \mathrm{~W} /\left(\mathrm{m}^{2} \cdot \mathrm{K}\right)$, which is much higher than any heat transfer coefficient that occurs due to convection (before point 1 on Figure 1-6) alone. Natural convection occurs at heat fluxes and excess temperatures below the onset of boiling.

\subsubsection{Transition Boiling}

In transition boiling, a thin layer of low thermal conductivity vapour starts to insulate/separate the solid surface from the liquid. This reduces the heat transfer coefficient between the fluid and solid surface; therefore, the heat flux absorbed must actually decrease below the critical heat flux to generate excess temperatures above $30^{\circ} \mathrm{C}$. Because there are continuous local oscillations between nucleate and film boiling regimes, this region is referred to as transition boiling.

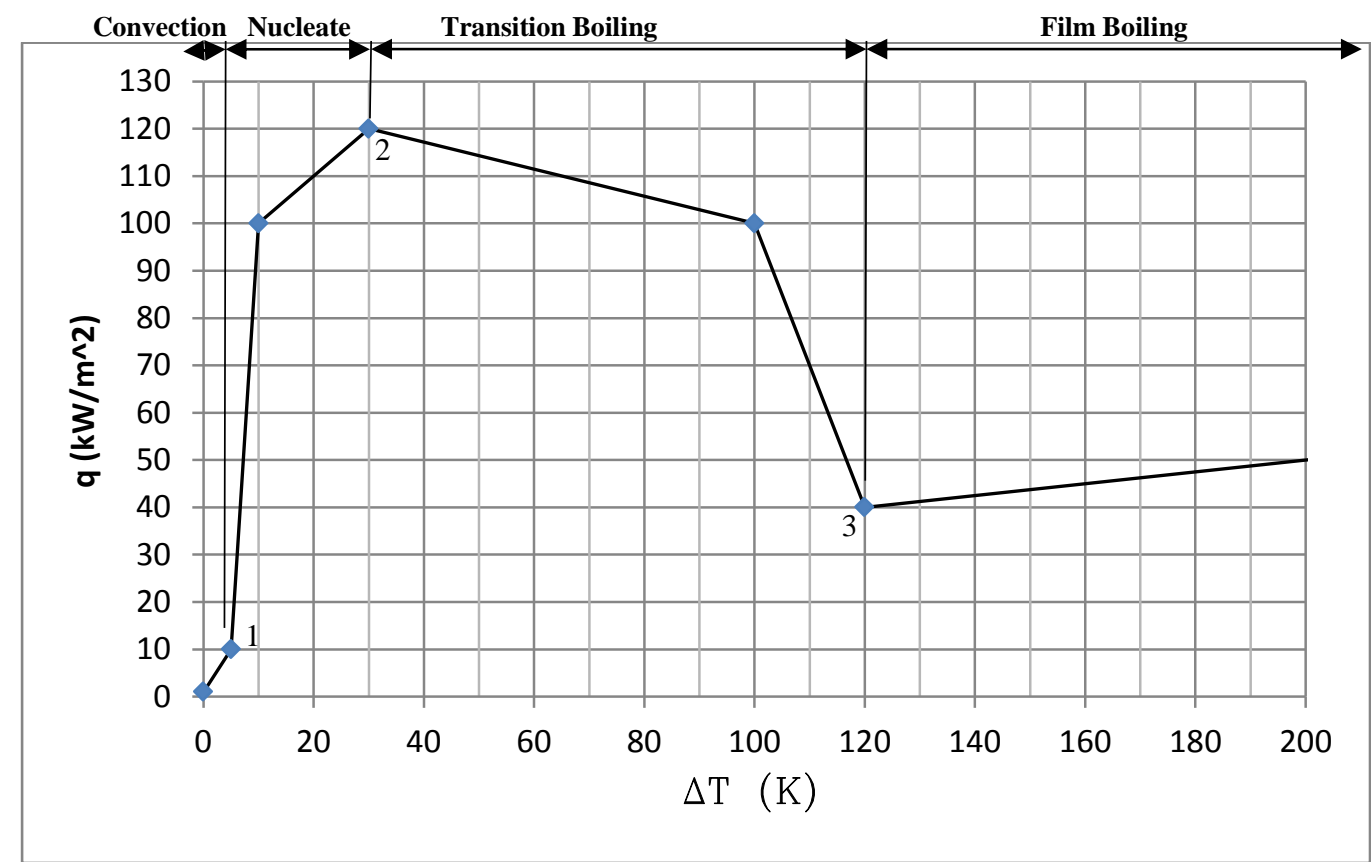

Figure 1-6: Boiling curve for water at atmospheric pressure $(101,325 \mathrm{~Pa})$. The same surface heat flux can result in different excess temperatures depending on the boiling regime [34]

\subsubsection{Film Boiling}

To sustain film boiling, the excess temperature and applied heat flux must be greater than the Leidenfrost Point, LFP, (point 3 on Figure 1-6). For water at atmospheric pressure, the start of 
film boiling corresponds to a heat flux of around $4 \times 10^{4} \mathrm{~W} / \mathrm{m}^{2}$ and an excess temperature $(\Delta \mathrm{T})$ of around $120^{\circ} \mathrm{C}$ (point 3). A layer of vapour continuously insulates the hot surface from the liquid and periodic shedding of vapour bubbles from the vapour/liquid interface occurs. An increase in the applied heat flux leads directly to an increase in excess temperature beyond the Leidenfrost point (point 3). At very high excess temperatures, conduction is not the only mechanism of heat transfer from the hot surface to the liquid, and radiation effects must be considered. As film boiling is relatively stable in nature, unlike nucleate and transition boiling, it is easier to simulate. Figure 1-6 shows how the applied heat flux varies with the excess temperature for the three main boiling regimes. There is disagreement between the experimental LFP values and those predicted by the various models; therefore, an accurate and robust theoretical model which effectively captures the LFP mechanism is currently unavailable. On a polished copper surface, LFP of $193^{\circ} \mathrm{C}$ is reported experimentally [35].

\subsection{Objective/Motivation}

With passive solar heating, in addition to south facing glass and thermal mass, which receives solar energy during the day and stores it for space heating, the share of space heating would diminish by using the TDP in cold regions. It transfers solar energy into the building and, concurrently, prevents heat transfer in reverse (i.e., no heat leaks from indoor to outdoor). In hot climates, TDP can be used in the roof in the opposite direction (i.e., blocks solar heat from the building and transfers heat from indoor to the sky at night). Therefore, it helps to attain NZEB by reducing heating load in cold regions and cooling load in hot regions due to the high thermal conductivity of the thermosyphon structure/tube. The only drawback for TDP mentioned in the literature, is thermal bridging while it works in cold regions. Two initiatives are being investigated in this dissertation: integrating a PCM layer to the TDP and introducing a Teflon ${ }^{2}$ piece to disconnect the evaporator and the condenser sections. Generally, this work intends to provide another avenue for the NZEB initiative. Clearly, the primary objective is to investigate the feasibility of using TDP in buildings as a means to reduce the heating demand. To reduce the thermal bridging effect of TDP, a PCM layer is added to the indoor face of TDP. This integrated PCM and TDP are analysed as a better alternative to TDP. To find the appropriate PCM, some simulation is done parametrically to select the optimum thermal properties for PCM.

\footnotetext{
${ }^{2}$ Teflon is a registered trademark of DuPont.
} 
This dissertation is composed of six chapters (including references) and appendices:

1. Introduction: this chapter covers basic information and theory necessary for readers to follow and understand the experimentations.

2. Literature Review: this chapter reviews the latest papers related to TDP, PCM, and relevant subjects aligned with the goals of this work. Recently published developments and any drawbacks of using PCM and TDP in buildings will be discussed.

3. Simulation: this chapter covers all work done with TRNSYS 16 and SolidWorks. Parametric investigation of PCM thermal properties and their effects on energy demand and indoor air temperature of a typical building (sustainable urbanism initiative, SUI) in Toronto will be investigated using TRNSYS 16. It also covers the effects of free convective heat transfer (h).

4. Simulation: a solution for the problem of thermal bridging across thermosyphon is proposed, and its results are simulated using SolidWorks. The size of the TDP is optimized using the Genetic Algorithm in Matlab to maximize the heat gain in winter and loss in summer by TDP. Finally, the performance of thermosyphon in TDP is simulated using Matlab codes. Toronto weather conditions are used in all simulations. It is possible to simulate for different cities by feeding the weather condition of the city into the Matlab codes. This is a generic code that can optimize TDP sizes by feeding the city weather information into it.

5. Experiment: description of the experiment will be presented in this chapter. Thermosyphon performance in TDP is checked. A thin film electrical heater is used to simulate heat flux from the sun on the evaporator side. Then, the transient surface temperature and energy transfer through the panel is measured on the condenser side.

6. Conclusion and future work: in this chapter a road map of what could be done to improve the quality of this dissertation is covered, and a conclusion of accessible works to date is presented. At the end of this chapter references are attached.

Finally, appendices are included: all developed computer codes and any supportive equations, calibration, and figures are attached to this section. 


\section{Literature Review}

This chapter reviews available literature dedicated to utilization of phase change material (PCM) and thermosyphon in buildings. It is organized in two separate sections: PCM applications in buildings and thermosyphon integrated into the building envelope.

\subsection{PCM in Buildings}

The building sector is the world dominant energy consumer with $28 \%$ of the overall energy consumption [36]. In western countries, this proportion is $45 \%$. Most of the energy goes to heating, ventilation and air-conditioning (HVAC) systems to ensure the thermal comfort of residents [37].

PCMs (as energy storage systems) play a key role in improving energy utilisation, as many sustainable energy sources including solar energy - are intermittent. Solar energy is available during the day, whilst there is a demand for domestic hot water, and space heating or cooling during times of low/no solar radiation [7].

PCMs are classified into five main groups: organic, inorganic, fatty acids, aromatics and eutectic systems $^{3}$. Most of them are solid-liquid, so they change the phase from solid to liquid. Table 2-1 summarises some of them. As Table 2-1 shows, PCMs have low thermal conductivity, which makes them a good alternative for thermal insulation purposes [7]. In addition, melting temperature of a PCM decides its application. For example, to keep the indoor temperature comfortable, the PCM should have the melting temperature inside set points (between lower and upper range). Recently, solid-solid PCM has also been developed that is best fit for integrating with the building envelope [38]. While solid-liquid PCMs should be encapsulated, solid-solid PCMs can be mixed with gypsum and integrated into dry wall [39]. It is reported that a block containing a 5\% (w/w) of micro-capsulated PCM reduces the gypsum thickness by $8.5 \%$ without affecting the insulating property. Thus, PCMs can be used to enhance comfort, reduce energy demand of buildings, and even lower the weight of drywalls [40].

\footnotetext{
${ }^{3}$ Adapted from [10]. A Eutectic system is an alloy of two or more substances that its melting point is lower than any of its constituents and has a single chemical composition
} 
Table 2-1: Thermal and physical Properties of some common PCMs [7]

\begin{tabular}{|c|c|c|c|c|c|}
\hline \multicolumn{2}{|c|}{ Compound } & $\begin{array}{c}\text { Melting } \\
\text { Temp } \\
\left({ }^{\circ} \mathrm{C}\right)\end{array}$ & $\begin{array}{c}\text { Heat } \\
\text { of fusion } \\
(\mathrm{kJ} / \mathrm{kg})\end{array}$ & $\begin{array}{c}\text { Thermal } \\
\text { Conductivity } \\
(\mathrm{W} / \mathrm{mK})\end{array}$ & Density $\left(\mathrm{kg} / \mathrm{m}^{3}\right)$ \\
\hline \multirow{7}{*}{ Inorganics } & $\begin{array}{l}\mathrm{MgCl}_{2} \cdot \\
6 \mathrm{H}_{2} \mathrm{O}\end{array}$ & 117 & 168.6 & $\begin{array}{l}0.57 \text { (liquid, } 120^{\circ} \mathrm{C} \text { ) } \\
0.694 \text { (solid, } 90^{\circ} \mathrm{C} \text { ) }\end{array}$ & $\begin{array}{l}1450 \text { (liquid, } 120^{\circ} \mathrm{C} \text { ) } \\
1569 \text { (solid, } 20^{\circ} \mathrm{C} \text { ) }\end{array}$ \\
\hline & $\mathrm{Mg}\left(\mathrm{NO}_{3}\right)_{2}$ & \multirow{2}{*}{89} & \multirow{2}{*}{162.8} & 0.49 (liquid, $95^{\circ} \mathrm{C}$ ) & 1550 (liquid, $94^{\circ} \mathrm{C}$ ) \\
\hline & $\cdot 6 \mathrm{H}_{2} \mathrm{O}$ & & & 0.611 (solid, $37^{\circ} \mathrm{C}$ ) & 1636 (solid, $25^{\circ} \mathrm{C}$ ) \\
\hline & $\mathrm{Ba}(\mathrm{OH})_{2}$ & \multirow{2}{*}{48} & \multirow{2}{*}{265.7} & 0.653 (liquid, $85.7^{\circ} \mathrm{C}$ ) & 1937 (liquid, $84^{\circ} \mathrm{C}$ ) \\
\hline & $8 \mathrm{H}_{2} \mathrm{O}$ & & & 1.225 (solid, $\left.23^{\circ} \mathrm{C}\right)$ & 2070 (solid, $\left.24^{\circ} \mathrm{C}\right)$ \\
\hline & $\mathrm{CaCl}_{2}$ & \multirow{2}{*}{29} & \multirow{2}{*}{190.8} & 0.54 (liquid, $38.7^{\circ} \mathrm{C}$ ) & 1562 (liquid, $32^{\circ} \mathrm{C}$ ) \\
\hline & $6 \mathrm{H}_{2} \mathrm{O}$ & & & 1.088 (solid, $23^{\circ} \mathrm{C}$ ) & 1802 (solid, $24^{\circ} \mathrm{C}$ ) \\
\hline \multirow{4}{*}{ Organics } & Paraffin & \multirow{2}{*}{64} & \multirow{2}{*}{173.6} & 0.167 (liquid, $63.5^{\circ} \mathrm{C}$ ) & 790 (liquid, 65 $\mathrm{C}$ ) \\
\hline & wax & & & 0.346 (solid, $\left.33.6^{\circ} \mathrm{C}\right)$ & 916 (solid, $\left.24^{\circ} \mathrm{C}\right)$ \\
\hline & Polyglycol & 22 & 1272 & 0 180 (liauid 38 & 1126 (liquid, $25^{\circ} \mathrm{C}$ ) \\
\hline & E600 & 22 & 121.2 & 0.109 (III) & 1232 (solid, $4^{\circ} \mathrm{C}$ ) \\
\hline \multirow{6}{*}{$\begin{array}{l}\text { Fatty } \\
\text { Acids }\end{array}$} & Palmitic & \multirow{2}{*}{64} & \multirow{2}{*}{185.4} & \multirow{2}{*}{0.162 (liquid, $68.4^{\circ} \mathrm{C}$ ) } & 850 (liquid, $65^{\circ} \mathrm{C}$ ) \\
\hline & Acid & & & & 989 (solid, $\left.24^{\circ} \mathrm{C}\right)$ \\
\hline & Capric & \multirow{2}{*}{32} & \multirow{2}{*}{152.7} & \multirow{2}{*}{0.153 (liquid, $38.5^{\circ} \mathrm{C}$ ) } & 878 (liquid, $45^{\circ} \mathrm{C}$ ) \\
\hline & Acid & & & & 1004 (solid, $\left.24^{\circ} \mathrm{C}\right)$ \\
\hline & Caprylic & \multirow{2}{*}{16} & \multirow{2}{*}{148.5} & \multirow{2}{*}{0.149 (liquid, $38.6^{\circ} \mathrm{C}$ ) } & 901 (liquid, $30^{\circ} \mathrm{C}$ ) \\
\hline & Acid & & & & 981 (solid, $13^{\circ} \mathrm{C}$ ) \\
\hline \multirow[t]{2}{*}{ Aromatics } & \multirow{2}{*}{ Naphthalene } & \multirow{2}{*}{80} & \multirow{2}{*}{147.7} & 0.132 (liquid, $83.8^{\circ} \mathrm{C}$ ) & 976 (liquid, $84^{\circ} \mathrm{C}$ ) \\
\hline & & & & 0.341 (solid, $\left.49.9^{\circ} \mathrm{C}\right)$ & 1145 (solid, $20^{\circ} \mathrm{C}$ ) \\
\hline \multirow{2}{*}{$\begin{array}{l}\text { Eutectic } \\
\text { Systems }\end{array}$} & Bi-Cd-In & 61 & 25 & & \\
\hline & Bi-Pb-In & 70 & 29 & & \\
\hline
\end{tabular}

PCMs are not the only materials for storing thermal energy. There are so many different ways of storing thermal energy. Figure 2-1 shows the most popular high energy storage density Sorption long-term Solar Heat Storage (SSHS) materials available for storing solar energy [1]. Sorption refers to adsorption and absorption here. 


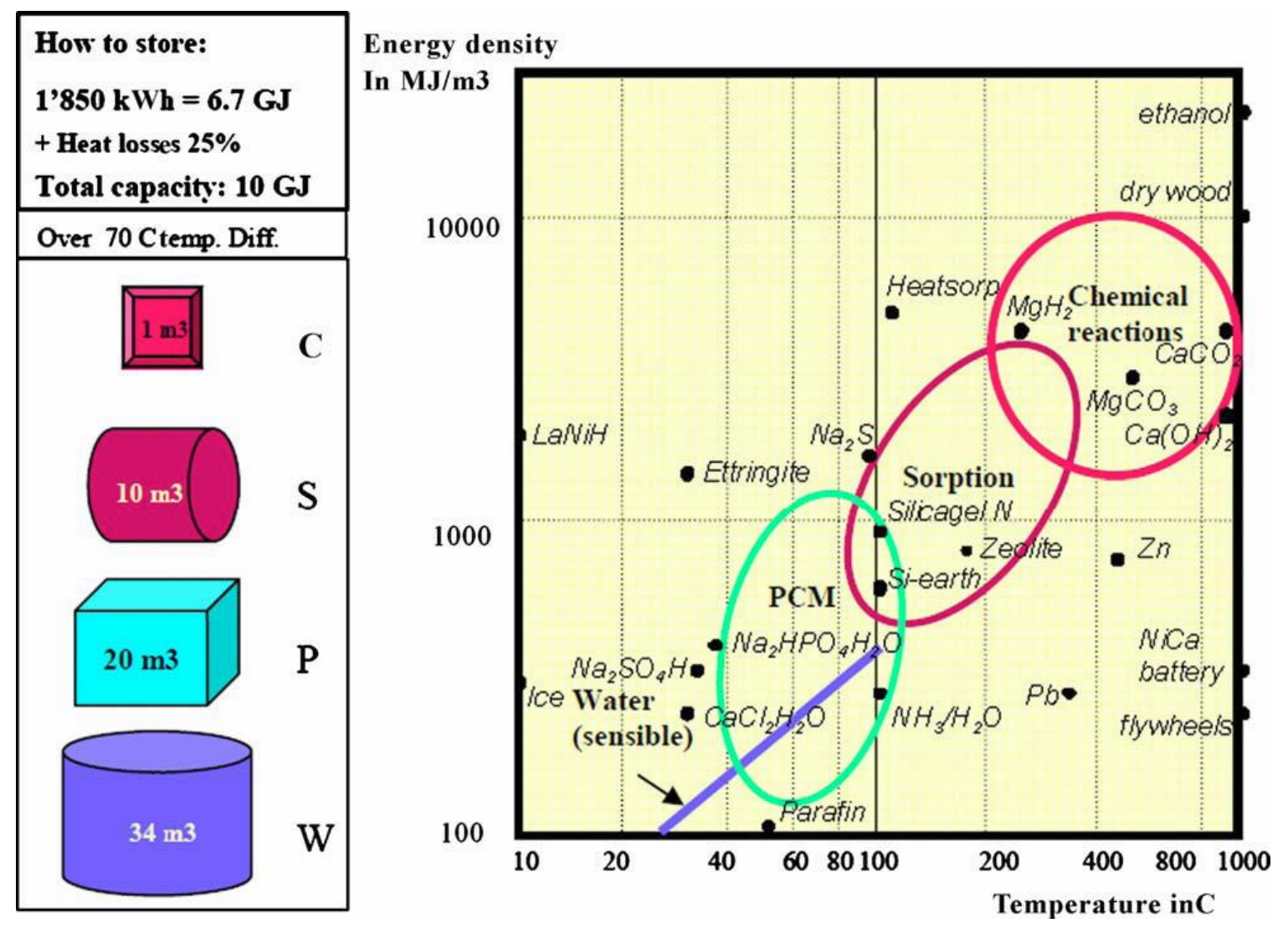

Figure 2-1: Energy density of high energy storage materials [1]

Figure 2-2 shows the classification of PCMs.

Passive and active means can provide thermal comfort. The passive means are desired due to providing the thermal storage in the building envelope. The active means transfer energy with mechanical or thermal systems. Several authors studied the performance of walls with PCM in cell tests and compared the experimental results with ones obtained by numerical simulation [40], [37]. Others conducted only numerical simulation on the whole building or on a part of the building [41], [42]. And extensive experimental and numerical simulation study was conducted on a cell test. The walls had their interior layer made of $25 \%, \mathrm{w} / \mathrm{w}$, butyl stearate (PCM) and plasterboard [43]. They found that the use of the PCM reduced the indoor temperature flactuations by $4^{\circ} \mathrm{C}$.

Review of dynamic charactristics and energy performance of buildings using PCMs showed that [44]:

- $\quad$ PCMs enhance building thermal and energy performance. 
- $\quad$ energy performance of buildings using PCMs are not sufficiently studied.

- $\quad$ the research on using optimal control strategies may increase the potential of using PCMs.

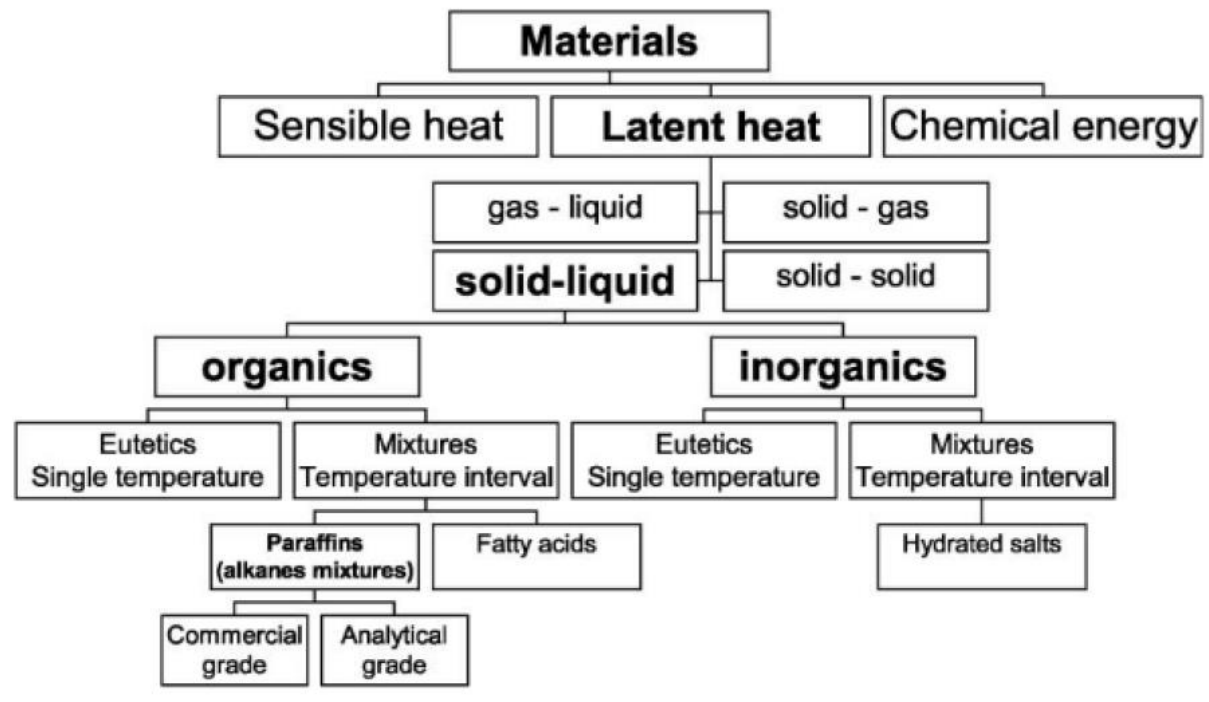

Figure 2-2: Classification of energy storage materials [45]

\subsubsection{Phase Change Material (PCM) Modelling}

Based on the utilization methods and type of application of PCMs, different assumptions and mathematical models can be found in literature. PCM storage capacity stems from the enthalpy change during phase change at constant temperature. Generally, enthalpy change has the form of [46]:

$$
\Delta E=\int_{T_{R f}}^{T} C_{p} d T+\int_{P_{R f}}^{P} \frac{1}{\rho}\left(1+\left.\frac{T}{\rho} \frac{\partial \rho}{\partial T}\right|_{p}\right) d P
$$

where Rf refers to reference condition. $\mathrm{P}, \rho$ and $\mathrm{T}$ are pressure, density and temperature, respectively. In PCM simulations, there is no pressure change, so the second term is zero. For PCM micro-capsulated in polystyrene containing 50\% (w/w) of Rubitherm RT27 inside the wallboard, the following assumptions were made [40]:

i. The total volume of the wallboard is constant. The porous gypsum allows the expansion of the microcapsules when the PCM melts.

ii. Microcapsules are homogenous and uniformly distributed inside the wallboard. 
iii. By varying of the apparent specific heat capacity $\left(c_{p}^{a p}\right)$ with temperature, the contribution of the latent heat of the PCM to the storage capacity of the wallboard is established. Curves of $c_{p}^{a p}$ for the gypsum with different PCM percentages were obtained by Modulated Differential Scanning Calorimetry (MDSC) and input to the model.

iv. The PCM density and thermal conductivity are related to the melted fraction (f).

v. The heat transfer through the wall is considered one-dimensional $(x)$.

vi. Due to the small range of working temperature, the variation of the thermo-physical properties of insulating material with the temperature is negligible.

Borreguero et al. (2010) developed the mathematical model based on the Fourier heat conduction equation. In the Equation (2-1), substituting reference enthalpy and temperature with zero, and considering constant specific heat capacity $\left(C_{p}\right)$, enthalpy $(E)$ is defined [40]:

$$
E=c_{p}^{a p}\left(T-T_{R f}\right)
$$

where $T$ and $T_{R f}$ are wallboard and reference temperatures, respectively. Taking into account the temperature dependence of $h$ and density $(\rho)$, Fourier equation becomes:

$$
\frac{\partial T}{\partial t}=\frac{\frac{\partial}{\partial x}\left(k \frac{\partial T}{\partial x}\right)}{c_{p}^{a p} \rho+\left(c_{p}^{a p} \frac{\partial \rho}{\partial T}+\rho \frac{\partial c_{p}^{a p}}{\partial T}\right)\left(T-T_{R f}\right)}
$$

They found a good agreement between experimental and predicted data by solving the above equation. In addition, it was concluded that the higher the PCM content in the wallboard, the higher storage energy capacity and the lower wall thickness were required in order to set the same level of comfort and reduce energy demand.

Not only amount and type of PCM, but also climate, design and orientation of the construction are factors affecting the thermal improvements of a building [47]. TRNSYS has been successfully used to simulate PCM effects in buildings. EnergyPlus, TRNSYS ${ }^{4}$ and ESP-r ${ }^{5}$ are found to be versatile and reliable to simulate PCM performance by Natural Resource Canada [47]. A joint report comparing various features of 20 building simulation softwares revealed that EnergyPlus, TRNSYS and ESP-r have the capability to simulate PCM [48]. Behavior of solid-

\footnotetext{
${ }^{4}$ TRNSYS is an acronym for a 'transient simulation program' and is a quasi-steady simulation model. This program was developed at the University of Wisconsin by the members of the Solar Energy Laboratory.

${ }^{5}$ ESP-r (energy systems performance-research) is an open-sourced building performance energy modeling software that was created by the University of Strathclyde.
} 
solid PCM in Toronto weather conditions was studied using TRNSYS [39]. They incorporated the gypsum drywall with different percentage of PCM and investigated the mechanical and thermal effects of PCM addition.

TRNSYS has so many component models with which thermal behavior of a building can be simulated. Type 56 is one of them for simulating a multi-zone building. It can simulate up to 25 thermal zones in a building. Type 56 has one air node for each zone. The thermal capacity of the zone air volume is represented by this node. In addition, Type 56 is not a shape/geometry balance model. Type 56 is controlled by other modules connected to TRNSYS. By introducing appropriate active wall temperature functions, TRNSYS modules can control Type 56. Figure 23 shows the interaction between different Types/components on TRNSYS when they are identified, and their mathematical descriptions are available. The proposed methodology was validated by the experiment. A 5\% (w/w) MICRONAL was incorporated into a concrete block [47]. Previous authors investigated how to optimize economically the use of the PCM by keeping in mind the following points:

i. The PCM panels can be mounted in walls, ceilings, floors or a combination of them.

ii. The capacity of the panels to store heat depends on the volume percentage of PCM included.

iii. The temperature at which the PCM transforms phase should be between lower and upper set points.

They concluded that indoor temperature fluctuation decreases up to $3^{\circ} \mathrm{C}$ (on average) with respect to ambient temperature fluctuation with the following recommendations:

1. The ceiling and west wall of the prototype room shall have the PCM.

2. For the maximum air temperature reduction, the required storage capacity of the panels in the ceiling and west is measured around $15 \mathrm{MJ} / \mathrm{m}^{3}$ and $37.500 \mathrm{MJ} / \mathrm{m}^{3}$, respectively.

3. It is well accepted that the momentum and mass conservation equations of Navier-Stokes equations are negligible in developing mathematical modelling of PCM in buildings [45]; therefore, the energy equation is the only one developed and solved.

4. Daily heat storage utilization of PCMs in walls was first discussed by [49]. They covered all the south-facing direct-sun-shine room with PCM panels. They impregnated fatty acid PCM into conventional 13-mm thick plasterboard. 


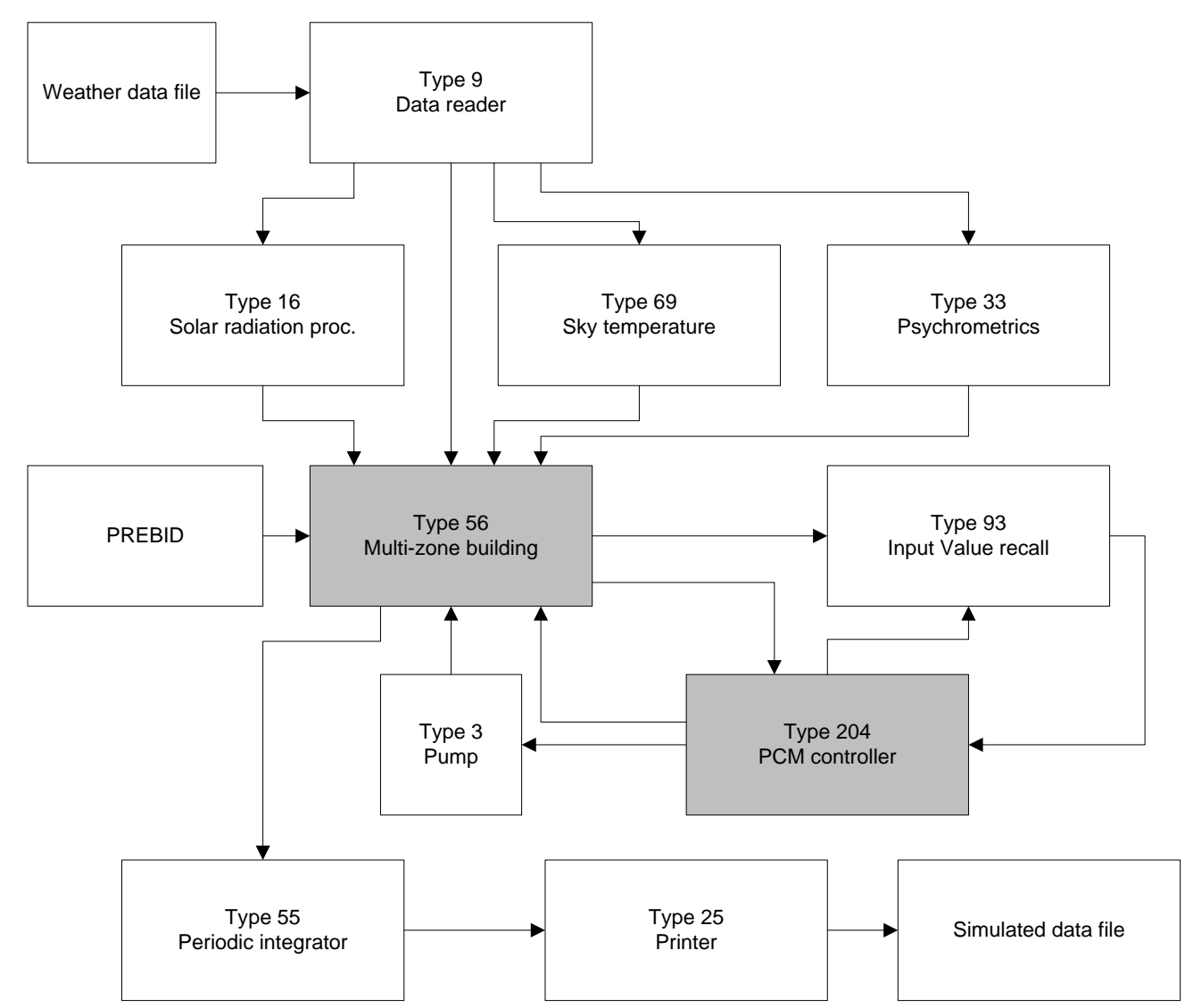

Figure 2-3: TRNSYS flow chart of information for the building containing PCM [50]

There are two main numerical methods to simulate PCMs: the effective/apparent specific heat capacity, $c_{p}^{a p}(T)$ and enthalpy, $E(T)$ methods. If the temperature change is described using heat capacity, the first method is employed. $c_{p}^{a p}(T)$ can be measured using a differential scanning colorimetry (DSC) in the dynamic mode. The dynamic DSC includes non-isothermal behavior during the phase change in PCMs that strongly depends on the scanning rate $\left({ }^{\circ} \mathrm{C} / \mathrm{min}\right)$ of the DSC and PCM sample size. This brings the potential deviation of the PCMs heat capacity with respect to the temperature [51]. This can be avoided by employing the second (enthalpy) method. It provides heat capacity in terms of its integral form, $E(T)$, with respect to temperature. TRNSYS and ESP-r use pre-defined heat capacity values as input data.

Simulation software solves the differential equation using numerical methods to find temperature at each node and at each time step. However, due to non-linear relationship between heat capacity and temperature during phase change, an explicit scheme is used mostly where the heat capacity is calculated from the nodal temperature values at the previous time instant. This has a 
potential for error during the phase change where the heat capacity changes abruptly with temperature. This error is investigated by writing a Matlab code and comparing the results with ESP-r [12]. The authors introduced a step function to express the heat capacity during phase change:

$$
c_{p}^{a p}(T)=a T+b ; \quad T_{i}<T<T_{e}
$$

The above equation was used as an input to ESP-r for $c_{p}^{a p}(T)$, where $\mathrm{a}=0$ and $\mathrm{b}=\mathrm{L} / \Delta \mathrm{T}$, L and $\Delta \mathrm{T}$ denote the latent heat capacity and phase change transition temperature range (i.e., $\left.T_{e}-T_{i}\right)$. A comparison of the apparent heat capacity method and the enthalpy method results during the phase change process shows that there is a potential error with the former method, especially when the time step is quite large. This was verified with a case study on the BESTEST Case 600 model subjected to Toronto weather conditions. It was found that the building simulation software ESP-r could give results that matched those of the Matlab using iterative enthalpy method only when the time step was reduced to as low as 2 minutes. Matlab results were however found to be fairly independent of the time step value. Building simulations are typically carried out for long time periods (a year or more); it might be impractical to run such long term simulations with small time steps [12].

In another work, PCMs were modelled using a 4-layer structure in ESP-r instead of a single layer, i.e., a given thickness of PCM was divided into 4 layers and added to the structure with each layer's thickness as $1 / 4$ of the original thickness. A total of 9 nodes were used in the 4 -layer PCM structure. This was done to improve simulation accuracy during the phase change [52]. Solidworks and Comsol are also capable of simulating PCM in different thermal applications, but they have not been used to simulate PCM performance in buildings.

\subsection{Thermodiode Panel (TDP)}

To study the performance of a TDP, its thermal properties (i.e., thermal conductivity and diffusivity and specific heat) shall be determined. Thus, the structure and specification of a TDP will be defined. Figure 2-4 shows the TDP diagram integrated with a PCM layer. Thermosyphon is the core of the TDP that transfers heat from outdoor (solar radiation) into indoor when the outdoor surface is warmed over $40^{\circ} \mathrm{C}$. The Clausius-Clapeyron equation is employed to calculate the pressure that makes water boil at the mentioned temperatures, [53]: 


$$
P=C e^{-\frac{h_{l v}}{R T}}
$$

where $\mathrm{C}$ is a constant $(\mathrm{Pa}), h_{l v}$ is latent heat of vaporization for water $(40.7 \mathrm{~kJ} / \mathrm{mol}), \mathrm{R}$ is gas constant (8. $3145 \mathrm{~J} / \mathrm{mol} . \mathrm{K})$, and $\mathrm{T}$ is temperature $(\mathrm{K})$. To make water boil at $40^{\circ} \mathrm{C}$ and using Equation (2-5), the inside absolute pressure of the thermosyphon should be less than $10 \mathrm{kPa}$. At this condition, the specific enthalpy of evaporation is $2393 \mathrm{~kJ} / \mathrm{kg}$.

Various types of thermosyphon can be made suitable for different applications. Conveniently, a gravity-assisted wickless heat pipe is a two-phase closed thermosyphon. Thermosyphon containers are generally circular cylinders, used for simplicity of design and manufacturing. However, other shapes, such as rectangular (flat plate), parallelepiped, micro/miniature, conical (rotating), and nose-cap (leading edge) geometries have also been investigated for special applications [28], [19].

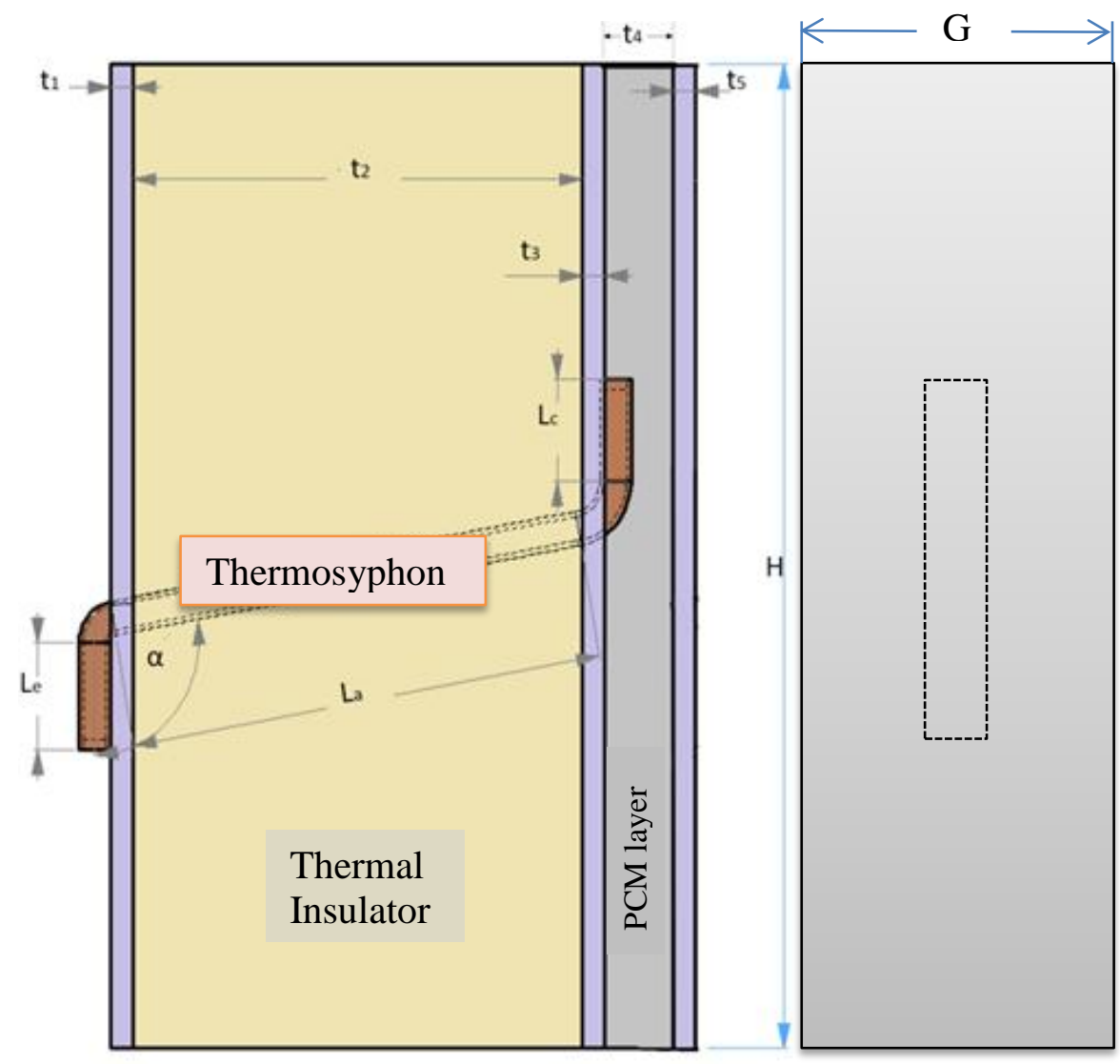

Figure 2-4: TDP structure, thermosyphon is passing across the panel. Three aluminum plates are shown with thicknesses of $t 1, t 3$ and $t 5$ 
Additionally, it is proved that by treating the internal surfaces of condenser (more hydrophobic) and evaporator (more hydrophilic), the average thermal performance of thermosyphon increases by $15.3 \%$ [54], [55].

Figure 2-5 shows the process, which occurs inside the thermosyphon. As soon as the surface is warmed above $40^{\circ} \mathrm{C}$ by solar radiation, water boils, and vapour moves up due to buoyancy force (dashed arrows). As the indoor temperature is less than $40^{\circ} \mathrm{C}$, the heat of vaporization transfers into the indoor air at the condenser section, and condensate moves back to the pool by gravity (solid arrows). For any thermosyphon, the maximum heat transport capacity is governed by six limits; namely, vapour pressure limit, the sonic limit, dry-out limit, the boiling limit, the flooding limit, and liquid fill limit. These limits could he calculated by using the techniques presented in literature [56], [27], [17], and the critical limit would be the minimum value calculated. For a

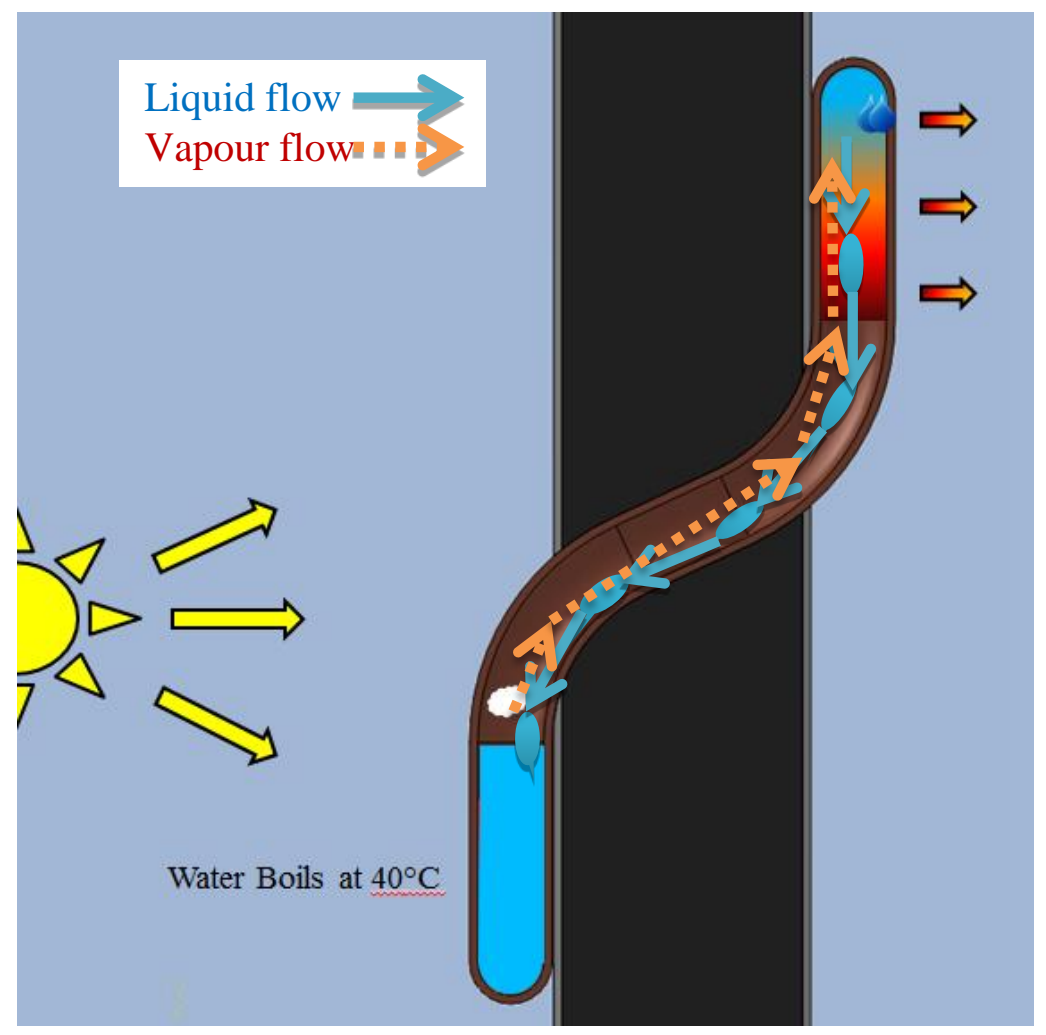

Figure 2-5: A section of thermosyphon inside the TDP structure, thermosyphon transfers heat across the TDP 
gravity heat pipe, filled liquid mass also influences its heat transfer to a certain extent, representing an additional limit which could be calculated by the method presented by others [57], [56].

\subsubsection{Heat transfer limitations in thermosyphon}

Heat transfer increases across the thermosyphon due to the temperature difference increase at both ends until the transfer reaches a maximum value. This maximum value may be due to:

- Vapour pressure limit: as operating pressure inside the thermosyphon for this design is about 0.1 atmosphere (water boils around $40^{\circ} \mathrm{C}$ at this pressure). The pressure drop of the vapour may be significant compared with the pressure in the evaporator. This limit prevails when thermosyphon starts at temperature below the normal operating temperature, e.g., from frozen condition. In this condition, the vapour pressure is near zero. An estimation of the vapour pressure limit is given in the Engineering Sciences Data Unit (ESDU).

- Sonic limit: when operating pressure is low, the vapour velocity may be high compared with sonic velocity in the vapour. While thermosyphon operates, vapour flows between evaporator and condenser. The vapour velocity reaches its maximum at the end of the evaporator. At the same time, the condensate is returning to the evaporator at the maximum vapour velocity point. The sonic limitation has positive correlation with respect to the evaporator temperature. An estimation of the sonic limit is given in the ESDU. This limit is $7.8 \mathrm{MW} / \mathrm{m}^{2}$ for water at $20^{\circ} \mathrm{C}$, while it increases to $277 \mathrm{MW} / \mathrm{m}^{2}$ at $100^{\circ} \mathrm{C}$.

- Dryout limit: this limit addresses the amount of fluid. In a vertical thermosyphon, Dryout is avoided if the filling meets some conditions. Generally, from the classical Nusselt theory, the minimum volume of the fluid $(V)$ can be determined [28]. As a rough estimation, it is advised that the fluid volume obey the following rule [31]:

$$
V>0.001 D\left(L_{e}+L_{a}+L_{c}\right)
$$

where $\mathrm{D}$ is the internal diameter of the thermosyphon tube. This equation provides a film thickness of more than $0.3 \mathrm{~mm}$ over the total length of the inner surface of the thermosyphon. Although Equation (2-6) provides a criterion for minimum filling of 
fluid, the optimum value is estimated experimentally [58]. ESDU suggests that $40 \%$ to $60 \%$ of the evaporator volume should be filled with the fluid [56].

- Boiling limit: this limit occurs between the fluid and heated wall of the evaporator when a stable film of vapour is formed in this region. If the ratio of the length to the internal diameter of the evaporator exceed $10\left(L_{e} / D>10\right)$, and the working temperature is $20^{\circ} \mathrm{C}$, or $68\left(L_{e} / D>68\right)$ while the working temperature is $100^{\circ} \mathrm{C}$, the sonic limit occurs before boiling limit [56].

- Flooding limit: this limit is sometimes called "entrainment" or "counter-current flow". When there is enough fluid to prevent dryout happening, the fluid may be entrained by vapour to flow back (downward) to the evaporator after condensing on the condenser surface. This limits the maximum axial vapour mass flux in a vertically operated thermosyphon as [56]:

$$
\frac{Q_{\max }}{A h_{l v}}=f_{1} f_{2} \rho_{v}^{0.5}\left[g\left(\rho_{l}-\rho_{v}\right) s\right]^{0.25}
$$

where $\mathrm{A}$ and $h_{l v}$ are the cross section area and latent heat of evaporation of the fluid, respectively, and $f_{1}$ is a function of the Bond number (Bo), which is defined as:

$$
B o=D\left[g\left(\rho_{l}-\rho_{v}\right) / S\right]^{0.5}
$$

where D is the internal diameter and $S$ is surface tension.

The value of $f_{2}$ is a function of the dimensionless pressure, $K_{p}$, which is defined as:

$$
\begin{gathered}
K_{p}=\frac{p_{v}}{\left[g\left(\rho_{l}-\rho_{v}\right) S\right]^{0.5}} \\
f_{2}=\left\{\begin{array}{l}
K_{p}^{-0.17} \text { if } K_{p} \leq 10^{4} \\
0.165 \text { if } K_{p}>10^{4}
\end{array}\right.
\end{gathered}
$$

and

The ESDU recommends that the thermosyphon be designed to operate at less than $50 \%$ of the maximum heat flux.

\subsubsection{Boiling water simulation/Formulation}

The boiling of water at normal pressure (one atmosphere) is well understood and its value is available in textbooks [59], [60]. The physical behavior of a boiling flow is driven by the interface dynamics. The governing partial differential equations are the standard Navier-Stokes and convection/conduction equations. The boundary conditions are, however, rather complicated because the interface between the liquid and vapour is moving. 
The first law of thermodynamics governs all heat transfer equations as the principle of conservation of energy [53]:

$$
\Delta E I=\Delta U+\Delta K E+\Delta P E
$$

where EI, U, KE, and PE are total, internal, kinetics, and potential energy, respectively. However, $\mathrm{U}$ is an inconvenient quantity to measure and use in simulations. Therefore, the law is usually written in terms of temperature, T. For a fluid, the heat transfer equation is [33]:

$$
\rho C_{p}(\partial \mathrm{T} / \partial \mathrm{t}+(\mathrm{u} \cdot \nabla) \mathrm{T})=-(\nabla \cdot q)+\tau: S r-\left.\frac{T}{\rho} \frac{\partial \rho}{\partial T}\right|_{p}\left(\frac{\partial P}{\partial t}+(u \cdot \nabla) p\right)+Q
$$

where:

- $\rho$ is the density $\left(\mathrm{kg} \cdot \mathrm{m}^{-3}\right)$

- $C_{\mathrm{p}}$ is the specific heat capacity at constant pressure $\left(\mathrm{J} \cdot \mathrm{kg}^{-1} \cdot \mathrm{K}^{-1}\right)$

- $T$ is absolute temperature $(\mathrm{K})$

$\cdot \mathrm{u}$ is the velocity vector $\left(\mathrm{m} \cdot \mathrm{s}^{-1}\right)$

$\cdot \mathrm{q}$ is the heat flux by conduction $\left(\mathrm{W} \cdot \mathrm{m}^{-2}\right)$

- $P$ is pressure $(\mathrm{Pa})$

- $\tau$ is the viscous stress tensor $(\mathrm{Pa})$

- $\mathrm{Q}$ contains heat sources other than viscous heating $\left(\mathrm{W} \cdot \mathrm{m}^{-3}\right)$

- $\mathrm{Sr}$ is the strain-rate tensor $\left(\mathrm{s}^{-1}\right)$ :

$$
S r=\frac{1}{2}\left(\nabla u+(\nabla u)^{T}\right)
$$

The operation ":" is a contraction and can in this case be written on the following form:

$$
\tau: S r=\sum_{i} \sum_{j} \tau_{i j} S r_{i j}
$$

It is assumed that mass is always conserved:

$$
\frac{\partial \rho}{\partial t}+\nabla \cdot(\rho u)=0
$$

The heat transfer interfaces use Fourier's law of heat conduction in each direction $(i)$ : 


$$
q_{i}=-\sum_{j} k_{i j} \frac{\partial T}{\partial x_{j}}
$$

where $k_{i j}$ is the thermal conductivity in different direction in $\mathrm{W} \cdot \mathrm{m}^{-1} \cdot \mathrm{K}^{-1}$.

In Equation (2-12), the third term represents working pressure. This term is responsible for the heating of a fluid under adiabatic compression and for some thermo-acoustic effects. If flows are in low speed, it is generally a small value. To consider thermo-elastic effects in solids, a similar term can be included. Substituting Equation (2-16) into Equation (2-12), reordering the terms and ignoring viscous heating and pressure work put the heat equation into a more familiar form:

$$
\rho C_{p} \frac{\partial T}{\partial t}+\rho C_{p} u \cdot \nabla T=\nabla \cdot(\mathrm{k} \nabla T)+Q
$$

To solve boiling equation in Comsol, the boiling flow problem is formulated with the exact equations and boundary conditions. Then, a series of approximations are made so that the problem can be solved on a fixed mesh where the interface is tracked by the phase field equation. The velocity field and pressure for the liquid phase are described by the incompressible ${ }^{6}$ NavierStokes equations [61]:

$$
\begin{gathered}
\rho_{l} \frac{\partial u_{l}}{\partial t}+\rho_{l}\left(u_{l} \cdot \nabla\right) u_{l}=\nabla \cdot\left[-P_{l} I+\eta_{l}\left(\nabla u_{l}+\left(\nabla u_{l}\right)^{T}\right)\right]+\rho_{l} g \\
\nabla \cdot u_{l}=0
\end{gathered}
$$

where $\rho_{l}$ is density $\left(\mathrm{kg} / \mathrm{m}^{3}\right), u_{l}$ is velocity $(\mathrm{m} / \mathrm{s}), \eta_{l}$ is viscosity $(\mathrm{Pa} \cdot \mathrm{s}), \quad \mathrm{I}$ is the identity tensor, $\mathrm{g}$ is gravitational acceleration, and $l$ denotes liquid phase. For the vapour phase, the weakly compressible Navier-Stokes equations are solved:

$$
\begin{gathered}
\rho_{v} \frac{\partial u_{v}}{\partial t}+\rho_{v}\left(u_{v} \cdot \nabla\right) u_{v}=\nabla \cdot\left[-P_{v} I+\eta_{v}\left(\nabla u_{v}+\left(\nabla u_{v}\right)^{T}\right)-\left(\frac{2}{3} \eta-\kappa_{v}\right)(\nabla \cdot u) I\right]+\rho_{v} g \\
\frac{\partial u_{v}}{\partial t}+\nabla \cdot\left(\rho_{v} u_{v}\right)=0
\end{gathered}
$$

The heat conduction equation is solved only in the vapour phase:

$$
\rho_{v} C_{p} \frac{\partial T_{v}}{\partial t}+\rho_{v} C_{p}\left(u_{v} \cdot \nabla\right) T_{v}=-\nabla \cdot k_{v} \nabla T_{v}
$$

\footnotetext{
${ }^{6}$ An incompressible flow is such that the velocity is solenoidal $(\nabla \cdot v=0$, this equation is satisfied when the density of the fluid is constant)
} 
where $C_{p}$ is the specific heat capacity $(\mathrm{J} /(\mathrm{kg} \cdot \mathrm{K}))$ and $k_{v}$ is the thermal conductivity of the vapour $(\mathrm{W} /(\mathrm{m} \cdot \mathrm{K}))$. The heat conduction equation is only solved in the vapour phase because the temperature at the liquid/vapour interface is set to the saturation temperature. This results in a constant temperature throughout the liquid phase, and so it is not necessary to solve the heat conduction equation.

\subsubsection{Steady/Transient two-dimensional analysis of thermosyphon}

In the TDP, thermosyphon transfers the input heat from one end to the other end. Thus, analysis of heat transfer across the thermosyphon is prime important. Comprehensive analysis of the heat transfer has been done by Faghri [28] with the following assumptions:

1. Sub-cooling of the liquid is negligible.

2. The vapour condenses film-wise with no interfacial wave.

3. There are negligible convection effects in the liquid.

4. There are negligible inertia effects in the liquid.

5. There are negligible circumferential liquid velocity and temperature gradients.

6. The vapour density is negligible with respect to liquid density.

7. The thickness of the liquid film is much smaller than the vapour radius.

These assumptions are demonstrated in Figure 2-6.

Referring to Cartesian coordinates in Figure 2-6, simplified equations (from momentum, mass and energy equations) describing the thin liquid film would be [28]:

$$
\frac{\partial^{2} u_{l}}{\partial y^{2}}=\frac{1}{\mu_{l}} \frac{d p_{l}}{d x}-\frac{\rho_{l} g}{\mu_{l}}
$$

and

$$
\frac{\partial^{2} T_{l}}{\partial y^{2}}=0
$$

where $\mathrm{y}$ is the distance from the pipe inside wall, $\mathrm{g}$ is the gravitational acceleration, $\mathrm{w}$ is the velocity, $\mu$ is viscosity, $\rho$ is density, and $\mathrm{x}$ is the distance from the condenser inside end cap.

Boundary conditions are:

$\left\{\begin{array}{c}\left.u_{l}=0 \text { at } y=0 \text { (due to no slip condition }\right) \\ \mu_{l} \frac{\partial u_{l}}{\partial y}=-\mu_{v} \frac{\partial u_{v}}{\partial r} \text { at } y=\delta(\text { the shear stress is equal at interface of liquid }- \text { vapor })\end{array}\right.$ 


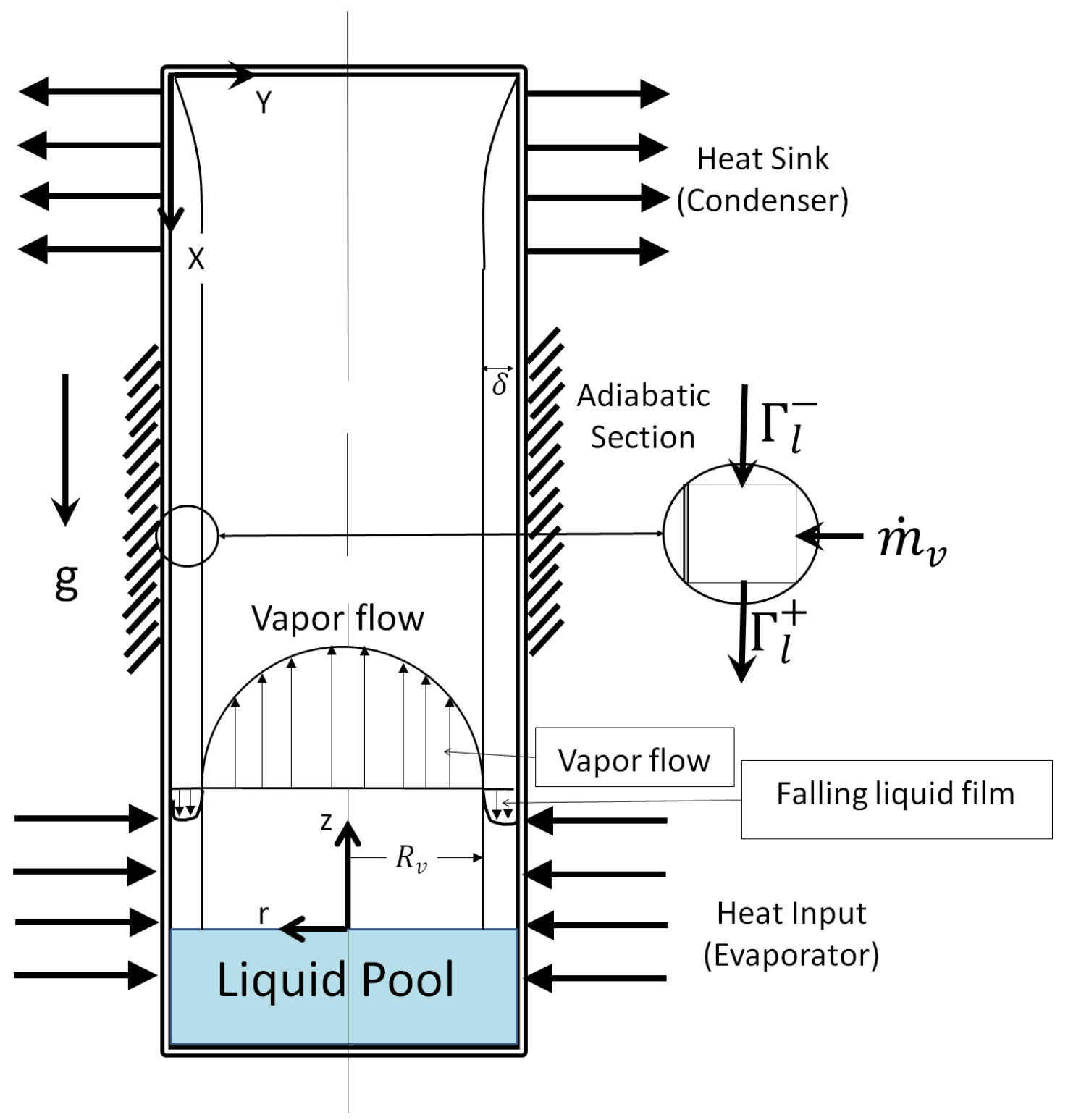

Figure 2-6: A section of thermosyphon inside, a control volume of falling liquid flow is magnified

If the liquid pressure is considered constant across its thickness, the pressure gradient in the liquid can be estimated by the liquid-vapour interface conditions $\left(\frac{d p_{l}}{d x}=-\frac{d p_{v}}{d z}\right)$. The author used cylindrical coordinates to investigate the vapour flow. Considering the above points, Equation 223 can be further simplified and solved:

$$
u_{l}(y)=\left(g \rho_{l}+\frac{d p_{v}}{d z}\right) \frac{\delta^{2}}{\mu_{l}}\left[\frac{y}{\delta}-\frac{1}{2}\left(\frac{y}{\delta}\right)^{2}\right]+\left.\frac{\mu_{v} y}{\mu_{l}} \frac{\partial u_{v}}{\partial r}\right|_{r=R_{v}}
$$


A new function was defined to represent the liquid axial mass flow rate per unit width:

$$
\Gamma_{l}=\int_{0}^{\delta} \rho_{l} u_{l} y d y
$$

Combining the above two equations gives the total mass flow rate:

$$
\Gamma_{l}=\left(g \rho_{l}+\frac{d p_{v}}{d z}\right) \frac{\rho_{l} \delta^{3}}{3 \mu_{l}}+\left.\frac{\mu_{v} \rho_{l} \delta^{2}}{2 \mu_{l}} \frac{\partial u_{v}}{\partial r}\right|_{r=R_{v}}
$$

Considering conservation of mass, $\frac{\partial \Gamma_{l}}{\partial x} d x=\Gamma_{l}^{+}-\Gamma_{l}^{-}=\dot{m}_{v}$

where $\dot{m}_{v}$ is the rate of vapour condensation/evaporation per unit width over the controlled volume (see Figure 2-6). The subscript - and + indicate the conditions at the entrance and the exit of control volume, respectively. $\dot{m}_{v}$ can be related to the radial mass flow rate as:

$$
\dot{m}_{v}=\rho_{\delta} u_{\delta} d x
$$

Combining the last two equations:

$$
\Gamma_{l}=\int_{0}^{x} \rho_{\delta} u_{\delta} d x=\int_{z}^{L} \rho_{\delta} u_{\delta} d z
$$

where $\mathrm{L}$ is the vertical length of water-vapour intersection (liquid film). Combining above equation with Equation (2-28):

$$
\left(g \rho_{l}+\frac{d p_{v}}{d z}\right) \frac{\rho_{l} \delta^{3}}{3 \mu_{l}}+\left.\frac{\mu_{v} \rho_{l} \delta^{2}}{2 \mu_{l}} \frac{\partial u_{v}}{\partial r}\right|_{r=R_{v}}=\int_{z}^{L} \rho_{\delta} u_{\delta} d z
$$

It is possible to estimate $\delta$ with neglecting the interfacial shear stress and vapour pressure drop. Additionally, $\delta=0$ at $x=0$. Thus, a closed-form solution for the liquid film thickness is:

$$
\delta=\left[\left(\int_{z}^{L} \rho_{\delta} u_{\delta} d z\right) \frac{3 \mu_{l}}{g \rho_{l}^{2}}\right]^{1 / 3}
$$

At the center line $(r=0)$, the radial gradients of the axial velocity and temperature and the radial vapour velocity are zero.

$$
\frac{\partial u_{v}}{\partial r}=\frac{\partial T}{\partial r}=v_{v}=0
$$

Using the Clausius-Clapeyron equation, the interface radial velocity was found:

$$
T_{s a t}=\left(\frac{1}{T_{R f}}-\frac{R_{g}}{h_{l v}} \ln \frac{p_{v}}{p_{R f}}\right)^{-1}
$$




$$
v_{\delta}=\frac{\left(k_{\delta} \frac{T_{\delta}-T_{S w}}{\delta}-k_{v} \frac{\partial T_{v}}{\partial r}\right)}{\left[h_{l v}+\left(C_{p v}-C_{p l}\right) T_{\delta}\right] \rho_{v}}
$$

where T, $\mathrm{k}$ and $\mathrm{p}$ are temperature, thermal conductivity and pressure, respectively. Subscripts $\delta$, w, v, l, and Rf are liquid-vapour interface, wall, vapour, liquid, and reference, respectively. Taking into consideration of all physical and thermal constrains, the author applied the SIMPLE scheme to develop a numerical method to solve for isotherm and velocity of the vapour inside the thermosyphon.

Dimension and properties of the thermosyphon were given to the numerical method as: $\mathrm{L}=0.66$ $\mathrm{m}, \mathrm{L}_{\mathrm{e}}=0.30 \mathrm{~m}, \mathrm{~L}_{\mathrm{a}}=0.12 \mathrm{~m}, \mathrm{~L}_{\mathrm{c}}=0.24 \mathrm{~m}, \mathrm{D}_{\mathrm{i}}$ (inside diameter) $=0.026 \mathrm{~m}, \mathrm{D}_{\mathrm{o}}$ (outside diameter) $=0.032 \mathrm{~m}, \mathrm{k}_{1}=60.5 \mathrm{~W} /(\mathrm{m} \cdot \mathrm{K})$, and $\mathrm{C}_{\mathrm{pl}}=434 \mathrm{~J} /(\mathrm{kg} . \mathrm{K})$. It was found that the maximum temperature variation across the entire thermosyphon was only $6^{\circ} \mathrm{C}$. The highest axial vapour velocity occurs at the centerline at the exit of adiabatic section.

Figure 2-7 shows schematically a low temperature heat pipe experimental setup [28], which had four independently-controlled electrical heaters in evaporator section. Each evaporator consisted of a $63.5 \mathrm{~mm}$ long, $257 \mathrm{~W}$ Minco Thermo-foil heater clamped to the heat pipe. Heat was removed from the condenser section by a long $(300 \mathrm{~mm})$ copper water-cooled manifold calorimeter assembled to the heat pipe. Heater voltages and thermometer readings were monitored by the data logger and PC. The entire length of the assembly was covered/insulated with $50 \mathrm{~mm}$ of Fiberfrax ceramic fiber insulation. Additionally, the assembly was mounted horizontally on an optical bench to adjust precise levelling of the assembly.

Mass flow rate and temperatures in the inlet and outlet calorimeter measurements provide information to calculate output. Comparison of the electrical power input records with output can accurately measure the heat loss of any type in the heat pipe assembly.

\subsubsection{Effect of inclination on a thermosyphon performance}

Inclination (angle of the thermosyphon center line with the horizon) has some effects on the performance of a thermosyphon. Thus, authors used the mean heat transfer coefficient [28], heat transfer value, or even surface temperature of the thermosyphon [62] as an indicator of the performance of a thermosyphon. Noie et al. [62] showed that inclination from 30 to 60 degree provides the best performance. 


\subsection{PCM and thermosyphon integration}

Thermosyphon has been used in building industry in HVAC systems to transfer heat from one end to the other. Integration of thermosyphon with PCM in a thermoelectric refrigeration system was also found helpful. This integration improved the storage capability, particularly during offpower periods, which allowed heat to flow in one direction. Moreover, the system suited operation with photovoltaic solar energy [63], [64]. This design and detailed results are published in $\mathrm{PhD}$ dissertation of Ma [65].

Unfortunately, there are few works available in the literature related to integration of PCM and thermosyphon.

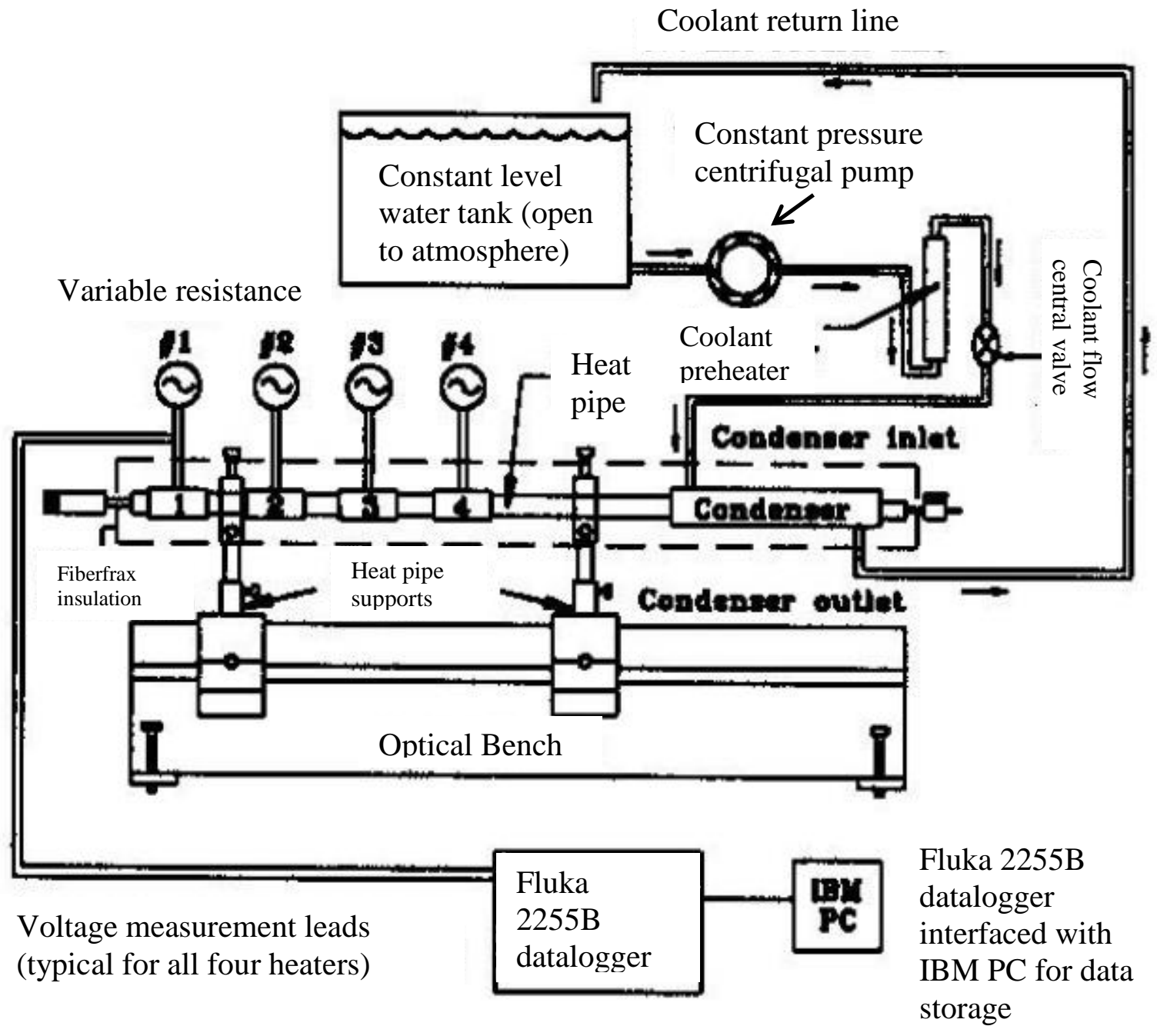

Figure 2-7: Low-temperature experimental setup [28] 


\section{PCM Simulation}

This chapter describes the methodology of all simulations that have been conducted. It is organized in two separate sections: performance of PCM in buildings and thermodiode panel integrated into the building envelope.

\subsection{Simulation of the PCM in Buildings}

Verma et al. [66] showed that available literatures have not investigated thermal energy storage systems that integrated with PCM. Efficiency of a system can be enhanced, if it is possible to eliminate the time periods required to $\mathrm{cool} / \mathrm{heat}$ the storage material below/above the melting temperature. The investigation of heat transfer problems during the phase change process (e.g., solidification/condensation and melting/evaporation) is called moving boundary problems. This analysis is complicated because the phase change boundary (e.g., solid-liquid) moves depending on how fast the latent heat is absorbed or released at the boundary; therefore, the exact position of the boundary is not clear in advance. Basically, the solidification occurs at a single temperature in pure substances; thus, its thermal analysis is simple. In mixtures, alloys and impure materials, the phase change occurs over a range of temperatures; therefore, there is a twophase zone between the two zones (e.g., solid and liquid zones). To simplify the mathematical model, it is appropriate to consider the energy equation in terms of enthalpy (E), which if the advection in the inner of the liquid is neglected (no motion), the model can be expressed as [66]:

$$
\rho \frac{\partial E}{\partial t}=\nabla \cdot(k \nabla T)
$$

Solving this equation needs knowledge of $\mathrm{E}(\mathrm{T})$ and $\mathrm{k}(\mathrm{T})$ (temperature functional dependency of enthalpy and thermal conductivity, respectively). This method is powerful as the equation is directly applicable to all present phases. At each point, the temperature can be determined and the value of thermo-physical properties is possible to evaluate, and finally according to the temperature field, the position of two boundaries can be found if required.

PCM is added to the walls and ceilings mixed with drywall layers. In each layer (i) covering the building envelope, the heat energy equation is [67]:

$$
\rho_{i} \frac{\partial E_{i}}{\partial t}=-\frac{\partial}{\partial x}\left(k_{i} \frac{\partial T}{\partial x}\right)
$$

where: 
$E_{i}=$ enthalpy of the PCM mixture layer i

$\rho_{\mathrm{i}}=$ density of the PCM mixture layer $\mathrm{i}$

$\mathrm{k}_{\mathrm{i}}=$ thermal conductivity of the PCM mixture layer $\mathrm{i}$

For the mixture with heat capacity of $C_{p e}$, Eq. (3-2) can be written as:

$$
\frac{\partial E_{i}}{\partial t}=\frac{\partial E_{i}}{\partial T} \frac{\partial T}{\partial t}=C_{p e} \frac{\partial T}{\partial t}
$$

where $C_{p e}$ is analytical expression of the effective heat capacity.

\subsubsection{Net Zero Energy Building (NZEB) Simulation in Toronto}

The Toronto Net Zero Energy house represents an award winning design initiative that collaborates between the Sustainable Urbanism Initiative (SUI) Toronto and a host of architectural and engineering firms, with the objective of increasing public awareness and adoption of energy efficient homes in Canada. More information about the SUI building is given in its website [68].

Figure 3-1 shows a computer generated 3-D model of the house. The building envelope of the SUI House is designed with intention of minimizing the heat transfer to the outside, thereby saving energy and contributing to occupant thermal comfort.

Polyisocyanurate foam spray on the external walls can maintain an overall insulation value of R60 (RSI-10.6). The external walls have been sprayed with this foam. Roof assembly was made up of drywall on $19 \times 19 \mathrm{~mm}$ furring and $0.15-\mathrm{mm}$ polyethylene vapour retarder attached to the bottom of the 294-mm pre-engineered I-joists. Sprayed polyisocyanurate foam is applied between joists as roof insulation. The various layers used within the wall and floor of the building envelope are summarized on Table 3-1. Thermo-physical properties of all layers are available in TRNSYS 16, except the PCM. PCM may be introduced as mass-less inside the envelope or added as a massive layer mixed with other material (e.g. plaster). 


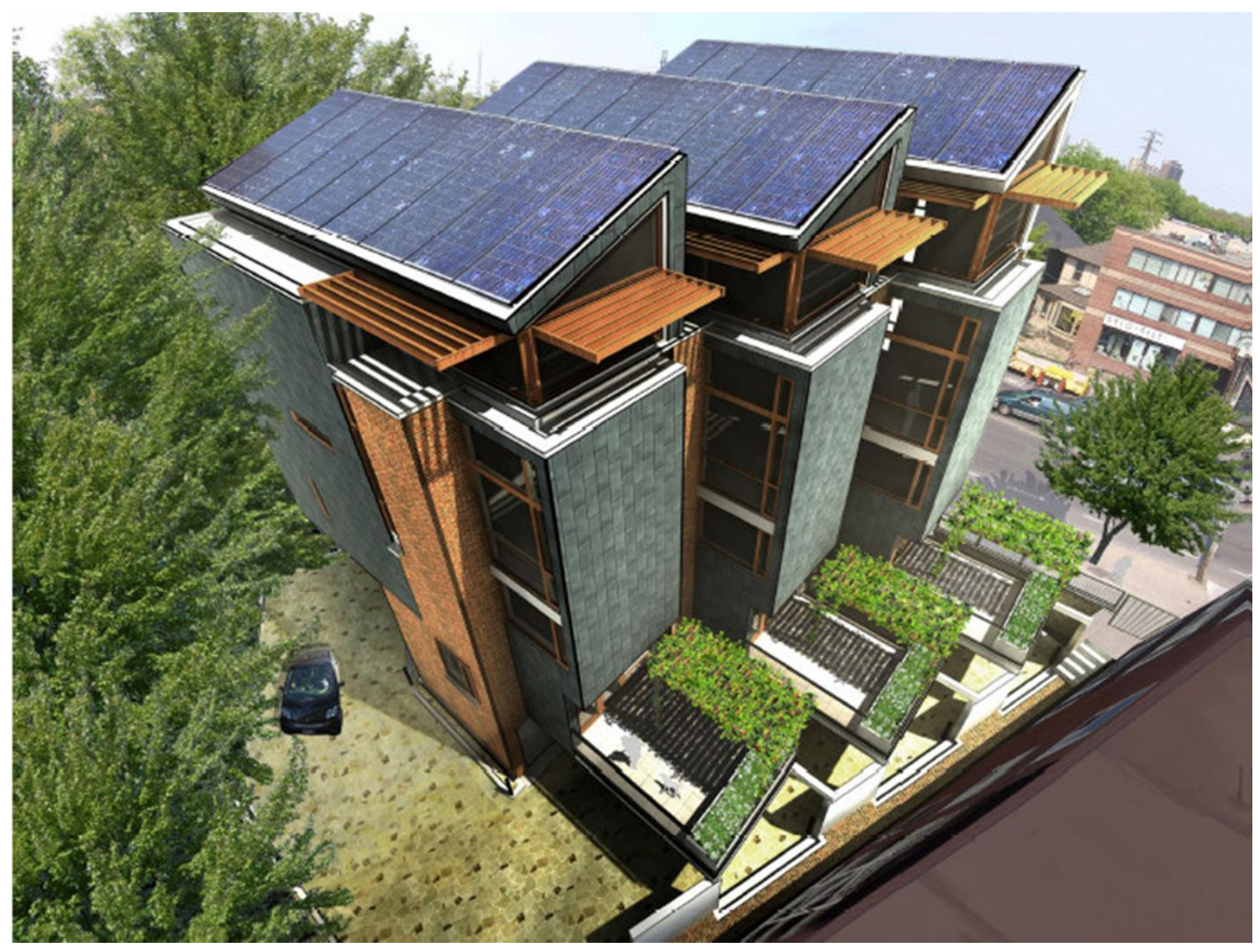

Figure 3-1: Three dimensional computer representation of the three identical NZEB [68]

The roof has an insulation value of R-76 (RSI-13.4). The windows used in the house are argon filled and have low emissivity with a fiberglass frame. The overall insulation value of the windows is R-4 (RSI-0.7). Under grade are walls of the insulating concrete form and have a 2.5" of rigid polystyrene board with a waterproof membrane. The overall insulation value of the below grade wall is R-35 (RSI-6.27).

\subsubsection{TRNSYS16 Building Simulator}

TRNSYS was developed at the University of Wisconsin by the members of the Solar Energy Laboratory. TRNSYS is comprehensive and powerful building simulation software that can provide whole building simulations with the added capability of easily integrating a variety of renewable energy and HVAC components. It is this software that would be utilized for 
conducting detailed energy simulations on a variety of building models to assess the impact of integrating thermal mass and PCM into the building envelope.

Table 3-1: The layers of the NZEB wall (left) and floor (right) [68]

\begin{tabular}{|c|c|}
\hline Wall Layers & Floor Layers \\
\hline \multirow{12}{*}{$\begin{array}{c}\text { Indoor air exposure } \\
\text { PCM Layer } 10 \mathrm{~mm} \\
\text { Plaster, } 13 \mathrm{~mm} \\
\text { Furring } 19 \mathrm{~mm} \\
\text { Polyethylene Vapour Retarder, } 0.15 \mathrm{~mm} \\
(2 \times 6) \text { Wood Studs @600mm O.C } \\
\text { Sprayed Polyisocyanurate closed cell foam } 139 \mathrm{~mm} \\
\text { RSI-6.5 } \\
\text { OSB Structural Sheathing with STO Gold Coat } 13 \mathrm{~mm} \\
\text { Rigid insulation-Extruded Polystyrene 100mm } \\
\text { RSI 3.48 } \\
\text { Air space } 25 \mathrm{~mm} \\
\text { Face Brick 100mm } \\
\text { External ambient exposure }\end{array}$} & Boundary with relevant zone \\
\hline & PCM Layer $10 \mathrm{~mm}$ \\
\hline & Plaster, $13 \mathrm{~mm}$ \\
\hline & Timber floor $25 \mathrm{~mm}$ \\
\hline & Common $50 \mathrm{~mm}$ \\
\hline & I-Joist $50 \mathrm{~mm}$ \\
\hline & Rigid insulation-Extruded Polystyrene $200 \mathrm{~mm}$ \\
\hline & $\begin{array}{l}\text { (R-7) } \\
\text { Furring 19 mm }\end{array}$ \\
\hline & Plywood $10 \mathrm{~mm}$ \\
\hline & Boundary with other zone \\
\hline & \\
\hline & \\
\hline
\end{tabular}

Each component in TRNSYS is defined as a TYPE and contains all the relevant mathematical parameters to integrate it in to the overall TRNSYS model. Building models are defined as TYPE.

Basically, TRNSYS is a modular simulation program, which is written in FORTRAN programming codes. Each component and mathematical module calculates part of the simulation problem and passes it to TRNSYS. TRNSYS communicates with modules for a wide variety of applications such as heat pumps and PV panels. It is user-friendly and interacts using graphical interface. To implement the simulation, each of these components can report to each other to represent the flow of information. There are some input files govern the TRNSYS engine to call the system components and iterates at each time-step until the simulation is done and solution(s) is/are reported and save into the defined output files. Hourly weather data for different locations are provided in a typical meteorological year (TMY) file to perform the simulations in TRNSYS.

\subsubsection{TRNSYS Suite}

One of the factors that makes TRNSYS especially user friendly is the interconnection of a suite of software programs that combine to form the overall software package. These include the TRNSYS Simulation Studio (TRNExe.exe), the building interface program called TRNBuild 
(TRNbuild.exe) and TRNED (TRNEd.exe). The Simulation Studio forms the heart of the package, and utilizes a graphical user interface whereby the user can visually drag and drop a variety of components into the workspace. These components can be connected to each other through the use of relationships that depend upon the logical flow of information. Each component has associated with it a set of inputs and outputs. As an example, a pump would have an input of total flow rate of water entering it, while an output could be the total electrical consumption of the pump. An output manager exists in the Simulation Studio where all the variables are printed, plotted or integrated, and a detailed error log that provides information on the source of errors that prevent a simulation from running to completion.

TRNSYS also includes a powerful building interface called TRNBuild, which is a comprehensive modeling tool that can be used to define a variety of parameters of a building envelope. It generates a BUI file that can be incorporated into the TRNSYS Simulation Studio.

\subsubsection{TRNSYS Type 204 PCM Components}

Prior to the development of the TYPE 204 model in TRNSYS, it was impossible to directly simulate the real effect of heat transfer through a wall containing PCM. While in the past, most of the work was focused on the experimental analysis of building integrated PCM. More recently, with the development of robust building simulation software, it is now possible to investigate in detail the thermal properties of a wide variety of PCMs without the need for elaborate experimentation. Building simulation also provides a valuable tool for validation of the experimental data.

Prior to the development of the TYPE 204 PCM module in TRNSYS, the only manner in which the effects of PCMs in buildings could be investigated was through the development of an active layer within the building envelope. Ibanez et al. [50] presented a methodology in TRNSYS whereby, through the definition of an active wall containing tubes through which a fluid was circulated, the overall thermal effect of phase change materials could be determined. Even though this approach did not simulate the real heat transfer process through a PCM wall, the overall impact in terms of energy transfer was quite similar to what would be expected with a PCM integrated wall [47].

A team at the Helsinki University of Technology programmed and developed the TYPE 204 component in FORTRAN and added it into TRNSYS as a new model [69]. The model considers 
9 nodes in each direction (729 nodes in the $x, y$ and $z$ directions) and calculates heat flow through 3-D composite-PCM wall components employing the finite difference method with a CrankNicholson scheme. All modes of heat transfer (i.e., the conduction, convection and radiation) and temperature are calculated at each node [37]. Depending on the percentage of each element in the wall, the wall components can be defined in three dimensions. In addition, the concentration and melting points of the PCM can be specified. The properties of the building composite material are calculated by summing the fraction of the element in the composite times the property of each element in the composite, including the PCM. The PCM changes its phase when temperature reaches its melting point; therefore, the specific heat capacity of PCM would be variable depending on the fraction of each phase. The effective heat capacity $\left(\mathrm{C}_{\mathrm{pe}}\right)$ is defined and used by the model to deal with this complication. The following equation is used to define the effective heat capacity:

$$
\mathrm{C}_{\mathrm{pe}}=\mathrm{C}_{\mathrm{p}}+\frac{\text { Latent Heat }}{\text { Phase Change Temperature Range }}
$$

The Type 204 PCM module in TRNSYS has the following input parameters that must be entered into the model to accurately represent a particular phase change material. These properties are described in detail below:

- Number of iterations: This parameter can be given any value between one and infinity and is used primarily for the sake of accuracy. Utilizing any number more than one for iteration would involve the solution of relevant heat transfer equations multiple times and generally provide more accurate solutions. The only drawback is increased computation time. To find a reasonable value for iteration, some preliminary simulations were conducted on ASHRAE Standard 140-2001 (BESTEST) Case 600 in Toronto weather conditions. Total annual energy demand to keep the indoor air temperature of the Case 600 in range of $21^{\circ} \mathrm{C}$ to $24^{\circ} \mathrm{C}$ versus the number of iterations is plotted in Figure 3-2. Three iterations provide reasonably good accuracy in this work. The total energy demand (y) can be expressed as a function of the number of iterations (x) employing the best fit using the least squares method $\left(y=-600.39 \mathrm{e}^{-0.15 \mathrm{x}}+7913.62\right)$. The maximum difference between the best number of iterations, 20, and 3 is about 5\%. This uncertainty is reasonable in this case because, comparing with 20 iterations; it saves at least four days of simulation time for each run. 


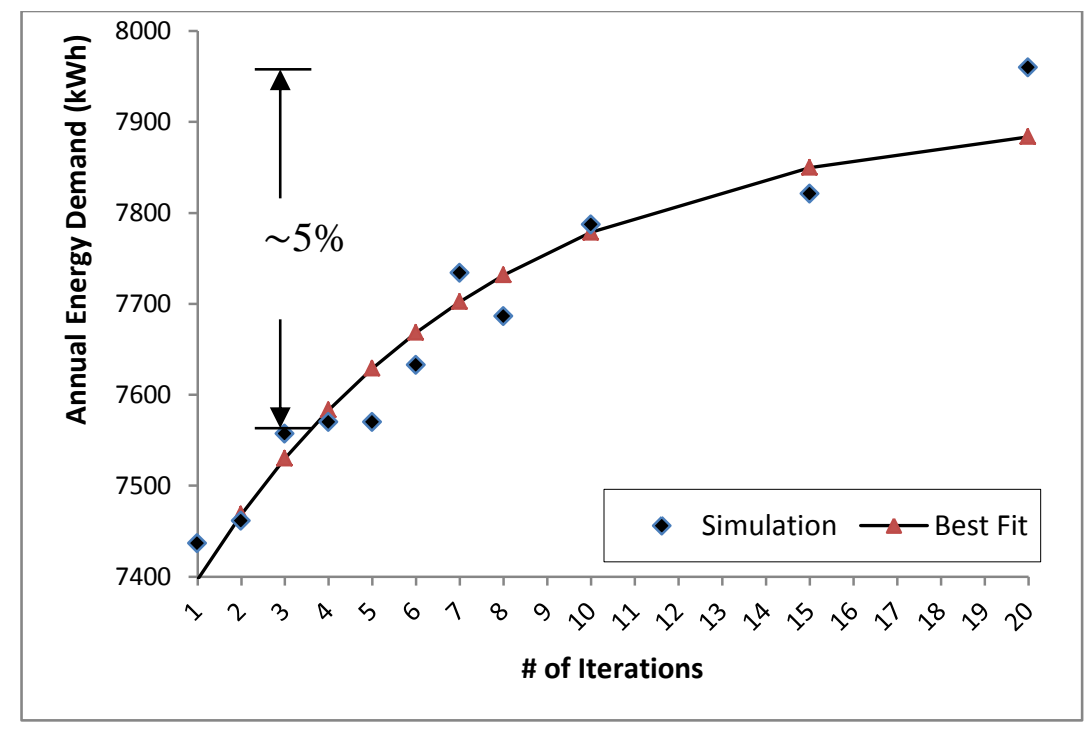

Figure 3-2: Effect of increasing iteration on ASHRAE Standard 140-2001 (Case 600 BESTEST) annual total energy demand

- Melting temperature: This characteristic is concerned with the initial temperature during which the phase change material undergoes phase transition.

- Crystallization temperature: The crystallization temperature is determined by the point where the PCM changes phase back to a solid. This temperature is always lower than the melting temperature. This is considered one degree lower than melting point.

- Range in crystallization temperature: Unlike pure materials such as water, which changes phase at a distinct temperature, most phase changes undergo the phase change process within a temperature range. This parameter could be used to define the phase change range of a particular PCM.

- Latent heat of PCM: This parameter measures the total heat storage / release capacity of a particular phase change material at the phase change temperature.

- PCM density: The density of the pure PCM can be entered into the model using this parameter. $800 \mathrm{~kg} / \mathrm{m}^{3}$ PCM is used in this work.

- PCM specific heat capacity $\left(\mathrm{C}_{\mathrm{p}}\right)$ : This parameter is concerned with the $\mathrm{C}_{\mathrm{p}}$ of the PCM. It is an important characteristic since it provides a measure of the energy storage/release capacity of a particular PCM at a temperature outside the temperature range of phase transition. 
- Density of other material in PCM node: The density of any other material that has been integrated with the PCM can be entered through this parameter. In this simulation, Plaster is used as other material.

- $\mathrm{C}_{\mathrm{p}}$ of other material: The specific heat capacity of any other materials incorporated with the PCM can be entered through this parameter.

- Volume fraction of PCM in node: The overall concentration of PCM in a particular specimen can be entered through this parameter. Since most studies characterize the overall concentration of PCM by weight, this value must be converted into volume fraction to reflect the input requirements of the parameter. For massless simulation, PCM is not mixed; therefore, volume fraction is 1 .

- Set points in summer and winter are considered $21^{\circ} \mathrm{C}$ and $24^{\circ} \mathrm{C}$, respectively. This is only applicable for investigating energy demand. Indoor air temperature is investigated with and without set point activation.

To add the PCM Type 204 to TRNSYS, the following parameters were fixed in the text file named "ALKU":

- The number of nodes ( $\mathrm{i}, \mathrm{j}, \mathrm{k}$ ), (fixed) $9 \times 9 \times 9=729$

- Dimensions of the wall component, [m]: 0.45, 0.45, 0.2 [meters], height (j), width (i) and depth (k). Windows' area is excluded.

- Convective heat transfer coefficient of the inside surface of the wall component, $h=2.0$ $\mathrm{W} / \mathrm{m}^{2} \mathrm{~K}$ (HILMA).

- $\quad$ Time step $=300$ second $($ LASVALI)

- Weighting factor of finite-difference method (The Crank-Nicholson method: ENKERROI $=0.5)$

- Initial temperature of the nodes $=20^{\circ} \mathrm{C}$

- Indoor temperature (fixed) $=20^{\circ} \mathrm{C}$

- Initial value of effective heat capacity $\mathrm{C}_{\mathrm{T}}=2.5 \mathrm{~kJ} / \mathrm{kgK}$

\subsubsection{Simulation for temperature effects}

Interior temperature of the SUI Net Zero House with no PCM was taken as baseline, and then the PCM added to simulate its effect on comfort of the house. As shown in Table 3-2, $465 \mathrm{~m}^{2}$ of the 
total wall and ceiling area was covered with PCM of one millimeter thickness. This is equal to a latent energy of $409 \mathrm{MJ}(114 \mathrm{kWh})$. Considering the total air volume inside the building, the latent energy of added PCM (mass of the PCM time L), see Table 3-3, can approximately contribute to a $2^{\circ} \mathrm{C}$ (this is $\Delta T$ in $\mathrm{mC}_{\mathrm{p}} \Delta T$ term, where $\mathrm{m}$ and $\mathrm{C}_{\mathrm{p}}$ are the mass and specific heat capacity of the indoor air, respectively. In other word, $\Delta T$ is the ratio of the total latent heat to product of mass and specific heat of the indoor air) reduction in temperature fluctuation of the indoor air (considering air as an ideal gas) every day for one year. So, theoretically, PCM can reduce the fluctuation of the inside air temperature, on the average, by about $2^{\circ} \mathrm{C}$ everyday during the whole year. To investigate the effects of PCM on interior temperature, the heating and cooling systems were eliminated from the building zones.

Table 3-2: The NZEB zones descriptions and the PCM sizes

\begin{tabular}{|c|c|c|c|c|c|c|c|}
\hline \multirow[b]{2}{*}{$\begin{array}{l}\text { Zone of } \\
\text { the House }\end{array}$} & \multirow{2}{*}{$\begin{array}{l}\text { Window } \\
\text { Area } \\
\left(\mathrm{m}^{2}\right)\end{array}$} & \multirow{2}{*}{$\begin{array}{l}\text { Total } \\
\text { Floor } \\
\text { Area }\left(\mathrm{m}^{2}\right)\end{array}$} & \multirow{2}{*}{$\begin{array}{l}\text { Total } \\
\text { Wall } \\
\text { Area }\left(\mathrm{m}^{2}\right)\end{array}$} & \multirow[b]{2}{*}{$\begin{array}{l}\text { Zone } \\
\text { Vol. }\left(\mathrm{m}^{3}\right)\end{array}$} & \multicolumn{3}{|c|}{ Total PCM area in part $\left(\mathrm{m}^{2}\right)$} \\
\hline & & & & & Wall & Floor & Total \\
\hline Garage & 1.03 & 11.16 & 32.49 & 27.2 & 0 & 0 & 0 \\
\hline $1^{\text {st }}$ Floor & 10.28 & 52.38 & 83.18 & 146.56 & 80 & 50 & 130 \\
\hline $2^{\text {nd }}$ Floor & 7.39 & 58.46 & 86.22 & 163.57 & 80 & 55 & 135 \\
\hline $3^{\text {rd }}$ Floor & 13.50 & 49.3 & 92.69 & 175.5 & 85 & 45 & 130 \\
\hline Mezzanine & 33.08 & 22.85 & 86.23 & 171.64 & 50 & 20 & 70 \\
\hline Total & 65.28 & 194.15 & 380.81 & 684.47 & 295 & 170 & 465 \\
\hline
\end{tabular}

Table 3-3: PCM properties

\begin{tabular}{|c|c|}
\hline PCM Properties & Value \\
\hline Density, $\rho: \mathrm{kg} / \mathrm{m}^{3}$ & 800 \\
\hline Thermal conductivity, $\mathrm{k}: \mathrm{W} / \mathrm{mK}$ & 0.3 \\
\hline Specific heat capacity, $\mathrm{C}_{\mathrm{p}}: \mathrm{J} / \mathrm{gK}$ & 1.6 \\
\hline Onset phase change temperature upon heating/cooling: $\mathrm{T}_{\mathrm{e}},{ }^{\circ} \mathrm{C}$ & $22 / 23$ \\
\hline Latent heat of fusion on heating, $\mathrm{L}: \mathrm{kJ} / \mathrm{kg}$ & 110 \\
\hline
\end{tabular}

\subsubsection{Shading Schedule}

To control the solar gain into the building and reduce cooling demand in summer and decrease heating demand in winter, a shading schedule is introduced. It is illustrated in Table 3-4. Each year is composed of 8760 hours. 
Table 3-4: Shading schedule

\begin{tabular}{|c|c|}
\hline Time of the year (hour) & \% Shading \\
\hline 0 to 2550 & 0 \\
\hline 2550 to 3300 & 50 \\
\hline 3300 to 6560 & 100 \\
\hline 6560 to 8760 & 0 \\
\hline
\end{tabular}

For the sake of the simulation, a typical phase change material is used. Table 3-3 shows the physical property of the PCM that was simulated. The melting point and conductivity were varied from $21^{\circ} \mathrm{C}$ to $28^{\circ} \mathrm{C}$ and from $0.1 \mathrm{~W} / \mathrm{mK}$ to $3 \mathrm{~W} / \mathrm{mK}$, respectively.

\subsubsection{Results}

Results are classified into two categories: effects of melting range and effects of thermal conductivity. Melting range is defined as the temperature difference between start of melting point during heating the solid and start of crystallization point during cooling the liquid. Crystallization temperature is always lower than melting point $\left(22^{\circ} \mathrm{C}\right.$ for this $\left.\mathrm{PCM}\right)$. PCM was considered as lump sum in all simulations.

A. Melting Range Sensitivity: Melting point of the PCM is an important factor in absorbing/releasing heat from/to the indoor air. To analyze the sensitivity of melting range, thermal conductivity of the PCM is fixed to a value of $0.3 \mathrm{~W} / \mathrm{mK}$. Melting range effects are investigated on indoor air temperature (IAT). To quantify the temperature fluctuation or swing, a dimensionless temperature swing index (TSI) is defined and calculated by taking the average hourly temperature fluctuations (AHTF) of each zone in 200 successive hours (1 to 200 in winter, the first week in January, and 4325 to 4524 in summer, the first week in July) relative to AHTF of outdoor.

where

$$
A H T F_{i}=\frac{\sum_{i=1}^{n}\left|Z T_{i}-Z T_{i+1}\right|}{n}
$$

$\mathrm{ZT}=$ the zone temperature in ${ }^{\circ} \mathrm{C}$

$\mathrm{i}=$ the specific hour of year (1 to 8759).

Then,

$$
T S I=\frac{A H T F \text { for the Zone }}{\text { AHTF for Outdoor }}
$$


The TSI can be between 0 and 1 . The closer the TSI is to 1 , the less effective the PCM would be in controlling temperature fluctuation with respect to the ambient.

A.1. Effects of Melting Range on IAT: For this investigation, heating and cooling are off. Mezzanine has the highest fluctuation in temperature out of all zones in NZEB (Table 3-2) because it has the maximum window area; therefore, its average temperature is investigated.

Figure 3-3 illustrates the Mezzanine temperature on a typical summer (July $2^{\text {nd }}$ ) and winter (Jan. $2^{\text {nd }}$ ) day. As Figure 3-3 shows (in summer), by increasing the start of melting point, the PCM effectiveness is slightly reduced. Daily fluctuation in indoor temperature changes from $7.6^{\circ} \mathrm{C}$ and $6.5^{\circ} \mathrm{C}$ to $5.3^{\circ} \mathrm{C}$ and $4.9^{\circ} \mathrm{C}$ in the typical winter and summer day, respectively, by using PCM. The melting range is not a determinant in IAT, as the room temperature is either lower (in winter) or higher (in summer) than the melting range. This means the PCM acts as a sensible material only (thermal inertia). If set points were activated, the results could have been different (see Section 3.1.8).

B. Effects of Thermal Conductivity on IAT: For this investigation, heating and cooling are off. Thermal conductivity was changed from 0.1 to $3 \mathrm{~W} / \mathrm{mK}$. The melting range is considered 22$23^{\circ} \mathrm{C}$. The average temperature of the Mezzanine zone is investigated. Analysis of data (Figure 34) clarifies that the indoor average temperature is not sensitive to the PCM thermal conductivity, but the presence of the PCM keeps the zone temperatures comfortable (between $21^{\circ} \mathrm{C}$ and $24^{\circ} \mathrm{C}$ ). As Figure 3-4 shows, all curves of different thermal conductivity are overlapping each other. It seems that $\mathrm{k}=1 \mathrm{~W} / \mathrm{m} \cdot \mathrm{K}$ is the best. Although TSI is not sensitive to thermal conductivity of the PCM, it has a higher value when the PCM is not used. Because of good insulation of the building, the temperature of the building does not have much fluctuation even without the PCM. In fact, PCM keeps the IAT warmer in winter and colder in summer than no PCM condition, which is expected from any thermal inertia materials. 


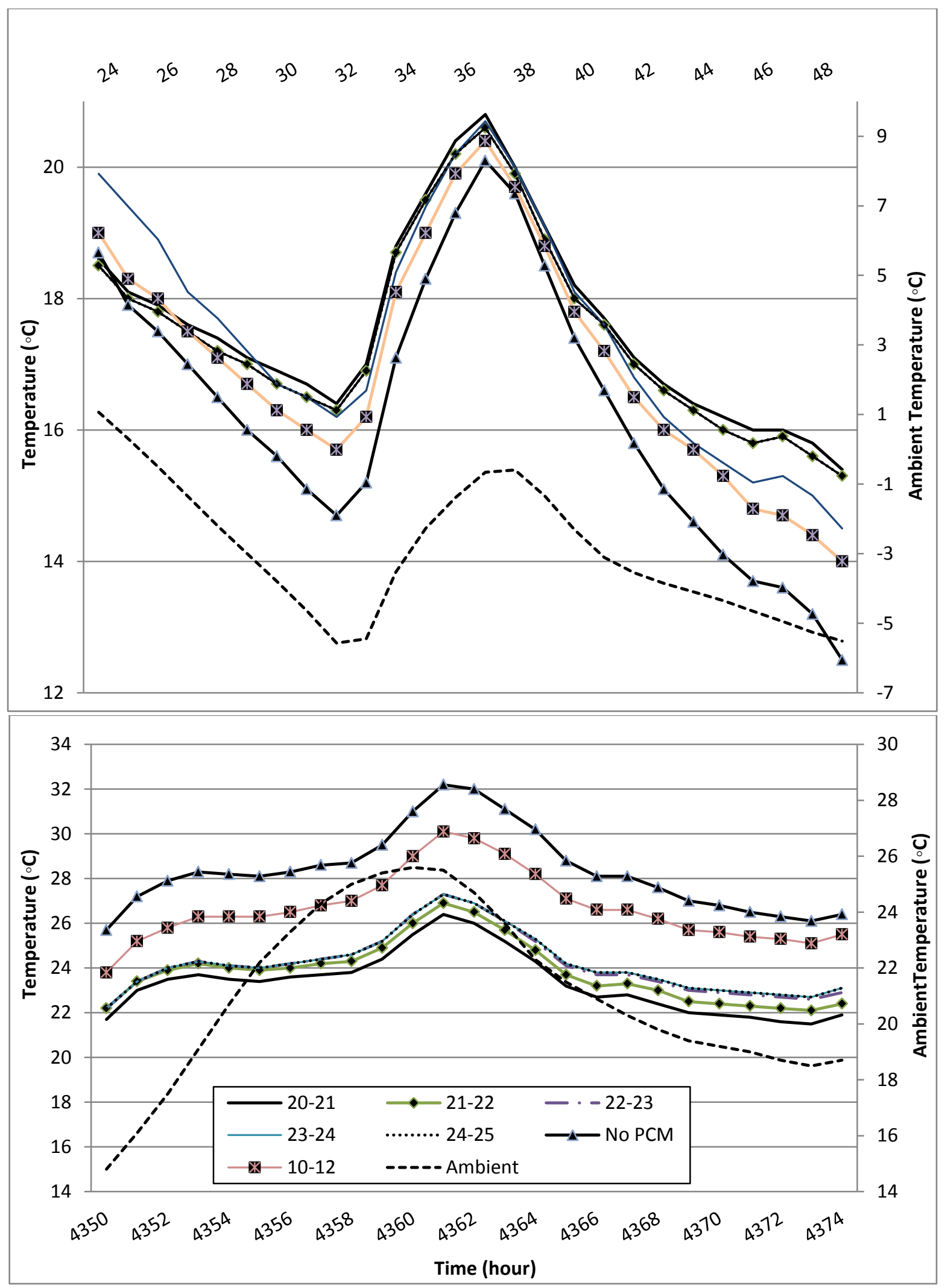

Figure 3-3: Sensitivity of IAT to the melting range in a typical summer (bottom), July 2nd, and winter (top), Jan. 2nd, day (both figures share the same legends) 


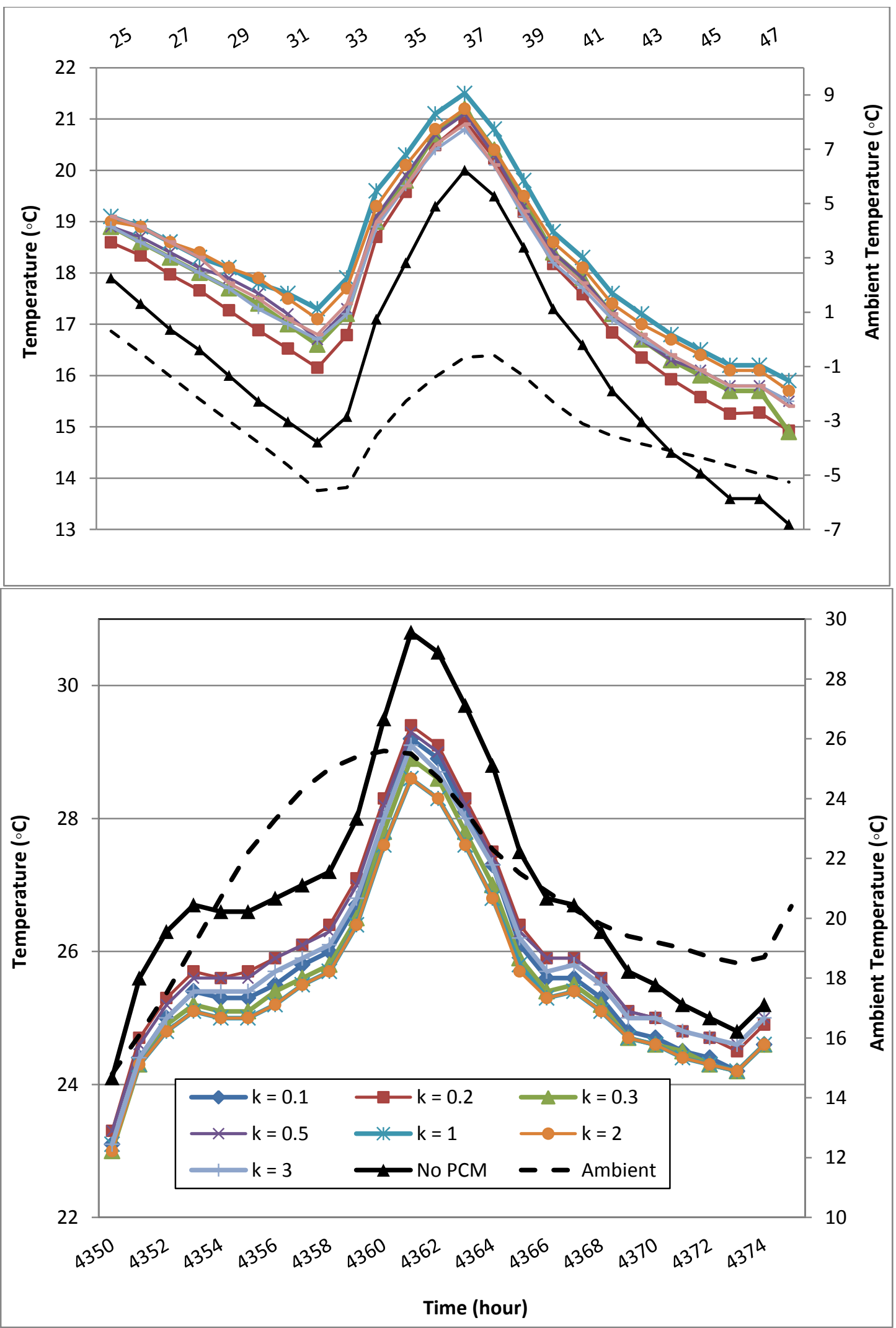

Figure 3-4: Temperature sensitivity on the PCM thermal conductivity (W/mK) in a typical winter, Jan. 2nd, (top) and summer, July 2nd, (bottom) day (both figures have the same legends) 


\subsubsection{Summary and discussion}

The primary reason to choose a PCM is its energy storage capacity due to its latent heat property. It is not justifiable to use PCMs as a sensible heat storage source. Therefore, neither the thermal conductivity nor the melting range of the PCM has any major effects on IAT because simulations show that there is no chance for the PCM to reach its phase change temperature in the NZEB in Toronto weather conditions. It is worth mentioning that, for investigating thermal conductivity effect, the melting range was fixed to the optimum PCM melting range (i.e., $22-23^{\circ} \mathrm{C}$ ). To investigate the melting range effects, thermal conductivity was fixed and taken from Table 3-3.

The analysis of all simulations is quite difficult, due to the amount of data generated. Therefore, only the main points are highlighted here. The TSI of the Mezzanine is higher in winter than summer ( 0.91 and 0.62 respectively). Although the TSI is not sensitive to the melting range of the PCM, the TSI has a higher value when the PCM is not used. Analysis of the data in Table 3-5 proves that using the PCM reduces the IAT fluctuations by 19\% and 17\% (comparing No PCM and Mezzanine columns) in winter and summer, respectively. No PCM column data in Table 3-5 is related to Mezzanine zone. Regarding temperature fluctuations in all zones, the PCM is more effective in summer than winter. Due to the large window area of the Mezzanine and solar heat gain, when PCM is not used, the Mezzanine has a higher AHTF than ambient in the winter. In the summer, due to thermal inertia of the building envelope and less solar gain due to shading, ambient has a higher AHTF.

\begin{tabular}{|c|c|c|c|c|c|c|c|c|}
\hline & Garage & $\begin{array}{l}1^{\text {st }} \\
\text { Floor }\end{array}$ & $\begin{array}{l}2^{\text {nd }} \\
\text { Floor }\end{array}$ & $\begin{array}{l}3^{\text {rd }} \\
\text { Floor }\end{array}$ & Mezzanine & $\begin{array}{l}\text { No } \\
\text { PCM }\end{array}$ & Ambient & TSI \\
\hline $\begin{array}{l}\text { AHTF } \\
\text { (winter) }\end{array}$ & 0.19 & 0.34 & 0.21 & 0.35 & 0.69 & 0.82 & 0.76 & 0.91 \\
\hline $\begin{array}{l}\text { AHTF } \\
\text { (summer) }\end{array}$ & 0.15 & 0.31 & 0.19 & 0.20 & 0.53 & 0.62 & 0.86 & 0.62 \\
\hline
\end{tabular}

In Toronto's climate condition with imposing set points $21^{\circ} \mathrm{C}$ and $24^{\circ} \mathrm{C}$ on the NZEB, the total energy demand decreases by increasing conductivity of the PCM because heat transfer to the inside layers of the PCM is faster. This decrease rate is faster at first and approaches zero. In addition, comparing the energy demands in the simulations, it can be seen that in all cases the 
effect of the PCM is present in the cases which contain PCM, with power differences of 0.2 to $0.9 \mathrm{~kW}$ in summer and 0.5 to $1.2 \mathrm{~kW}$ in winter. In the Mezzanine, due to the thermal inertia, the peak occurs 2 to 4 hours after the outdoor temperature is in its maximum point in summer; and in winter, due to the steady state of outside conditions, the peak occurs almost at the same time that ambient temperature is in its minimum. That means, the PCM is more effective in summer (TSI $=0.62)$ than in winter $(\mathrm{TSI}=0.91)$ in Toronto weather conditions.

\subsubsection{Simulation for energy demand effects}

In this section, results are also classified in two categories: effects of melting range and effects of thermal conductivity. Melting range is defined as the temperature difference between the start of the melting point during heating of the solid and the start of the crystallization point during cooling of the liquid. Crystallization temperature is always lower than the melting point. PCM was considered massless in all simulations.

A. Melting Range Sensitivity: The melting point of the PCM is an important factor in absorbing/releasing heat from/to the building envelope and/or indoor air. To analyze the sensitivity of the melting range, the conductivity of the PCM is fixed to a value of $0.3 \mathrm{~W} / \mathrm{mK}$. Melting range effects are investigated on energy demand.

To simulate the energy demand of the NZEB, the heating and cooling are considered unlimited to make the indoor air temperature (IAT) inside the set points $\left(21^{\circ} \mathrm{C}\right.$ to start heating and $24^{\circ} \mathrm{C}$ to start cooling). Figure 3-5 illustrates the effect of the melting range of the PCM on heating and total (cooling plus heating) energy demand of the NZEB. The range of $22^{\circ} \mathrm{C}$ to $23^{\circ} \mathrm{C}(22-23)$ provides the minimum demand (about 35\% saving with respect to No PCM), i.e., it is the best range. To investigate the effect of the amount of PCM, the PCM was eliminated from the Mezzanine zone in the melting range of 23-24 (23-24NM). This increased the energy by 22.11 kWh per year. Also, to check the reproducibility of the TRNSYS simulation, 23-24NM simulation was repeated (marked as "Repeat" on Figure 3-5) and results were almost same (less than $0.5 \%$ difference). Having said that heating, ventilation, and air conditioning (HVAC) system keeps the interior temperature of the zones between set points, the melting range of 25-26 is outside the set point range (21 to 24); therefore PCM acts as sensible material. When sun shines (during the day), solar energy (heat) is stored in PCM as latent heat only if the melting range is inside the set points. This heat is released at night, which reduces the heating demand. 


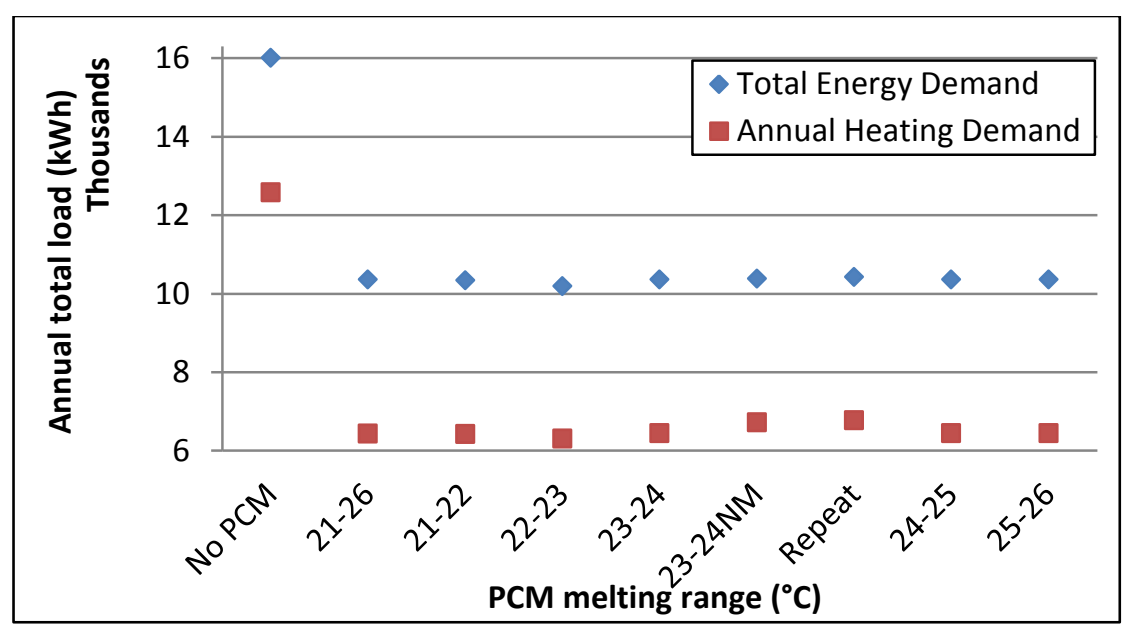

Figure 3-5: Melting range sensitivity of the annual energy demand of the SUI house

Figure 3-6 illustrates that peak power is not sensitive to melting range, although reducing the amount of PCM reduces the cooling peak and increases the heating peak power (as simulation 23-24NM stipulates). Conveniently, peak should be reduced by adding PCM into the envelope. Repetition of the simulation for "No PCM" reveals that peak is between 5 and $5.5 \mathrm{~kW}$, and it always occurs at hour 7022 (mid of October), when there is no shading on windows.

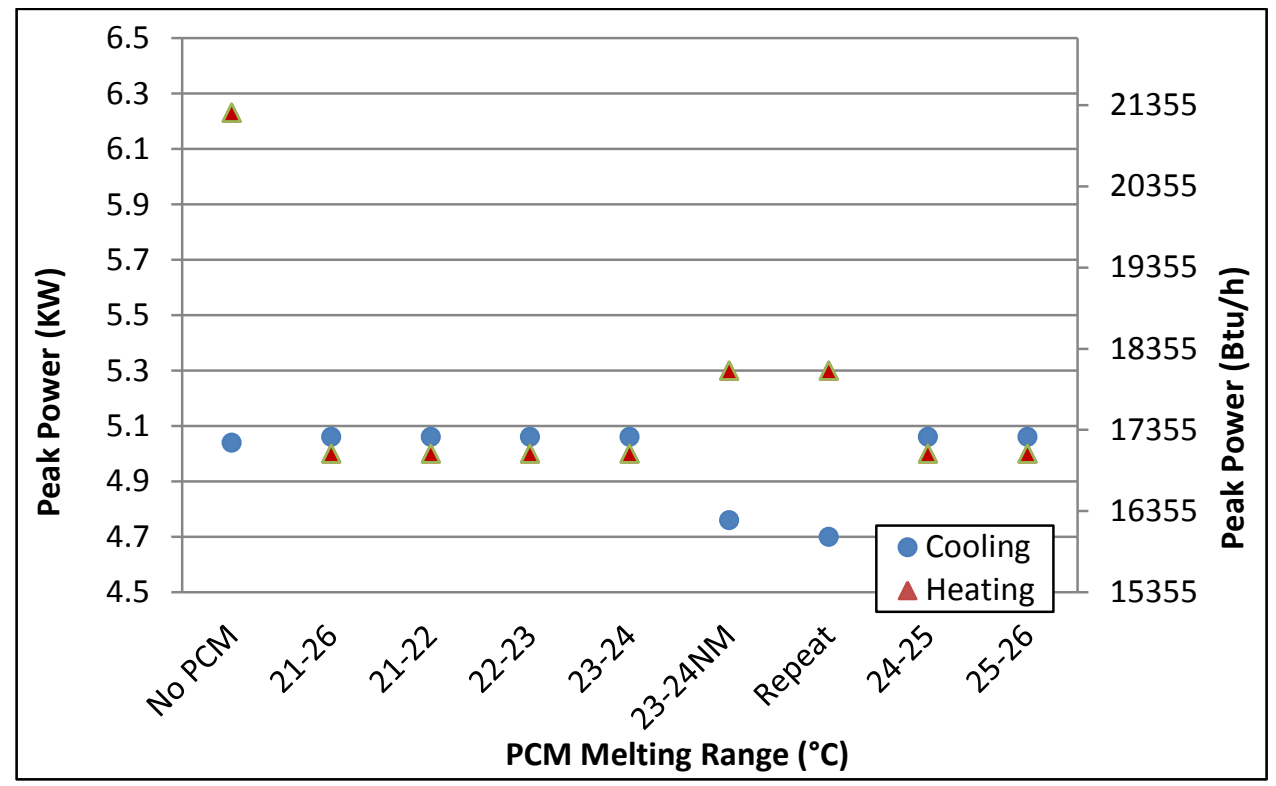

Figure 3-6: Melting range sensitivity of the peak power demand of the SUI house 
Investigation of the daily power demand in summer (Figure 3-7) and winter (Figure 3-8) shows that the energy (hourly power) demand reduces by adding PCM. In addition, the energy demands per hour (power) fluctuations are closely related to ambient temperature fluctuations. The hourly power of PCM with "22-23" is completely overlapped with "21-22" and "23-24" in summer (Figure 3-7) and winter, respectively. That is why it is not shown as a separate plot in Figures 3-7 and 3-8.

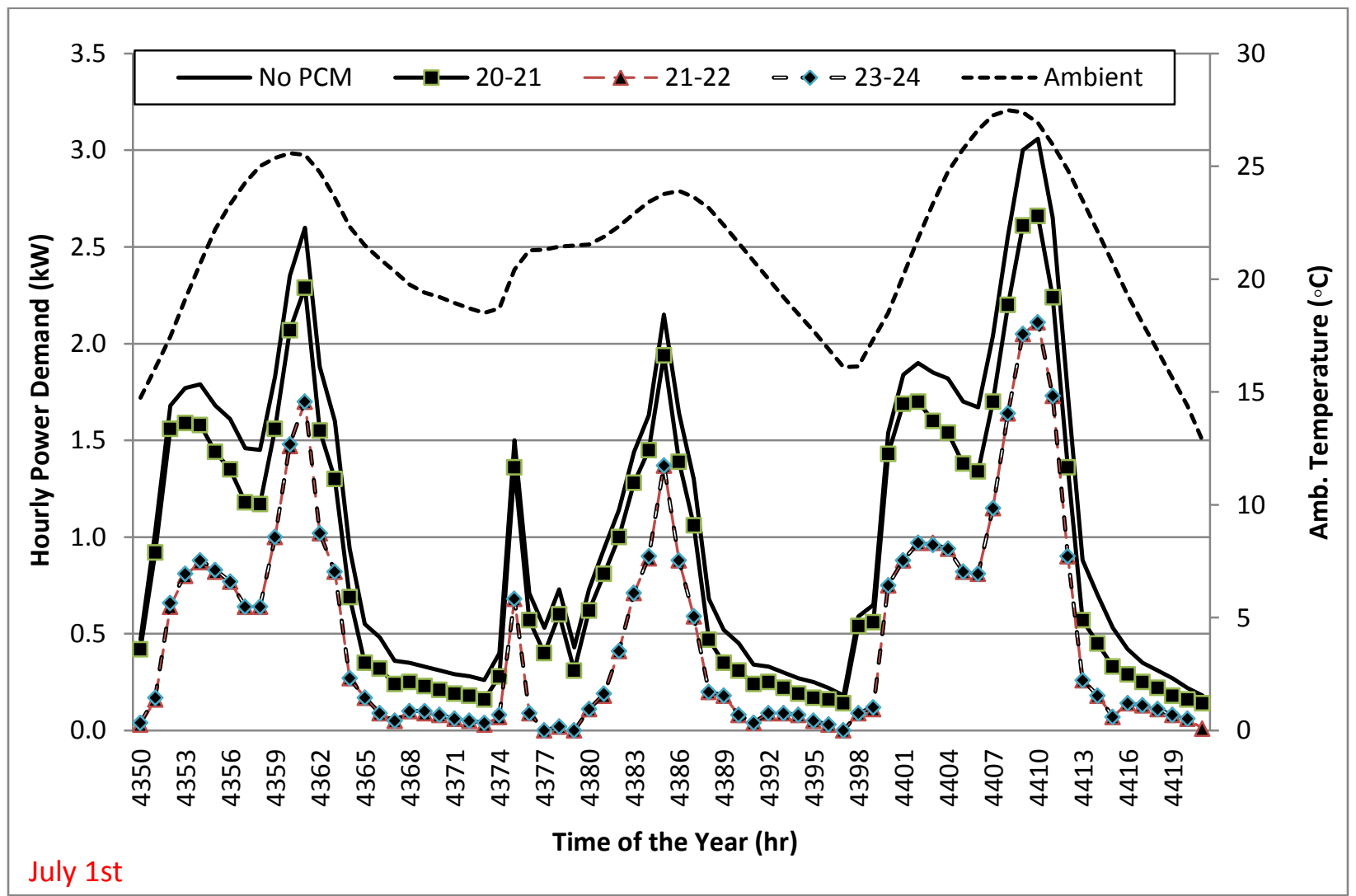

Figure 3-7: Sensitivity of hourly power demand to the melting range in typical summer days, July 1st to 3rd

In the winter, when the ambient temperature decreases to $-6^{\circ} \mathrm{C}$ (at hour 92) the power demand (heating load per hour) increases to $2.3 \mathrm{~kW}$ (No PCM), showing a negative correlation (see Figure 3-8). On the other hand, in the summer, when the ambient temperature increases to $25^{\circ} \mathrm{C}$ (at hour 4361) the power demand (cooling load per hour) increases to $2.6 \mathrm{~kW}$ (No PCM), showing a positive correlation (see Figure 3-7). Practically, the simulations were run for no PCM 
and different melting range from 20 to $26^{\circ} \mathrm{C}$ (e.g., 21-22, 22-23). In Figures 3-7 and 3-8, only a few of the temperature ranges are shown because other ranges overlapped each other.

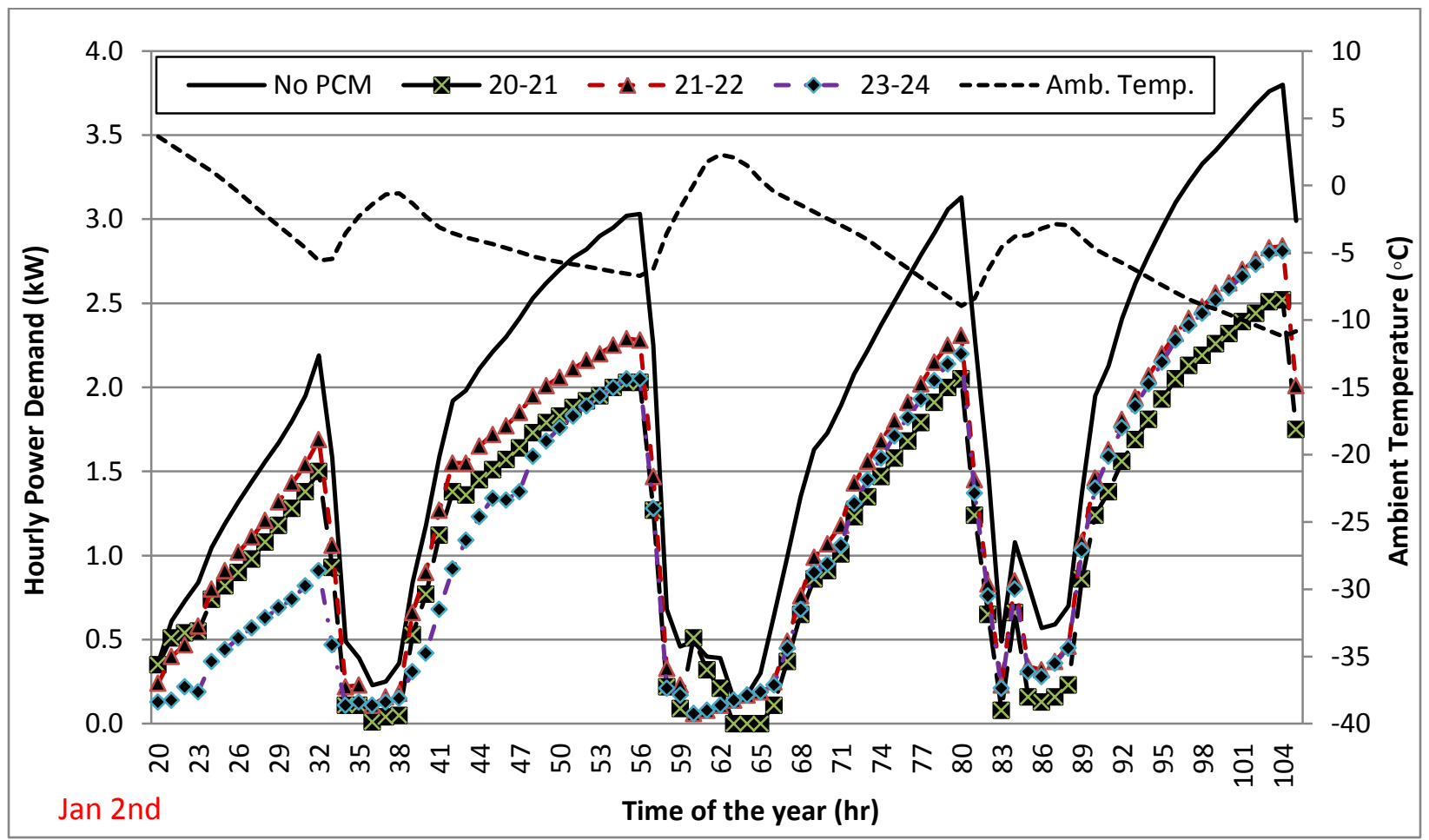

Figure 3-8: Sensitivity of hourly power demand to the melting range in typical winter days, Jan. 2nd to 5th

B. Thermal Conductivity Sensitivity: The thermal property of PCM (Table 3-3) was used to simulate the effects of thermal conductivity on energy demand and peak power of the NZEB. The SUI building was designed with high quality materials. Because of good insulation of the building, the temperature of the building does not have much fluctuation in the garage (with no PCM).

Neither peak power nor annual load is sensitive to the thermal conductivity of PCM (Figure 3-9). Comparing the total annual load demand for the building with PCM of conductivity $0.14 \mathrm{~W} / \mathrm{mK}$ with $1.39 \mathrm{~W} / \mathrm{mK}$ (increasing the thermal conductivity by about 10 times) shows a reduction of about 2\% load demand (Figure 3-10). The total energy demand (y) can be expressed as a function of the PCM conductivity ( $\mathrm{x}$ ) employing the best fit using the least squares method $(\mathrm{y}=$ $\left.548 \mathrm{e}^{-4.2 \mathrm{x}}+7525\right)$. The best fit prediction of energy demand has a maximum difference of $0.3 \%$ from the true value. 


\subsubsection{Summary and discussion}

For investigating thermal conductivity effect, the melting range was fixed to the value given in Table 3-3 (i.e., $22-23^{\circ} \mathrm{C}$ ). To investigate the melting range effects, thermal conductivity was fixed and taken from Table 3-3.

The analysis of all simulations is quite difficult, due to the amount of data generated, and may not be valuable. Therefore, only the main points are highlighted here.

Adding the PCM into the building envelope stores the solar energy during the day (as the latent heat) and releases it at night when the temperature goes lower than the melting temperature of the PCM. To take advantage of the latent heat storage, the PCM melting range should be inside the set points range. Figure 3-5 shows that annual energy demand in increasing order is: 22-23, 21-22, 23-24, 25-26, and 24-25. Figure 3-5 also shows that when the melting range is in the middle of the set points, the energy demand of the building is the lowest of all other options. Moreover, the amount of PCM has the effect on the energy demand. Comparing "23-24" with "23-24NM" (this stands for melting range of 23-24 with no PCM in Mezzanine) depicts that by decreasing the amount of PCM, the energy demand increases due to the lower storage capacity. While PCM has the melting range above or under the set points, it acts as sensible materials with constant specific heat capacity because the interior temperature is kept within set points.

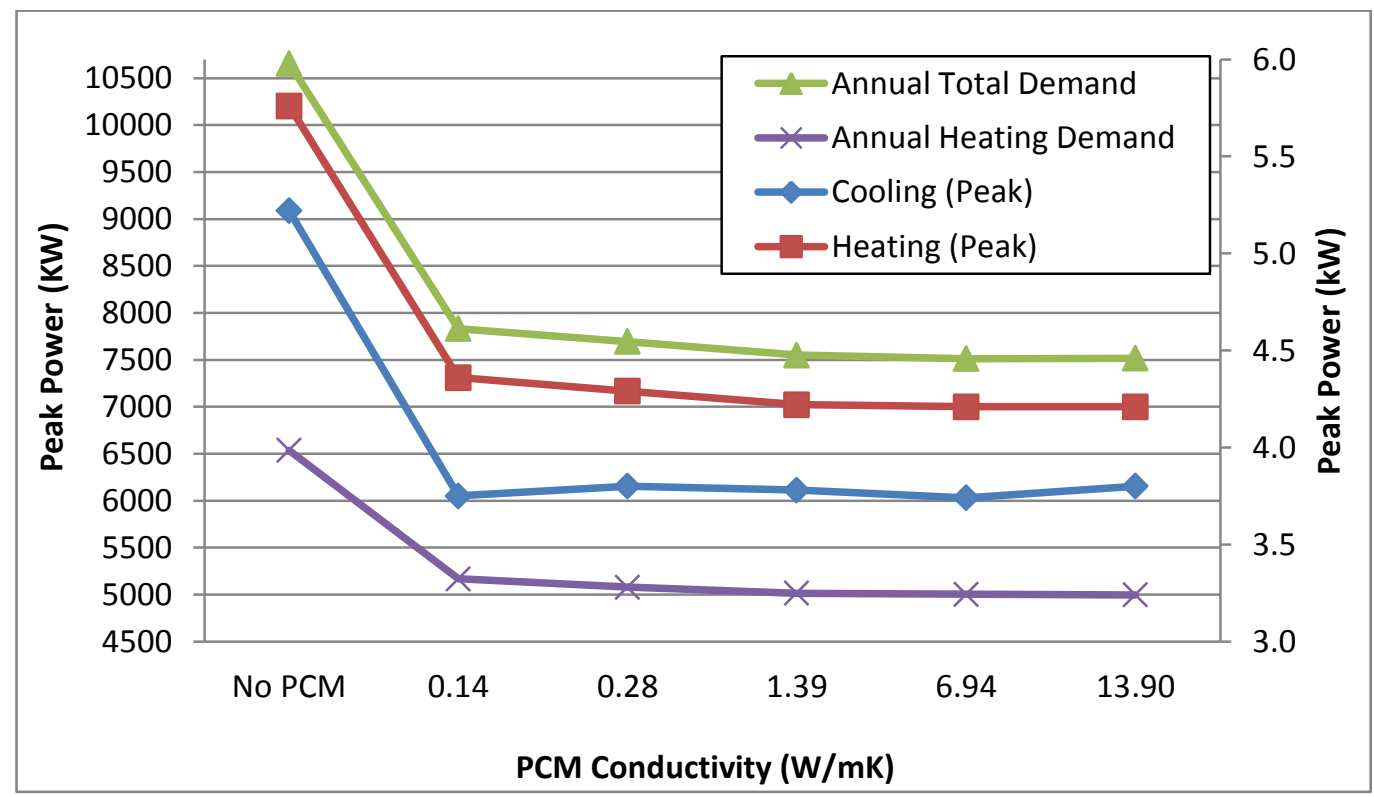

Figure 3-9: Sensitivity of peak power and energy demand to the PCM thermal conductivity 
Peak power is extracted from the maximum power demand in the whole year ( 8760 hours). Figure 3-6 reveals:

- Heating peak is higher when PCM is not used or eliminated from the Mezzanine

- Cooling peak is reduced when the PCM is eliminated from Mezzanine because, in this zone, there are about $33 \mathrm{~m}^{2}$ of windows that could have let radiation in and stored solar energy during the day and would increase the cooling load. In this zone with no PCM, "23-24NM", not only the cooling peak but also the cooling load is the lowest of all. It seems that "No PCM" case has the cooling peak slightly lower than PCM -incorporated envelope with the same reason.

- With the stated conditions, peak power is not sensitive to melting range.

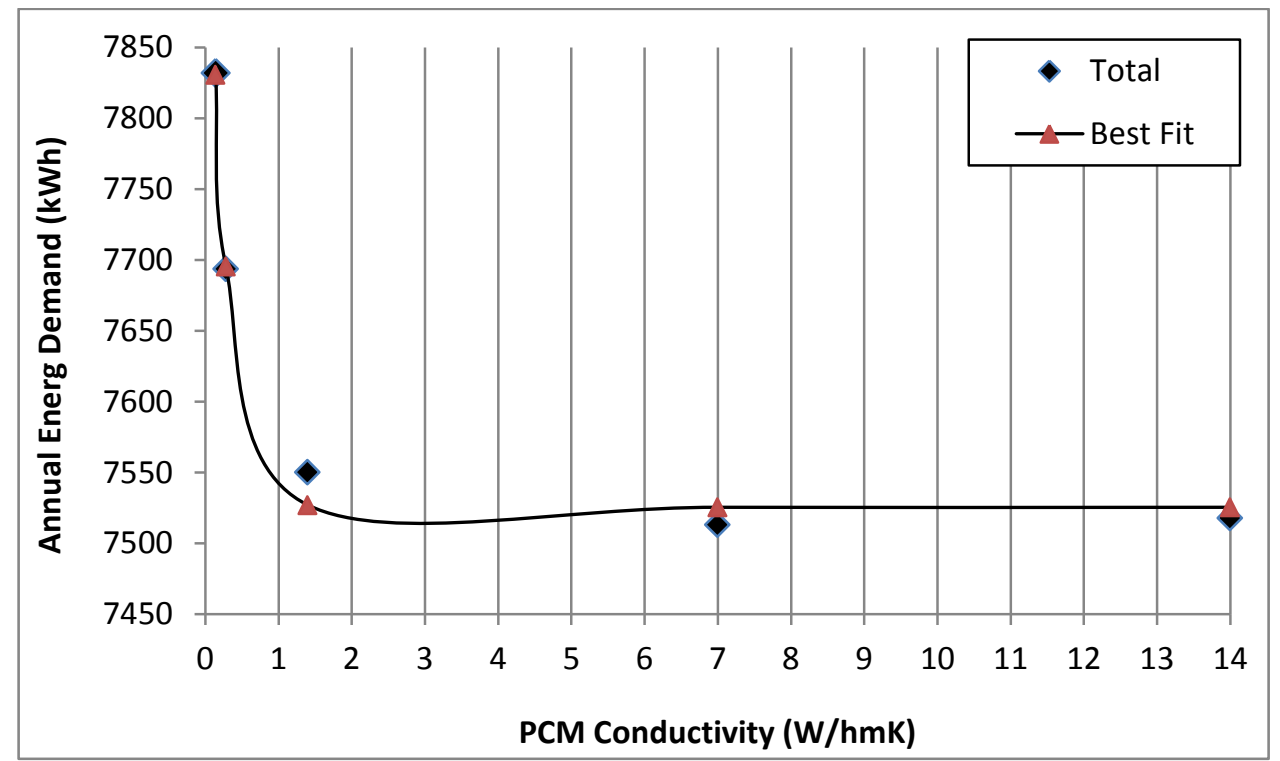

Figure 3-10: Annual energy demand (y) versus PCM thermal conductivity (x). The best fit regression equation is also shown

In Toronto, the heating demand period ( $87 \%$ of the time in a year the ambient temperature is less than $20^{\circ} \mathrm{C}$ ) is longer than cooling period; therefore, there is a chance of having higher heating peak increases while reducing the amount of PCM.

Although about 2\% reduction in energy consumption is seen with increasing thermal conductivity, with the condition PCM is added to the envelope (i.e., $10 \mathrm{~mm}$, in one layer), energy demand is not sensitive to thermal conductivity. In the Figure 3-10, energy/peak versus PCM 
thermal conductivity is almost a horizontal line for $\mathrm{k}>0.14 \mathrm{~W} / \mathrm{mK}$ (representative of lightweight Plasters).

\subsubsection{Simulation of effects of convective heat transfer coefficient on the ability of a PCM to reduce building energy demand}

Energy consumption of the ASHRAE Standard 140-2001 (BESTEST) Case 600 with PCM is calculated with different h-values to investigate its effect on the energy consumption of the house. The energy demand is simulated using Toronto weather conditions. Results are given as plots of energy demand versus h-value. The h-value, which transfers heat between the PCM layer and the indoor air, is changed from $1.0 \mathrm{~W} / \mathrm{m}^{2} \mathrm{~K}$ to $10 \mathrm{~W} / \mathrm{m}^{2} \mathrm{~K}$. The sensitivity of the energy demand on the h-value is given in two sections (A for cooling, and B for heating):

A. Effects of h-value on the Cooling Energy Demand: Cooling energy demand is investigated in three different occasions. In all occasions, operative temperature is found to be about $25^{\circ} \mathrm{C}$ where it is used:

A.1. At the warmest outdoor temperature hour, which is 4839 (on $21^{\text {th }}$ of July): Figure 3-11 illustrates the cooling load variation with h-value at the warmest hour of the year. The graph shows that the sensitivity increases with PCM reduction (from $3 \mathrm{hm}^{2} \mathrm{~K}$ to $115 \mathrm{hm}^{2} \mathrm{~K}$, with $10 \mathrm{~mm}$ PCM and no PCM respectively). The results for 1-mm PCM and 10-mm PCM are shown in the figure.

A.2. In August (from hour 5080 to 5832), the cooling load is at its maximum with respect to other months of the year: Figure 3-12 illustrates the cooling load variation with h-value in the warmest month of the year. Again, the sensitivity increases with PCM reduction (from -1.2327 $\mathrm{hm}^{2} \mathrm{~K}$ to $19.032 \mathrm{hm}^{2} \mathrm{~K}$ ) with $10-\mathrm{mm} \mathrm{PCM}$ and no PCM respectively. Another point is that cooling load decreases as PCM thickness (amount) increases.

A.3. And finally, annual cooling load: Figure 3-13 illustrates annual cooling load variation with h-value. Again, the sensitivity increases with PCM reduction (from $-2.819 \mathrm{hm}^{2} \mathrm{~K}$ to 150.73

$\mathrm{hm}^{2} \mathrm{~K}$ ) with 10-mm PCM and no PCM respectively. Obviously, cooling load decreases as PCM thickness (amount) increases.

B. Effects of $h$ on the Heating Energy Demand: Heating energy demand is also investigated on three different occasions: 


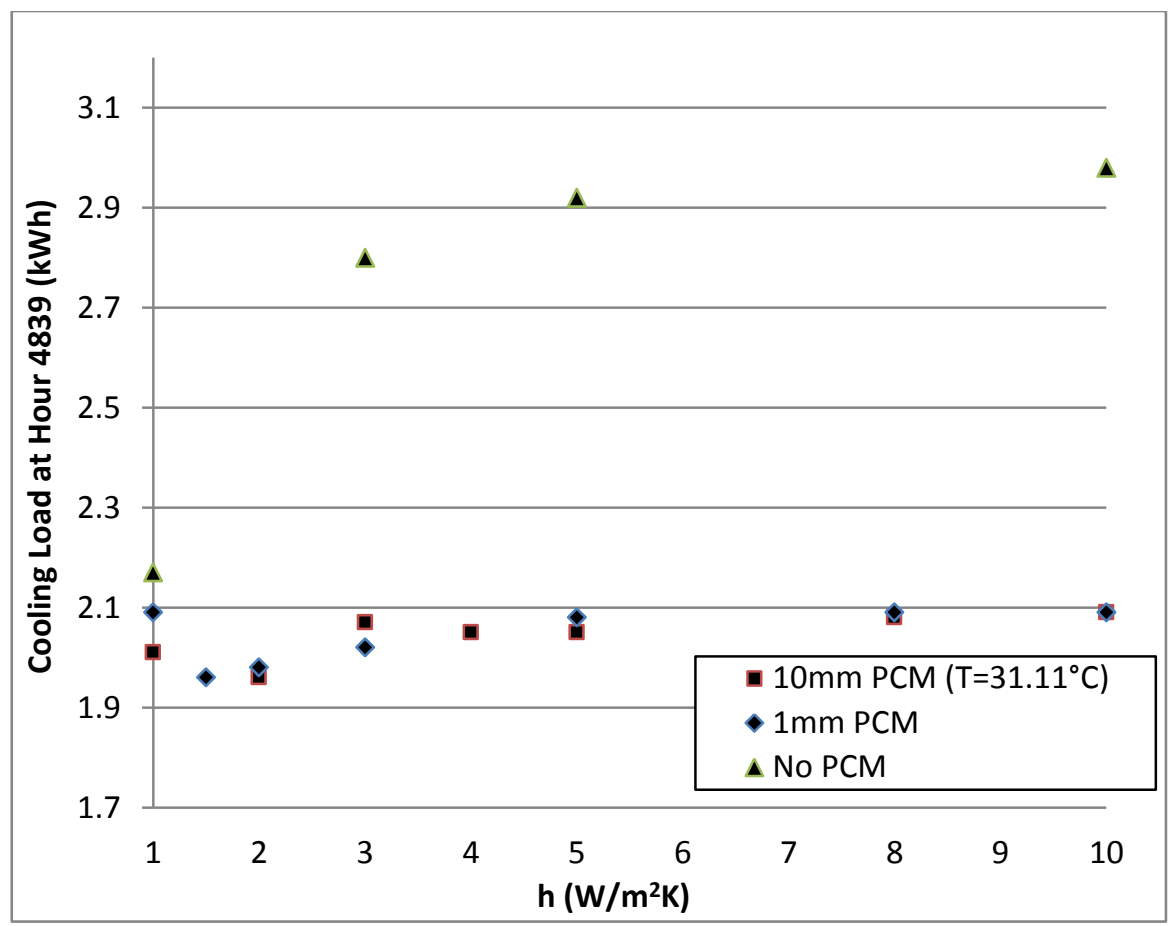

Figure 3-11: Effect of $h$-value on cooling energy demand at the warmest hour (4839) of the year

B.1. At the coldest hour, which is 289 (on $13^{\text {th }}$ of January): Figure 3-14 illustrates the heating load variation with h-value at the coldest hour of the year. The graph shows that the sensitivity is the lowest with 1-mm PCM $\left(7.3 \mathrm{hm}^{2} \mathrm{~K}\right)$. The maximum sensitivity goes to no PCM condition again. In addition, heating load demand is reduced for 10-mm PCM with respect to 1-mm PCM and no PCM conditions.

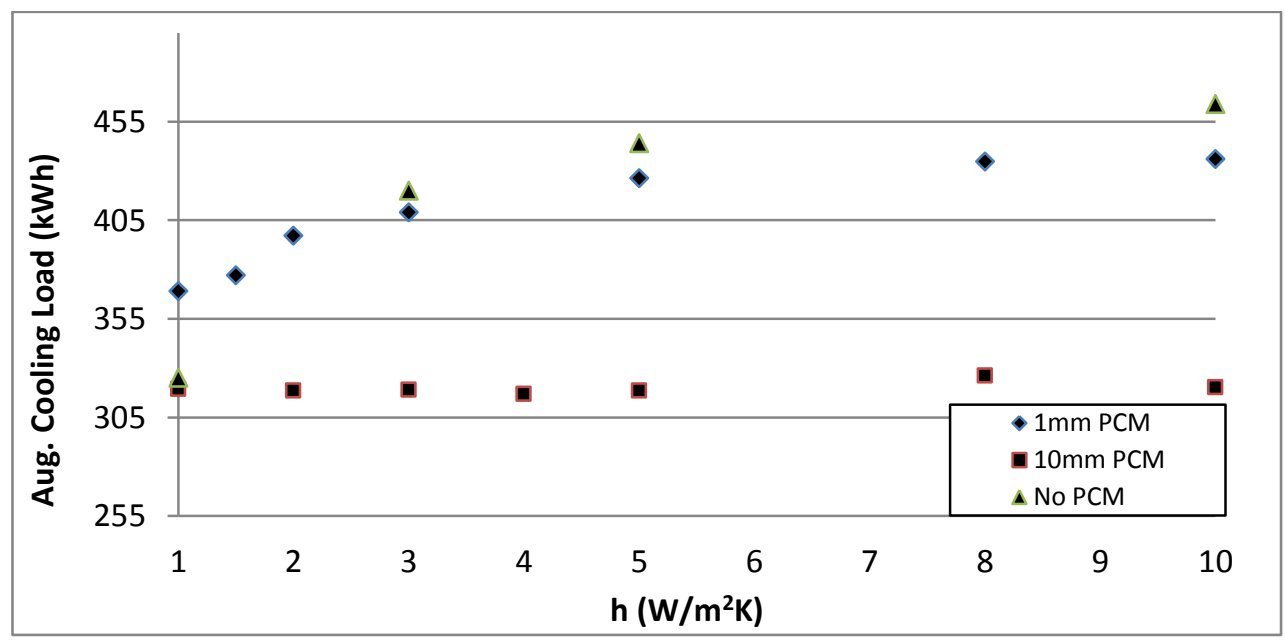

Figure 3-12: Effect of $h$ on cooling energy demand in one of the warm month of the year, August 


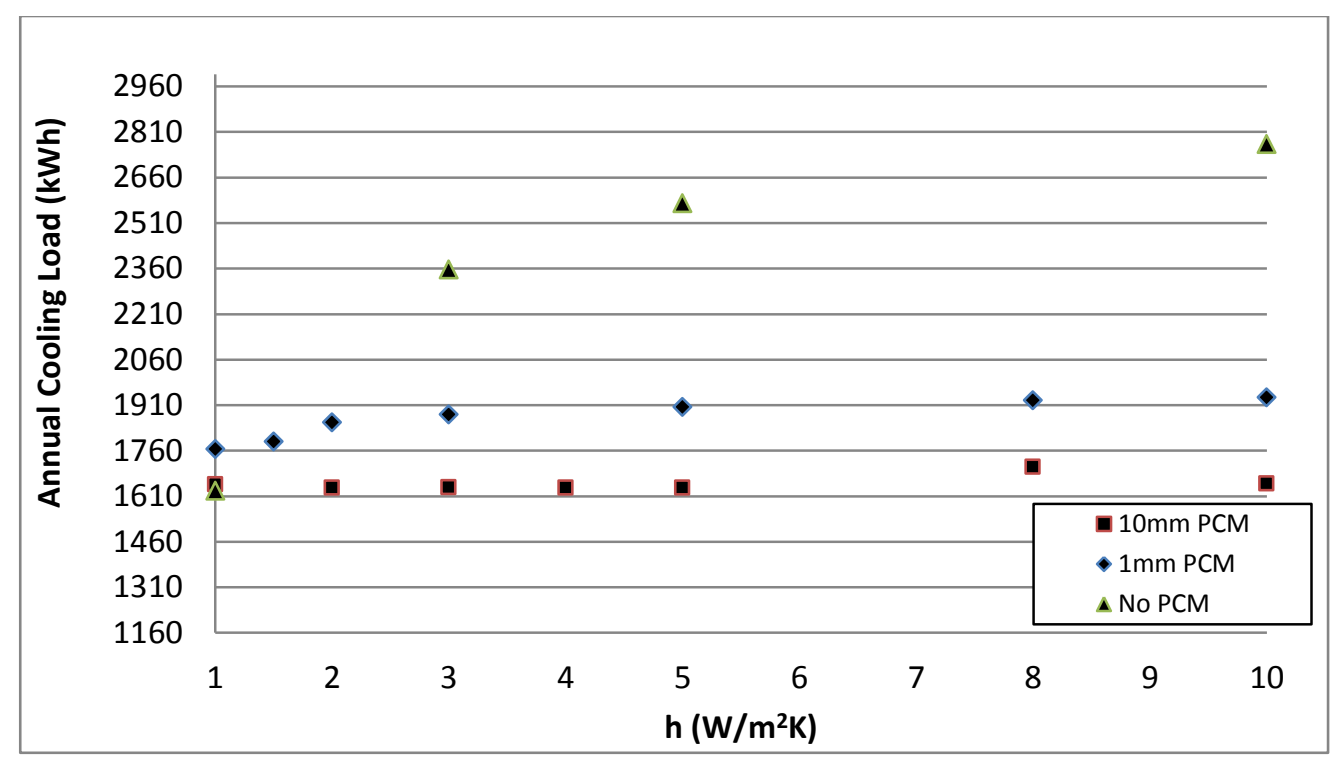

Figure 3-13: Effect of $h$ on annual cooling energy demand

B.2. In February (from hour 744 to 1416): The heating load is the maximum with respect to other months of the year in February. Figure 3-15 illustrates the heating load variation with the h-value in the coldest month of the year. The best fits are also added to the plots. The graph shows that the sensitivity is the lowest value with $1-\mathrm{mm}$ PCM $\left(7249 \mathrm{hm}^{2} \mathrm{~K}\right)$. Again, the maximum sensitivity goes to no PCM condition. In addition, heating load decreases as the PCM amount (thickness) increases. The best fits for 1-mm PCM and 10-mm PCM are both polynomials with power four.

Figure 3-16 illustrates annual heating load variation with h-value. The graph shows that the sensitivity is the lowest with 1-mm PCM $\left(70745 \mathrm{~h} / \mathrm{m}^{2} \mathrm{~K}\right)$. Again, the maximum sensitivity goes to no PCM condition. In addition, heating load decreases with increasing the PCM amount (thickness).

B.3. And finally, annual heating load: Depending on the h-value, the operative temperature, which depends on the surface temperature of the PCM, would be different at different hours of the day. Observation of the hourly operative temperatures reveals that the temperature is higher than $24^{\circ} \mathrm{C}$ about $36 \%$ of the time in August. Also, the temperature is found to be less than $21^{\circ} \mathrm{C}$ about $83 \%$ of the time in February. Generally, by increasing the h-value, deviation of the operative temperature from the set points increases. By increasing the PCM thickness: 1) the chance of the PCM surface temperature goes below $21^{\circ} \mathrm{C}$ increases in February, but the chance 
of increasing the PCM surface temperature above $24^{\circ} \mathrm{C}$ decreases in August, and 2) operating temperature is less sensitive to h-value.

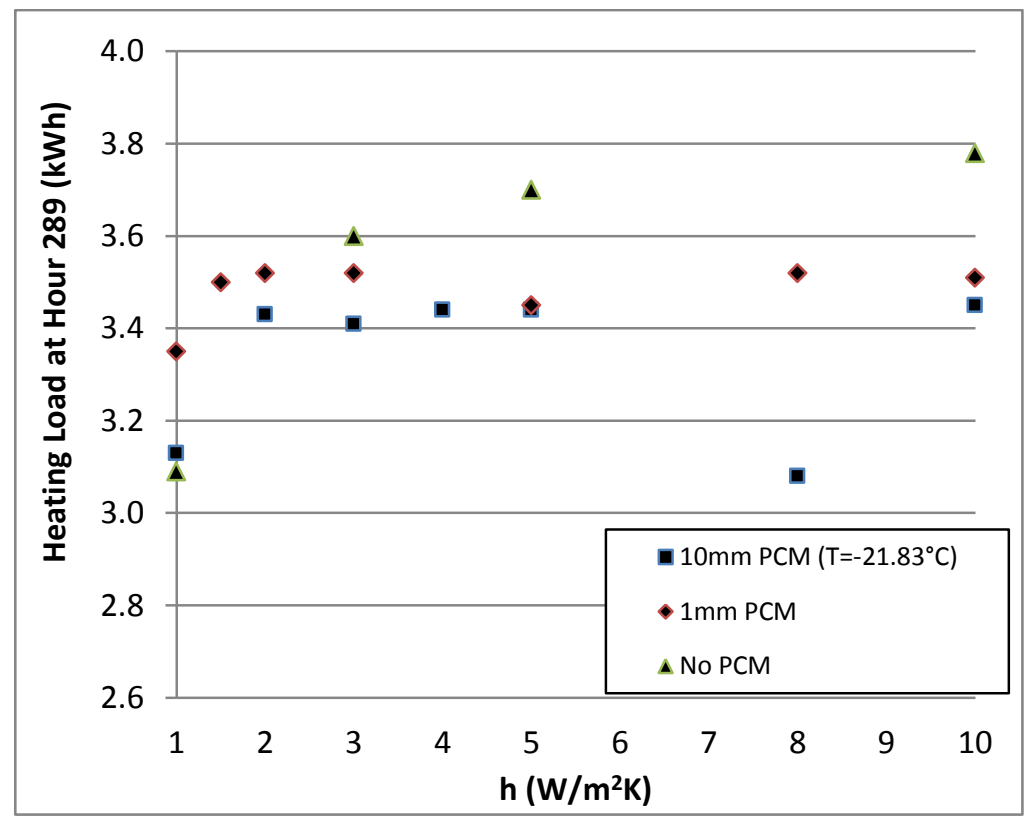

Figure 3-14: Effect of $h$ on heating energy demand at the coldest hour (289) of the year

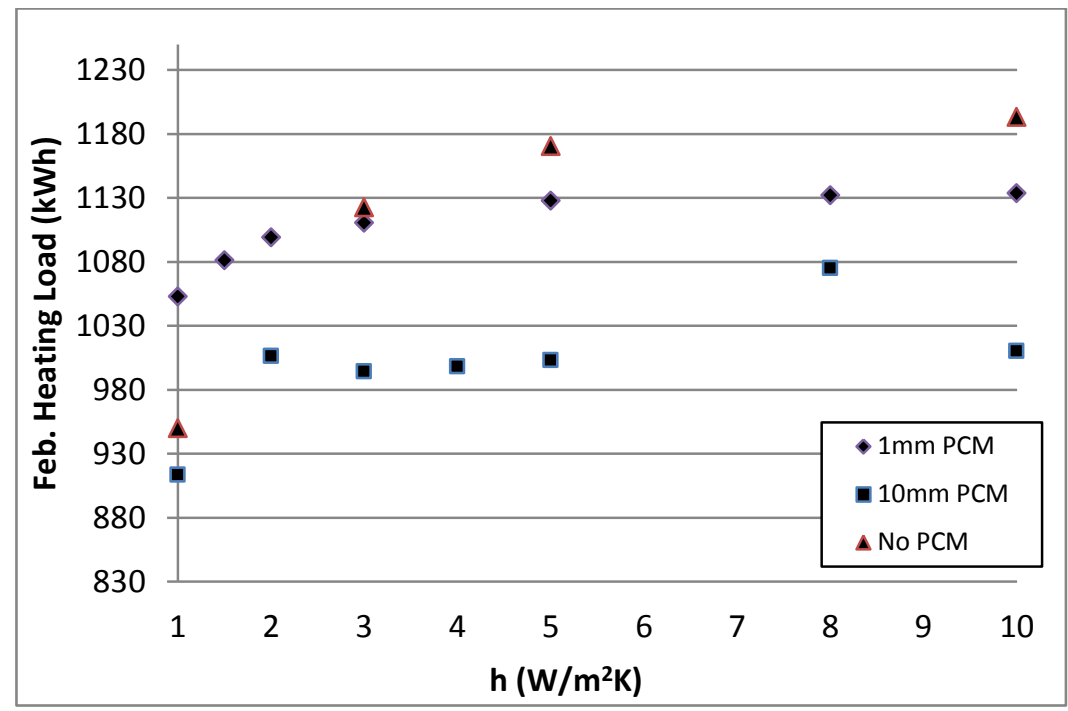

Figure 3-15: Effect of $h$ on heating energy demand in the coldest month of the year, February 


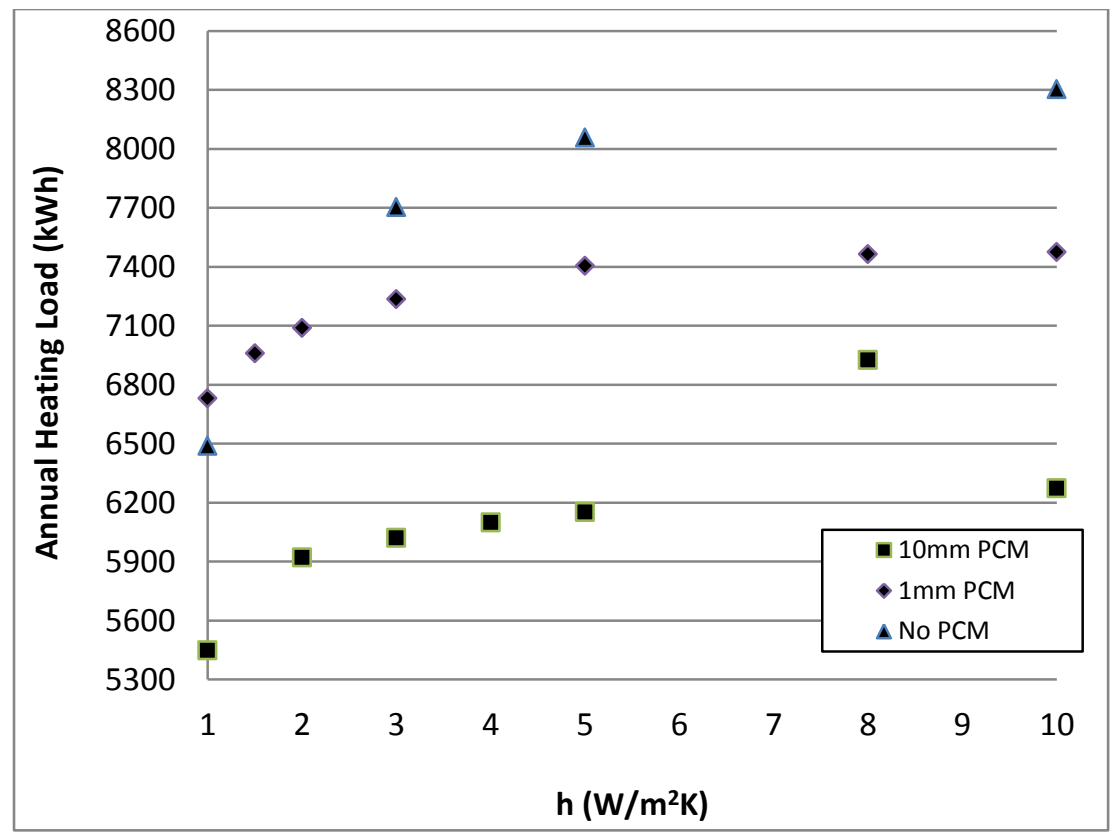

Figure 3-16: Effect of $h$ on annual heating energy demand

\subsubsection{Summary and discussion}

Analysis of data shows that during the investigated periods, outdoor (ambient) temperature is less than $24^{\circ} \mathrm{C}$ most of the time in summer (it is over $24^{\circ} \mathrm{C}$ about $18 \%$ of the time) and always less than $21^{\circ} \mathrm{C}$ in winter in Toronto. Therefore, increasing the h-value helps the transfer of heat (by reducing the thermal resistance of the interior surface layer) from inside to outside to balance the convection heat transfer increase. In the other words, in summer it acts in favor of comfort by decreasing the energy demand and keeping the zone temperature inside the set points' range $\left(21^{\circ} \mathrm{C}-24^{\circ} \mathrm{C}\right)$, and in winter it acts against comfort which means more energy demand to keep the zone temperature higher than $21^{\circ} \mathrm{C}$. The duration of summer is much less than that of winter in Toronto that justified the higher slope of the graph (h versus Energy Demand) in winter than in summer.

When comparison is made between no PCM and PCM condition while $\mathrm{h}$ is very low (1.0 $\mathrm{W} / \mathrm{m}^{2} \mathrm{~K}$ ), envelope with no PCM always demands less energy, except the annual heating load case. It is worth mentioning that the operative temperature is about $25^{\circ} \mathrm{C}$ in summer and $20^{\circ} \mathrm{C}$ in winter, which is one degree centigrade above and below the set points respectively. 
To check the effectiveness of the PCM in different seasons, regardless of its thickness, the operative temperature is extracted from TRNSYS outputs. Recalling Equation (1-5), PCM surface temperature can be calculated as follows:

$$
\mathrm{T}_{\mathrm{s}}=\frac{T_{o p}-A T_{\infty}}{1-A}
$$

When $T_{o p}$ is above $24^{\circ} \mathrm{C}$ or below $21^{\circ} \mathrm{C}, T_{\infty}$ is $24^{\circ} \mathrm{C}$ or $21^{\circ} \mathrm{C}$, respectively. In both cases, as the above equation stipulates, $T_{o p}$ is an estimator for $T_{s}$. Due to the thermal mass, by increasing the thickness of the PCM, sensitivity of the surface temperature to h-value reduces. In Toronto, ambient temperature is always less than $21^{\circ} \mathrm{C}$ in winter. On the other hand, this temperature is usually less than $24^{\circ} \mathrm{C}$ in summer; therefore, the PCM surface temperature is less than $21^{\circ} \mathrm{C}$ most of the time in winter $(65 \%)$ and about $30 \%$ of the time is above $24^{\circ} \mathrm{C}$ in summer. This implies that phase transformation happens more frequently in winter than in summer (information was extracted from the simulation data). As a result, the chosen PCM is more effective in winter than in summer.

\subsubsection{Simulation for effects of PCM on temperature fluctuation in set-point- controlled $\left(21-24^{\circ} \mathrm{C}\right)$ buildings}

Interior temperature of the SUI Net Zero House with no PCM was taken as baseline, and then the PCM added to simulate its effect on comfort of the house. In all calculations, the operative temperature $\left(T_{o p}\right)$ is employed [70]. In TRNSYS 16, the operative room temperature is a function of both the air $\left(T_{\text {air }}\right)$ and surface $\left(T_{s}\right)$ temperatures in the zone. Recalling Equation (1$5)$ :

$$
\mathrm{T}_{\mathrm{op}}=\mathrm{A} T_{\text {air }}+(1-\mathrm{A}) \mathrm{T}_{\mathrm{s}}
$$

where $\mathrm{A}$ is a weighting factor between 0 and 1 ; it was selected 0.5 for this project.

The comfort is measured by calculating temperature fluctuation inside each zone (Equations 3-8 to 3-10). Equation (3-8) calculates the difference in zone temperature with and without PCM at any moment. To quantify the temperature fluctuation or swing, a dimensionless relative fluctuation index (RFI) is defined and calculated by taking the average hourly temperature fluctuations (AHTF) of each zone with PCM in 8759 successive hours (whole year) relative to AHTF of same zone without PCM. 
To describe the temperature difference (TD) between PCM and no PCM condition, quantitatively, in each zone, $\Delta \mathrm{T}$ is defined:

$$
\begin{aligned}
& \Delta \mathrm{T}=\left|\mathrm{T}_{\mathrm{PCM}}-\mathrm{T}_{\text {noPCM }}\right| \\
& \overline{\Delta T}=\frac{\sum_{i=1}^{8760} \Delta \mathrm{T}_{\mathrm{i}}}{8760}
\end{aligned}
$$

where $\overline{\Delta T}$ is the annual average $\mathrm{TD}, \mathrm{T}_{\mathrm{PCM}}$ and $\mathrm{T}_{\text {noPCM }}$ are the zone temperatures, all in degree centigrade, with and without PCM at any moment, respectively. Average of the TD over the entire year (i.e., 8760 hours) is reported as an indicator of the PCM effectiveness in the zone. The higher the average TD is the more effective the PCM would be in that zone (see Table 3-6). This is a simple and quick-to-calculate indicator. Equation (3-10) measures the average of the successive hour temperature change of the year.

$$
A H T F=\frac{\sum_{i=1}^{8759}\left|Z T_{i}-Z T_{i+1}\right|}{8759}
$$

where ZT is the zone temperature in ${ }^{\circ} \mathrm{C}$, which is summed over $\mathrm{i}$, in the specific hour of year. Then,

$$
R F I=\frac{A H T F \text { for the Zone with PCM }}{A H T F \text { for the Zone without PCM }}
$$

The RFI is an indicator of the PCM effectiveness in reducing the temperature fluctuation of the zone. It is between 0 and 1 . The lower value indicates that the PCM reduces more the zone temperature fluctuation.

\subsubsection{Results}

Generally, PCM addition to the building envelope reduces the indoor temperature fluctuations due to both thermal mass and latent heat. To reduce the effect of thermal mass, only $10-\mathrm{mm}$ of PCM layer is added to the building envelope. PCM effects are due to latent heat of fusion or phase change. To investigate the PCM effects closely, the warmest and the coldest days of the year are selected. Hourly temperature fluctuations (HTF) at the warmest and the coldest hours of the year are also calculated (see Table 3-7). The warmest hour occurs on July $21^{\text {st }}$ (Figure 3-17)

and the coldest hour occurs on January $13^{\text {th }}$ (Figure 3-18). Temperature fluctuations are lower in case PCM is used as shown by Figures 3-17 and 3-18. This is always true; whether it is winter or summer season. 
Figure 3-17 shows the condition with complete shading; and Figure 3-18 shows the PCM effect without shading. The PCM plots on these figures reveal that PCM keeps the indoor temperature close to its melting range.

TD is decreased from garage (with no PCM) to Mezzanine (see Table 3-6). Table 3-6 represents the average values throughout the year.

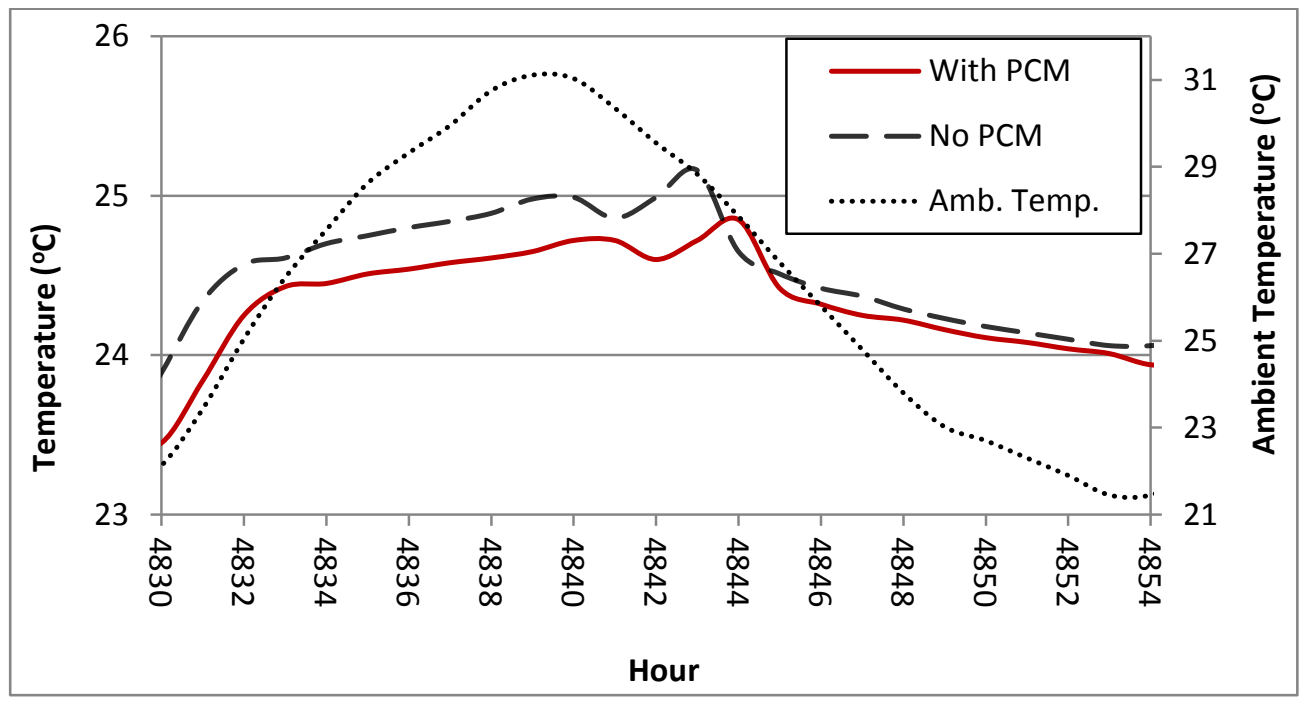

Figure 3-17: Temperature fluctuation inside the set points (21 to 24) in Mezzanine on July 21st

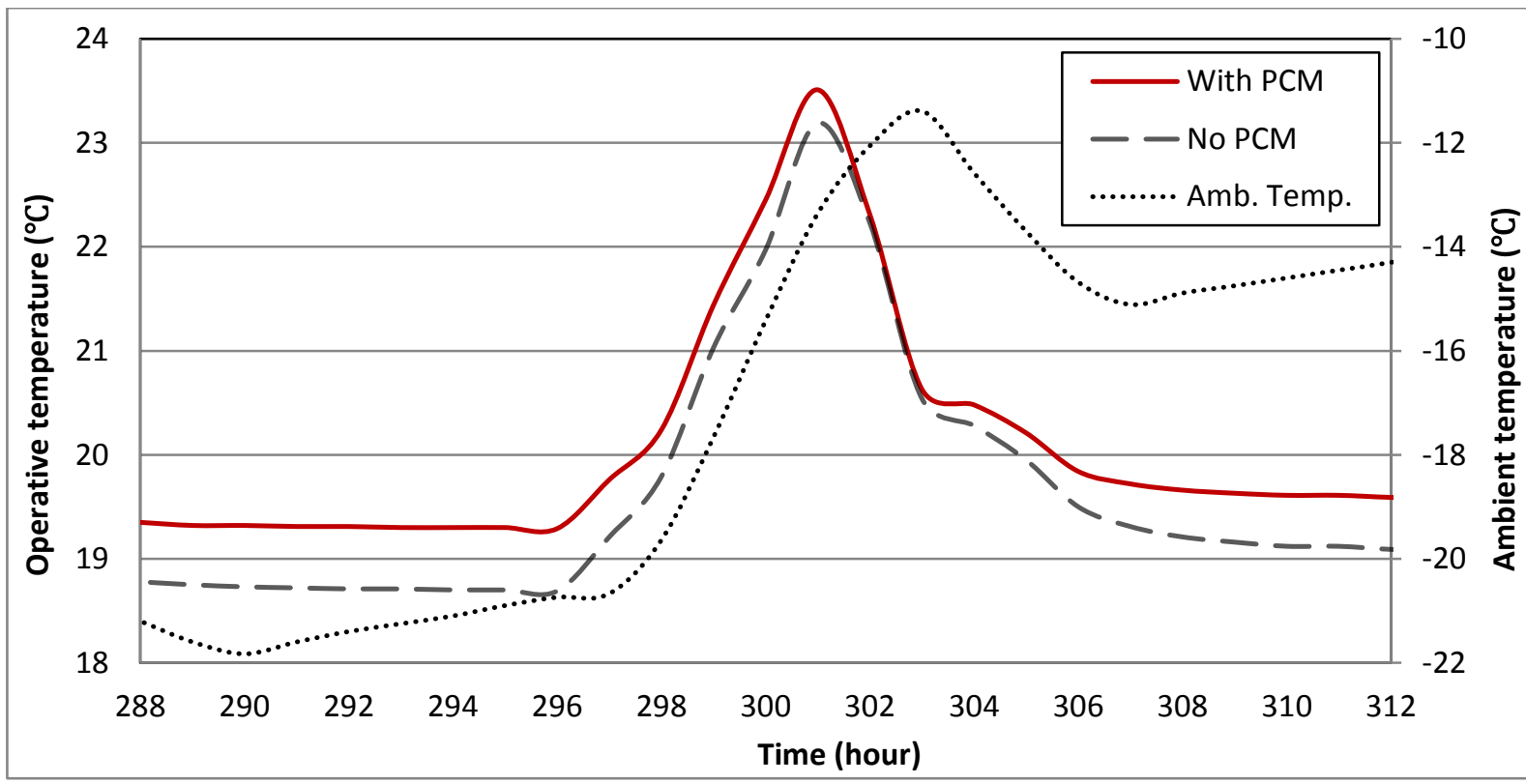

Figure 3-18: Temperature fluctuation inside the set points (21 to 24) in Mezzanine on January 13th 
Table 3-6: Average temperature difference and RFI in different zones

\begin{tabular}{|c|c|c|c|c|c|}
\hline Zone name & Garage & $1^{\text {st }}$ Floor & $2^{\text {nd }}$ Floor & $3^{\text {rd }}$ Floor & Mezzanine \\
\hline$\overline{\Delta T}$ & 0 & 0.31 & 0.31 & 0.28 & 0.26 \\
\hline RFI & 1 & 0.83 & 0.95 & 0.92 & 0.89 \\
\hline
\end{tabular}

Table 3-7: Temperature fluctuations in Mezzanine at the coldest and the warmest hours of the year

\begin{tabular}{|c|c|c|c|}
\hline Temperature $\left({ }^{\circ} \mathrm{C}\right)$ & HTF With PCM & HTF No PCM & $\Delta \mathrm{T}\left({ }^{\circ} \mathrm{C}\right)$ \\
\hline-21.83 (Coldest) & 0 & 0.02 & 0.57 \\
\hline 31.11 (Warmest) & 0 & 0.01 & 0.26 \\
\hline
\end{tabular}

\subsubsection{Summary and discussion}

It is clear from Figures 3-17 and 3-18 that PCM tends to keep the temperature close to midpoint of the set points (i.e., $22.5^{\circ} \mathrm{C}$ ), which is the mid of the melting range of the PCM. Hourly temperature fluctuation (HTF) is almost zero at the peak temperature (coldest and warmest hour) no matter PCM is used or not (see Table 3-7). This is due to the change in temperature trend (max or min values of the outdoor temperature). At the peak moments, shading makes a difference in TD. Shading reduces TD from $0.57^{\circ} \mathrm{C}$ to $0.26^{\circ} \mathrm{C}$. In garage, $\mathrm{PCM}$ is not used; thus, TD and RFI are zero and one, respectively. TD and RFI show that PCM has maximum effect on first floor (see Table 3-6). This might be due to the fact that first floor has the minimum volume and having same amount of PCM with respect to the other zones. The first, second, third, and mezzanine volumes are $146.56 \mathrm{~m}^{3}, 163.57 \mathrm{~m}^{3}, 175.5 \mathrm{~m}^{3}$, and $171.64 \mathrm{~m}^{3}$, respectively. All ceilings are covered with about $130-\mathrm{m}^{2}$ PCM. But mezzanine has only $70 \mathrm{~m}^{2}$ of PCM coverage.

Previous work showed that PCM is more effective in summer than in winter in reducing temperature fluctuations in Toronto weather conditions, when there is no set point. By adding set points in this work, AHTF reduction due to the PCM addition into the building envelope reduces from $16 \%$ to $11 \%$ (100-89) in mezzanine (see Table 3-6). This is due to the limitation of the temperature range. Heating/cooling is on as soon as indoor temperature touched the set points to keep it back to the set point range.

\subsubsection{Conclusions}

The Net-Zero Building was simulated using TRNSYS incorporated with TYPE 204 PCM. The best melting range and thermal conductivity of the PCM were sought to make the lowest energy demand and peak power along with less IAT swing. Considering the set points of $21^{\circ} \mathrm{C}$ and $24^{\circ} \mathrm{C}$, 
the best melting range for the PCM was found to be $22^{\circ} \mathrm{C}$ to $23^{\circ} \mathrm{C}$, which is in the middle of the set points range. This provides $35 \%$ saving in the total annual energy demand. In terms of thermal conductivity, although it is not worthwhile to work on thermal conductivity to achieve a maximum of $2 \%$ reduction in energy demand, higher thermal conductivity is preferred. The dependence of the total energy demand on the thermal conductivity may be expressed as an exponential function with less than $0.3 \%$ between the simulation result and the best fit: $y=548 \mathrm{e}^{-}$ $4.2 \mathrm{x}+7525$, where $\mathrm{x}$ is the thermal conductivity $(\mathrm{W} / \mathrm{mK})$ and $\mathrm{y}$ is the demand $(\mathrm{kWh})$. Although IAT swing is neither much sensitive to the melting range nor to the thermal conductivity, it is lower when the PCM is present.

ASHRAE Standard 140-2001 (BESTEST), case 600, in Toronto was simulated. Two different thicknesses of PCM, one and ten millimeter, are covered on all of the wall and ceiling surfaces. Simulations are conducted for inside convective heat transfer coefficient $(\mathrm{h})$ from 1.0 to 10 $\mathrm{W} / \mathrm{m}^{2} \mathrm{~K}$ and the specifications of DAL HSM PCM, developed at Dalhousie University. Generally, increasing the amount (thickness) of the PCM (layer) reduces the energy demand. In summer (cooling demand), by increasing the h-value the energy demand slightly decreases (negative correlation). In winter (heating conditions), energy demand is sensitive to h-value with positive correlation in Toronto climate conditions. In addition, it is concluded that PCM brings more benefits in winter than summer in terms of saving energy.

PCM reduces the indoor temperature fluctuations, even when the set points are activated. AHTF reduction due to the PCM addition into the building envelope reduces $11 \%$ in mezzanine, which is less than the condition with no set points. Although hourly TD at peaks (the coldest and warmest hour of the year) shows PCM is more effective in reducing temperature fluctuations in the coldest hour. 


\section{Simulation of the thermodiode panel (TDP) in buildings}

A TDP performance is investigated in Toronto weather conditions, which is a typical city in North America.

Figure 4-1 shows the sketch of the design. To analyse the evaporator surface temperature, which is exposed to the solar radiation, one dimensional energy balance is employed, see Figure 4-2. Equations are derived based on the first law of thermodynamics as follows:

$$
\alpha A q_{\text {Solar }}=q_{\text {in }} A_{\text {hp }}+\left(q_{\text {con }}+q_{\text {rad }}\right) A
$$

where: $Q=q A, A$ is the radiated area, $q_{\text {solar }}$ is the solar radiation to the surface, $A_{h p}$ is the thermosyphon cross section area, $q_{i n}$ is the power transmitted to the building envelope through the condenser of the thermosyphon, $q_{\text {con }}$ is the convection power loss due to the wind outside, $\alpha$ is the surface's solar absorptivity, and $q_{\text {rad }}$ is the net radiation power loss to the surroundings due to the surface and ambient temperatures $\left(\varepsilon \sigma\left(T^{4}-T_{\infty}{ }^{4}\right)\right.$ ). All heat flux (q) units are in watt per square meter $\left(\mathrm{W} / \mathrm{m}^{2}\right)$.
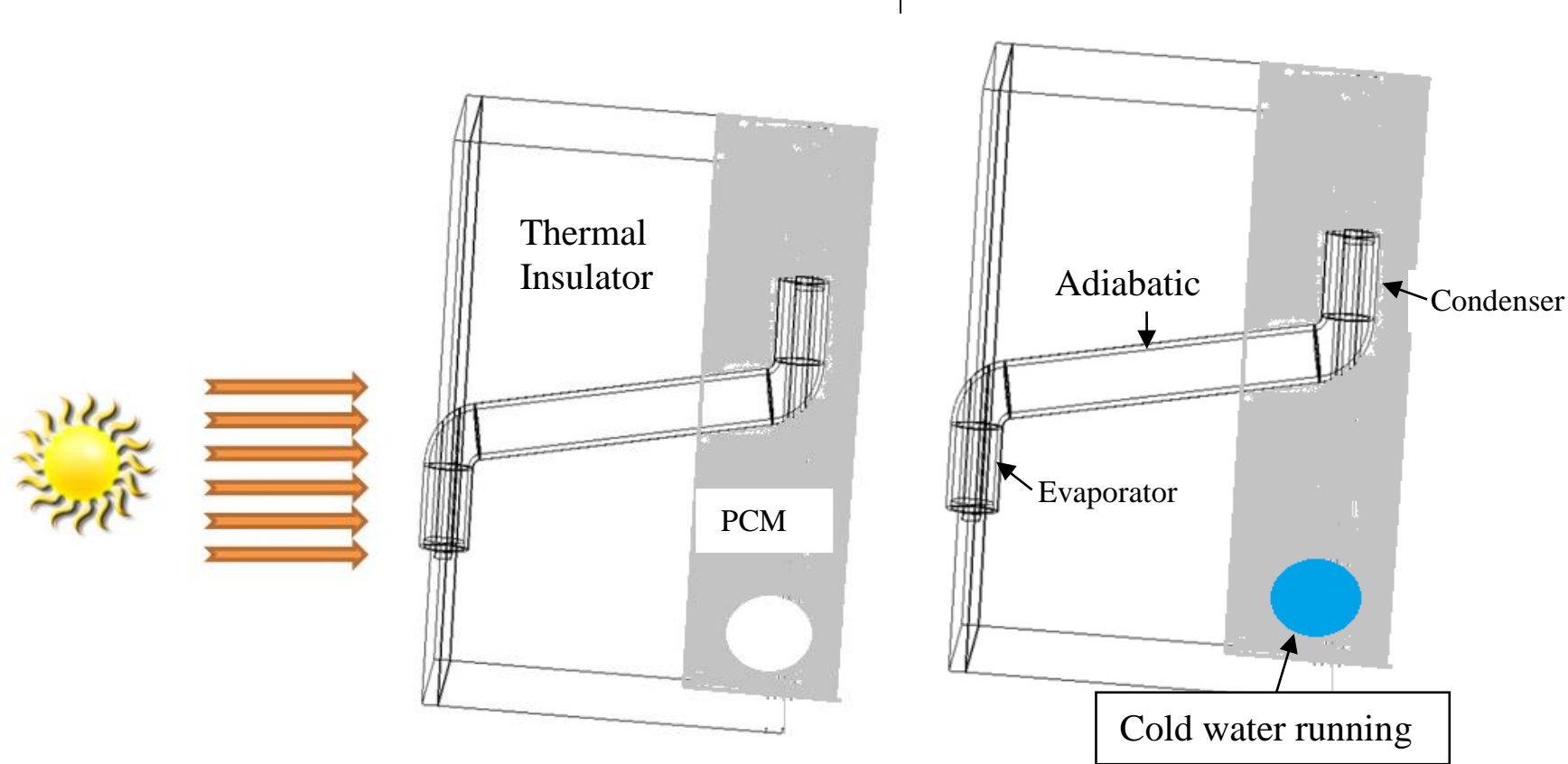

Figure 4-1: PCM-thermosyphon combination in charging (left) and discharging (right) conditions 


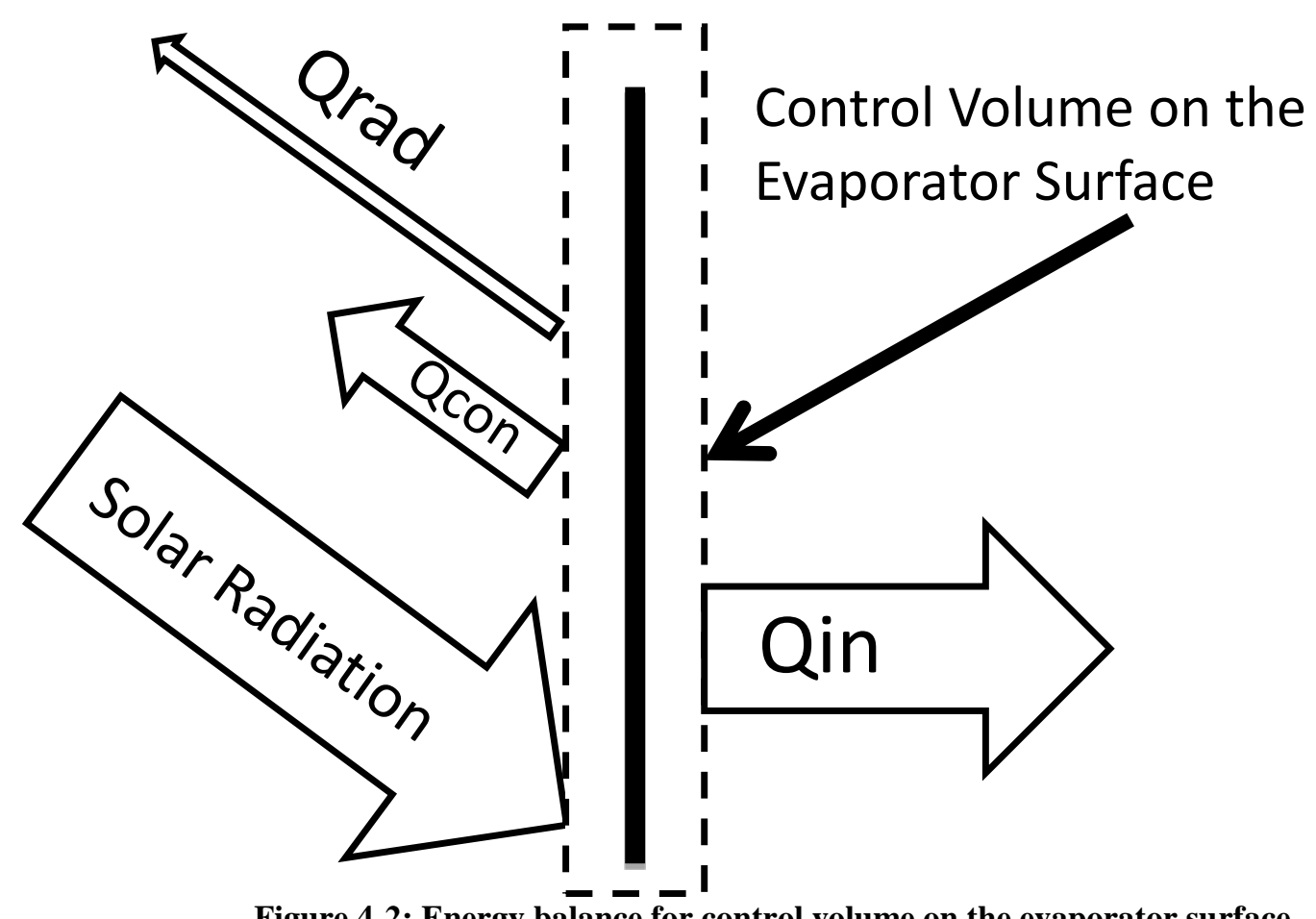

Figure 4-2: Energy balance for control volume on the evaporator surface

As Equation (4-2) implies, to maximise the $Q_{i n}$, the other terms on the right side of the equation should be minimised. Therefore, it is important to cover the evaporator surface with a transparent material (e.g., Plexiglas or glass same as solar thermal collectors) in order to reduce outside convection heat transfer. Based on the Equation (4-2), the steady-state governing equation for calculating the surface temperature $(\mathrm{T})$ would be:

$$
A \alpha q_{\text {solar }}=Q_{\text {in }}+\left[\bar{h}_{o}\left(T-T_{\text {air }}\right)+\varepsilon \sigma\left(T^{4}-T_{\infty}{ }^{4}\right)\right] A
$$

where: $\varepsilon$ is emissivity of the surface under investigation, $\sigma$ is Stephen-Boltzmann constant (5.67 $\left.\mathrm{x} 10^{-8} \mathrm{~W} / \mathrm{m}^{2} \mathrm{~K}^{4}\right), T_{\infty}$ is sky temperature $(K)$ that is assumed equal to ambient temperature, $T_{\text {air }}$ is air temperature $(K)$ (this is close to the $T_{\infty}$ ), T is the surface temperature $(\mathrm{K}), \bar{h}_{o}$ is average convective heat transfer coefficient $\left(\mathrm{W} / \mathrm{m}^{2} \mathrm{~K}\right)$, and $\mathrm{A}$ is the exposed surface to radiation $\left(\mathrm{m}^{2}\right)$.

To calculate $Q_{i n}$, the thermal resistance of the panel should be estimated. Figure 4-3 shows the physical shape or geometry (top) and the thermal resistant network (bottom) of the problem. Arrows point from the relevant surfaces of the geometry to their corresponding temperatures in the network. Thickness of each layer is noted on top of the geometry. $\mathrm{G}, 10 \mathrm{~cm}$, and H, $20 \mathrm{~cm}$, 


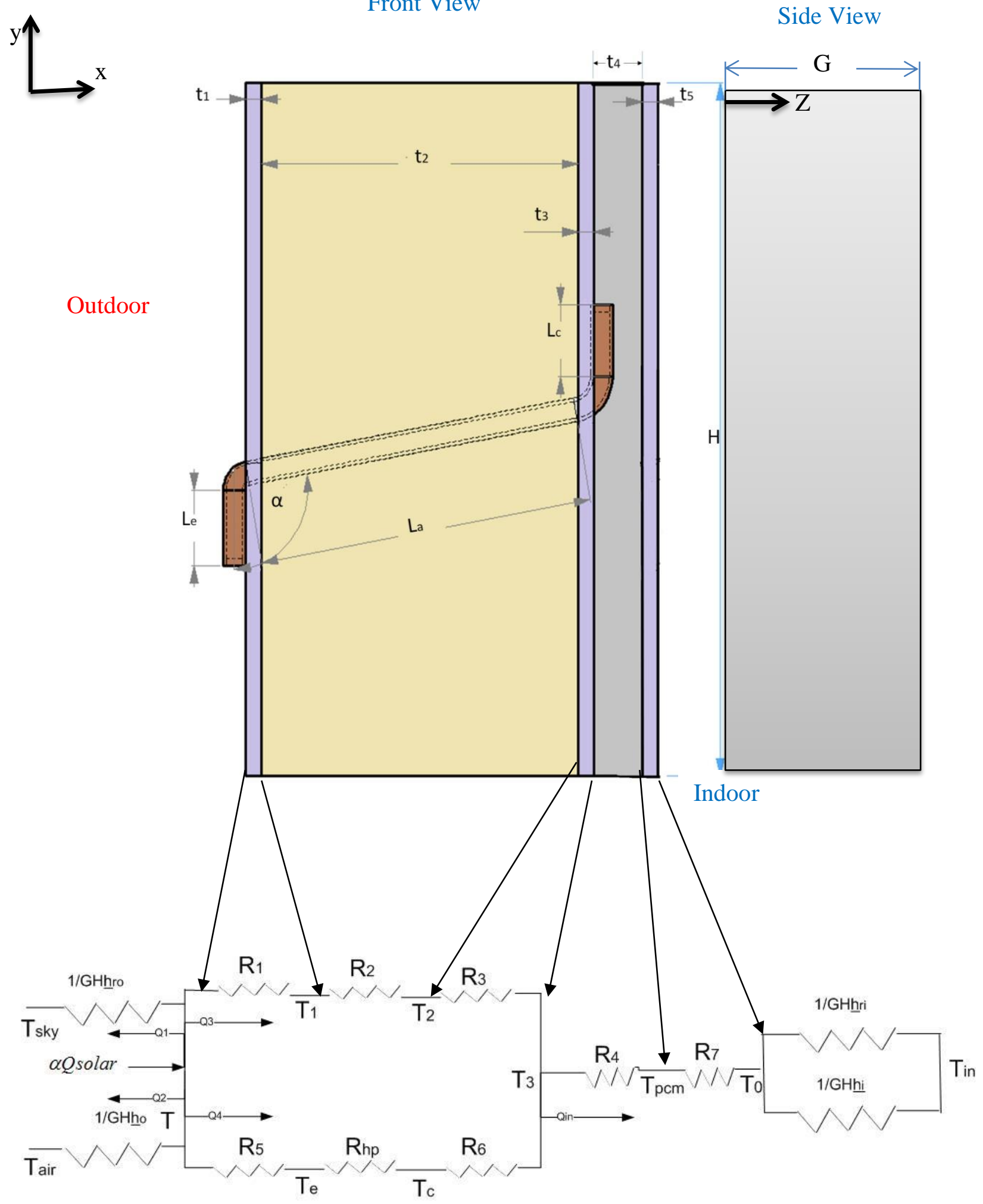

Figure 4-3: TP panel (top) and its thermal resistance network (bottom), related surfaces are connected by arrows. $T$ and $T 3$ represent the average temperature of the surfaces $\left(T_{p c m}\right.$ is $T_{4}$ in the text) 
are the width (into the page) and height of the panel (i.e., the surface area whose temperature is under investigation is $\mathrm{GH}$ ).

Recalling the notations in Figures 4-3, the resistances $\left(\mathrm{R}_{1}\right.$ to $\left.\mathrm{R}_{7}\right)$ are calculated as follows:

$$
\begin{aligned}
R_{1} & =\frac{t_{1}}{k_{1}\left(G H-A_{p}\right)} \\
R_{2} & =\frac{t_{2}}{k_{2}\left(G H-A_{p}\right)} \\
R_{3} & =\frac{t_{3}}{k_{3}\left(G H-A_{p}\right)} \\
R_{4} & =\frac{t_{4}}{k_{4}\left(G H-A_{p}\right)} \\
R_{7} & =\frac{t_{5}}{k_{5} G H}
\end{aligned}
$$

Calculation of fin effect ( $\mathbf{R}_{5}$ ): starting energy balance on one element (see Figures 4-4 \& 4-5) and assuming that the heat transfer into the insulation is negligible,

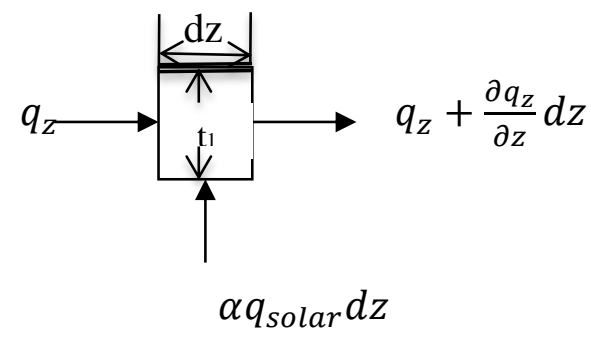

Figure 4-4: Energy balance on the element shown in Figure 4-5

$$
\begin{aligned}
& q_{z}=-k_{1} t_{1} \frac{d T}{d z} \\
& \alpha q_{\text {solar }} d z=\frac{\partial q_{z}}{\partial z} d z
\end{aligned}
$$

Therefore, from Equations (4-8) and (4-9): $\frac{d T}{d z}=-\frac{\alpha q_{\text {solar }}}{k_{1} t_{1}} z+C$

Considering $\left.\frac{\partial T}{\partial z}\right|_{z=G / 2}=0 \Longrightarrow C=\frac{\alpha G q_{\text {solar }}}{2 k_{1} t_{1}}$

Integration of Equation (4-10) with boundary condition (i.e., $\left.T\right|_{z=0}=T_{e}$ ): 


$$
\begin{aligned}
& \int_{T_{e}}^{T} d T=\int_{0}^{Z}\left(-\frac{\alpha q_{\text {solar }}}{k_{1} t_{1}} Z+\frac{\alpha G q_{\text {solar }}}{2 k_{1} t_{1}}\right) d z ; \text { Therefore, } \\
& T=\frac{\alpha q_{\text {solar }}}{2 k_{1} t_{1}}\left(-z^{2}+G z\right)+T_{e} \\
& Q=-\left.L_{e} t_{1} k_{1} \frac{\partial T}{\partial z}\right|_{Z=0}=-L_{e} t_{1} k_{1} \frac{\alpha G q_{\text {solar }}}{2 k_{1} t_{1}}=-L_{e} \alpha G q_{\text {solar }} / 2
\end{aligned}
$$

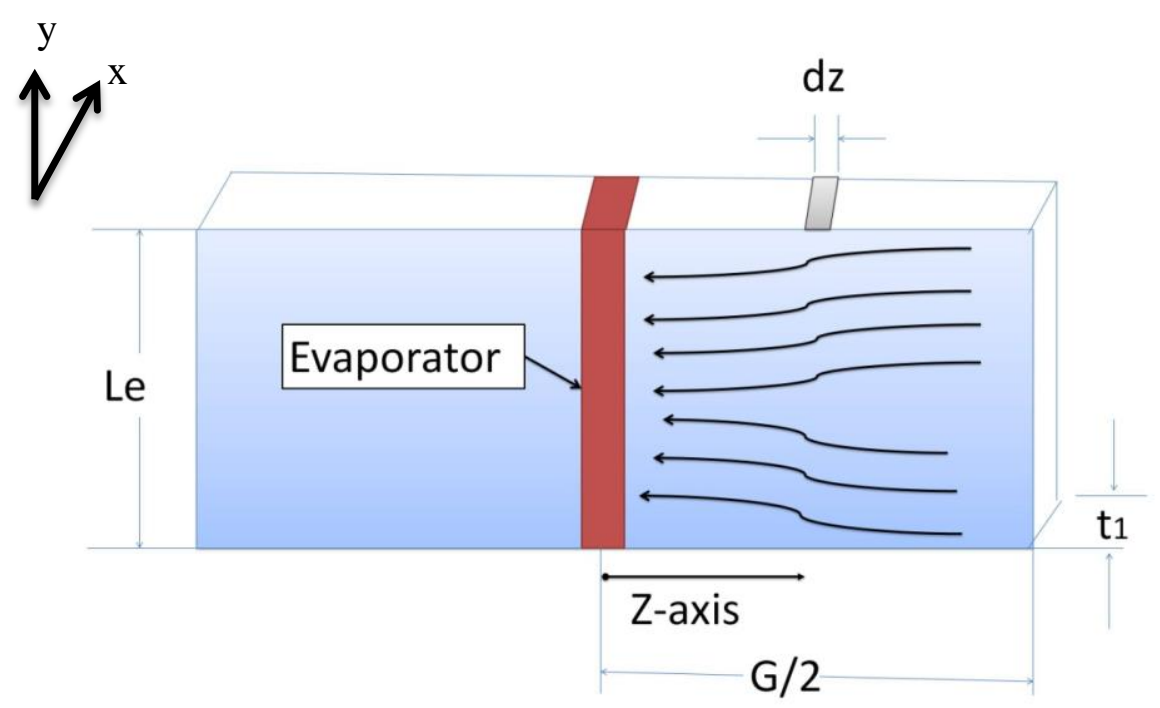

Figure 4-5: Evaporator side of the TDP

Negative sign on Equation (4-13) shows that the direction of the heat transfer is against arrows on Figure 4-5 in $\mathrm{z}$ direction. Because of the assumption of no heat loss to insulation, this $\mathrm{Q}$ is equal to the solar radiation on the surface.

$$
\begin{gathered}
\bar{T}=\frac{\int_{0}^{\frac{G}{2}} T d z}{G / 2}=\frac{\int_{0}^{\frac{G}{2}}\left(\frac{\alpha q_{\text {solar }}}{2 k_{1} t_{1}}\left(-z^{2}+G z\right)+T_{e}\right) d z}{G / 2}=\frac{\left[\frac{\alpha q_{\text {solar }}}{2 k_{1} t_{1}}\left(-\frac{z^{3}}{3}+\frac{G z^{2}}{2}\right)\right]+\left.T_{e} z\right|_{0} ^{\frac{G}{2}}}{G / 2}= \\
\frac{\alpha G^{2} q_{\text {solar }}}{12 k_{1} t_{1}}+T_{e} \\
\mathrm{R}_{5}=\frac{\Delta T}{Q}=\frac{\bar{T}-T_{e}}{Q}=\frac{\frac{\alpha G^{2} q_{\text {solar }}}{12 k_{1} t_{1}}}{L_{e} \alpha G q_{\text {solar }} / 2}=\frac{G}{6 k_{1} t_{1} L_{e}}
\end{gathered}
$$

Calculation of fin effect ( $\mathbf{R}_{\mathbf{6}}$ ): starting energy balance on one element (see Figures 4-6 \& 4-7). This time the heat flows to PCM instead of gaining from the sun. $T$ and $T_{4}$ represent $T_{3}$ and $T_{P C M}$ on Figure 4-3, respectively. 


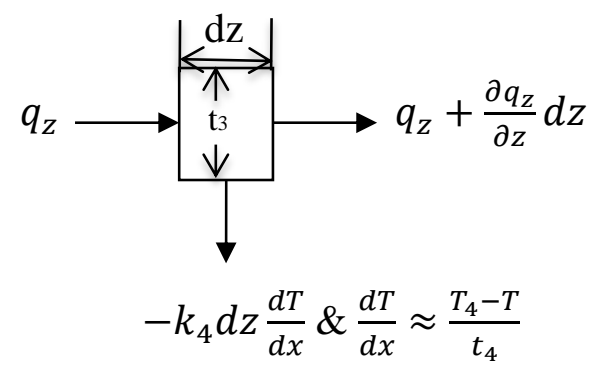

Figure 4-6: Energy balance on the element shown in Figure 4-7

It is assumed that there is no phase change, no heat to insulation, and condition is steady state.

$$
\begin{gathered}
q_{z}=-k_{3} t_{3} \frac{d T}{d z} \\
k_{4} \frac{T_{4}-T}{t_{4}} d z=-\frac{\partial q_{z}}{\partial z} d z \quad \& B=\frac{k_{4}}{t_{3} t_{4} k_{3}}
\end{gathered}
$$

Therefore, from Equations (4-17) and (4-18): $\frac{d^{2} T}{d z^{2}}+B\left(T_{4}-T\right)=0 \quad$ then:

$$
T=C_{1} e^{\sqrt{B} z}+C_{2} e^{-\sqrt{B} z}+T_{4}
$$

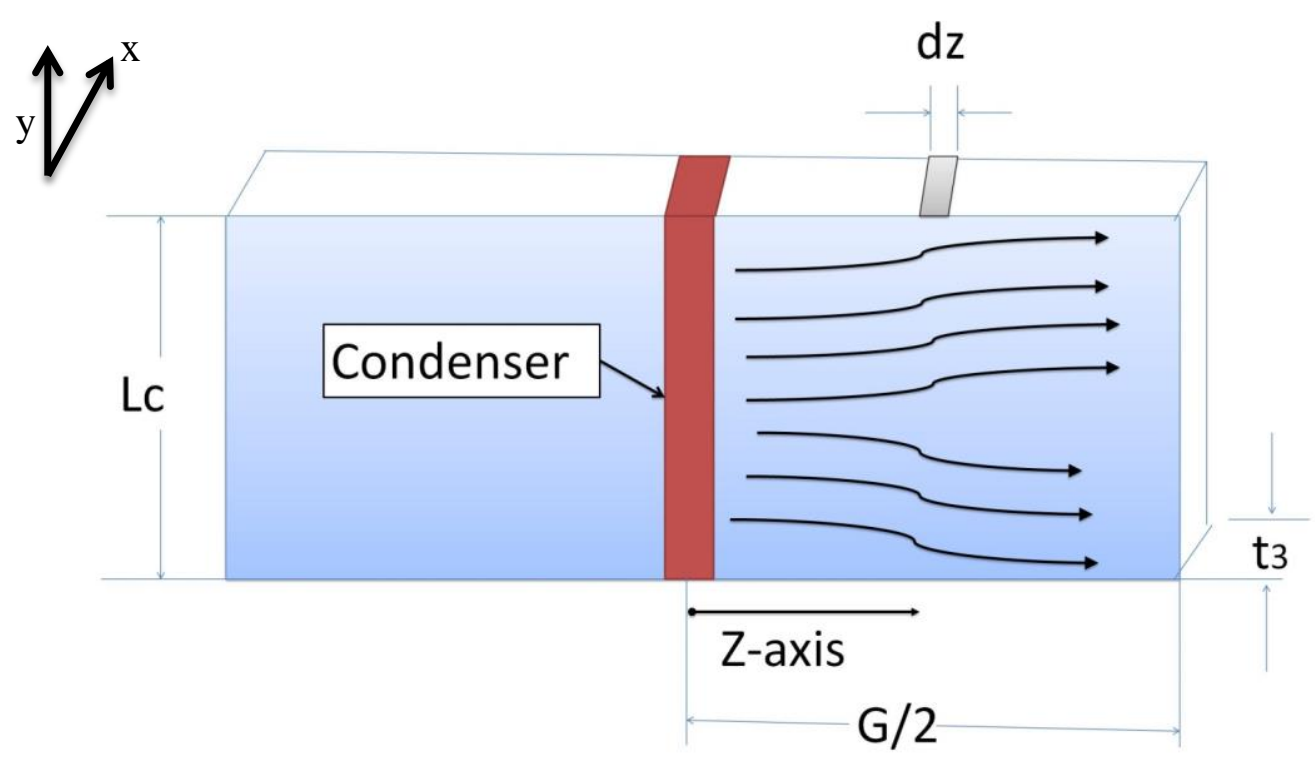

Figure 4-7: Condenser side of the TDP

Considering boundary conditions (i.e., $\left.T\right|_{Z=0}=\left.T_{C} \& \frac{\partial T}{\partial z}\right|_{Z=G / 2}=0$ ): 
$C_{1}=\frac{T_{C}-T_{4}}{1+e^{\sqrt{B} G}} \& C_{2}=\frac{e^{\sqrt{B} G}\left(T_{C}-T_{4}\right)}{1+e^{\sqrt{B} G}}$, and finally: $T-T_{4}=\frac{\left(e^{\sqrt{B} Z}+e^{\sqrt{B}(G-z)}\right)\left(T_{C}-T_{4}\right)}{1+e^{\sqrt{B} G}}$

$$
\mathrm{R}_{6}=\frac{\Delta T}{Q}=\frac{T_{c}-\bar{T}}{Q}
$$

Taking $\frac{\left(T_{C}-T_{4}\right)}{1+e^{\sqrt{B} G}}=C, \bar{T}=\frac{\int_{0}^{G / 2} T d z}{G / 2}=\frac{2 C}{G \sqrt{B}}\left(e^{G \sqrt{B}}-1\right)+T_{4}$

$$
Q=-\left.L_{c} t_{3} k_{3} \frac{\partial T}{\partial z}\right|_{Z=0}=\frac{L_{c} t_{3} k_{3} \sqrt{B}\left(T_{c}-T_{4}\right)}{e^{G \sqrt{B}}+1}\left(e^{G \sqrt{B}}-1\right)
$$

Substituting Equations (4-22) and (4-23) into Equation (4-21):

$$
\mathrm{R}_{6}=\frac{\left(1+e^{\sqrt{B} G}\right) G \sqrt{B}-2\left(e^{G \sqrt{B}}-1\right)}{L_{c} t_{3} k_{3} G \sqrt{B}\left(e^{G \sqrt{B}}-1\right)}
$$

In case that there is no PCM $\left(\mathrm{t}_{4}=0\right.$ in Equation (4-18)):

$$
\lim _{t_{4} \rightarrow 0} B=\lim _{t_{4} \rightarrow 0} \sqrt{B}=\infty
$$

$R_{6}=\frac{\left(1+e^{\sqrt{B} G}\right) G \sqrt{B}-2\left(e^{G \sqrt{B}}-1\right)}{L_{c} t_{3} k_{3} G \sqrt{B}\left(e^{G \sqrt{B}}-1\right)}$

$\lim _{\sqrt{B} \rightarrow \infty} R_{6}=\lim _{\sqrt{B} \rightarrow \infty} \frac{\left(1+e^{-\sqrt{B} G}\right) G \sqrt{B}+2\left(e^{-G \sqrt{B}}-1\right)}{-L_{c} t_{3} k_{3} G \sqrt{B}\left(e^{-G \sqrt{B}}-1\right)}=\lim _{\sqrt{B} \rightarrow \infty} \frac{G\left[\left(1+e^{-\sqrt{B} G}\right)-G^{2} \sqrt{B} e^{-G \sqrt{B}}-2 e^{-G \sqrt{B}}\right]}{-L_{c} t_{3} k_{3} G\left(1+e^{-G \sqrt{B}}+G \sqrt{B} e^{-G \sqrt{B}}\right)}$

$\lim _{\sqrt{B} \rightarrow \infty} \sqrt{B} e^{-G \sqrt{B}}=\lim _{\sqrt{B} \rightarrow \infty} \frac{\sqrt{B}}{e^{G \sqrt{B}}}=\lim _{\sqrt{B} \rightarrow \infty} \frac{1}{G e^{G \sqrt{B}}}=0$

$\lim _{\sqrt{B} \rightarrow \infty} R_{6}=\frac{G}{L_{c} t_{3} k_{3} G}=\frac{1}{L_{c} t_{3} k_{3}}$

$\mathrm{R}_{6}$ approaches to $1 /\left(L_{c} t_{3} k_{3}\right)$ when $t_{4}$ approaches to zero (no PCM).

[26] derived the thermal resistance of a thermosyphon as:

$$
\begin{gathered}
R_{h p}=\frac{\ln \frac{r_{o}}{r_{i}}}{2 \pi k_{C u}}\left(\frac{1}{L_{c}}+\frac{1}{L_{e}}\right)+\frac{\pi r_{o}^{2} T_{v} F_{v}\left(\frac{L_{e}}{6}+L_{a}+\frac{L_{c}}{6}\right)}{\rho_{v} h_{l v}} \\
F_{v}=\frac{8 \mu_{v}}{\rho_{v} h_{l v} r_{h, v}^{2} A_{v}}
\end{gathered}
$$

where $F_{v}$ is frictional coefficient for circular vapour-flow passage [26], subscript $v$ refers to vapour phase, $r_{h, v}$ is hydraulic radius of vapour $\left(\approx r_{i}\right), r_{i}, r_{o}$, and $A_{h p}$ are the internal and external radius, and cross section area of the thermosyphon, respectively, $L_{e}, L_{a}, L_{c}$ are evaporator, 
adiabatic and condenser length, respectively. Considering uniform temperature for walls and inside air $\left(T_{i n}\right)$, the total thermal resistance between investigating surface and the inside zone would be:

$$
\sum \mathrm{R}=\frac{\left(R_{5}+R_{h p}+R_{6}\right)\left(R_{1}+R_{2}+R_{3}\right)}{\left(R_{5}+R_{h p}+R_{6}\right)+\left(R_{1}+R_{2}+R_{3}\right)}+\frac{1}{G H\left(h_{r i}+h_{i}\right)}+R_{4}+R_{7}
$$

where:

$$
\bar{h}_{r i}=\varepsilon \sigma\left(T_{0}^{2}+T_{i n}^{2}\right)\left(T_{0}+T_{i n}\right)
$$

and

$$
\bar{h}_{r o}=\varepsilon \sigma\left(T^{2}+T_{\text {air }}^{2}\right)\left(T+T_{\text {air }}\right)
$$

Now, Equation (4-2) can be solved for $T$ by substituting $Q_{i n}$ as follows:

$$
Q_{\text {in }}=\frac{T-T_{\text {in }}}{\sum \mathrm{R}}
$$

Assuming the interior air temperature, $\bar{h}_{i}$ and $\bar{h}_{o}$ as $20^{\circ} \mathrm{C}, 2 \mathrm{~W} / \mathrm{m}^{2} \mathrm{~K}$ and $20 \mathrm{~W} / \mathrm{m}^{2} \mathrm{~K}$, respectively, simulation of the hot end surface of the thermosyphon can be estimated in Toronto. The outdoor convective heat transfer coefficient $\left(\bar{h}_{o}\right)$ is estimated based on average air speed [13]. As it is known from information taken from The Weather Network website ${ }^{7}$, the lowest daily average ambient temperature is about $-7^{\circ} \mathrm{C}$ in January (the coldest month of the year); therefore, it is very important to get maximum possible heat from the sun in this month. The surface temperature of the TDP is calculated in this month to investigate the potential energy that can be transferred into the building through the TDP. Taking into account that the Sun is not always available, it is very important that TDP not only is fast in transferring the solar energy (by using thermosyphon) but also stores heat for near future use (in the PCM).

\subsection{Results}

A Matlab code is developed to calculate the surface temperature (T). It takes Toronto weather conditions (e.g., $T_{\infty}$ and $q_{\text {solar }}$ ) as an input and provides the $\mathrm{T}$ and $Q_{\text {in }}$ on an hourly basis. The physical parameters are given based on the properties of pure aluminum for material with thickness $t_{1}, t_{3}$ and $t_{5}$, pure copper for the thermosyphon and urethane foam (two-part mixture) for thickness $t_{2}$. In addition, the width and height of the panel are considered as $10 \mathrm{~cm}$ and $30 \mathrm{~cm}$ respectively, and the inside and outside diameters of the pipe are $10 \mathrm{~mm}$ and $12 \mathrm{~mm}$ respectively, with condenser, adiabatic and evaporator length of $10 \mathrm{~cm}, 15 \mathrm{~cm}$ and $10 \mathrm{~cm}$ in turn. Table 4-1

\footnotetext{
${ }^{7}$ The sampling period for this data covers 30 years. Record maximums and minimums are updated annually.
} 
presents the calculated values of some thermal resistances. As Equation (4-2) implies, $T_{i n}$ and $T_{0}$ affect the value of R. By fixing the difference between the temperatures $\left(T_{0}-T_{\text {in }}=10\right)$, interior convective heat transfer $\left(\bar{h}_{i}=2 \mathrm{~W} / \mathrm{m}^{2} \mathrm{~K}\right)$, and changing the interior temperature $\left(T_{\text {in }}\right)$ from $1^{\circ} \mathrm{C}$ to $20^{\circ} \mathrm{C}$, the R-value changes from $17.001 \mathrm{~K} / \mathrm{W}$ to $16.243 \mathrm{~K} / \mathrm{W}$.

Table 4-1: Some thermal resistances (in K/W) in the TDP area $\left(0.02 \mathbf{~ m}^{2}\right)$

\begin{tabular}{|c|c|c|c|c|c|c|c|}
\hline $\mathrm{R}_{1}$ & $\mathrm{R}_{2}$ & $\mathrm{R}_{3}$ & $\mathrm{R}_{4}$ & $\mathrm{R}_{5}$ & $\mathrm{R}_{6}$ & $\mathrm{R}_{\mathrm{hp}}$ & $\mathrm{R}$ \\
\hline 0.00043 & 169.093 & 0.00014 & 8.953 & 0.234 & 2.801 & 0.00042 & 16.654 \\
\hline
\end{tabular}

Aside from a 1-mm aluminum plate $\left(R_{3}\right)$, the thermosyphon $\left(R_{h p}\right)$ has the least thermal resistance (in order of -4). This causes the panel to transfer all the radiation heat through the thermosyphon and heat up the PCM as soon as the sun shines. The thermosyphon has three distinct thermal resistors at the two ends (evaporator and condenser) with resistance of $0.000724 \mathrm{~K} / \mathrm{W}$ at each end and vapour resistance in the middle of the pipe with $2.24 \times 10^{-9} \mathrm{~K} / \mathrm{W}$ resistance. This implies that thermal resistance of a thermosyphon is dependent on the quality of the surfaces and materials of both ends. The maximum thermal resistance goes to PCM $\left(\mathrm{R}_{4}\right)$, which is not really intended to transfer heat; it is intended to store the heat and the aluminum plate in contact with $\operatorname{PCM}\left(t_{5}\right)$, which conducts its heat to the indoor air.

Recalling Equation (4-2), the variation of power transferred and surface temperature in January in Toronto is shown in Figure 4-8. For this calculation, the temperature of the air around the surface is taken equal to the sky temperature of the outdoor $\left(T_{s k y}\right)$. In this month, $79.6 \mathrm{kWh} / \mathrm{m}^{2}$ (1592 Wh on the $0.1 \mathrm{~m}$ by $0.2 \mathrm{~m}$ surface) solar energy is gained, whereas $213 \mathrm{Wh}$ energy is transferred into the building. Recalling the property of the thermosyphon (thermodiode), this is the net energy transfer into the building during the first month of the year. This condition (i.e., the sizes and type of materials) has yet to be optimised for the weather conditions in Toronto (see next section). Meanwhile, the calculations are based on typical available materials and thermosyphon, which is possible to manufacture from stock materials. The values are calculated based on the worst case scenario (i.e., continuous heat loss due to the convection on the surface, and inside temperature in assumed $20^{\circ} \mathrm{C}$ ). Practically, the convection can be substantially reduced by covering the surface with a transparent material (e.g., Plexiglas). As is seen from 
Figure $4-8$, assuming that the interior temperature is $20^{\circ} \mathrm{C}$, as soon as the surface temperature is above $20^{\circ} \mathrm{C}$, heat can flow inside spontaneously. The temperature of the surface reaches as high as $54.5^{\circ} \mathrm{C}$ in the coldest month of the year. This value increases to $83^{\circ} \mathrm{C}$ during the year.

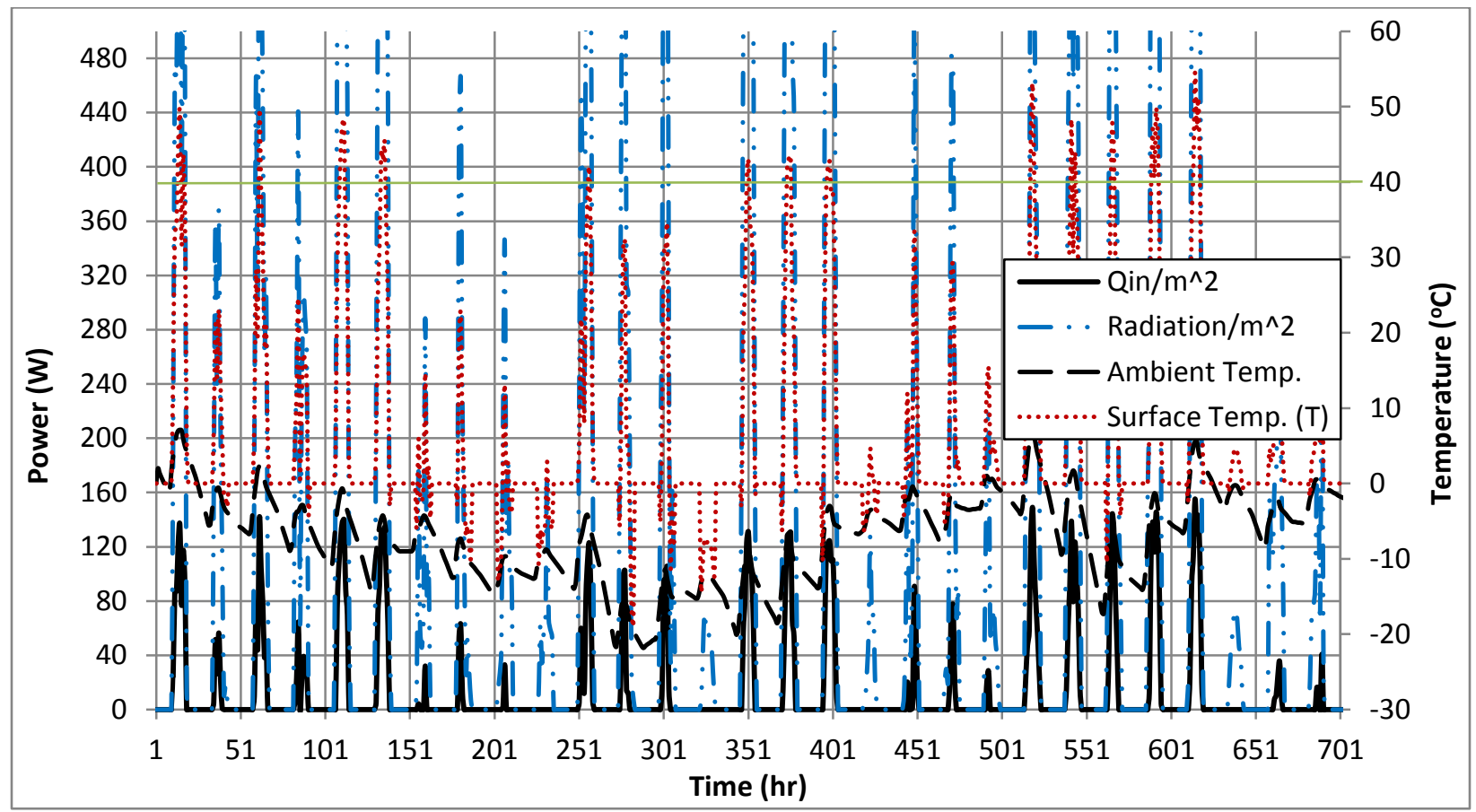

Figure 4-8: Maximum power that can be transferred ( $Q$ _in) per $\mathrm{m}^{2}$, radiation power, surface and ambient temperatures in Toronto in January

The input file is source of information for most of the energy simulators (e.g., TRNSYS). Facts given in Table 4-2 are taken from the input file. It depicts that, on the average, more than one mega-watt-hour per square meter $\left(\mathrm{MWh} / \mathrm{m}^{2}\right)$ thermal energy can be harvested from the Sun in a year.

Table 4-2: Annual (8760 hours) solar radiation facts in Toronto [71]

\begin{tabular}{|l|c|}
\hline \multicolumn{1}{|c|}{ Component } & Fact \\
\hline Average air temperature when the sun shines $\left({ }^{\circ} \mathrm{C}\right)$ & 11 \\
\hline Average solar radiation $\left(\mathrm{W} / \mathrm{m}^{2}\right)$ & 231 \\
\hline Maximum solar radiation $\left(\mathrm{W} / \mathrm{m}^{2}\right)$ & 927 \\
\hline Number of hours the sun shines per year $(\sim 50 \%$ of the year $)$ & 4375 \\
\hline
\end{tabular}




\subsection{Optimization of the TDP sizes}

A Generic Algorithm (GA) code is developed to optimise the sizes of the TDP for Toronto weather conditions to gain maximum solar thermal energy on an annual basis. GA codes are written in Matlab for five main sizes of the TDP components: front, middle and back aluminum plate thicknesses, thermosyphon outer diameter and its thickness. The thermosyphon is constructed from copper tube, which passes through the adiabatic layer of the TDP to transfer heat from outside (evaporator) to inside (condenser).

\subsubsection{Genetic Algorithm (GA)}

Genetic Algorithms (GAs) are a series of computational types inspired by evolution. GAs were mostly developed in the 1970s as an optimization toolbox, though some work had already been done in the field of evolutionary computation. These algorithms are often viewed as function optimizers. In 1967, Bagley introduced the words "genetic algorithm" and published the first application of GAs. However, Holland [72] and De Jong were the first who started using the GA in their works. In the 1980s, Grefenstette, Baker and Goldberg contributed to significant advancements in GAs. A more complete history of GAs and other evolutive computation methods are given in [73].

In canonical GA, fitness is defined by $f_{i} / \bar{f}$ where former/numerator is the evaluation associated with string I and latter/denominator is the average evaluation of all the strings in the population. Most of the time, the initial population is generated randomly. A fitness value is evaluated and assigned after creating an initial population. GA starts with the current population and creates an intermediate population from the current one. Later, recombination and mutation are applied to the intermediate population to create the next population. This is the execution of one generation process [74].

The employment of GAs in the field of heat transfer is new. This might be because most numerical problems in the heat transfer calculations are computationally long. Moreover, several simulations should be performed in a typical GA optimization process. For example, if CFD analysis is part of the simulation, the overall computational time required for the GA to run could be too long to be approached. In the mid-1990s, GAs was used in heat transfer. At first, it was used fearfully but it is a regular process now [73]. Due to availability of high performance computers, recently much more complicated mathematical heat transfer problems can be solved 
easily. GAs are very popular in the field of heat transfer. Although GAs have some shortfalls, they seem as a good alternative for the optimization and design of thermal systems [73].

The GA is a search algorithm (by probability) that evolves a population of given arrays iteratively. It works as a computer simulation in which a set of chromosomes, the genotype, or the genome (abstract representations) of individuals, creatures, or phenotypes (candidate solutions) to an optimization problem. It evolves for better solutions or optimize objective functions. At first, randomly generated phenotypes/individuals make a population and the fitness of each individual in the generation is evaluated.. Then, the population is evolved based on each of its phenotype/individual fitness value. According to their fitness, some of individuals are modified (cross over or mutation process) in the generation. Finally, a new population is formed from the selected individuals. The process (next iteration of the algorithm) is repeated on the new population. Figure 4-9 summarizes a general GA procedure. There are several simulations in each objective function evaluation; therefore, this process is prohibitively time consuming inside the total GA implementation. The other alternative is the approximation of the design space; thus many researchers would rather use an approximation technique to evaluate the objective function value of each individual.

\subsubsection{Methodology}

The GA module of Matlab is used to optimize the main five sizes of the TDP. These sizes are selected based on the price contribution into the final product (TDP). A TDP is composed of the thermosyphon (sealed copper tube), aluminum sheets and insulating materials (thermal insulator). The TDP under investigation is integrated with a layer of phase change material (PCM); therefore, there are three aluminum plates separating layers. These are five main sizes under optimization: front $\left(\mathrm{t}_{1}\right)$, middle $\left(\mathrm{t}_{3}\right)$ and back aluminum plate thicknesses $\left(\mathrm{t}_{5}\right)$, copper outer diameter (OD) and thickness $\left(\mathrm{t}_{\mathrm{c}}\right)$, (see Figure 4-3).

The objective of the GA code is to maximize the solar thermal energy gain $\left(Q_{i n}\right)$ for Toronto weather conditions on an annual basis. Two scenarios are investigated as follows:

$$
\begin{aligned}
& \text { Objective function } 0=\sum_{0}^{8760}\left\{\begin{array}{l}
0 \text { if } 2881<\text { time }<6552(\text { summer }) \\
Q_{\text {in }} \text { if time is other values }(\text { winter })
\end{array}\right. \\
& \text { Objective function } 1=\sum_{0}^{8760}\left\{\begin{array}{c}
-Q_{\text {in }} \text { if } 2881<\text { time }<6552 \text { (summer) } \\
Q_{\text {in }} \text { if time is other values (winter) }
\end{array}\right.
\end{aligned}
$$




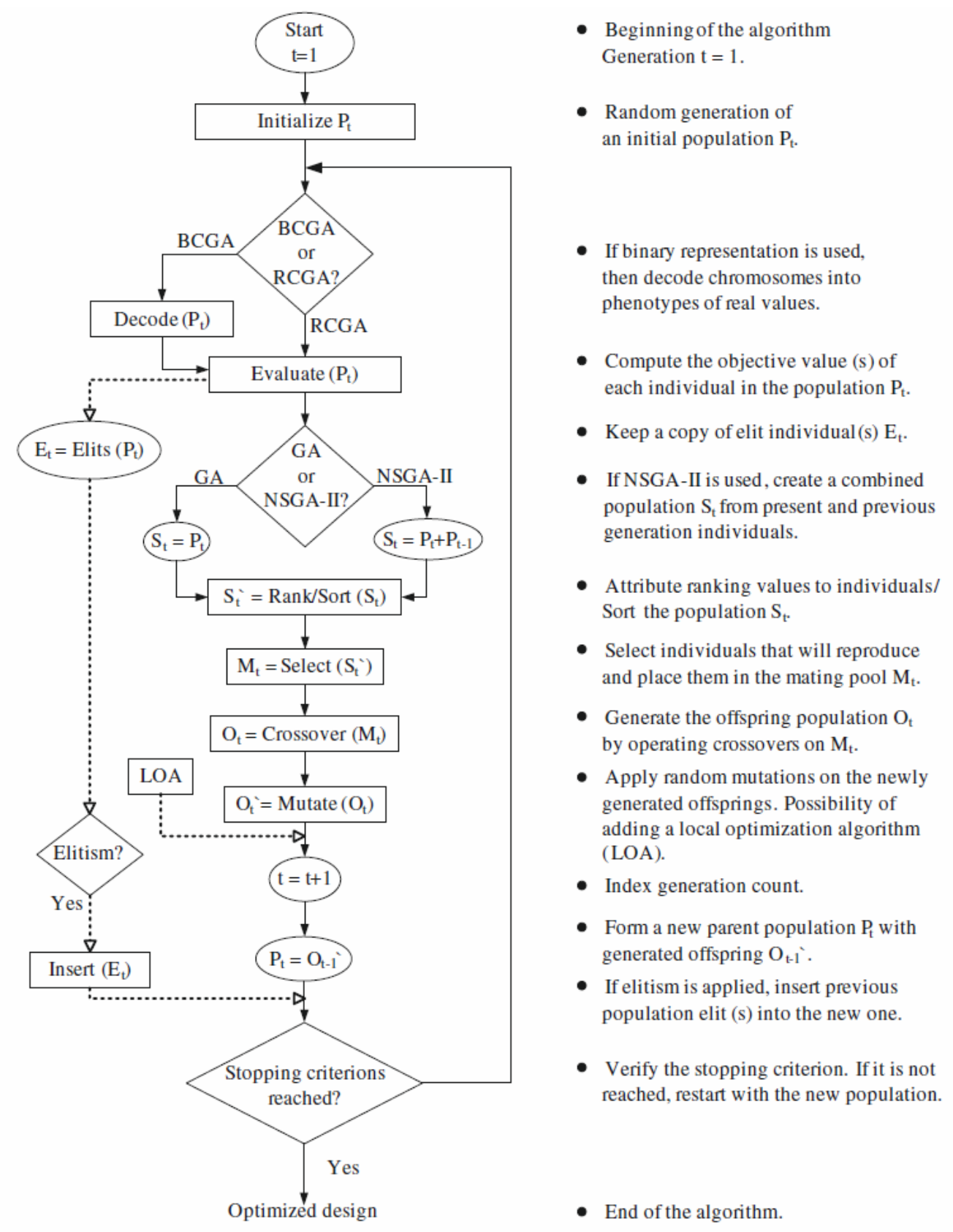

Figure 4-9: The main steps of a typical GA [73]

Objective function (Of0) is focused on calculating winter heat gain and maximizes it. Summer is considered from hour 2881 to 6552 ; the other time of the year is considered to be winter. Objective function1 (Of1) is calculated in favor of comfort, i.e., it adds $Q_{i n}$ in forward (positive values) in winter with $Q_{i n}$ in reverse (negative values) in summer. The number of hours in one year is 8760 . 
Recalling Equation (4-27), $R_{h p}$ is the thermosyphon thermal resistance inside the panel. The value of $R_{h p}$ changes according to the direction of the heat transfer and the outside surface temperature of the panel (T). Figure 4-10 shows the algorithm of calculating $Q_{\text {in }}$ and the objective function value. In forward direction, the thermosyphon thermal resistance $\left(R_{t s}\right)=R_{h p}$.

Surface temperature (T) and $Q_{i n}$ are calculated from Equations (4-2) and (4-30), respectively.

The input array for each of the three aluminum thickness is $[1,1.5,2,2.5,3]$ and for copper pipe outer diameter (OD) and thickness are [25:50] and [1:10], respectively. All units are in millimeter. Population size, (pop_size), generation size, mutate rate and cross rate are given by operator interactively. The range of the first two values is an integer number between 5 and 100 and the range of the two latter is real number between 0 and 1. Figure 4-11 demonstrates the flow chart of the GA. The thermosyphon is designed to boil water at $40^{\circ} \mathrm{C}$; therefore, when the surface temperature is higher than $40^{\circ} \mathrm{C}$, heat transfers in the forward direction is calculated by Equation (4-30). When the surface temperature is less than $40^{\circ} \mathrm{C}$ (backward in Figure 4-10), the thermal resistance of the thermosyphon is calculated as the resistance of the copper pipe as

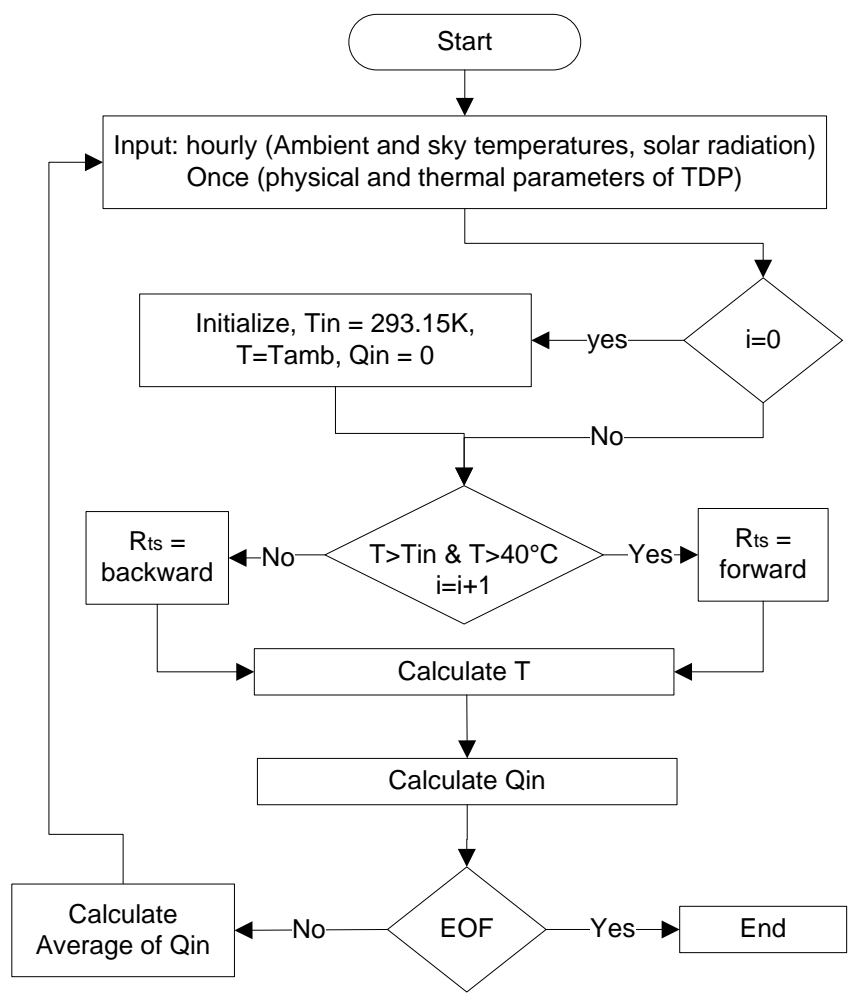

Figure 4-10: Flow chart for calculating objective function 
follows:

$$
R_{t s}=\frac{L}{k_{\mathrm{Cu}} \pi\left(r_{o}^{2}-r_{i}^{2}\right)}
$$

where $L$ is the length of thermosyphon structure (i.e., $L_{e}+L_{a}+L_{c}$ ).

Finally, the displacement or strain due to the thermal stress is analysed for the design parameters suggested by the GA.

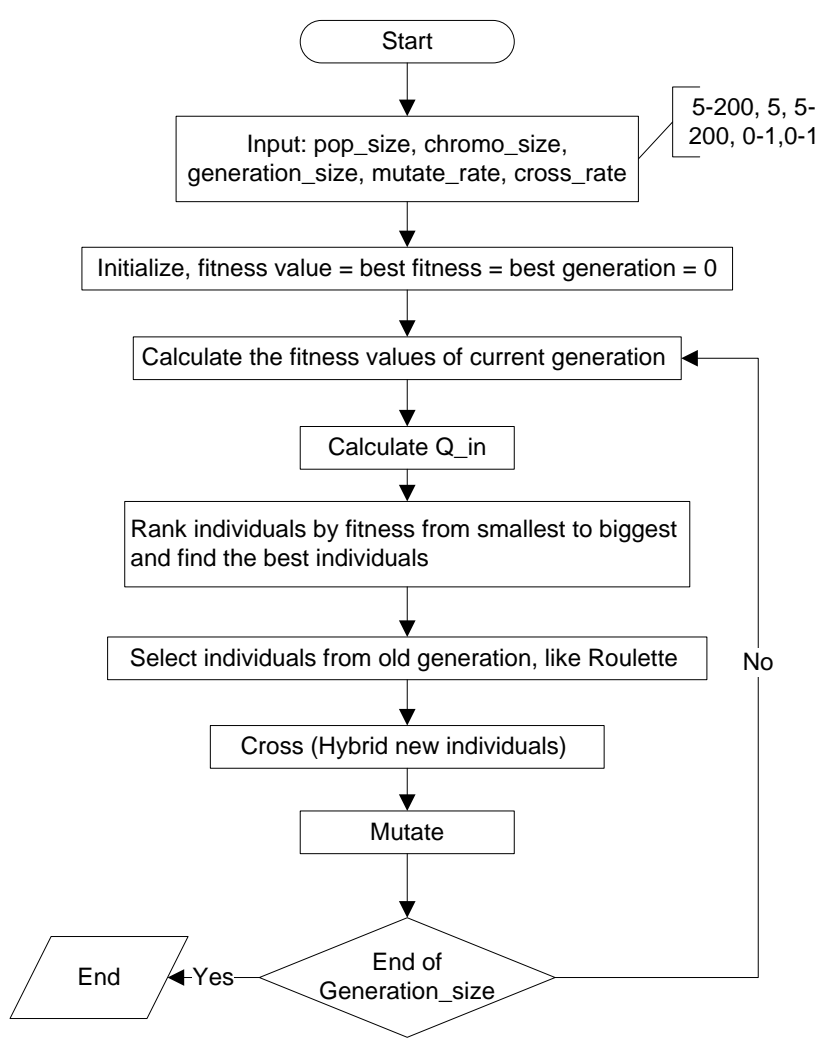

Figure 4-11: Flow chart for Genetic Algorithm process

\subsubsection{Results and discussions}

GA codes are written in Matlab 2013. A 64-bit operating system with 16 GB RAM and Intel® Core $^{\mathrm{TM}}$ i7-2600 CPU processor at $3.40 \mathrm{GHz}$ desktop computer is employed for this work. It has four processor cores. The input matrices are given as follows:

The three aluminum thickness: $\mathrm{v} 1=\mathrm{v} 2=\mathrm{v} 3=[1,1.5,2,2.5,3]$, and copper pipe outer diameter $(\mathrm{OD})$ is v4 $=$ [25:50], 25 to 50 with one increment, and thickness of v5 $=[1: 10]$. Population and generation sizes, hybrid and mutate rates are given interactively to the GA. 
Table 4-3 provides a summary of the results for two objective functions (Of0 and Of1). Population size multiplied by the Generation size is the number of cases that GA evaluates for optimization each time (first column in the Table 4-3). The time for each optimization varies from 0.34 hour (6 cases) to 66.45 hours (1800 cases). The last column of the table represents the GA suggestions (optimal values). The solutions in the last column are underlined. For Of0 and Of1 the solutions are $[1.5,2.5,2,32,9]$ and $[3,3,2,25,10]$, respectively.

Figure 4-12 shows average fitness versus generation size for four different conditions. The information related to each simulation is added below the plots.

Figure 4-13 represents the different values selected by GA to evaluate the objective function. It represents 100 cases (20 populations multiplied by 5 generations). The randomly selected 20 populations are shown in Table 4-4. V1 to V5 are selected randomly from the input matrices. During GA, new generation is produced by mutation and cross over process (five times in this case); therefore, altogether hundred scenarios are evaluated.

Table 4-3: GA suggestions based on Of1 and Of0 (green/shaded rows) with different interactive inputs

\begin{tabular}{|l|l|c|c|c|c|c|c|}
\hline $\begin{array}{l}\text { \# of } \\
\text { Cases }\end{array}$ & $\begin{array}{l}\text { Pop. } \\
\text { Size }\end{array}$ & $\begin{array}{l}\text { Gen. } \\
\text { size }\end{array}$ & $\begin{array}{c}\text { Hybrid } \\
\text { rate }\end{array}$ & $\begin{array}{c}\text { Mutate } \\
\text { rate }\end{array}$ & $\begin{array}{c}\text { Obj. Fun. } \\
\text { Value }(\mathrm{J})\end{array}$ & $\begin{array}{c}\text { Comp. } \\
\text { Time }(\mathrm{h})\end{array}$ & $\begin{array}{c}\text { GA Suggestion, } \\
{[\mathrm{v} 1, \mathrm{v} 2, \mathrm{v3}, \mathrm{v} 4, \mathrm{v} 5]}\end{array}$ \\
\hline 10 & 5 & 2 & 0.2 & 0.3 & 760.35 & 2.12 & {$[3,2,1,28,3]$} \\
\hline 6 & 3 & 2 & 0.6 & 0.9 & 758.68 & 0.34 & {$[2.5,2,3,26,4]$} \\
\hline 12 & 4 & 3 & 0.8 & 0.9 & 793.55 & 0.42 & {$[3,2.5,1.5,28,3]$} \\
\hline 12 & 4 & 3 & 0.8 & 0.9 & 361.23 & 0.51 & {$[1.5,2.5,2,32,9]$} \\
\hline 48 & 12 & 4 & 0.8 & 0.9 & 353.40 & 1.32 & {$[2.5,3,2,25,2]$} \\
\hline 100 & 20 & 5 & 0.8 & 0.8 & 791.09 & 3.84 & {$[2.5,1.5,1,25,7]$} \\
\hline 100 & 10 & 10 & 0.9 & 1 & 805.38 & 3.71 & {$[1.5,3,2,27,6]$} \\
\hline 100 & 10 & 10 & 0.9 & 1 & 333.13 & 3.63 & {$[1.5,3,2,27,6]$} \\
\hline 220 & 22 & 10 & 0.8 & 0.6 & 818.41 & 8.33 & {$[3,3,2,26,8]$} \\
\hline 220 & 22 & 10 & 0.8 & 0.6 & 336.47 & 8.21 & {$[3,3,2,25,7]$} \\
\hline 400 & 50 & 8 & 0.9 & 0.7 & 820.04 & 13.76 & {$[3,3,1,26,10]$} \\
\hline 800 & 40 & 20 & 0.9 & 0.7 & 818.41 & 30.19 & {$[3,3,1,26,8]$} \\
\hline 1000 & 100 & 10 & 0.6 & 0.2 & 820.58 & 35.95 & {$[3,3,1.5,25,7]$} \\
\hline 1000 & 50 & 20 & 0.8 & 0.7 & 823.52 & 37.84 & {$[3,3,2,25,10]$} \\
\hline 1000 & 50 & 20 & 0.8 & 0.7 & 334.51 & 37.16 & {$[3,3,1,26,9]$} \\
\hline
\end{tabular}




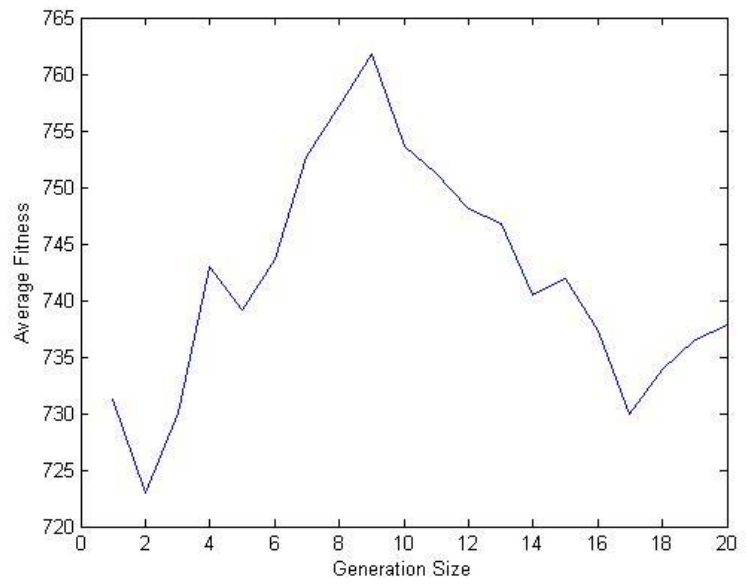

A) Pop_size $=50 ;$ Hybrid $\&$ Mutate rates $=0.8 \& 0.7$

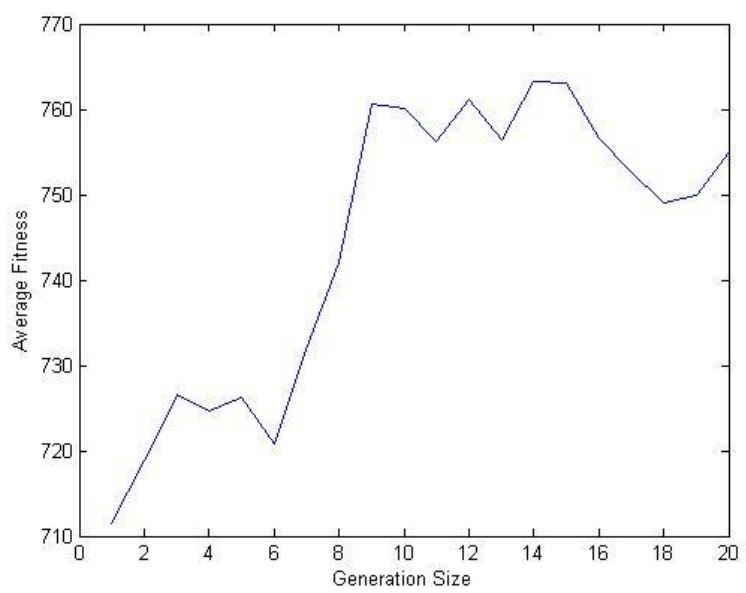

C) Pop_size $=40 ;$ Hybrid $\&$ Mutate rates $=0.9 \& 0.7$

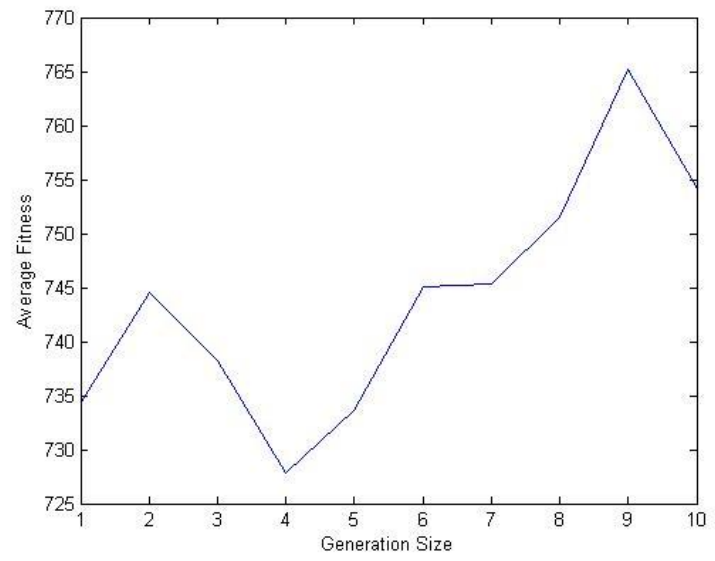

B) Pop_size $=22$; Hybrid $\&$ Mutate rates $=0.8 \& 0.6$

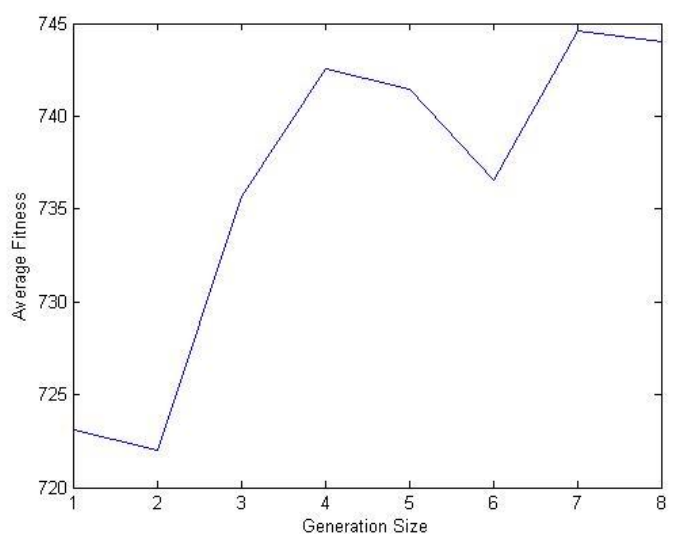

D) Pop_size $=50 ;$ Hybrid \& Mutate rates $=0.9 \& 0.7$

Figure 4-12: Generation size versus average fitness in two different conditions based on OJ1

The results of thermal analysis in SolidWorks are transferred for displacement analysis (see Section 4.3.1 for details). The results show that the displacement of the suggested design is in safe condition. The maximum resultant displacement and strain are found to be $0.29 \mathrm{~mm}$ and 0.007, respectively (Figure 4-14).

There are $31,250(25 \times 10 \times 5 \times 5 \times 5)$ different ways that one can make a TDP with the given values on Table 4-3. Only one of the above combinations (desired one) maximizes the objective function $\left(\mathrm{Q}_{\text {in }}\right)$. Using genetic algorithm technique, it is possible to reach to the best (optimal) solution fast. As Figure 4-15 stipulates, the maximum value for $\mathrm{Q}_{\text {in }}$ increases by increasing the number of cases (best fits are also shown in the plots). Time is linearly dependant on the number of the cases. 

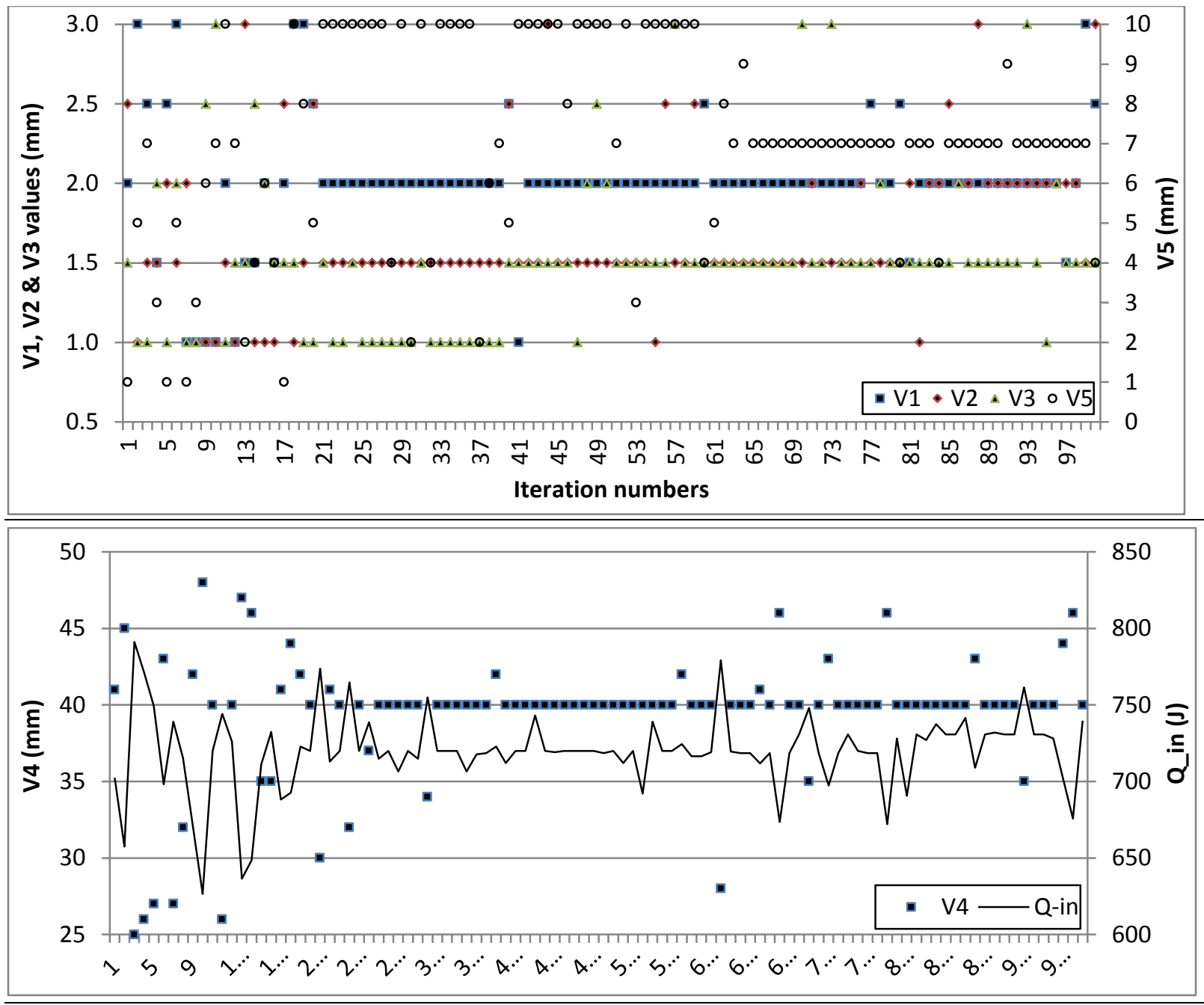

Figure 4-13: Graphical results for the number of cases of 100 ( 20 populations times 5 generations), V5 (top) and $Q_{\text {in }}($ bottom) are shown on the secondary axes (based on OJ1)

Analysis of graphs in Figure 4-12 shows that generation size of more than 10 does not increase the fitness values for this specific study. Checking the data generated by GA shows that some individuals are repeating themselves when the generation size is higher than 10. By increasing the generation size the chance of repetition increases. In addition, comparison of case $\mathrm{A}$ with $\mathrm{C}$ reveals that fitness reaches its maximum value faster when the population size is higher. 


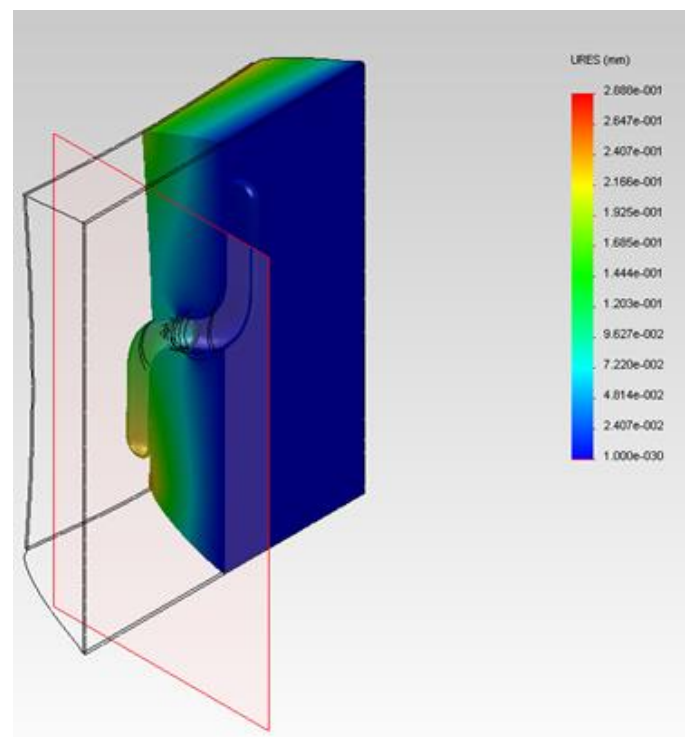

A) Max. resultant displacement is $0.2889 \mathrm{~mm}$ at Node: 249049

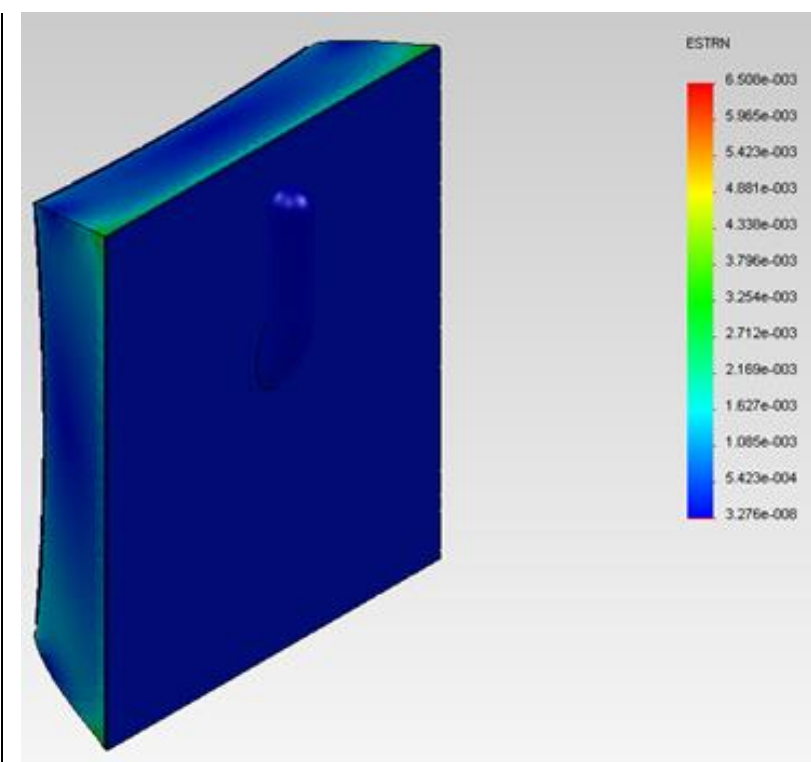

B) Max. equivalent strain is 0.00650757 at Element: 22470

Figure 4-14: Displacement (A) and strain (B) on TDP at severe condition

Table 4-4: Randomly selected population, when Pop_size $=20$

\begin{tabular}{|c|c|c|c|c|c|}
\hline$\#$ & V1 & V2 & V3 & V4 & V5 \\
\hline 1 & 1.5 & 2 & 1.5 & 40 & 7 \\
\hline 2 & 2 & 1 & 1.5 & 30 & 2 \\
\hline 3 & 1 & 2 & 1.5 & 34 & 4 \\
\hline 4 & 2 & 2 & 1.5 & 35 & 1 \\
\hline 5 & 2 & 2.5 & 1.5 & 25 & 10 \\
\hline 6 & 2 & 2 & 2 & 40 & 7 \\
\hline 7 & 2 & 2 & 1.5 & 28 & 3 \\
\hline 8 & 2 & 3 & 1.5 & 40 & 7 \\
\hline 9 & 2 & 2 & 1.5 & 43 & 7 \\
\hline 10 & 2 & 2 & 1.5 & 40 & 7 \\
\hline 11 & 2 & 2 & 1.5 & 27 & 9 \\
\hline 12 & 2 & 2 & 1.5 & 40 & 8 \\
\hline 13 & 1 & 2 & 3 & 45 & 7 \\
\hline 14 & 2 & 2 & 1.5 & 35 & 7 \\
\hline 15 & 1.5 & 2 & 1 & 41 & 5 \\
\hline 16 & 2 & 2 & 2 & 36 & 6 \\
\hline 17 & 1.5 & 2 & 1.5 & 40 & 7 \\
\hline 18 & 2 & 2 & 1.5 & 50 & 1 \\
\hline 19 & 3 & 1.5 & 1.5 & 46 & 7 \\
\hline 20 & 2.5 & 3 & 1.5 & 48 & 4 \\
\hline
\end{tabular}




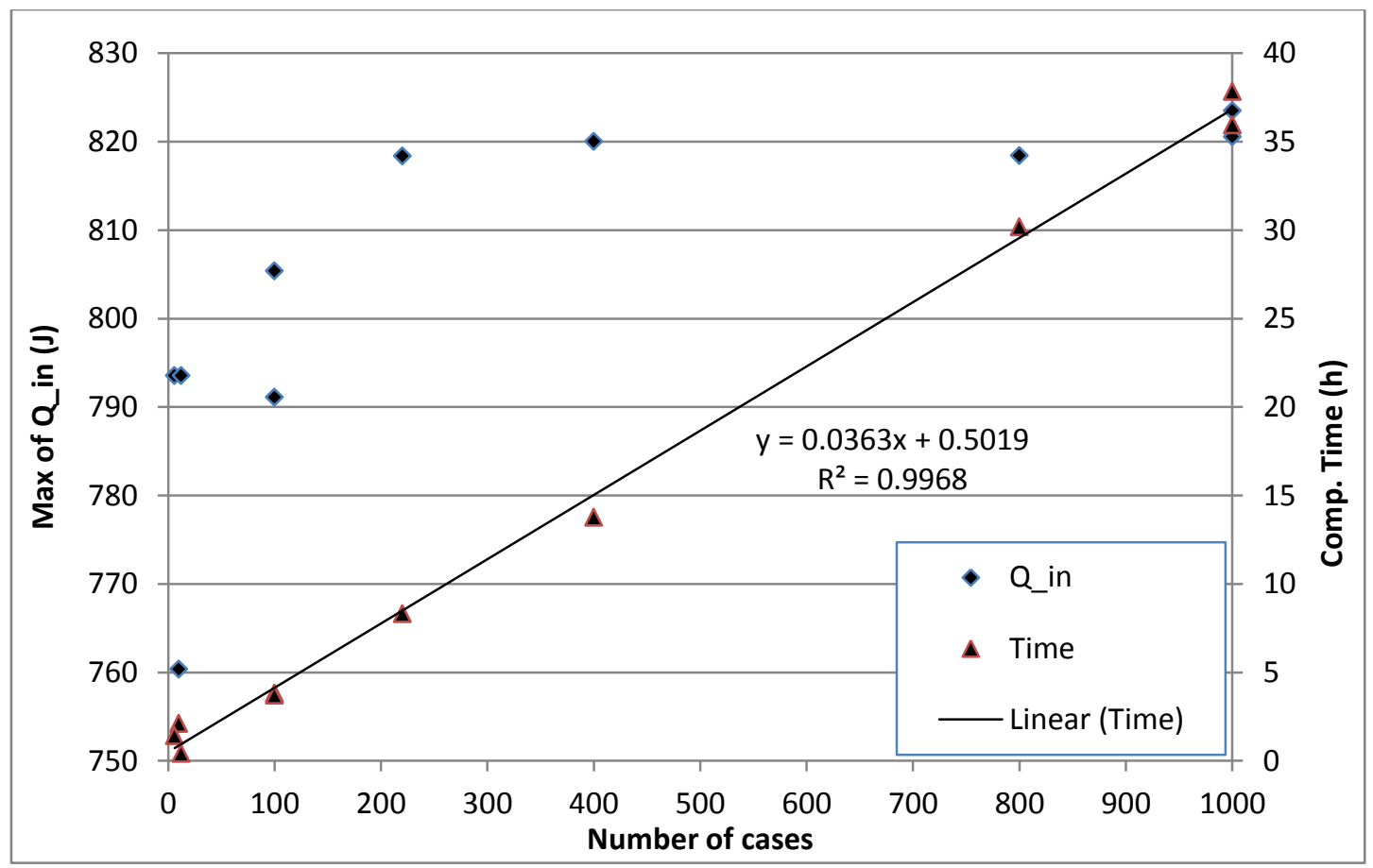

Figure 4-15: Graphical results for different cases of Of1

The difference between maximum and minimum values in different cases (Figure 4-15) is less than 4 percent. This means if results are sought with less than 5 percent, any of the above cases could bring optimized parameters. The implication is that GA can provide optimized parameters no matter what the values of population and generation sizes, and mutation and hybrid rates are. By increasing the population and generation sizes, computational time and objective function value increase, which produce better individuals (design parameters). Rate of increase of $\mathrm{Q}_{\text {in }}$ is high at first (up to number of cases equals to 200) and hardly increases after 220. That means, GA approaches to the best individuals very fast. After this point, increasing the number of cases is not very effective.

\subsection{Thermal bridging solution}

Thermal bridging is a problem that all researchers reported in using thermosyphon as a passive part of the building envelope in south facing walls in cold regions. A solution is proposed and investigated in this section. A finite element analysis, FEA, (4 points Jacobian) is employed to measure temperature and heat flux at different surfaces of the thermosyphon. In forward direction analysis, a constant insolation of $500 \mathrm{~W} / \mathrm{m}^{2}$, ambient temperature of $-20^{\circ} \mathrm{C}$, emissivity of 0.97 with free convective heat transfer coefficient of $20 \mathrm{~W} / \mathrm{K} . \mathrm{m}^{2}$ is considered on the radiated 
surface. Inside temperature was fixed to $20^{\circ} \mathrm{C}$. In forward direction, the thermosyphon is defined as a new material into SolidWorks library with thermal conductivity equal to calculated value for thermosyphon of same size $(0.00042 \mathrm{~K} / \mathrm{W})$.

\subsubsection{Methodology}

\subsubsection{Exact solution}

During thermal bridging, fluid is condensed in the evaporator (outside), and heat passes through the adiabatic section of the thermosyphon, which is the copper pipe. In this case, indoor temperature is higher than outdoor temperature; therefore, heat flows/leaks from indoor to outdoor through the most thermal conductive part of the TDP (i.e., copper). Figure 4-16 shows the sketch of this section with its electric circuit analogy. $T_{o}$ and $T_{i}$ are outside and inside temperatures of the zone where the panel is installed on its wall. Teflon is inserted in the middle of the copper pipe to disconnect, thermally conductive copper pipes. The insert has a hole same size as the copper pipe; therefore, it does not impede flow of water vapour to transfer heat from the two ends. The length of each copper section and Teflon is $L$ and $l$, respectively.

The total thermal resistance in the backward direction is calculated with the following assumption:

- Steady state one dimension of heat flow (only along the pipe)

- Negligible contact resistance and thermal conductivity of water vapour inside the pipe

- Isotropic thermal properties for copper and Teflon

- Constant temperature on both ends $\left(-20^{\circ} \mathrm{C}\right.$ outside and $20^{\circ} \mathrm{C}$ inside $)$

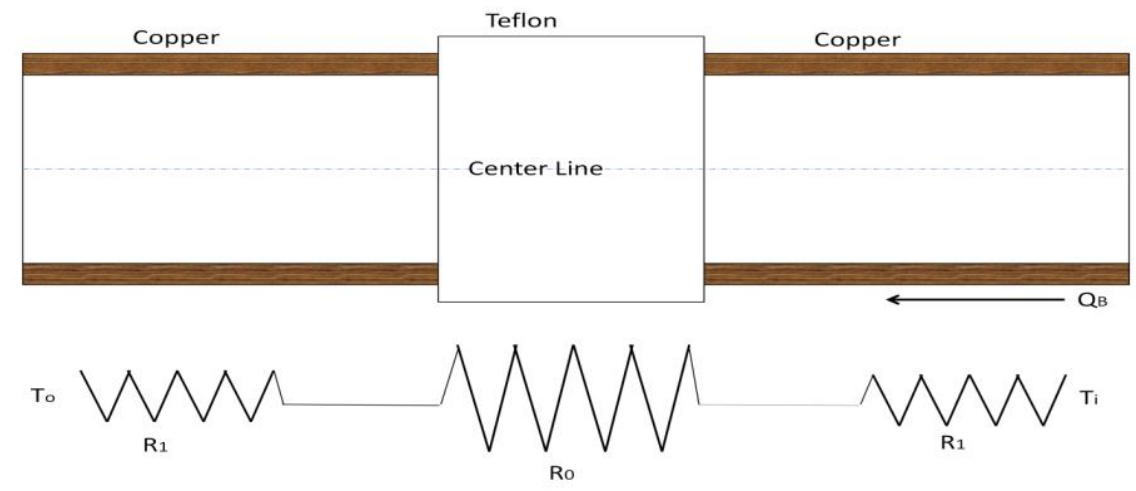

Figure 4-16: Sketch of the adiabatic section of the thermosyphon with its electric circuit network 
Therefore,

$$
\begin{aligned}
& R t=\sum R t_{i}=\frac{2 L}{k_{1} A r_{1}}+\frac{l}{k_{0} A r_{0}} \\
& Q_{B}=\frac{\Delta T}{R t}
\end{aligned}
$$

as $\Delta T$ is constant for two cases:

$$
\text { Ratio }=\frac{Q_{B, o l}}{Q_{B, n}}=\frac{\frac{2 L}{k_{1} A r_{1}}+\frac{l}{k_{0} A r_{0}}}{\frac{2 L+l}{k_{1} A r_{1}}}=\frac{2 L}{2 L+l}+\frac{l k_{1} A r_{1}}{2 L k_{0} A r_{0}}
$$

where k, Q, L, l, and Ar are thermal conductivity, heat transfer, half of the copper length, Teflon piece length, and cross section area, respectively. Subscripts 1, 0, B, ol, and n refer to copper, Teflon, backward, conventional/old design and suggested/new design, respectively.

Conventional design does not have the second term $\left(\frac{l}{k_{0} A r_{0}}\right)$ of Equation (4-39); therefore the ratio, in Equation (4-41), is always bigger than one because the first fraction $\left(\frac{2 L}{2 L+l}\right)$ is close to one and $\frac{k_{1}}{k_{0}}$ is much bigger than $\frac{l A r_{1}}{2 L A r_{0}}$. For the values given in Table 4-5, the ratio in Equation (4-41) is about 76. Obviously, Ar is $\pi\left(r_{o}^{2}-r_{i}^{2}\right)$.

Table 4-5: Values of the parameters used in Equation (4-41). Lengths, areas and thermally conductivities are in $\mathbf{m m}, \mathbf{m m}^{2}$, and $\mathrm{W} / \mathrm{mK}$, respectively. Subscripts $I$ and $O$ refer to inside and outside radius

\begin{tabular}{|c|c|c|c|c|c|c|c|c|c|c|}
\hline$k_{1}$ & $k_{0}$ & $l$ & $L$ & $r_{i 1}$ & $r_{o 1}$ & $r_{i 0}$ & $r_{o 0}$ & $A r_{1}$ & $A r_{0}$ & Ratio \\
\hline 390 & 0.25 & 10.6 & 35.11 & 12.5 & 15.5 & 12.5 & 20.5 & 263.76 & 828.96 & 75.80 \\
\hline
\end{tabular}

To make the backward heat transfer $\left(Q_{B, c}\right)$ as low as possible, the thermal conductivity of the new coupling $\left(k_{0}\right)$ should be minimized. To find the right coupling material, a decision matrix was devised (Table 4-6). Seven low thermal conductivity $(<0.5 \mathrm{~W} / \mathrm{mK})$ materials, which are available in the market, were investigated for selecting the best option. Ten important characteristics were ranked from 1 (the least important) to 10 (the most important). Each material was scored from 1 (the worst) to 10 (the best) for that characteristic. Finally, the total score can be calculated as follows:

$$
\text { Total }=\sum_{i=1}^{10}(\text { Rank } * \text { Score })_{i}
$$


Table 4-6: Coupling material decision matrix

\begin{tabular}{|c|c|c|c|c|c|c|c|c|c|c|c|c|c|c|c|c|c|}
\hline & \multirow{2}{*}{\multicolumn{3}{|c|}{ COMPLETE NAME }} & \multirow{2}{*}{\multicolumn{2}{|c|}{ POLYAMIDE 6}} & \multicolumn{2}{|c|}{$\begin{array}{l}\text { POLYAMIDE - } \\
\text { IMIDE }\end{array}$} & \multicolumn{2}{|c|}{$\begin{array}{l}\text { POLYACÉTAL- } \\
\text { COPOLYMÈRE }\end{array}$} & \multicolumn{2}{|c|}{$\begin{array}{c}\text { POLYÉTHILÈN } \\
\text { E TRÈS HAUTE } \\
\text { DENSITÉ }\end{array}$} & \multicolumn{2}{|c|}{$\begin{array}{l}\text { POLYTÉTRAFL } \\
\text { UORE }\end{array}$} & \multicolumn{2}{|c|}{$\begin{array}{l}\text { POLYESTER } \\
\text { THERMO- } \\
\text { PLASTIQUE }\end{array}$} & \multicolumn{2}{|c|}{$\begin{array}{c}\text { POLYÉTHERETHÉ } \\
\text { RCETONE }\end{array}$} \\
\hline & & & & & & TORI & ON & $\begin{array}{r}\text { ERTAC } \\
\text { DEL }\end{array}$ & $\begin{array}{l}\text { TAL - } \\
\text { IN }\end{array}$ & & & TEFL & & $\begin{array}{r}\text { ARNI } \\
\text { ERTAI }\end{array}$ & & & \\
\hline & & UNIT & $\begin{array}{l}\mathbf{W} \\
\mathrm{T}\end{array}$ & VALUE & $\begin{array}{c}\text { SCO } \\
\text { RE }\end{array}$ & VALUE & $\begin{array}{c}\text { SCO } \\
\text { RE }\end{array}$ & VALUE & $\begin{array}{c}\text { SCO } \\
\text { RE }\end{array}$ & VALUE & $\begin{array}{l}\text { SCO } \\
\text { RE }\end{array}$ & VALUE & $\begin{array}{c}\text { SCO } \\
\text { RE }\end{array}$ & VALUE & $\begin{array}{c}\text { SCO } \\
\text { RE }\end{array}$ & VALUE & $\begin{array}{c}\text { SCO } \\
\text { RE }\end{array}$ \\
\hline \multirow{4}{*}{ 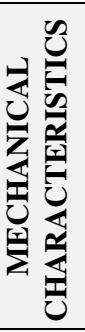 } & Density & $\mathrm{gr} / \mathrm{cm}^{3}$ & 2 & 1.14 & 9 & 1.41 & 6 & 1.42 & 6 & 0.96 & 10 & 2.2 & 5 & 1.37 & 7 & 1.32 & 8 \\
\hline & $\begin{array}{l}\text { Saturated } \\
\text { water } \\
\text { absorption } \\
\end{array}$ & $\%$ & 3 & 1.8 & 4 & 2.5 & 3 & 0.25 & 8 & 0.01 & 10 & 0.01 & 10 & 0.25 & 8 & 0.3 & 7 \\
\hline & $\begin{array}{l}\text { Tensile } \\
\text { strength }\end{array}$ & $\mathrm{N} / \mathrm{mm}^{2}$ & 8 & 78 & 7 & 120 & 10 & 65 & 6 & 24 & 3 & 27 & 3 & 74 & 7 & 92 & 8 \\
\hline & $\begin{array}{l}\text { Corrosion } \\
\text { Resistance }\end{array}$ & & 10 & Bad & 3 & good & 7 & good & 7 & good & 7 & Excellent & 10 & good & 7 & Very good & 9 \\
\hline \multirow{4}{*}{ 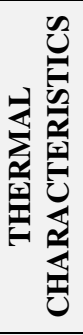 } & $\begin{array}{l}\text { Coefficient } \\
\text { of linear } \\
\text { expansion }\end{array}$ & $10^{-6} /{ }^{\circ} \mathrm{C}$ & 10 & 70 & 7 & 30 & 10 & 100 & 6 & 200 & 3 & 100 & 6 & 70 & 7 & 70 & 7 \\
\hline & $\mathrm{T}_{\max }$ & ${ }^{\circ} \mathrm{C}$ & 10 & 100 & 3 & 250 & 9 & 100 & 4 & 80 & 2 & 260 & 10 & 100 & 3 & 250 & 9 \\
\hline & $\mathrm{T}_{\min }$ & ${ }^{\circ} \mathrm{C}$ & 2 & -40 & 10 & -200 & 10 & -40 & 10 & -100 & 10 & -200 & 10 & -20 & 7 & -60 & 10 \\
\hline & $\begin{array}{l}\text { Thermal } \\
\text { conductivity }\end{array}$ & $\begin{array}{l}\mathrm{W} / \mathrm{m}^{\circ} \\
\mathrm{C}\end{array}$ & 8 & 0.23 & 9 & 0.4 & 6 & 0.31 & 8 & 0.43 & 6 & 0.23 & 9 & 0.21 & 10 & 0.25 & 9 \\
\hline \multirow{3}{*}{ 畨 } & Cost & & 10 & low & 8 & high & 2 & low & 8 & low & 8 & Medium & 5 & low & 8 & high & 2 \\
\hline & $\begin{array}{l}\text { Manufactu- } \\
\text { rability }\end{array}$ & & 8 & good & 7 & bad & 3 & Excellent & 10 & Medium & 6 & Excellent & 10 & Good & 7 & Good & 7 \\
\hline & \multicolumn{3}{|l|}{ Total } & & 444 & & 473 & & 498 & & 390 & & $\underline{546}$ & & 494 & & 519 \\
\hline
\end{tabular}


As shown in Table 4-6, Teflon had the maximum total score, 546, and was selected as a coupling material for this design. Based on the selection and the panel dimensions, Table 4-5 is produced.

\subsubsection{Thermal simulation results}

To determine the thermal properties of the TDP, a finite element analysis, FEA, (4 points Jacobian) is employed using SolidWorks 2011. In backward direction thermal analysis, the inside and outside temperatures of the building are fixed to $20^{\circ} \mathrm{C}$ and $-20^{\circ} \mathrm{C}$, respectively. The mesh quality is selected as high with maximum and minimum element size of $15 \mathrm{~mm}$ and $3 \mathrm{~mm}$, respectively. In forward direction analysis, a constant insolation of $500 \mathrm{~W} / \mathrm{m}^{2}$, ambient temperature of $-20^{\circ} \mathrm{C}$, emissivity of 0.97 with a free convective heat transfer coefficient of 20 $\mathrm{W} / \mathrm{Km}^{2}$ is considered on the radiated surface. In the forward direction, the thermosyphon is defined as a new material in the SolidWorks library with thermal conductivity equal to calculated value for the thermosyphon of the same size $(0.00042 \mathrm{~K} / \mathrm{W})$. In the backward direction, the thermal conductivity is calculated based on the thermal specifications of the materials in the drawing.

The problem domain is subdivided into 267,411 nodes and 188,025 tetrahedron (triangular base) elements. Static analysis and the FFEPlus ${ }^{8}$ solver with a mesh size of 3 to $8 \mathrm{~mm}$ (with no distortion and high quality) are employed.

Based on SolidWork simulation, roughly, the ratio of the backward heat flux for the current design and the suggested one is about 80 (Figure 4-17). To find the approximate ratio, the heat flux on similar sections on the new design are divided to the current/old ones.

To obtain a more accurate ratio than the above value (80), the heat flux at the cross section of the similar length (L) of the two designs was investigated (see Figures 4-18 and 4-19).

The sections are selected consistent with the values given in Table 4-6. Twelve different elements on each section were selected and their heat flux extracted from simulation results.

The coefficient of variation ( $\mathrm{COV}=\mathrm{SD} /$ Average) of the heat flux values is found to be about 0.45 (see Table 4-7), which means the average is not a good representative of the heat flux. As ratio

\footnotetext{
8 "The FFEPlus solver is an iterative solver. After having the CAD model set up with the appropriate boundary conditions, the FFEPlus solver makes an educated guess about the deformation, [U], of the model. Then it evaluates the matrix equations to see how good the guess was, and adjusts the deformation accordingly, depending upon the error in the calculation. This process repeats until the calculation balances".
} 
values on Table 4-7 stipulate, the ratio is between 42 and 91. It is interesting that the average value of the maxima (90.8 \& 91) and minima (64.4 \& 42.1) on Table 4-7 is 72.1, which is slightly lower than the exact value calculated from Equation (4-41), 75.8. The difference is only $4.9 \%$, which is reasonable.

Table 4-7: Backward heat flux $\left(\mathrm{W} / \mathrm{m}^{2}\right)$ statistics for 12 nodes on each section

\begin{tabular}{|l|l|c|c|c|}
\cline { 2 - 4 } \multicolumn{1}{l|}{} & New design & Old design & Ratio (Old/New) \\
\hline \multirow{5}{*}{ Indoor side } & Average & 421 & 38509 & 91.4 \\
\cline { 2 - 4 } & Max & 703 & 63800 & 90.8 \\
\cline { 2 - 4 } & Min & 88.7 & 5710 & 64.4 \\
\cline { 2 - 4 } & SD & 194.7 & 18901 & \multicolumn{1}{|c}{} \\
\cline { 2 - 4 } & $\mathrm{COV}$ & 0.46 & 0.49 & \\
\hline \multirow{5}{*}{ Outdoor side } & $\mathrm{SD}$ & 194.4 & 17919 & \\
\cline { 2 - 4 } & $\mathrm{COV}$ & 0.42 & 0.47 & \\
\cline { 2 - 4 } & Max & 720.3 & 65540 & 91 \\
\cline { 2 - 4 } & Min & 129.3 & 5449 & 42.1 \\
\cline { 2 - 4 } & Average & 464.9 & 38311 & 82.4 \\
\hline
\end{tabular}

\subsubsection{Displacement/strain results of simulation}

In this section, the displacement or strain due to the thermal stress is analysed for the new design. In this analysis, the forward heat transfer is simulated with the same solver as the thermal analysis. In addition, the thermal loads on the evaporator surface are as follows:

- Convection coefficient

- Bulk ambient temperature

- Ambient/sky temperature

- Emissivity

- View factor

- Constant heat flux

- Indoor temperature
$2 \mathrm{~W} / \mathrm{K} \cdot \mathrm{m}^{2}$

$-20^{\circ} \mathrm{C}$

$-20^{\circ} \mathrm{C}$

0.97

1

$1000 \mathrm{~W} / \mathrm{m}^{2}$

$20^{\circ} \mathrm{C}$ 

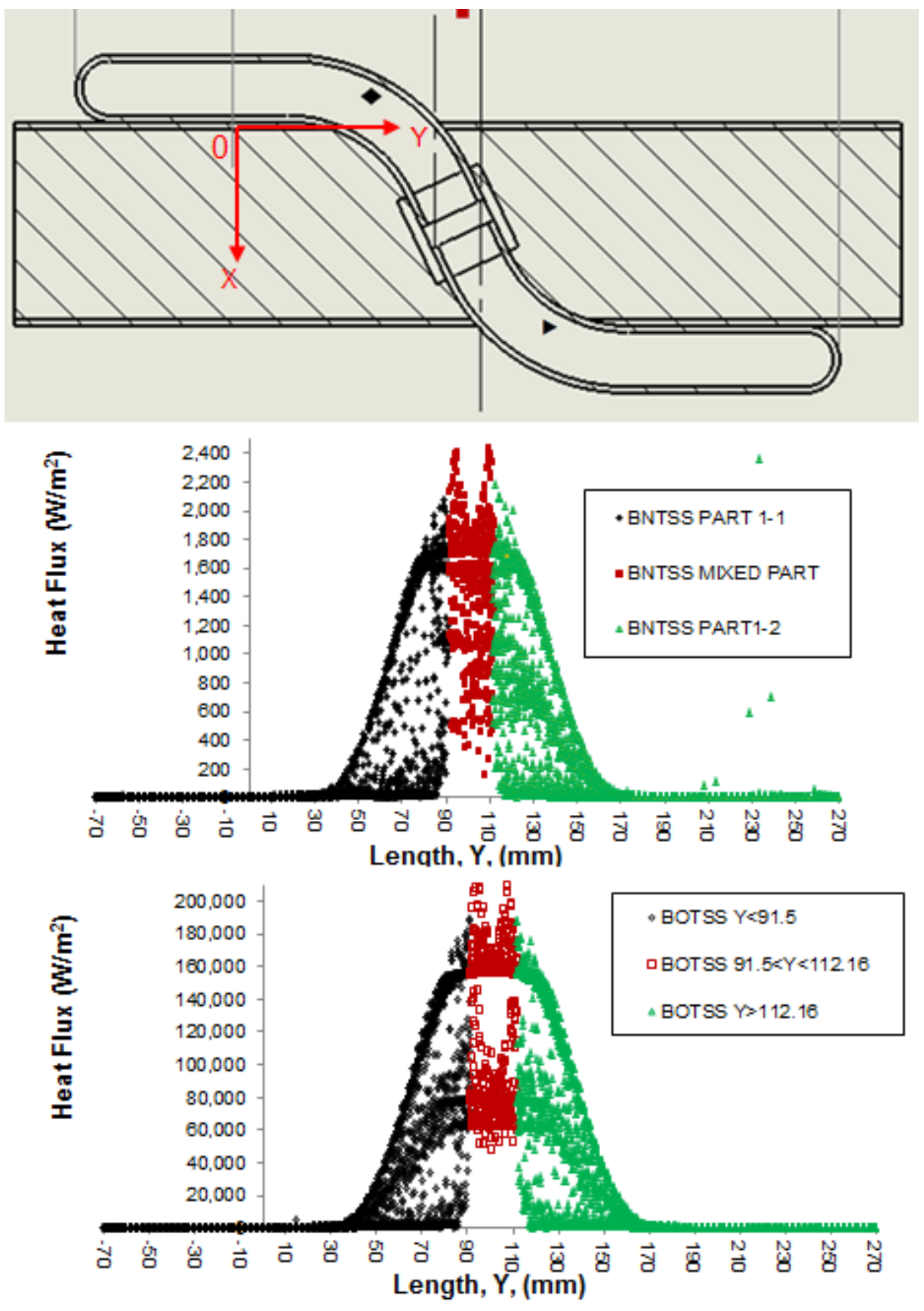

Figure 4-17: Heat flux distribution at different length (Y-value) of the thermosyphon. The top sketch shows the location of the heat flux measurement, the middle graph represents the new design backward heat flux (BNTSS), and the bottom graph shows the current/old design backward heat flux (BOTSS). In the middle graph, PART 1-1 and 1-2 are the cupper pieces around the Teflon piece (MIXED PART) 


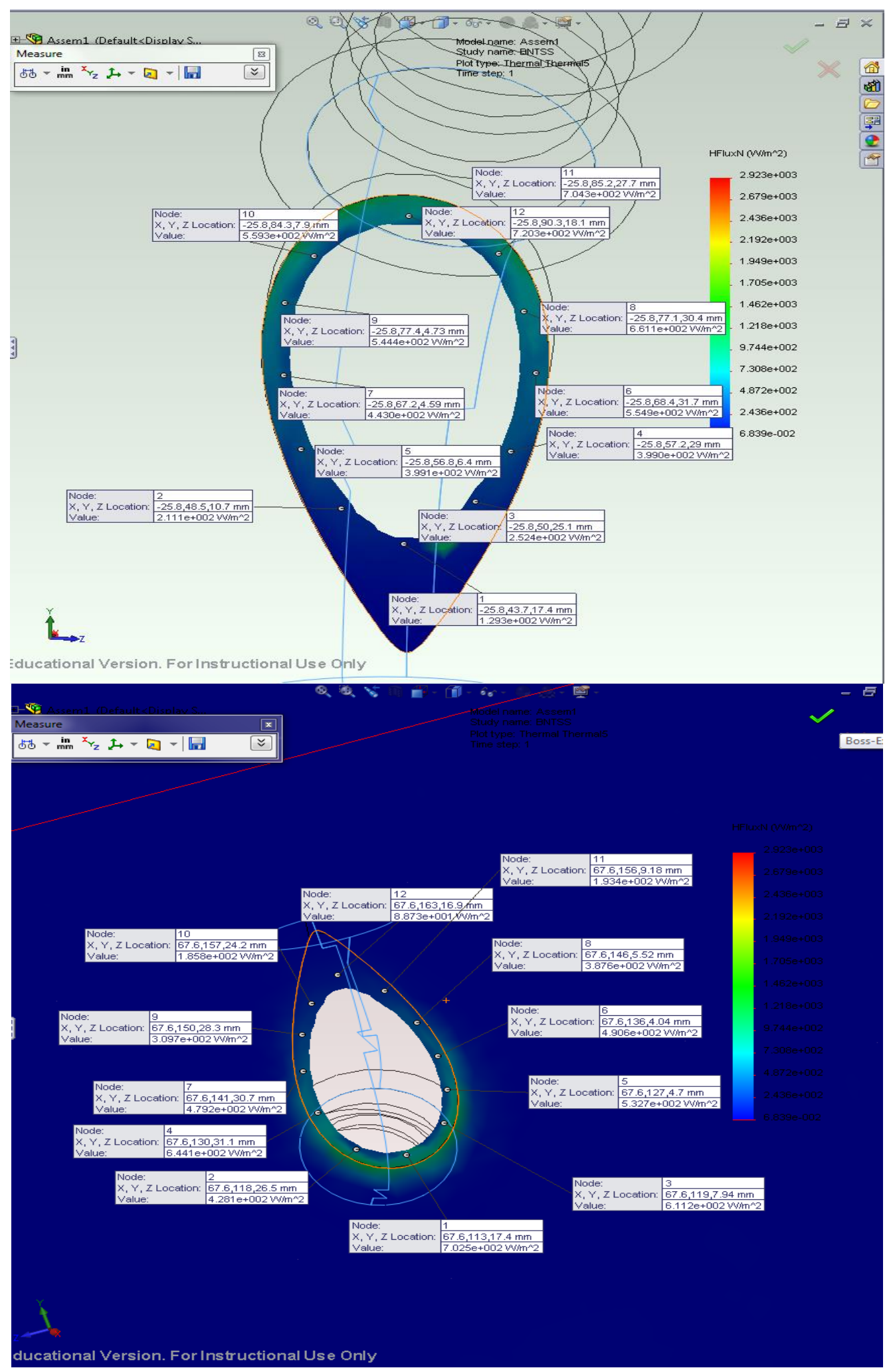

Figure 4-18: Heat flux distribution at different points of the cross section (same $Y$-value) of the new/suggested design in backward direction. The pictures show the heat flux at $y=60 \mathrm{~mm}$ (top) and $y=140 \mathrm{~mm}$ (bottom) 

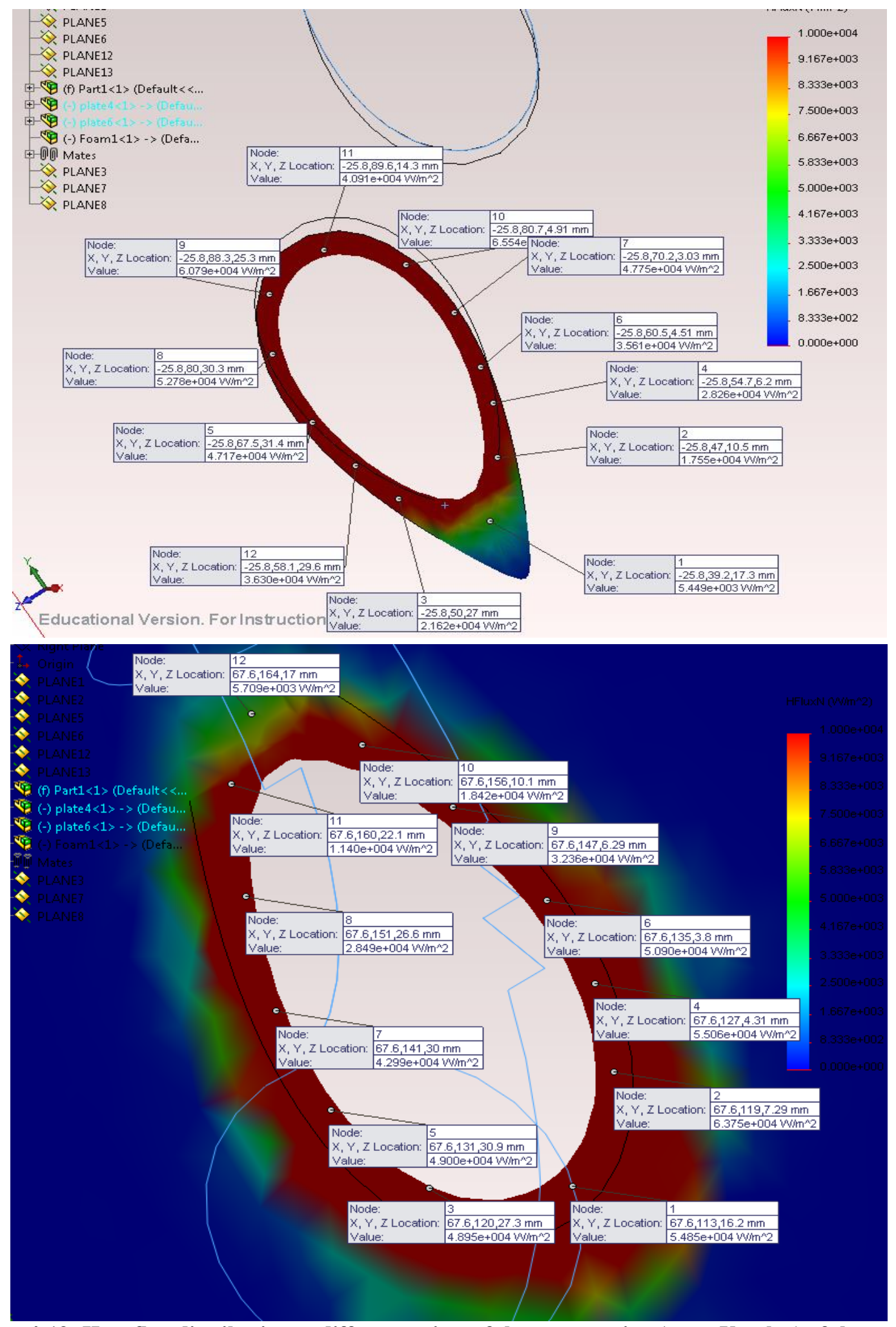

Figure 4-19: Heat flux distribution at different points of the cross section (same Y-value) of the current design in backward direction. The pictures show the heat flux at $y=60 \mathrm{~mm}$ (top) and $y=140 \mathrm{~mm}$ (bottom) 
The results of thermal analysis are transferred for displacement analysis. The results show that the displacement of the Teflon part is compatible with the other connected copper parts (Figure 4-19). The maximum resultant displacement and strain are found to be $0.026 \mathrm{~mm}$ and 0.0007 , respectively.

\subsubsection{Results and discussion}

Thermal bridging can be reduced by about 76 times using a Teflon part in the middle of the thermosyphon structure (Figures 4-16 and 4-20). Thermal bridging occurs in the backward (unwanted) direction when the indoor temperature is higher than the outdoor temperature in current TDPs. As this panel is supported by a south wall, there is no external mechanical/physical stress on it; therefore, thermal load is the only source of stress on the thermosyphon. The thermal stress analysis in severe conditions (see the previous section) on the Teflon part (the weakest part, mechanically) shows that the maximum resultant strain is less than $0.1 \%$. At this strain level, all polymers are safe and in the elastic limit [75]. It appears that the average of extrema is closer to the exact solution than the arithmetic average value. This will be the focus of future investigation.
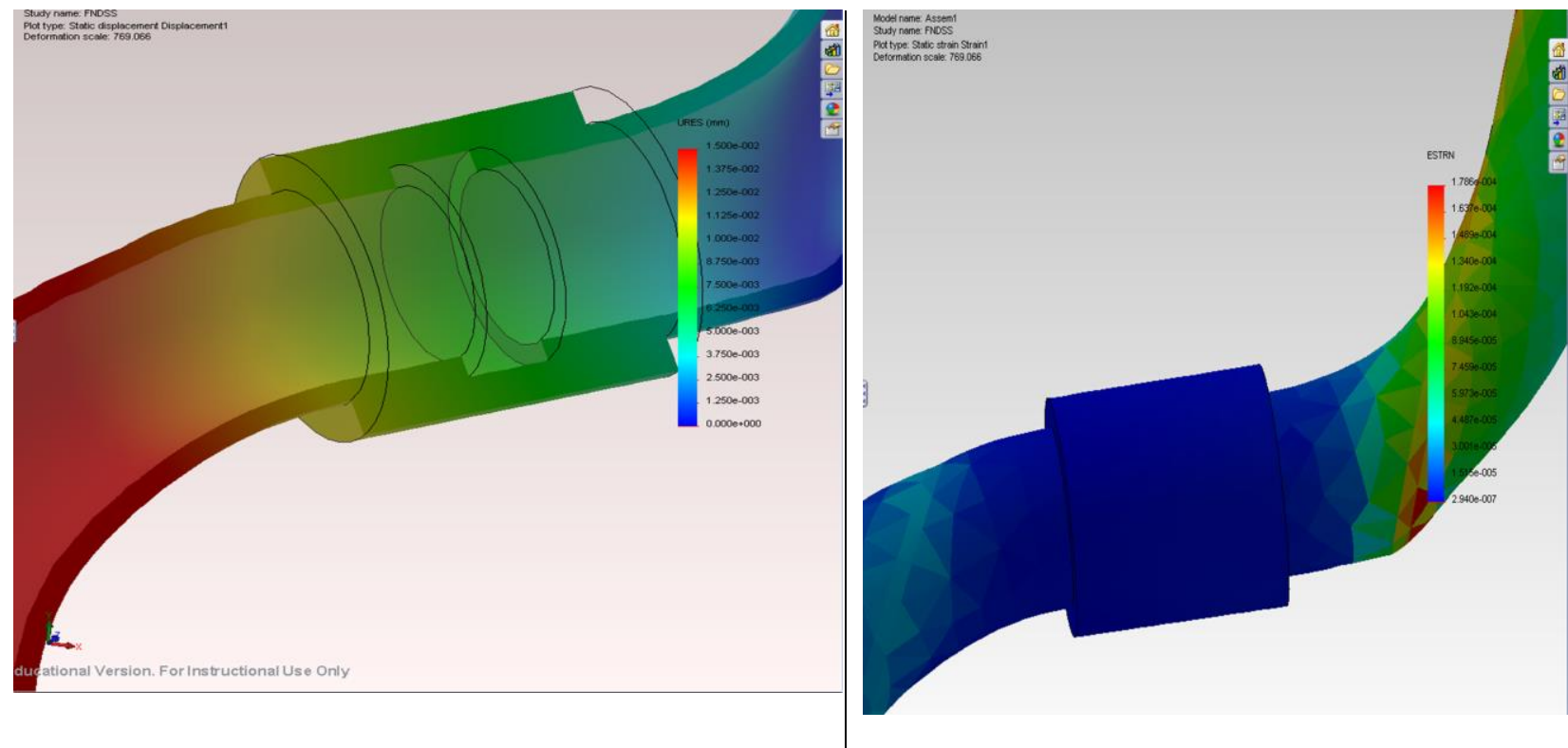

Figure 4-20: Displacement (left) and strain (right) distribution of the new design parts (Teflon and copper parts attached to it) in the forward heat transfer condition. 


\subsection{Conclusions}

A typical TDP is designed to transfer solar energy directly into the indoor air in Toronto. It is estimated that up to one mega-watt-hour (MWh) of energy be taken from each square meter of the TDP from the sun for heating buildings in Toronto annually. The surface temperature of the TP can be as high as $83^{\circ} \mathrm{C}$, which proves the potential of flowing heat from the surface into the other side of the panel (either to heat up cold water for DHW tank in summer or to store energy into the PCM).

The performance of a typical thermosyphon is simulated with SolidWork 2011. The thermal bridging effect of adding a piece of Teflon in the thermosyphon assembly is investigated and compared with the conventional design (one piece of copper sealed tube containing fluid). The thermal bridging is investigated on a typical winter day (indoor temperature and outdoor temperature are considered $20^{\circ} \mathrm{C}$ and $-20^{\circ} \mathrm{C}$, respectively). The results show that the backward heat transfer can be reduced 76 times by adding a piece of Teflon in the current thermosyphon assembly.

A Generic Algorithm code is developed to optimize the dimensions of the TDP for Toronto weather conditions to gain maximum solar thermal energy on an annual basis. GA codes are written in Matlab for optimizing the physical size of the five main TDP components: front, middle and back aluminum plate thicknesses, thermosyphon outer diameter and its thickness. Thermosyphon is constructed from copper tube, which passes through the adiabatic layer of the TDP to transfer heat from outside (evaporator) to inside (condenser). The plate thicknesses of 1.5 $\mathrm{mm}, 2.5 \mathrm{~mm}$, and $2 \mathrm{~mm}$ and thermosyphon diameter and thickness of $32 \mathrm{~mm}$ and $9 \mathrm{~mm}$, respectively, provide the maximum fitness value; therefore, they are the best individuals (optimum values). The determined TDP optimal dimensions are then checked for mechanical stability using SolidWorks 2012. The resulting maximum strain is found less than $0.01 \%$ due to combined thermal and mechanical stress, which makes the reliable structure. 


\section{Experiments on the TDP performance}

This chapter describes the Thermosyphon performance in TDP. It is intended to validate the theoretical study or simulation results. A thin film electrical heater is used to simulate heat flux from the sun on the evaporator side of thermosyphon. Then, the transient surface temperature and energy transfer through the panel is measured on the condenser side. Manufacturing process of a thermosyphon is also explained in this chapter.

\subsection{Manufacturing a Thermosyphon}

In the fridge manufacturing industry, a hermetic compressor is assembled into a fridge body as shown in the Figure 5-1. When a certain vacuum is reached (left sketch), the pipe is pressed/crimped and blocked by a clamp (right sketch). Finally, the pipe is disconnected from vacuum and brazed to keep the compressor sealed. At this moment, the clamp is removed and assembling is finished. This technique is used to make the thermosyphon.

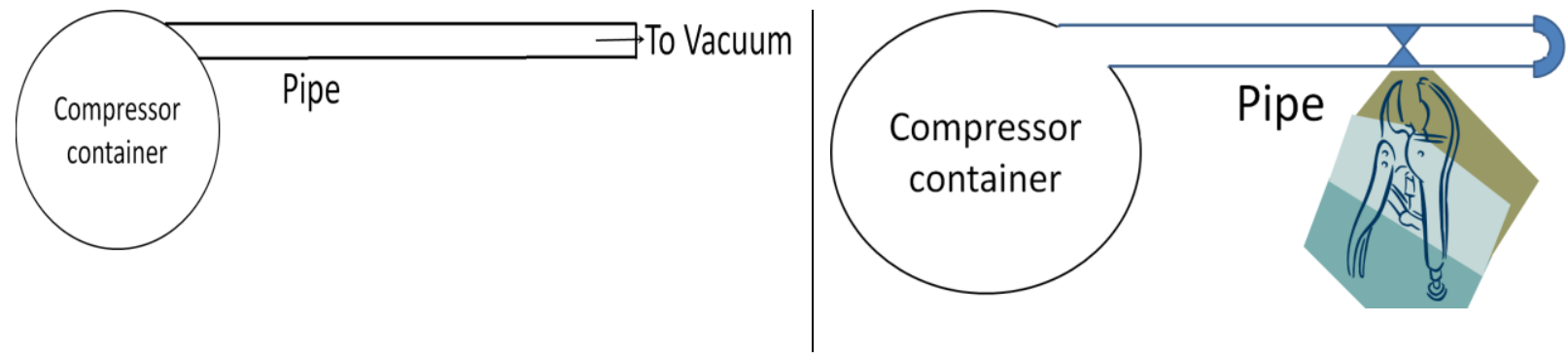

Figure 5-1: The last step of connecting compressor to a fridge (not to scale)

Figure 5-2 shows the manufacturing steps of the thermosyphon. The body of the thermosyphons are made of type L drawn copper tube. This tube is certified for potable water applications.

Figure 5-3 shows the picture of final products. The adiabatic section of the S-shape thermosyphon is made of ferretic stainless steel. Since thermal conductivity of stainless steel is lower than copper, thermal bridging is reduced. Table 5-1 shows the manufacturing records for each thermosyphon. They are assigned a number (identification) for traceability. Mechanical Engineering Machine Shop facilities were used for manufacturing. The vacuum pump of the Electron Microscopy was employed to vacuum (0.1 atmosphere) inside the tubes. A pressure 
gauge was permanently assembled on the first thermosyphon to check the durability of the vacuum inside the tubes after final brazing (sealing), see right picture of Figure 5-3. In the table, tolerances reveal the limitation of measurements. It was understandable that the vacuum inside the thermosyphons would not be the same because the clamping pressure cannot be the same.

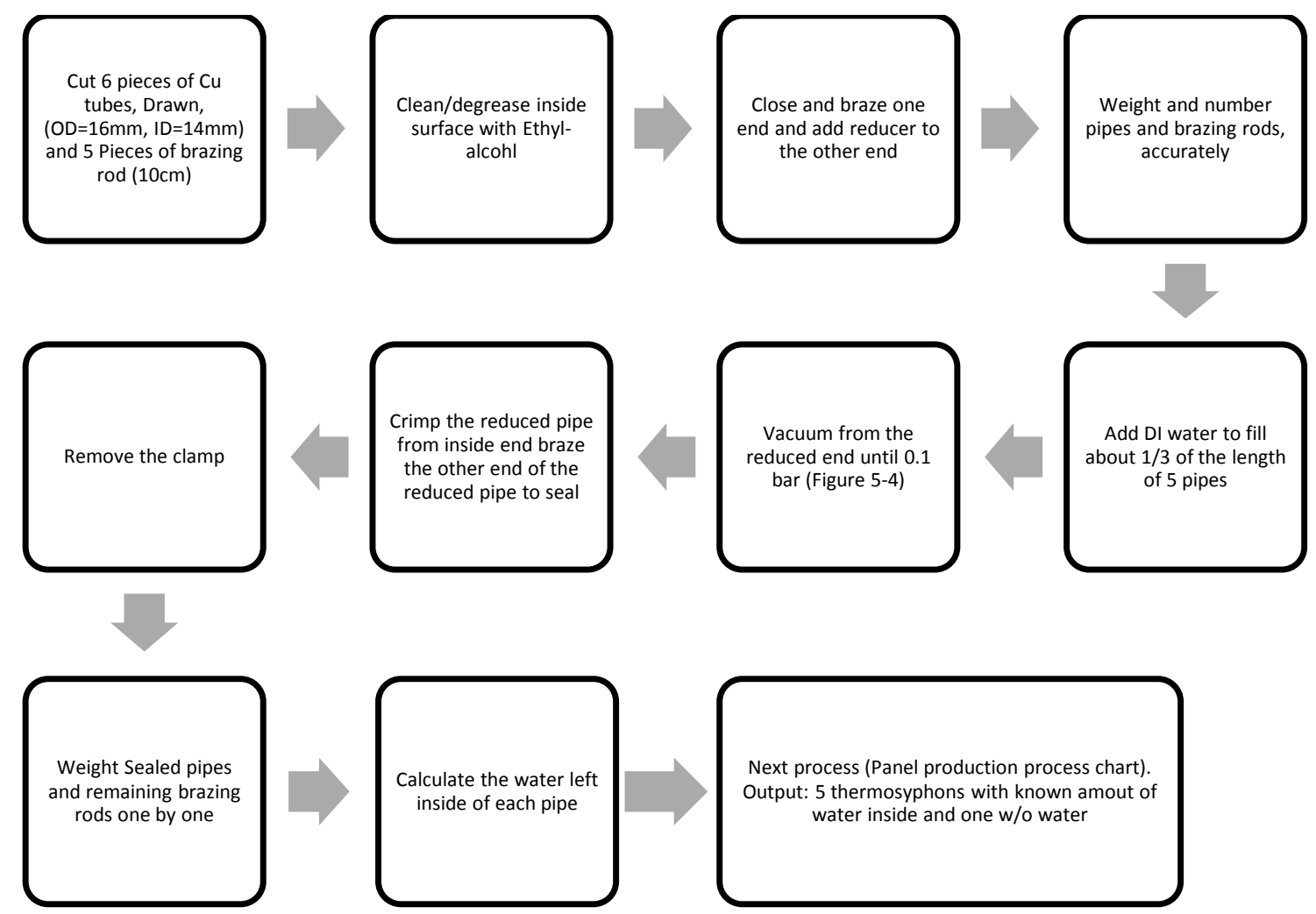

Figure 5-2: The manufacturing process of the thermosyphon
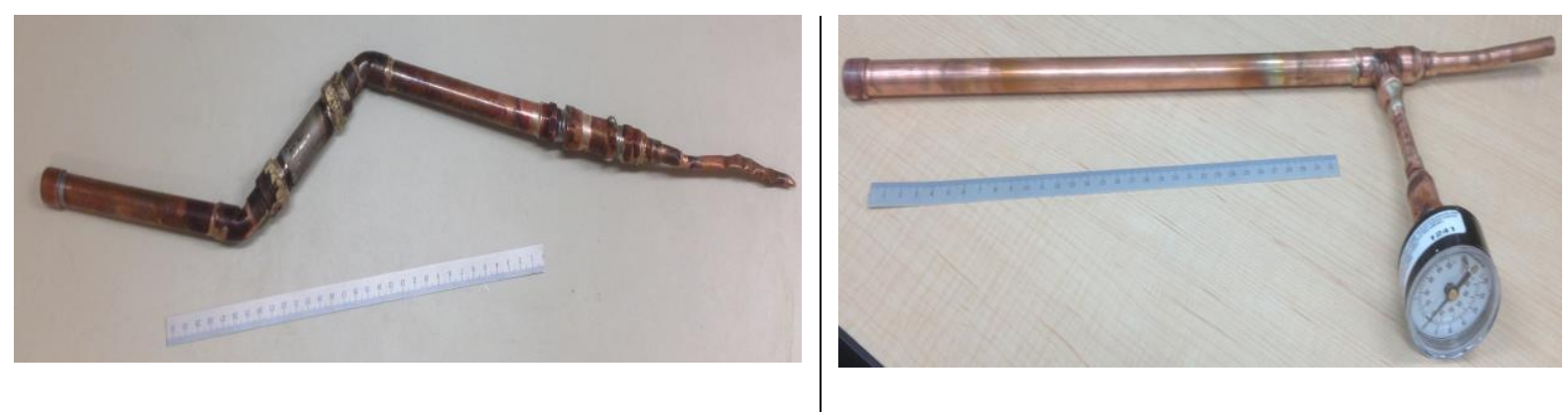

Figure 5-3: The manufactured thermosyphon, $S$ (left) and I (right) shape

Ideally, the thermosyphon should be S-shaped in order to touch the inner and outer surfaces of the panel (see Figure 4-3). The S-shape has more thermal mass, as its adiabatic section is made 
of stainless steel and brazed to copper pipes at each end (see Figure 5-3); therefore, transfer of heat across the ends (evaporator to condenser) is slower than the I-shape. To make the tests easier and to get faster results, the I-shape thermosyphons would be used. The quality of the products are checked (QC) by immersing them into a constant heat bath and comparing the rate of heat transfer of them with a copper pipe of the same length and size. Details are given in the next section with an illustration of the results. Since the amount of water in each thermosyphon is different, the response of them to the heat bath would be different.

Table 5-1: Record of manufactured thermosyphons Unit Tolerance

\begin{tabular}{|c|c|c|c|c|c|c|c|c|c|}
\hline Shape & & & $\mathrm{I}$ & I & $S$ & $\mathrm{I}$ & $S$ & I & $\mathrm{I}$ \\
\hline Identification & & & $\begin{array}{l}\text { With } \\
\text { Gauge }\end{array}$ & III & V1.0 & II & V1.1 & IV & V \\
\hline QC passed? (Y/N) & & & $\mathrm{Y}$ & $\mathrm{Y}$ & $\mathrm{N}$ & $\mathrm{Y}$ & $\mathrm{Y}$ & $\mathrm{Y}$ & $\mathrm{Y}$ \\
\hline Weight before & gr & \pm 0.05 & & 219 & 402 & 183 & 328 & 190 & 191 \\
\hline Volume of water inside & $\mathrm{cm}^{3}$ & \pm 0.5 & 15 & 15 & 19 & 15 & 18 & 10 & 13 \\
\hline $\begin{array}{r}\text { Water filling with respect to } \\
\text { evaporator volume }\end{array}$ & $\%$ & & & 51 & 86 & 58 & 70 & 35 & 43 \\
\hline $\begin{array}{r}\text { Weight with water before } \\
\text { vacuum }\end{array}$ & gr & \pm 0.05 & & 232 & 434 & 198 & 346 & 200 & 203 \\
\hline Weight of brazing material & gr & \pm 0.05 & & 1 & 1 & 4 & 3 & 1 & 1 \\
\hline End weight & gr & \pm 0.05 & & 233 & 434 & 202 & 349 & 200 & 203 \\
\hline Evaporator Length & $\mathrm{mm}$ & \pm 0.5 & & 170 & 180 & 170 & 170 & 170 & 170 \\
\hline Adiabatic Length & $\mathrm{mm}$ & \pm 0.5 & & 180 & 110 & 180 & 110 & 180 & 180 \\
\hline Condenser Length & $\mathrm{mm}$ & \pm 0.5 & & 170 & 250 & 170 & 170 & 170 & 170 \\
\hline Total Length & $\mathrm{mm}$ & \pm 0.5 & 520 & 530 & 540 & 520 & 450 & 520 & 520 \\
\hline Inside Diameter (ID) & $\mathrm{mm}$ & \pm 0.05 & 14.0 & 14.0 & 14.0 & 14.0 & 14.0 & 14.0 & 14.0 \\
\hline Outside Diameter (OD) & $\mathrm{mm}$ & \pm 0.05 & 16.0 & 16.0 & 16.0 & 16.0 & 16.0 & 16.0 & 16.0 \\
\hline $\begin{array}{r}\text { Check water mass before } \\
\text { vacuum }\end{array}$ & gr & & 0 & 13 & 32 & 15 & 18 & 10 & 12 \\
\hline Water mass after welding & gr & & 0 & 13 & 31 & 15 & 18 & 9 & 11 \\
\hline Water volume deduced & $\mathrm{cm}^{3}$ & & 0 & 13 & 31 & 15 & 18 & 9 & 11 \\
\hline Deviation & $\mathrm{cm}^{3}$ & & & 2 & -12 & 0 & 0 & 1 & 2 \\
\hline
\end{tabular}

\subsubsection{Preliminary test}

Preliminary test was conducted to analyse the heat transfer sensitivity of each thermosyphon. The production of thermosyphons was not controlled accurately. It relies on operator expertise. 
After calibrating the constant temperature heat bath and four channels of the data logger thermometer (HH147U) by the High Accuracy Digital Thermometer (DP97), the heat transfer across a copper tube was investigated to make sure that the equipment is working properly. Figures 5-4 and 5-5 show that apparatus and the setup of the test, respectively. DP97 was used to monitor the heat bath temperature and HH147U was monitoring the surface temperature along the copper tube in four different heights as shown in Figure 5-5. Surface temperatures were collected at 10 seconds interval until the steady-state was maintained. Figure 5-6 shows the transient readings of the surface temperatures at four points. Additionally, uncertainties are extracted from calibrator that Table 5-2 is constructed upon. The calibrator uncertainty is considered $\pm 0.1^{\circ} \mathrm{C}$. Uncertainty is added/shown only on one plot in Figure 5-6. The bath temperature was fixed at $40^{\circ} \mathrm{C}$. Table 5-2 shows the calibration record of the data logger thermometer channels. It seems that channel T1 has the best reading and channels T3 and T4 are the worst in accuracy. $\mathrm{T} 2$ readings are almost close to $\mathrm{T} 1$ in accuracy. The reading resolution is $0.1^{\circ} \mathrm{C}$.

Table 5-2: Record of calibration of HH147U channels

\begin{tabular}{|r|l|l|l|l|r|r|r|r|}
\cline { 2 - 9 } \multicolumn{1}{c|}{} & \multicolumn{3}{c|}{ Sensors' readings } & \multicolumn{4}{c|}{ Uncertainties } \\
\hline Calibrator & T1 & T2 & T3 & T4 & dT1 & dT2 & dT3 & dT4 \\
\hline 31.74 & 31.9 & 31.3 & 31.1 & 31.3 & -0.2 & 0.4 & 0.6 & 0.4 \\
\hline 40.80 & 40.6 & 40.6 & 40.5 & 40.3 & 0.2 & 0.2 & 0.3 & 0.5 \\
\hline 51.31 & 51.3 & 51.1 & 50.7 & 50.7 & 0.0 & 0.2 & 0.6 & 0.6 \\
\hline
\end{tabular}

The last 30 readings of each point from Figure 5-6 were selected and averaged. Figure 5-7 represents the steady state temperature of the four selected points. Recalling the one-dimensional conduction heat transfer, $T(x, t)$ :

$$
k \frac{d^{2} T}{d x^{2}}=\rho C \frac{d T}{d t}
$$

As the transient plots on Figure 5-6 for the last 30 readings are horizontal for all points, the right side of the Equation $(5-1)$ is equal to zero $\left(\frac{d T}{d t}=0\right)$. Thus, temperature versus distance (T vs $\mathrm{x}$ ) should be a line $\left(\frac{d^{2} T}{d x^{2}}=0\right)$. 


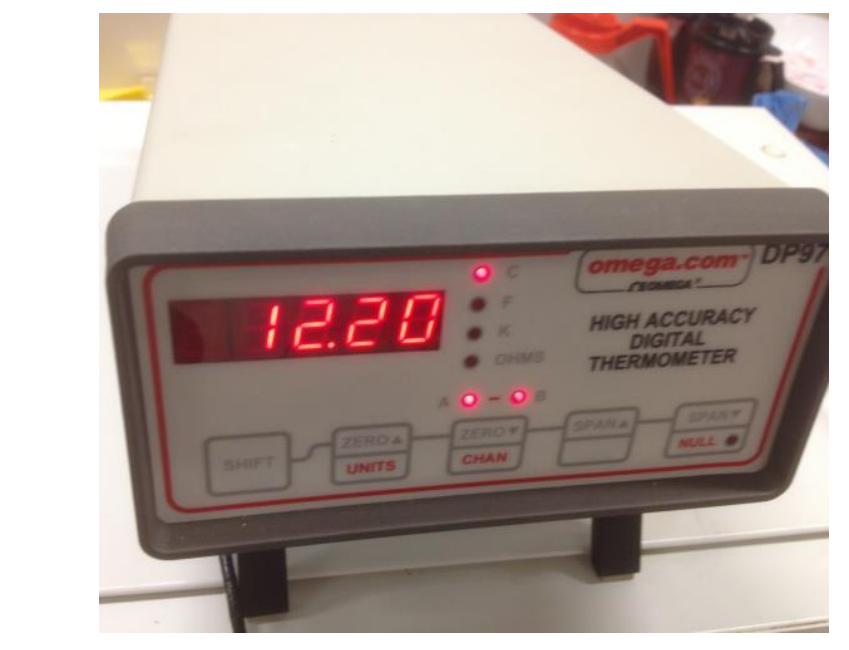

High Accuracy Digital Thermometer (DP97)

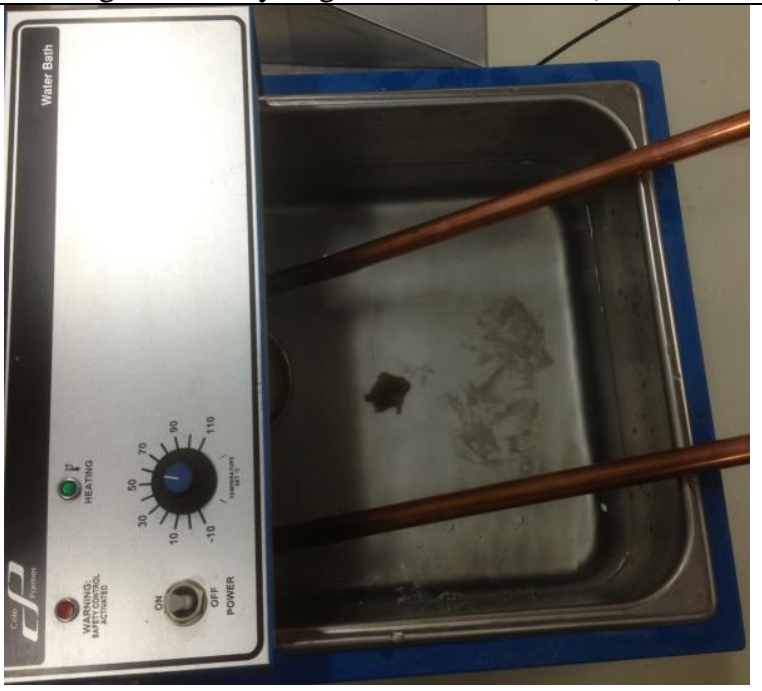

Constant temperature heat bath

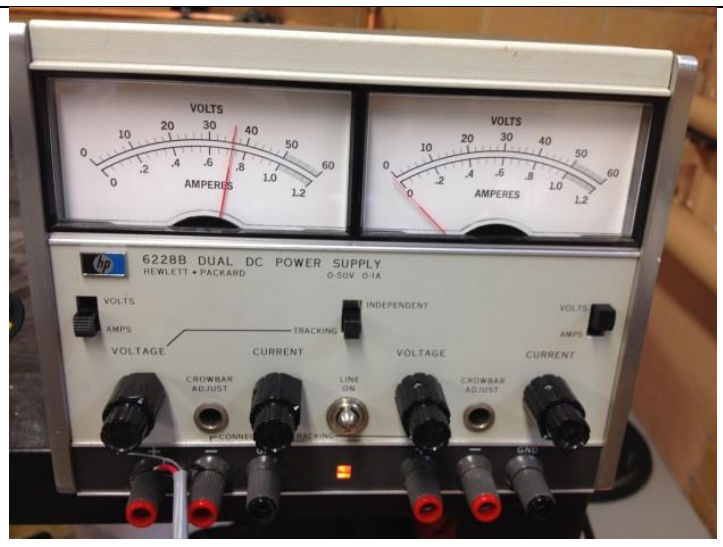

DC power supply (6228B HP)

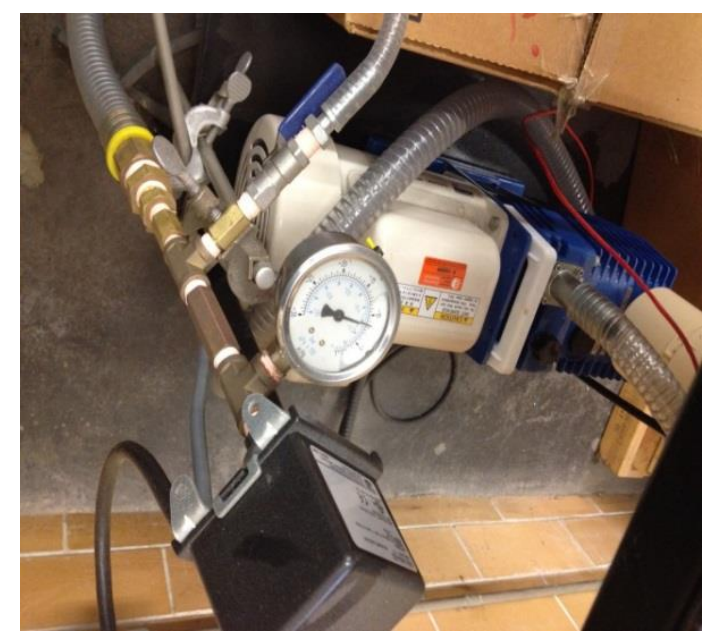

Vacuum Pump

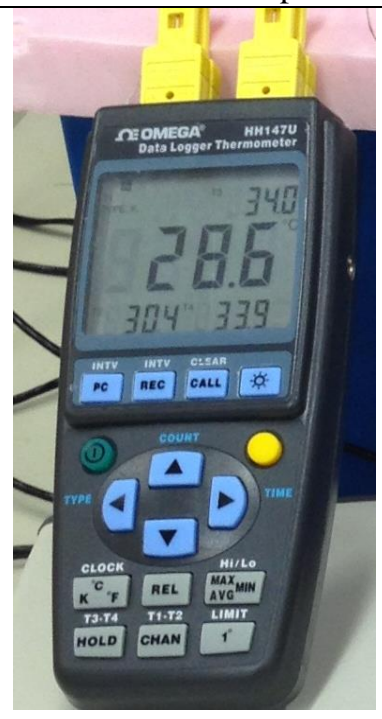

Data Logger Thermometer (HH147U)

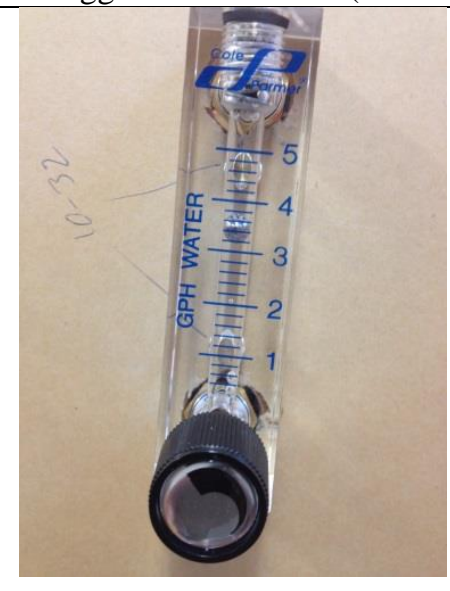

Rotameter (Cole-Parmer, 0.4-5 GPH)

Figure 5-4: The measuring devices used for the experiment 


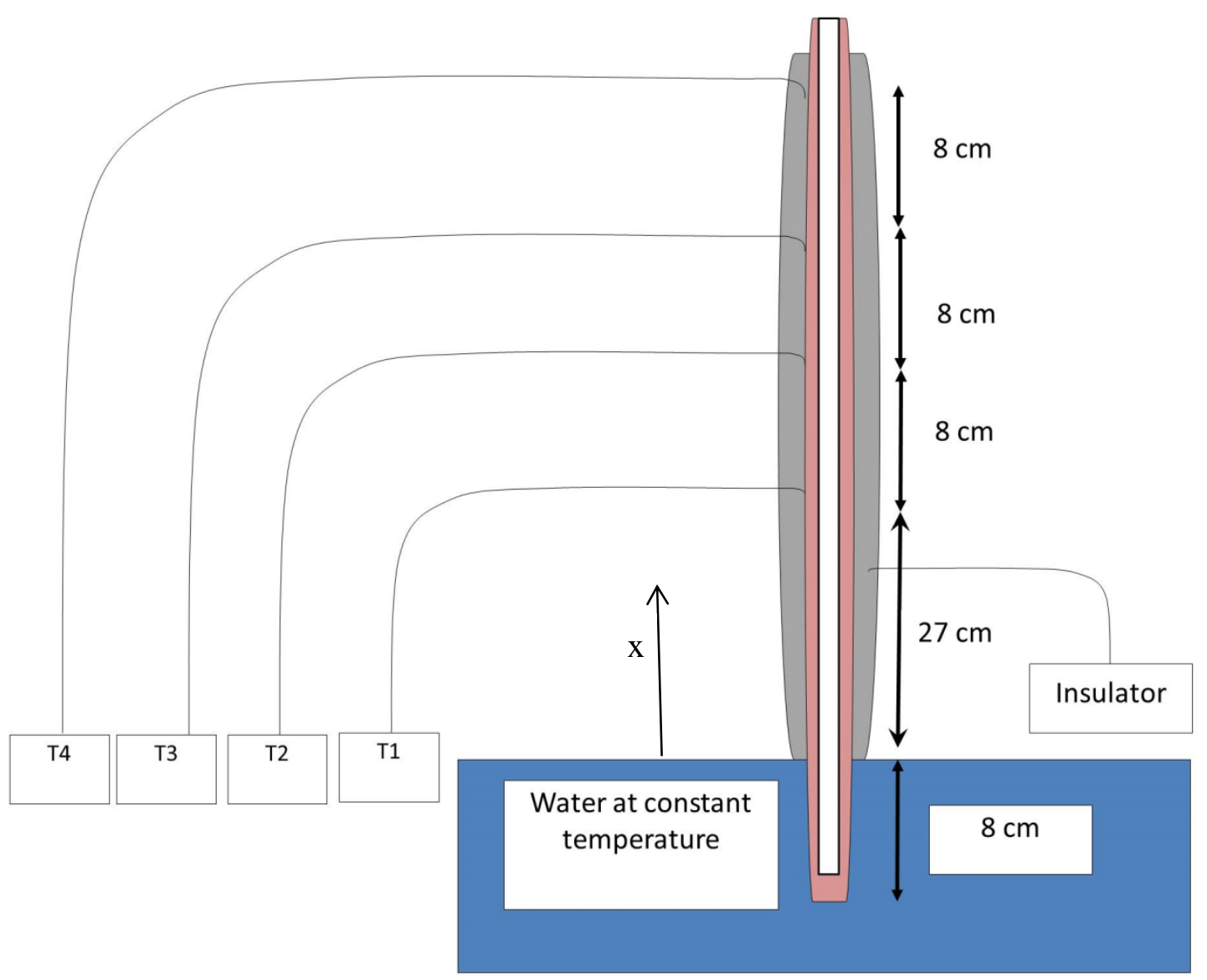

Figure 5-5: The set-up for the copper tube test (vertical position)

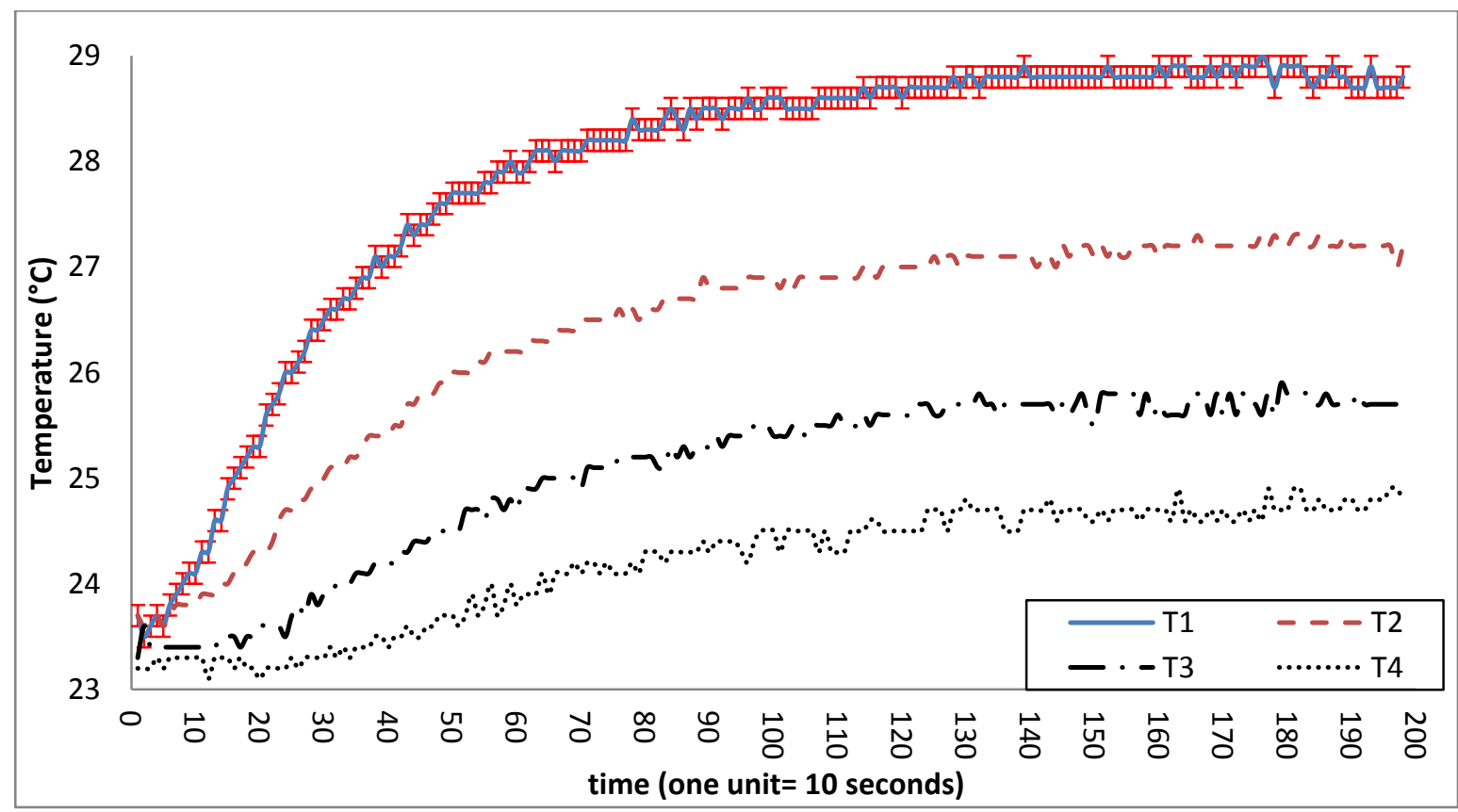

Figure 5-6: Transient temperature of the surface points on the copper tube at heat bath temperature of $40^{\circ} \mathrm{C}$ 
Plot on Figure 5-7 is better fit with a quadratic equation. $\mathrm{R}^{2}$ for line fit is 0.9506 and for quadratic fit is 0.9995 . Because the heat transfer rate is proportional to the slope of $\mathrm{T}$-x curve at any point ( $\dot{q}=-k \frac{d T}{d x}$ ), the heat flux from the heat bath is more than the heat flux that goes out from T4 and T3 points. This point justifies the heat loss from the surface of the copper tube through insulator cover. The loss of about $3 \% \dot{q}$ is reported in literature in the similar conditions [76]. Uncertainty of $\pm 0.63^{\circ} \mathrm{C}$ (standard deviation) and $\pm 0.5 \mathrm{~cm}$ are shown of the plot.

Critical radius $\left(r^{*}=k / h\right)$ was checked for this design [77]. The value of the $\mathrm{r}^{*}$ will be the largest when $\mathrm{k}$ (thermal conductivity of insulator) is large and $\mathrm{h}$ (free convection coefficient over the external surface of the insulator) is small. Practically, the lowest value of the $\mathrm{h}$ is $5 \mathrm{~W} / \mathrm{m}^{2} . \mathrm{K}$, and that of common insulating materials is about $0.05 \mathrm{~W} / \mathrm{m} . \mathrm{K}$; therefore, the maximum $\mathrm{r}^{*}$ is $0.05 / 5=$ $0.01 \mathrm{~m}$, or $1 \mathrm{~cm}$. In this experiment, insulator radius was $1.4 \mathrm{~cm}$ that is bigger than $\mathrm{r}^{*}$, i.e., the loss due to insulation is not worrisome [77].

So far, it was shown that the set up can measure the one-dimensional conduction heat transfer along the copper tube. To check the quality of the manufactured thermosyphons, all of them are immersed from evaporator section into the heat bath at the same time $(t=0)$, see Figure 5-8. The surface temperature of the condenser at point T1, in Figure 5-5, is monitored. The temperature is compared with the surface temperature of a copper tube at the same position (T1) in the same condition.

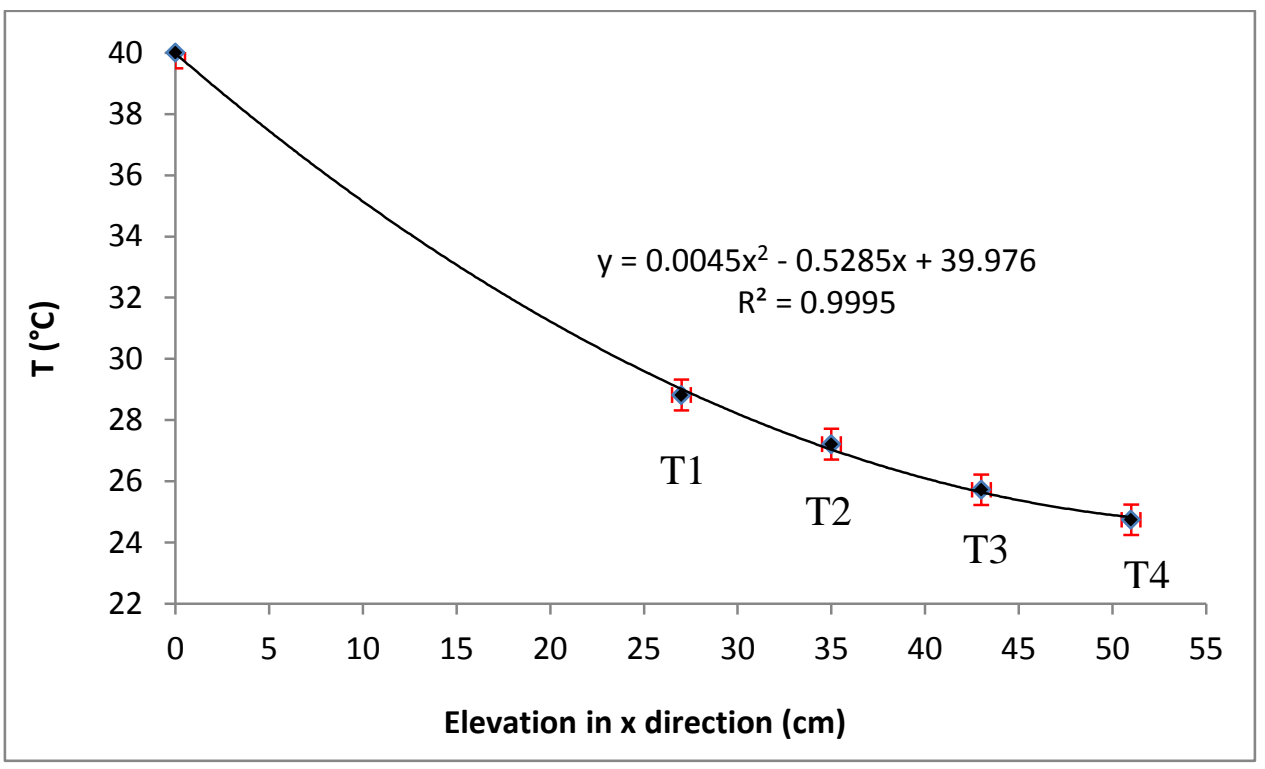

Figure 5-7: Steady state temperature of the selected points on the surface of the Cu-tube 


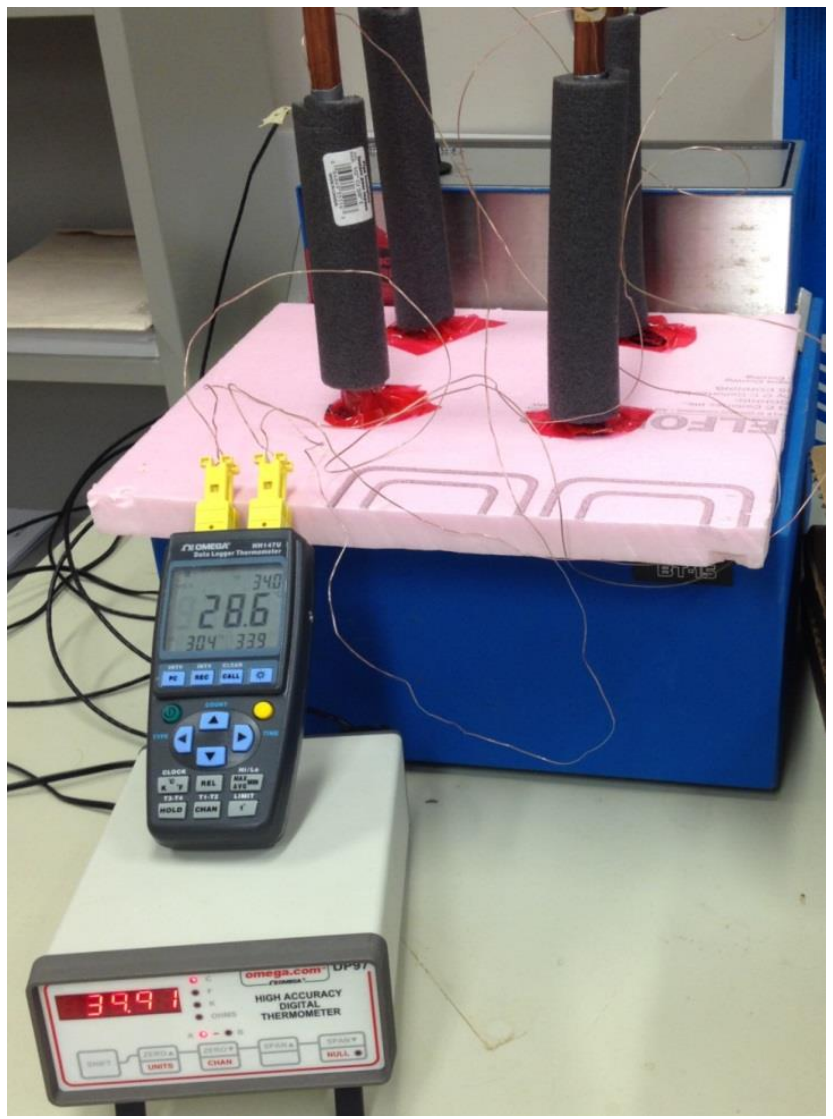

Figure 5-8: The setup for preliminary test

Figure 5-9 shows that thermosyphons II and III work well at $40^{\circ} \mathrm{C}$ (heat bath temperature). That means, the inside pressure is $0.1 \mathrm{~atm}$; therefore, water pool inside of them boils at $40^{\circ} \mathrm{C}$. On the other hand, thermosyphons IV and V are behaving similar to copper tube; therefore, it is concluded that the inside pressure is higher than the design (intention) value, $0.1 \mathrm{~atm}$. By increasing the heat bath temperature to $45^{\circ} \mathrm{C}$, all thermosyphons respond fast to the heat transfer within 300 seconds (see Figure 5-10). Error bars $\left( \pm 0.1^{\circ} \mathrm{C}\right)$ are shown only on one plot. All plots have same uncertainty because same data logger is used all over experiment. 


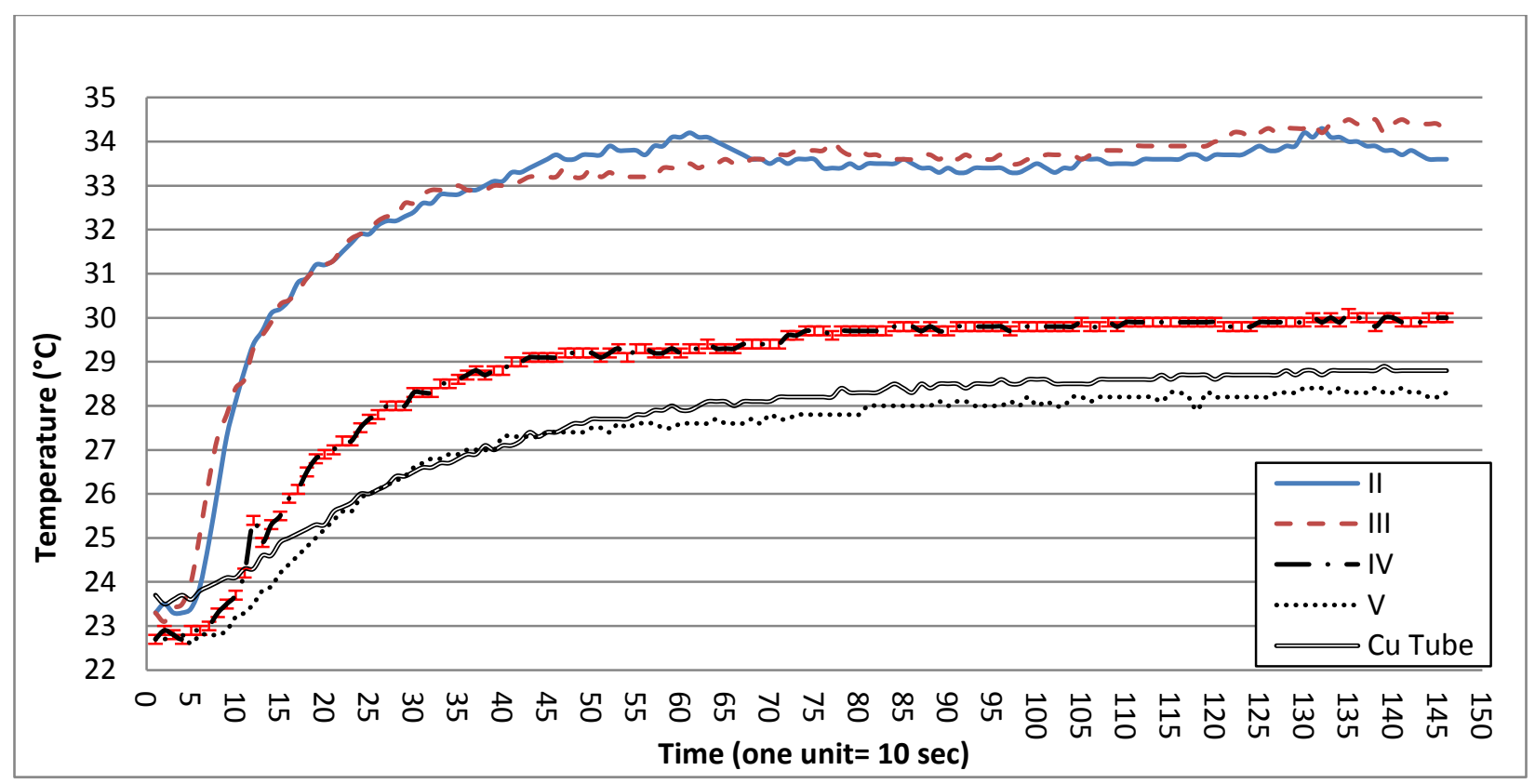

Figure 5-9: Transient temperature of the surface point $\mathrm{T} 1$ on the copper tube and thermosyphons at $40^{\circ} \mathrm{C}$

To investigate the thermal behavior of the manufactured thermosyphons at different temperature, thermosyphon II was selected. As Figure 5-11 shows, increasing the evaporator section temperature increases the condenser temperature. On the other hand, the difference between steady state temperature of the condenser and evaporator increases with increasing evaporator temperature (Table 5-3). This is because the condenser does not have a heat sink to transfer heat that is transferred by steam inside the thermosyphon. Heat is transferred to ambient air, which is at $23^{\circ} \mathrm{C}$, by free convection only. Table 5-3 also shows that a maximum temperature difference of $6.4^{\circ} \mathrm{C}$ can be attained across the thermosyphon, while it works. The steady state temperature of the condenser is calculated by averaging the last 30 readings from Figure 5-11. Moreover, by increasing the heat bath temperature above $40^{\circ} \mathrm{C}$, at some times, wiggling occurs. This phenomenon (boiling) is clear on plots of 50 and 55 degrees in Figure 5-11. Boiling occurs because the condenser wall is much higher than boiling temperature and there is no more water to boil and absorb the heat. While heat is transferred to the air inside the room, condensation occurs and reduces the wall temperature. This process continues repeatedly. Error bars are shown on the plots based on calibration table/data. 


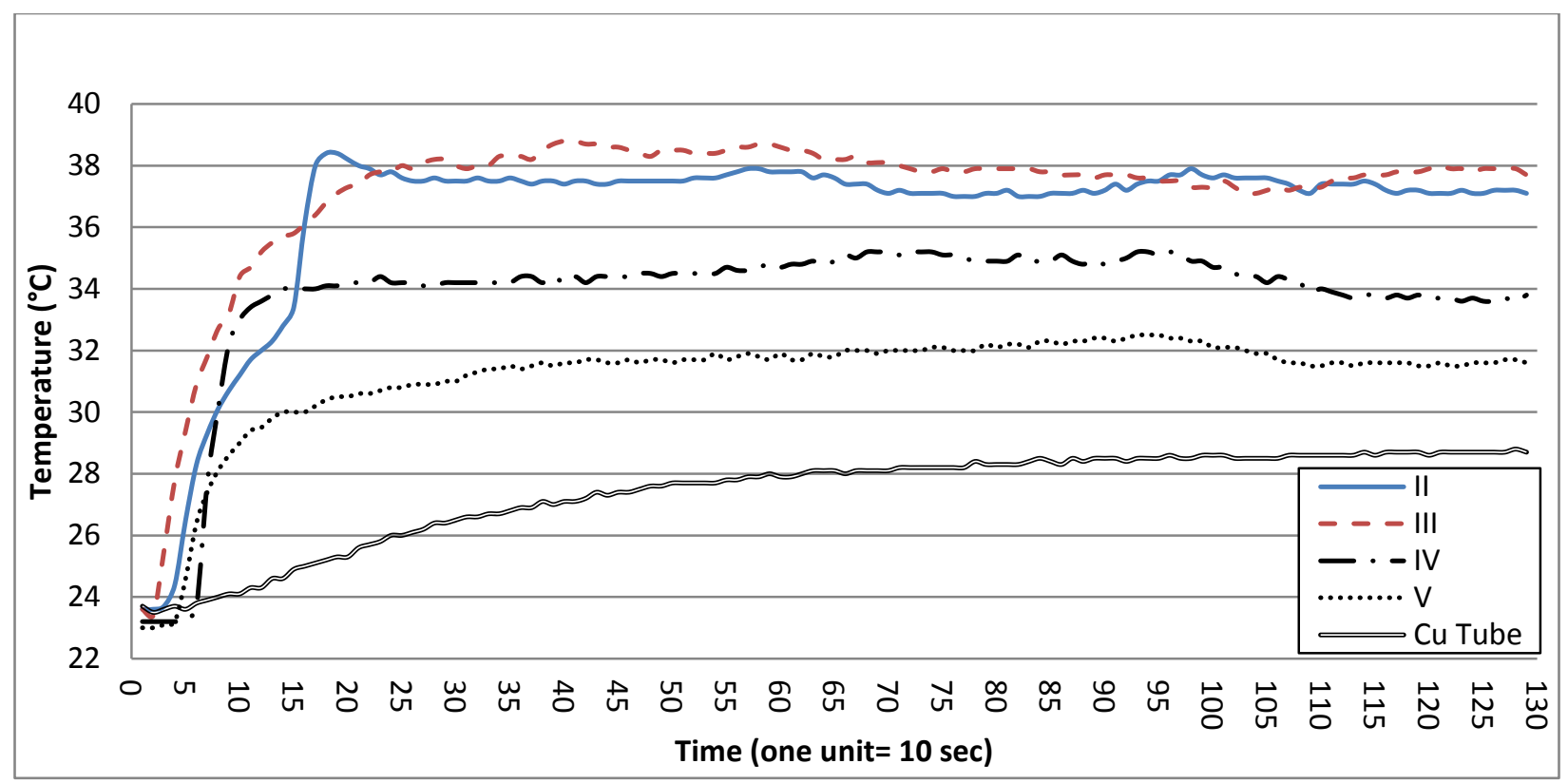

Figure 5-10: Transient temperature of the surface point $\mathrm{T} 1$ on the copper tube and thermosyphons at $45^{\circ} \mathrm{C}$

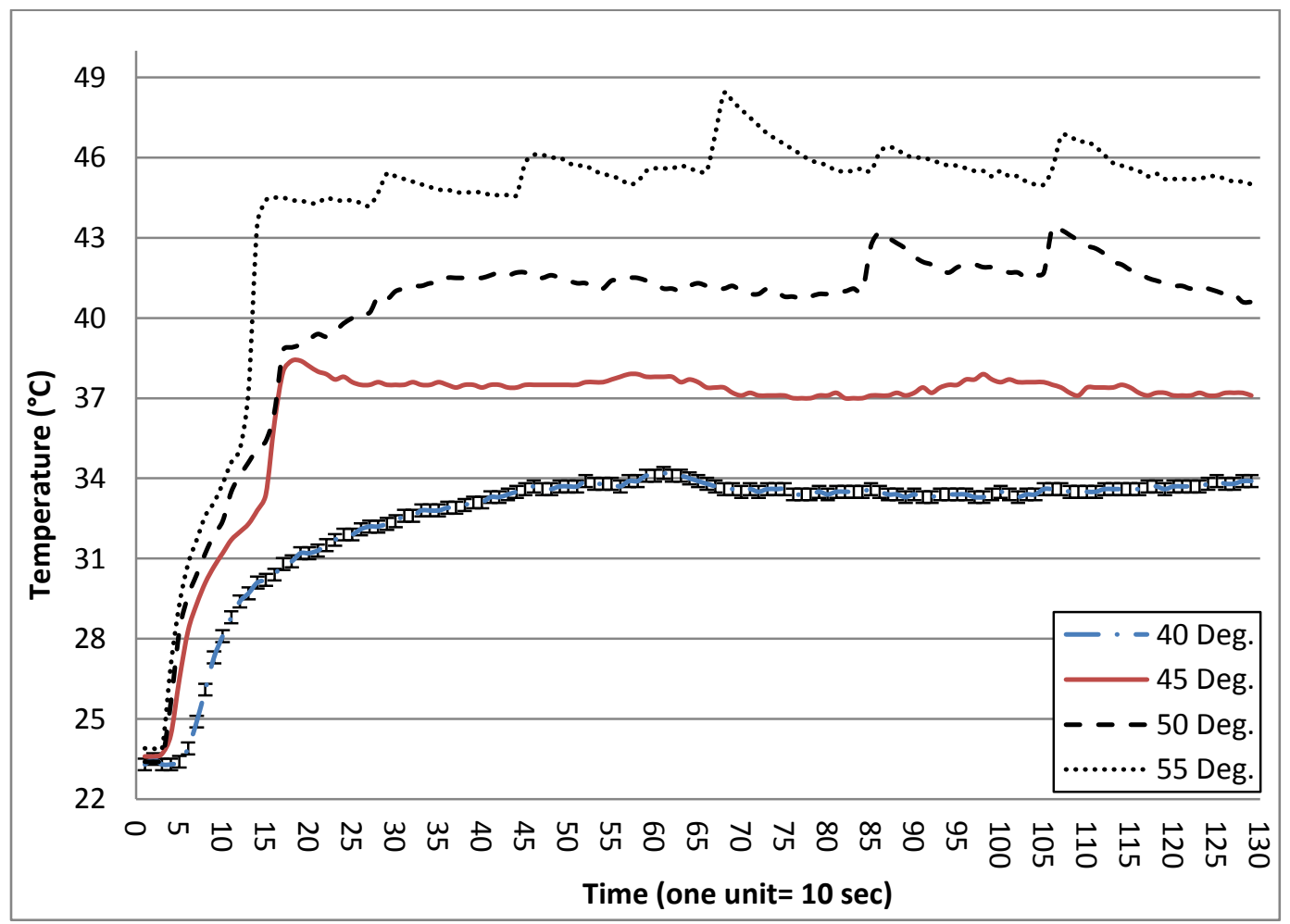

Figure 5-11: Transient temperature of the surface of the condenser (point T1) of the thermosyphon II at different heat bath temperature

From the above paragraph, it is concluded that free convection does not have enough power to transfer heat from condenser; therefore, provisions should be made (e.g., using fin or force 
convection) to transfer the heat from condenser when the evaporator temperature increases. This is especially important when thermosyphon is exposed to sun in summer.

Table 5-3: The difference between evaporator and condenser temperatures

\begin{tabular}{|c|c|c|}
\hline Evaporator Temp. $\left({ }^{\circ} \mathrm{C}\right)$ & Condenser Temp. $\left({ }^{\circ} \mathrm{C}\right)$ & Difference $\left({ }^{\circ} \mathrm{C}\right)$ \\
\hline 40 & 33.6 & 6.4 \\
\hline 45 & 37.4 & 7.6 \\
\hline 50 & 41.8 & 8.2 \\
\hline 55 & 45.5 & 9.5 \\
\hline
\end{tabular}

Back to Figure 5-11, there is no wiggling at $40^{\circ} \mathrm{C}$ plot, because the water inside the evaporator is in equilibrium with its vapour.

$$
\text { liquid } \rightleftarrows \text { Vapour } \quad \text { at } \mathrm{T}=40^{\circ} \mathrm{C} \& \mathrm{P}=0.1 \text { atm }
$$

By increasing the evaporator temperature, the equilibrium shifts to the vapour (right) in the evaporator side and excess vapour moves to the condenser. At the condenser, the vapour condenses into the liquid and moves back to the evaporator by gravity; therefore, temperature fluctuates at the condenser and wiggling starts when temperature is $45^{\circ} \mathrm{C}$ and up.

\subsection{Design of Experiment (DOE)}

To simulate the solar radiation flux (in $\mathrm{W} / \mathrm{m}^{2}$ ), the right electrical resistance and power supply should be selected. In addition, an appropriate flow of water (using rotameter) should be selected to transfer heat from the condenser section as fast as heat is generated from the evaporator section.

\subsubsection{Power and electrical heater selection}

If $\mathrm{SR}$ is the desired solar radiation and $\mathrm{Ar}$ is the heater area (Width $\times$ Length), the required power from supply would be $\mathrm{SR} \times \mathrm{Ar}$. For example, for $\mathrm{SR}=1000 \mathrm{~W} / \mathrm{m}^{2}, \mathrm{Ar}=0.1 \times 0.2 \mathrm{~m}^{2}, 20 \mathrm{~W}$ power $(\mathrm{Po})$ is required. Thus, $\mathrm{I}=$ Power/Voltage gives the electric current ( $\mathrm{I}$ in Ampere) and voltage $(\vartheta$ in Volt) relationship. For example, if the power supply provides $110 \vartheta$ (DC), $182 \mathrm{~mA}$ is drawn from the power supply. 
$\dot{Q}=\vartheta^{2} / \mathcal{R}$, where $\mathcal{R}(43 \Omega)$ and $\vartheta$ are the electrical resistance of the heater and applied voltage, respectively. Thus, a direct current voltage of $30 \vartheta$ across the $43 \Omega$ thermal resistance provides $20 \mathrm{~W}$ powers.

\subsubsection{Rotameter flow calculation}

In the previous section, it was assumed that $20 \mathrm{~W}$ powers are radiated on the evaporator section. Assuming no heat is lost, water flow should take this heat away from condenser section. Using first law of thermodynamics, the increase in temperature of water flow $(\dot{m})$ should be equal to 20 $\mathrm{W}$. The specific heat capacity $\left(C_{p}\right)$ of water at $20^{\circ} \mathrm{C}$ is equal $4.186 \mathrm{~J} / \mathrm{g} \cdot{ }^{\circ} \mathrm{C}$; therefore, transferred heat into the water flow is:

$$
\dot{Q}=\dot{m} C_{p} \Delta T
$$

Assuming a minimum temperature difference of $1^{\circ} \mathrm{C}$, using Equation (5-3), the maximum flow of 4.78 gram per second should be passed over the condenser surface. This translate the maximum reading of the rotameter should be about 0.287 liter per minute, $1 / \mathrm{m},(20 \times 60 / 4.186=287 \mathrm{~g} / \mathrm{min})$. Assuming uncertainty of $C_{p}$ is negligible and solving Equation (5-3) for $\dot{m}$, uncertainty of the $\dot{m}$ $(d \dot{m})$ can be calculated by using the Law of Propagation of Uncertainty:

$$
d \dot{m}=\frac{1}{C_{p}}\left[\left(\frac{\partial \dot{m}}{\partial \dot{Q}} d \dot{Q}\right)^{2}+\left(\frac{\partial \dot{m}}{\partial \Delta T} d(\Delta T)\right)^{2}\right]^{1 / 2}=\frac{1}{C_{p}}\left[\left(\frac{d \dot{Q}}{\Delta T}\right)^{2}+\left(\frac{\dot{Q}}{\Delta T^{2}} d(\Delta T)\right)^{2}\right]^{1 / 2}
$$

The following table shows some options for $d \dot{m}$ based on different values of other terms, in gram per second:

Table 5-4: The best option for $\boldsymbol{d m}$ is underlined

\begin{tabular}{|l|c|c|c|c|c|}
\hline$C_{p}\left(\mathrm{~J} / \mathrm{g} \cdot{ }^{\circ} \mathrm{C}\right)$ & 4.186 & $\underline{4.186}$ & 4.186 & 4.186 & 4.186 \\
\hline$\dot{Q}(\mathrm{~W})$ & 20 & $\underline{20}$ & 20 & 20 & 40 \\
\hline$\Delta T\left({ }^{\circ} \mathrm{C}\right)$ & 1 & $\underline{1}$ & 2 & 3 & 3 \\
\hline$d(\Delta T)\left({ }^{\circ} \mathrm{C}\right)$ & 0.01 & $\underline{0.5}$ & 0.01 & 0.01 & 1 \\
\hline$d \dot{Q}(\mathrm{~W})$ & 1 & $\underline{1}$ & 1 & 1 & 1 \\
\hline$d \dot{m}(\mathrm{~g} / \mathrm{s})$ & 0.244 & $\underline{2.401}$ & 0.120 & 0.080 & 1.065 \\
\hline
\end{tabular}

Based on the above uncertainty analysis, the rotameter was purchased. It should not have more than $2.4 \mathrm{~g} / \mathrm{s}$ uncertainty in measuring water flow. 


\subsubsection{Inclination effects}

Researchers concluded that thermosyphon inclination affects its performance (see section 2.2.4). To find the best angle, which provides the best performance, thermosyphon $\mathrm{V}$ was selected. The surface temperature of the condenser is considered to be an indicator of the thermosyphon performance. As the thermosyphon is inclined, the top part of the condenser surface would be warmer than the lower. This is because the condensed water flows back to the pool through the lower surface due to gravity. As Figure 5-12 shows, the thermosyphon is secured at an angle of 30 degrees with horizon. Figure 5-13 shows the result of monitoring transient temperature of the point T1. It is evident that about 100 seconds after the evaporator is immersed into the constant heat bath of $50^{\circ} \mathrm{C}$, the lower and upper temperatures of the point $\mathrm{T} 1$ show a gap of about $2^{\circ} \mathrm{C}$. This is the moment that condensed water reach back to the point of measurement (T1). Due to good thermal conductivity of the copper pipe, upper and lower temperatures are equal after 1500 seconds. Steady state condition starts at the point T1 at this moment. The arithmetic average of the upper and lower temperatures is reported as the surface temperature of the condenser at the point T1.

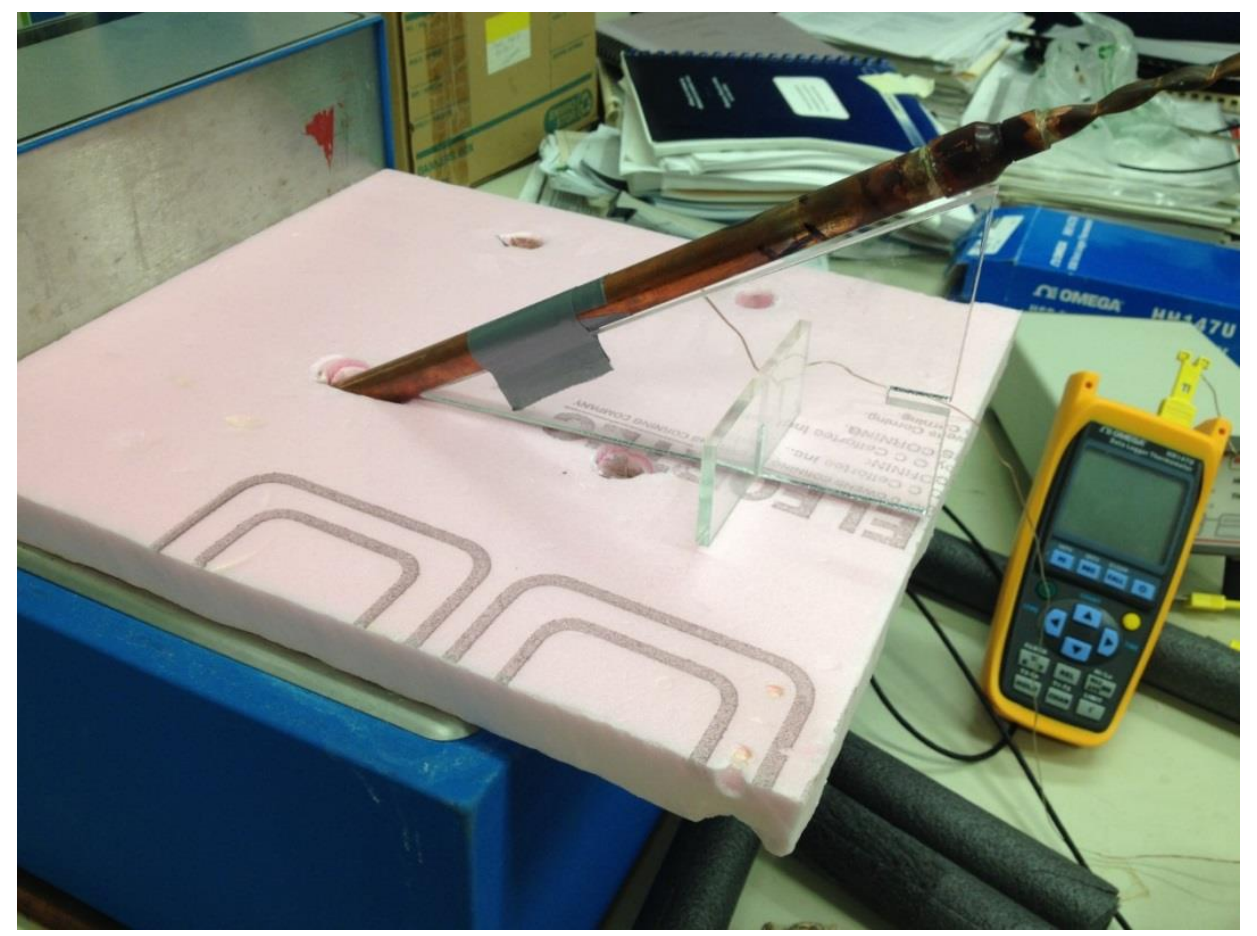

Figure 5-12: The setup of thermosyphon at 30 degrees 


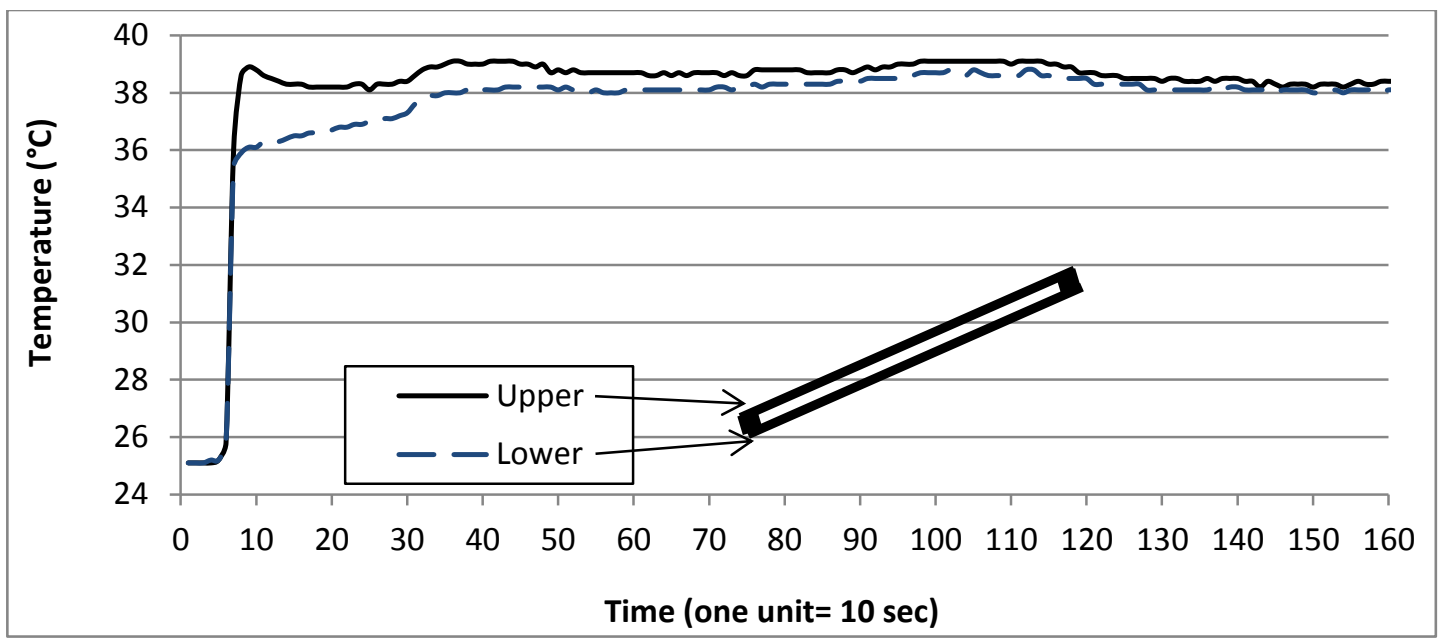

Figure 5-13: The upper and lower surface temperature (at the point $\mathrm{T} 1 \mathrm{on}$ Figure 5-5) of the condenser of the thermosyphon $\mathrm{V}$ at 30 degree inclination in constant heat bath temperature of $50^{\circ} \mathrm{C}$

Figure 5-14 shows the transient temperatures of the point $\mathrm{T} 1$ at different angles. Clearly, the thermosyphon works the best in an angle between 30 and 45 .

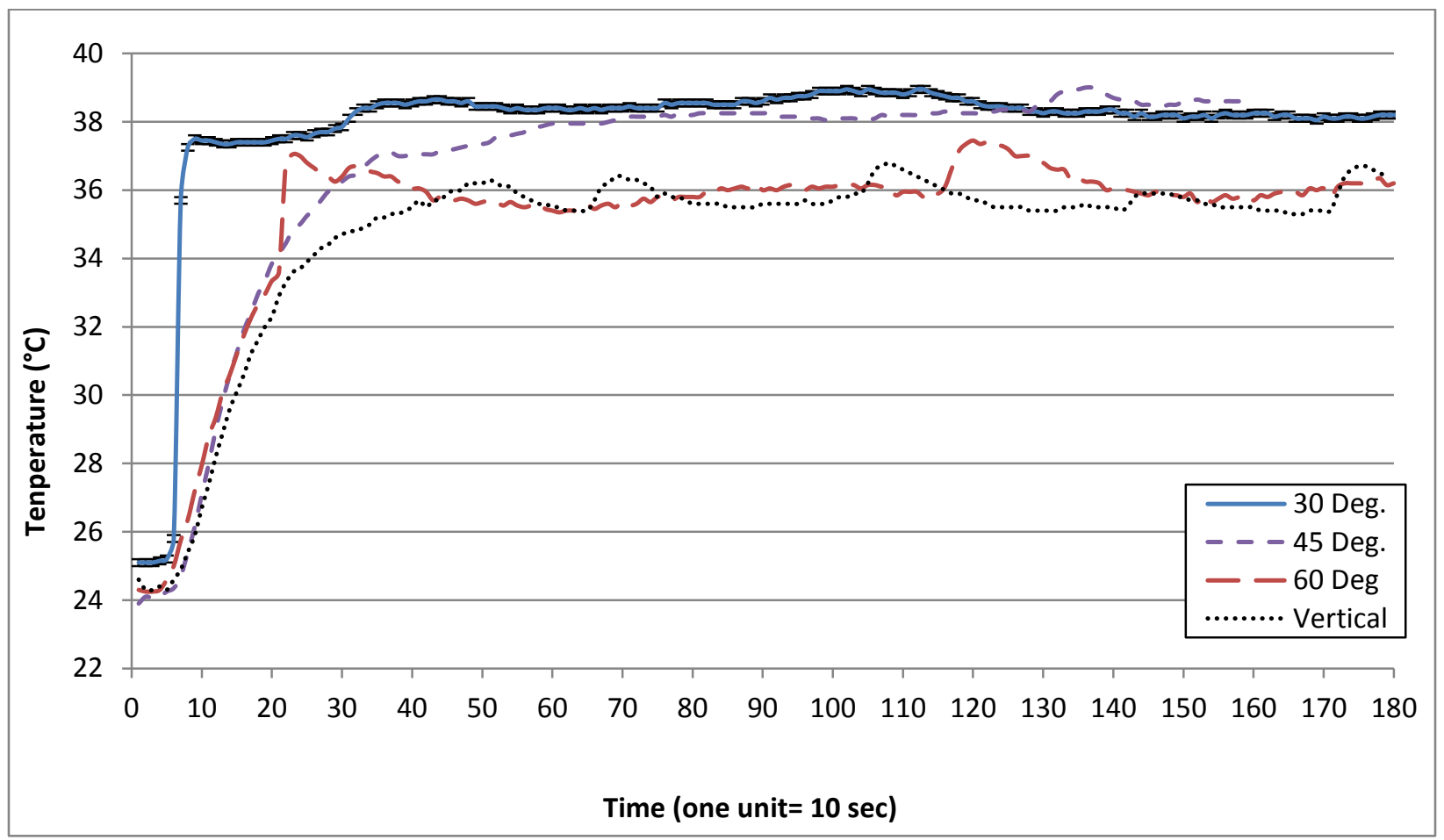

Figure 5-14: The average surface temperature (at the point $\mathrm{T} 1$ on Figure 5-5) of the condenser of the thermosyphon $\mathrm{V}$ with different inclination in constant heat bath temperature of $50^{\circ} \mathrm{C}$ 


\subsubsection{Experiment conduction}

This is the step by step operation to conduct the experiment:

1. Solder the copper plate $(10 \mathrm{~cm}$ by $20 \mathrm{~cm})$ to the evaporator end of the thermosyphon.

2. Construct the Plexiglas container as per blue print submitted to the shop. The plates have already been cut and are ready to assemble.

3. Connect rotameter to the container as per Figure 5-15.

4. Provide drain to the container as per Figure 5-15.

5. Connect the Plexiglas container to the condenser section of the thermosyphon.

6. Lay the electrical heater (KH-408) on the copper plat. Make sure about complete contact of right side of the heater and the copper plate!

7. Connect the electrical heater to the power supply (hp 6228B) using proper length of wirings, as the whole heater shall be covered by insulator/blanket completely. Make sure the power supply is off!

8. Connect the assembly from adiabatic section to a stand. Secure the thermosyphon as vertical as possible. The contact materials should be thermally insulated.

9. Add water to the Plexiglas container by opening the rotameter.

10. Check the container for any leakage. No leakage is accepted!

11. When the water starts to drain, close the rotameter. At this time, 2.68 liter water is in the container at 45 degree inclination).

12. Connect the sensors of the High Accuracy Digital Thermometer (DP97), both of them, to the water in and out of the container and fix them securely. Check the temperature to make sure all connections are right. Turn off the DP97.

13. Connect four sensors of the HH147U to the A, B, C, and D point (see Figure 5-15) and secure them with glue or tape. Loose contact gives wrong readings! Check the readings once, and disconnect the sensors from the data collector (HH147U).

14. Cover all assembly with thermal insulator. Rotameter and end of sensor wires shall be accessible.

15. Connect the electric resistor to the power supply and load it to $50 \mathrm{~V}$.

16. Increase the current slightly until reading is $0.5 \mathrm{~A}$.

17. Start monitoring the temperatures using DP97 and HH147U. 
18. As soon as the water temperature start increasing, open the rotameter as slow as possible to get the delta $\mathrm{T}$ of about $2^{\circ} \mathrm{C}$.

19. Record details on experiment log sheet.

20. Repeat number 8 to 19 for different thermosyphon angles (e.g., 30 and 45 degree) with respect to horizon.

\subsubsection{Rotameter calibration}

To pay less money for measuring water flow in the condenser section (Figure 5-15), a conventional 0.4-5 GPH (0.0252-0.3154 lit/min) rotameter was purchased. Each US GPH (gallon per hour) is about 0.0631 liter per minute (lit/min). A stopwatch and accurate measuring flask are used to calibrate it. The rotameter is adjusted at different readings (see column one of Table 5-5). At specific time, which stop-watch started to read, drain is collected into a dry flask. Flask is removed and water volume was recorded one minute after. The readings are repeated 8 times for each flow rate. Finally, the uncertainty of the rotameter reading is calculated and recorded in Table 5-6.

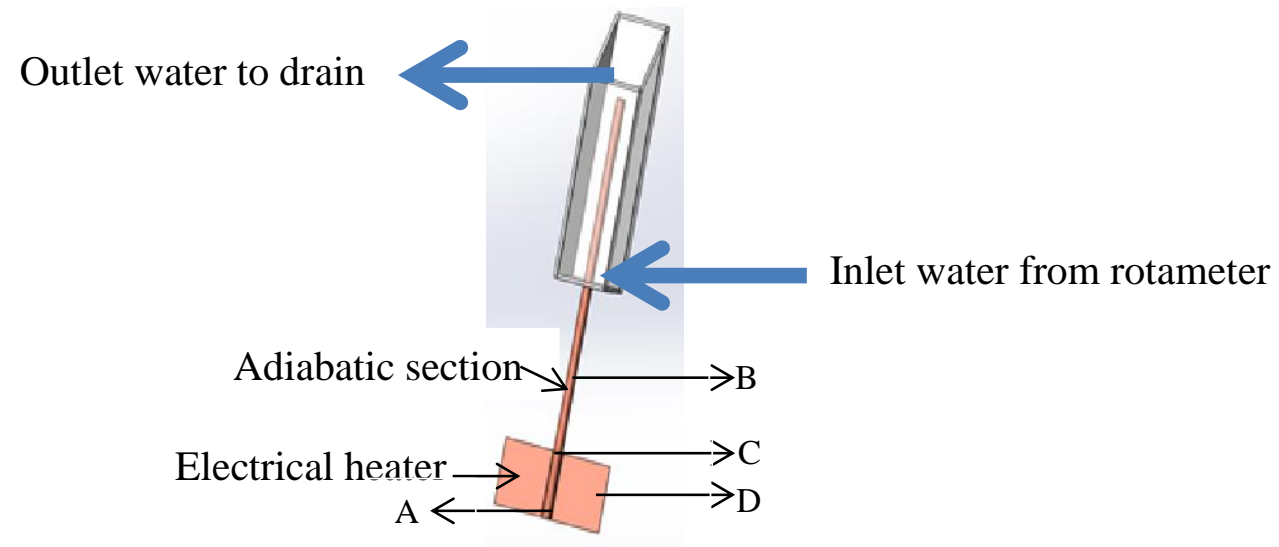

Figure 5-15: Experiment configuration, which shows electrical heat and data logger sensors (A to D) mounting

Uncertainty of the measurement $\left(U_{D}\right)$, in liter per minute, was calculated based on estimation of uncertainty of the flask reading $(\mathrm{dV}=1 \mathrm{cc})$ and stop watch $(\mathrm{dt}=1 \mathrm{~s}=0.015 \mathrm{~min})$. As the parameters are independent, the measurement uncertainty was determined by using the Law of Propagation of Uncertainty: 


$$
\mathrm{U}_{\mathrm{D}}=\left[\left(\frac{\partial D}{\partial t} d t\right)^{2}+\left(\frac{\partial D}{\partial v} d V\right)^{2}\right]^{1 / 2}
$$

Table 5-5: The summary of rotameter calibration results

\begin{tabular}{|c|c|c|c|c|c|c|c|c|c|c|}
\hline $\begin{array}{c}\text { Rotameter } \\
\text { Reading }\end{array}$ & \multicolumn{7}{c|}{ Measured water volume (cc/min) } & \multicolumn{1}{c|}{ Ave. } & SD \\
$(\mathrm{cc} / \mathrm{m})$ & $(\mathrm{cc} / \mathrm{m}) / \%$ \\
\hline $1 \mathrm{GPH}(63.1 \mathrm{cc} / \mathrm{m})$ & 60 & 62 & 63 & 62 & 64 & 64 & 63 & 63 & 62.6 & $1.3 / 2.1$ \\
\hline 2GPH $(126.2 \mathrm{cc} / \mathrm{m})$ & 126 & 123 & 127 & 120 & 121 & 123 & 122 & 125 & 123.4 & $2.4 / 1.9$ \\
\hline $3 \mathrm{GPH}(189.3 \mathrm{cc} / \mathrm{m})$ & 180 & 185 & 183 & 184 & 185 & 188 & 186 & 187 & 184.8 & $2.5 / 1.3$ \\
\hline $4 \mathrm{GPH}(252.4 \mathrm{cc} / \mathrm{m})$ & 250 & 252 & 251 & 253 & 254 & 248 & 249 & 250 & 250.9 & $2.0 / 0.8$ \\
\hline $5 \mathrm{GPH}(315.5 \mathrm{cc} / \mathrm{m})$ & 325 & 320 & 315 & 314 & 318 & 319 & 320 & 310 & 317.6 & $4.6 / 1.4$ \\
\hline
\end{tabular}

$\mathrm{D}=\mathrm{V} / \mathrm{t}$; therefore, $\frac{\partial D}{\partial t}=V / t^{2}$ and $\frac{\partial D}{\partial V}=1 / t$. Substituting the values in Equation (5-5), the uncertainty of the rotameter can be calculated. It is found to be $0.0011 \mathrm{lit} / \mathrm{min}$. The table shows that the rotameter reads very well at $4 \mathrm{GPH}$ and the next good one is $5 \mathrm{GPH}$. The percentage of standard deviation (SD) is calculated by dividing the SD to the reading value (column 1 of the Table 5-5) multiplied by 100. The average (Ave.) of 8 measurements is recorded in column 10.

Figure 5-16 shows the calibration curve/plot of the rotameter and error bars (horizontal and vertical). Horizontal error bars (green color) are fixed to $0.1 \mathrm{GPH}(63.1 \mathrm{cc} / \mathrm{min})$ because the discrimination on rotameter was engraved to show 0.2 GPH (see Figure 5-4). Vertical error bars (red color) demonstrate the data on the last column of Table 5-5. It is clear that the working range of 244-248 cubic centimeters per minute (4 GPH) provides the least error.

Table 5-6 shows the values used to calculate the uncertainty of the rotameter.

Table 5-6: The summary of the values and uncertainty of the rotameter

\begin{tabular}{|l|c|c|c|c|c|c|}
\hline $\mathrm{V}(\mathrm{l})$ & $\mathrm{T}(\mathrm{min})$ & $\mathrm{dv}(\mathrm{cc})$ & $\mathrm{dt}(\min )$ & $\frac{\partial D}{\partial v} d v$ & $\frac{\partial D}{\partial t} d t$ & $\mathrm{U}_{\mathrm{D}}(\mathrm{cc} / \mathrm{min})$ \\
\hline 0.287 & 1 & 1 & 0.0015 & 0.001 & 0.000431 & 1.089 \\
\hline
\end{tabular}




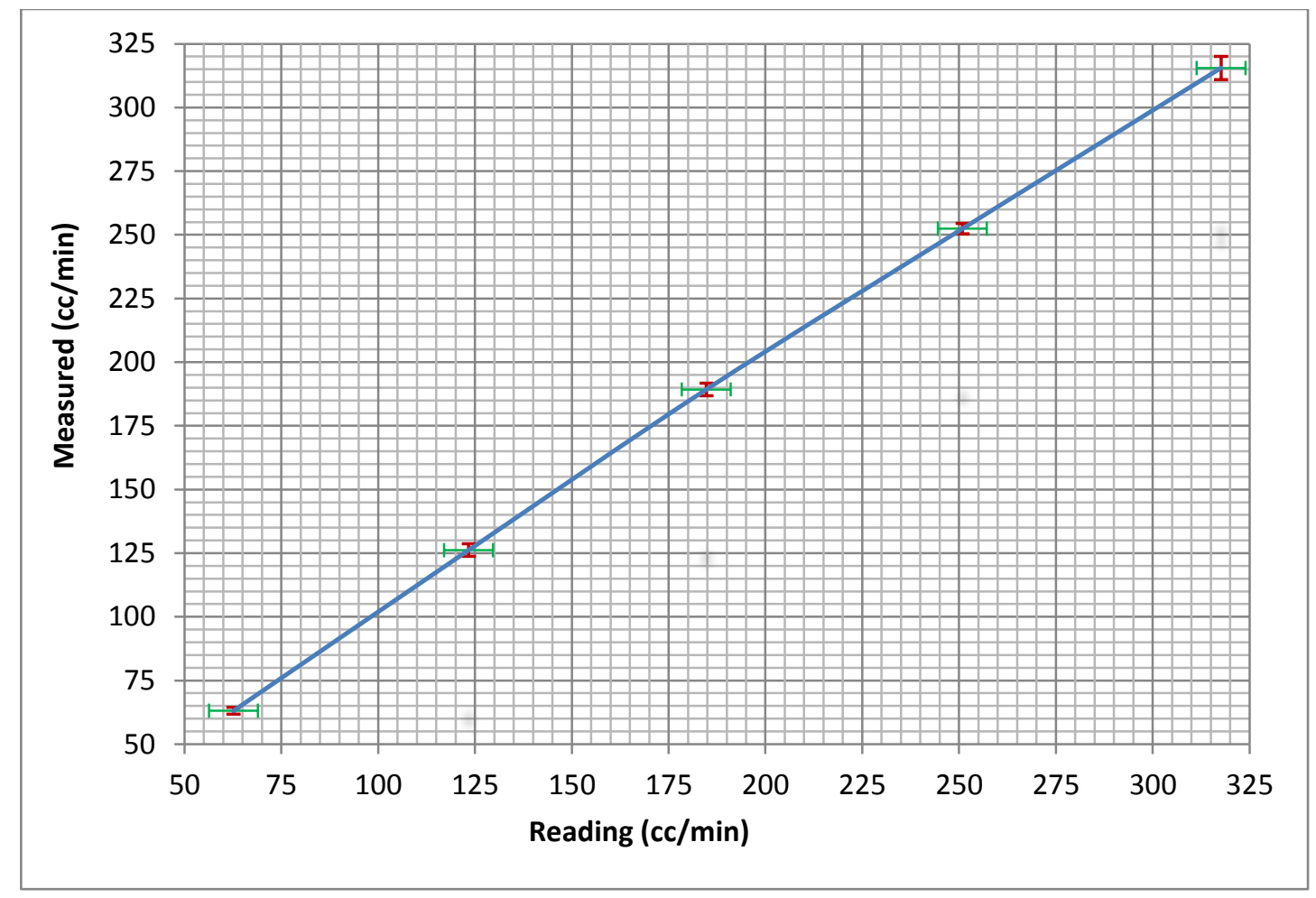

Figure 5-16: Calibration curve for the rotameter

\subsection{Results}

A copper sheet $(10 \mathrm{~cm} \times 21 \mathrm{~cm} \times 1.55 \mathrm{~mm})$ was soldered along evaporator section as shown in Figure 5-17. Points T1 to T4 are also shown on the figure. These are the points, which will be connected with sensors to monitor their temperatures after the performance of the thermosyphon is accepted. To check the performance of this soldered thermosyphon, another test was conducted and temperature of the point T1 (see Figure 5-5) was monitored. Clearly, in steady state condition (after 750 seconds), both (with and without copper sheet) thermosyphons perform similar; while evaporator is kept at $40^{\circ} \mathrm{C}$ (see Figure 5-18). Plot "with $\mathrm{Cu}$ sheet" on Figure 5-18 shows slight reduction in temperature at 670 seconds. This may be due to contact resistant between the sensor and the copper surface. The sensors were secured on the surface using tape. Normally, the temperature should increase continuously towards $40^{\circ} \mathrm{C}$ (vapour/heat bath temperature). 


\subsection{Summary and discussion}

Back to Figure 5-17 and instruction in Section 5.2.4, sensors are connected to the points T1 to T4. The TDP was adjusted at 45 degree. At first try/run, sensor T1 was attached at the point 215 $\mathrm{mm}$ above the copper sheet edge (point A on Figure 5-15). It was possible to reach steady state condition after 165 minutes (see Figure 5-19). The condition was ended after 200 minutes. The flow was adjusted on $3 \mathrm{GPH}$, but it had been fluctuating irregularly. Clearly, $\Delta T$ (difference between input water temperature and drain from container) was not found fixed either. Although input power to evaporator was fixed to $22.5 \mathrm{~W}(\vartheta=30$ Volt and $\mathrm{I}=0.75$ Ampere), it was impossible to calculate the output power taken by water from the condenser. Maximum error bars $\left(0.5^{\circ} \mathrm{C}\right)$ are shown on the T4 plot on Figure 5-19.

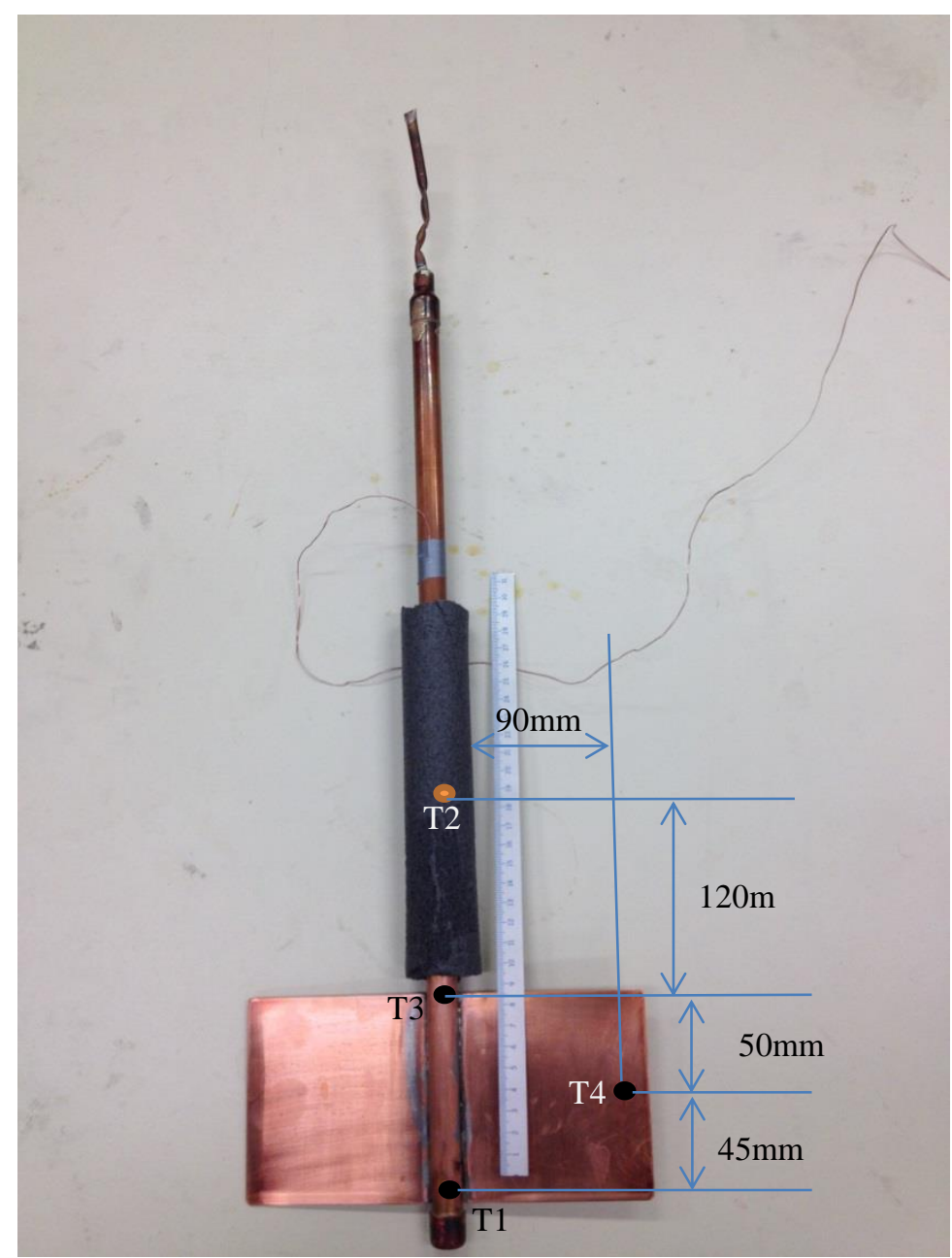

Figure 5-17: Thermosyphon III after soldering a copper sheet $(10 \mathrm{~cm} \times 21 \mathrm{~cm} \times 1.55 \mathrm{~mm})$ on its evaporator. Electrical heater is attached evenly on this copper sheet to simulate solar radiation 


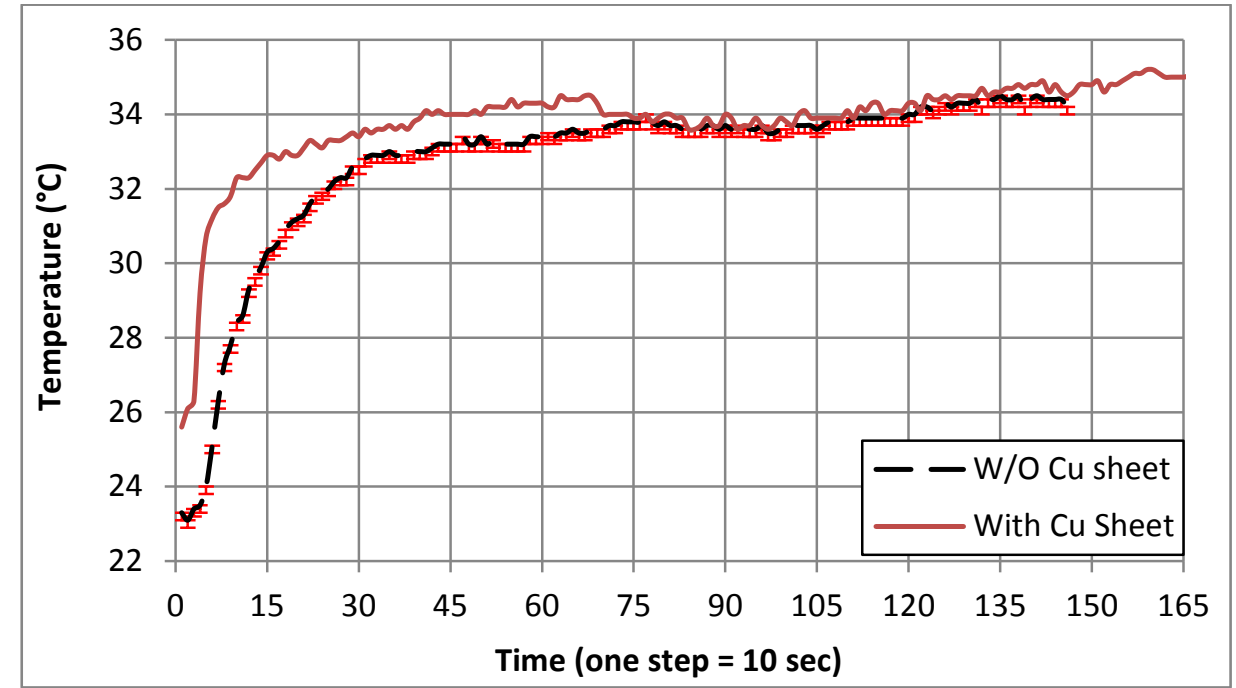

Figure 5-18: Transient temperature of the thermosyphon III at point $T 1$ with and without attaching/soldering copper sheet in constant heat bath temperature of $40^{\circ} \mathrm{C}$

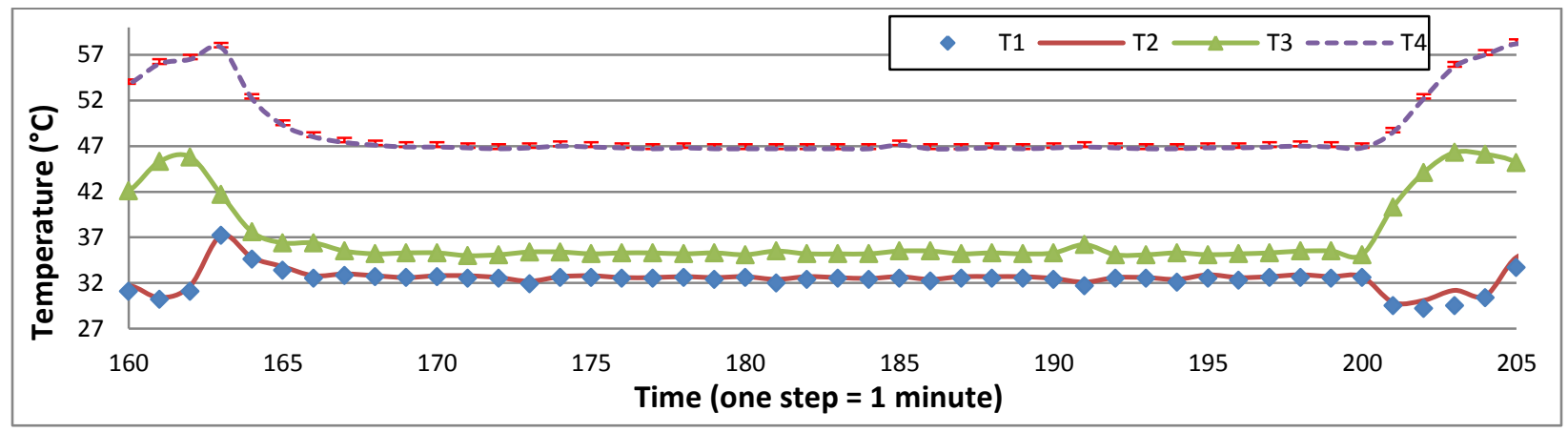

Figure 5-19: Transient temperatures of the points T1 to T4 (run 1, 45 degree)

In the first run, it was noticed that $\mathrm{T} 1$ and $\mathrm{T} 2$ have same temperature; therefore, as Figure 5-17 shows, the location of the point T1 was changed. In the new arrangement, two points on top of the evaporator, one point on the copper plate surface, and one point on the adiabatic section were monitored. Moreover, monitoring input water temperature showed that it was kept changing. It changed from 14 to $20^{\circ} \mathrm{C}$ within one hour!

In the second run, flow and $\Delta T$ was recorded manually at different time. $\Delta T$ was measured by accurate thermometer, DP97 (see Figure 5-4) and flow was measure by rotameter in GPH. The average of flow and $\Delta T$ was calculated using the following formula: 


$$
\bar{P}=\frac{\int P d t}{\int d t}
$$

$\bar{P}$, in the above equation, can be flow $(\overline{\dot{m}})$ or temperature difference $\overline{\Delta T}$. The denominator is 92 minutes. Adapting appropriate conversion, average values for flow and $\Delta T$ is calculated as $231.41 \mathrm{~g} / \mathrm{min}$ and $1.39^{\circ} \mathrm{C}$, respectively. Finally, average heat output $(\overline{\dot{m}} C \overline{\Delta T})$ would be $22.43 \mathrm{~W}$. Using Equation (5-5), uncertainty of this calculation is about $6.2 \mathrm{~W}$. The input power is $22.5 \mathrm{~W}$ $(30 \times 0.75)$. Although test results make sense, but there is no conclusive value for heat loss unless the uncertainty is ignored!

To find a better way to calculate power transferred across thermosyphon, last column of Table 57 data are investigated. The average and standard deviation are 22.32 and 13.65, respectively. Clearly, the highlighted numbers are outliers (three from the highest and three from lowest values). Excluding outliers, the power output would be $17.39 \pm 4.17 \mathrm{~W}$ for this run.

The start and end time of recording data, which are given in Table 5-7, was 2:13pm and 3:45pm, respectively. Figure 5-20 shows the temperature of the points T1 to T4 during that time. It is clear that the condition was not in steady state either. Any increase in adiabatic temperature (T2) accompanies with decrease in temperature of the evaporator section (T1 and T3), because at this moment, water boils and takes heat from the evaporator to accommodate the boiling process.

The flow of water and temperature difference were planned to monitor at 10 minutes interval, as it was not possible to control them. Water flow and its temperature were changing due to the city water pressure change. In the $3^{\text {rd }}$ run, flow was found constant (4.6 GPH, $290.26 \mathrm{~g} / \mathrm{min}$ ). Due to high uncertainty of the rotameter reading $(0.1 \mathrm{GPH}, 63.1 \mathrm{~g} / \mathrm{min})$, the uncertainty was found to be same as other runs (6.2 W for $\dot{\mathrm{Q}})$. The heater supplied $22.5 \mathrm{~W}$ of power. Using same method employed for run 2, the power transmitted by thermosyphon was calculated $22.72 \pm 3.19 \mathrm{~W}$. It was noticed that sometimes water inlet temperature was higher than condenser surface temperature! This could be one reason that output power was found higher than input power from the electrical heater (evaporator). Figure 5-21 shows the temperatures of points T1 to T4 after 5000 second start of the run. At 5020 second, water inside the evaporator was boiled; therefore, temperature of the adiabatic section (T2) increased and evaporator temperature (T1 \& T3) decreased. At 5660, condensed water was coming back to evaporator and the water pool increased its temperature. 
Table 5-7: The record of flow and $\Delta T$ at different time

\begin{tabular}{|c|c|c|c|c|c|}
\hline Flow (GPH) & $\Delta T\left({ }^{\circ} \mathrm{C}\right)$ & $t(\min )$ & flow*t & $\Delta T * \mathrm{t}$ & $\dot{Q}$ \\
\hline 2.4 & 1.37 & 0 & & & \\
\hline 3 & 1.35 & 7 & 21 & 9.45 & 17.83 \\
\hline 4 & 1.37 & 5 & 20 & 6.85 & 24.12 \\
\hline 3.8 & 1.37 & 6 & 22.8 & 8.22 & 22.92 \\
\hline 3.5 & 0.70 & 4 & 14 & 2.8 & 10.79 \\
\hline 3.2 & 1.15 & 8 & 25.6 & 9.2 & 16.20 \\
\hline 3.4 & 2.91 & 4 & 13.6 & 11.64 & 43.56 \\
\hline 3.8 & 2.91 & 8 & 30.4 & 23.28 & 48.68 \\
\hline 3.8 & 1.35 & 10 & 38 & 13.5 & 22.58 \\
\hline 3.8 & 1.35 & 8 & 30.4 & 10.8 & 22.58 \\
\hline 3.8 & 0.72 & 10 & 38 & 7.2 & 12.04 \\
\hline 3.8 & 1.13 & 8 & 30.4 & 9.04 & 18.90 \\
\hline 3.8 & 2.71 & 4 & 15.2 & 10.84 & 45.33 \\
\hline 3.8 & 0.65 & 6 & 22.8 & 3.9 & 10.87 \\
\hline 3.8 & 0.28 & 4 & 15.2 & 1.12 & 4.68 \\
\hline \multicolumn{3}{|c|}{ Summation } & 337.4 & 127.84 & \\
\hline
\end{tabular}

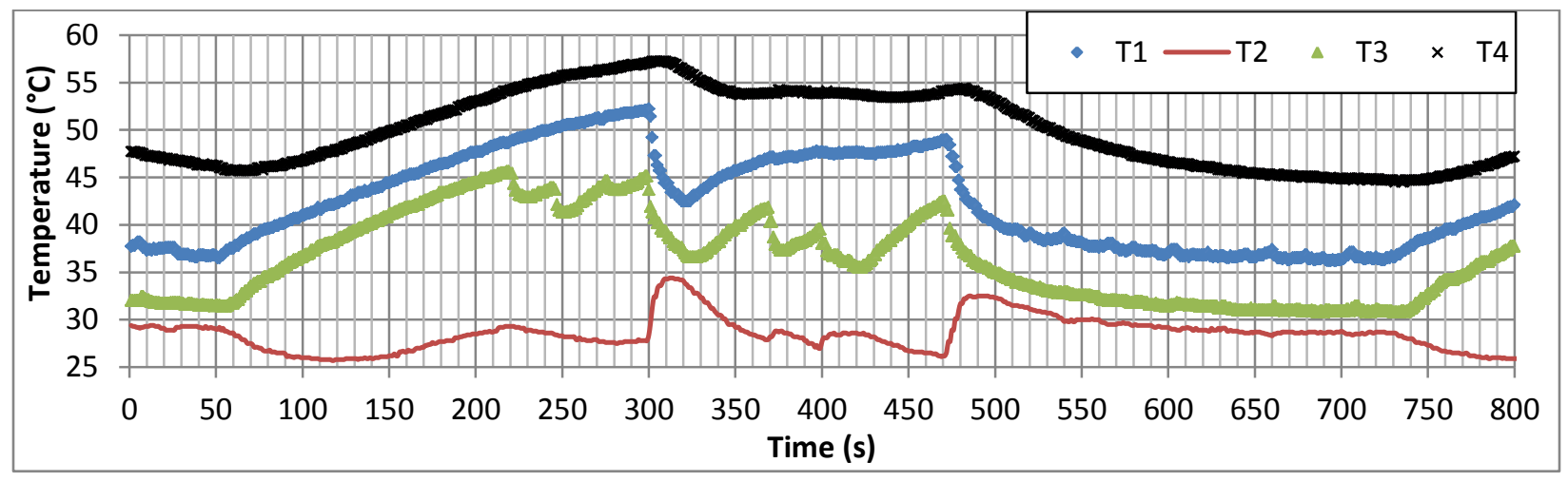

Figure 5-20: Transient temperatures of the points T1 to T4 (run 2, 45 degree) 


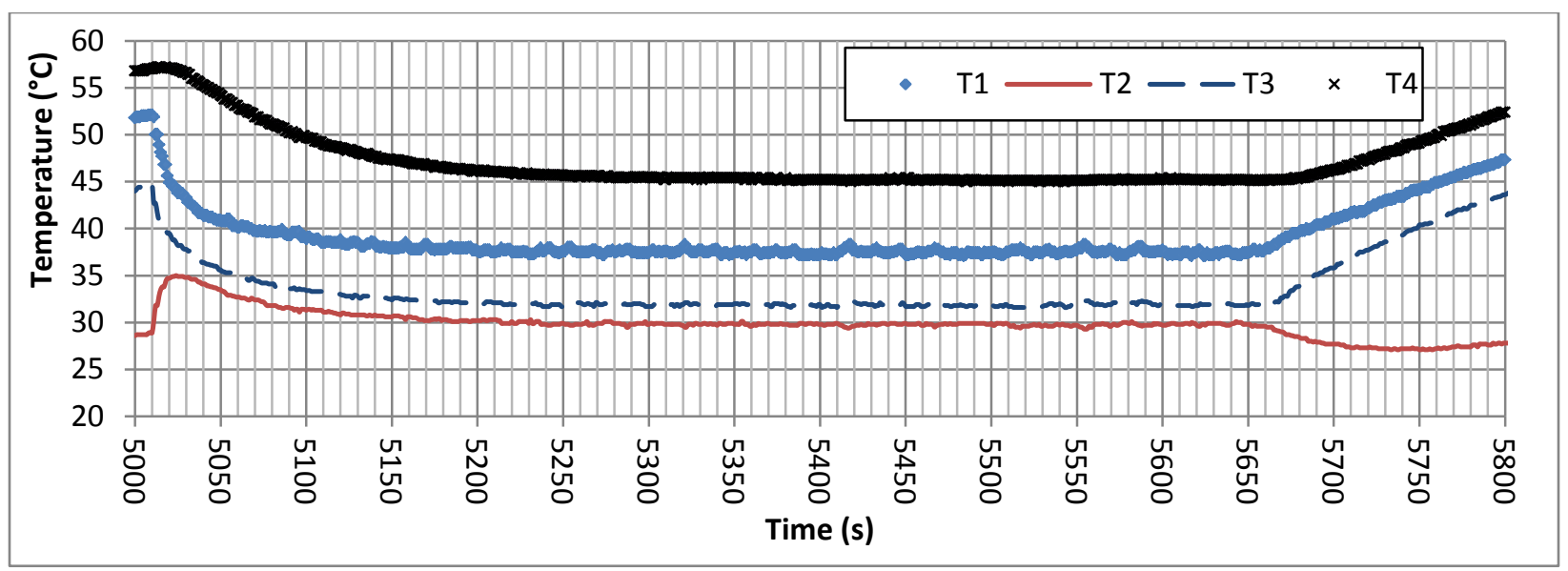

Figure 5-21: Transient temperatures of the points T1 to T4 (run 3, 45 degree)

In this condition (i.e., heat flux of $1125 \mathrm{~W} / \mathrm{m}^{2}$ and 45 degree thermosyphon angle), it takes about 190 seconds, 3.17 minutes, (bending point of $\mathrm{T} 3$ and passing $40^{\circ} \mathrm{C}$ for $\mathrm{T} 1$ point in Figure 5-22) to start transferring solar radiation, by boiling, into the building envelope.

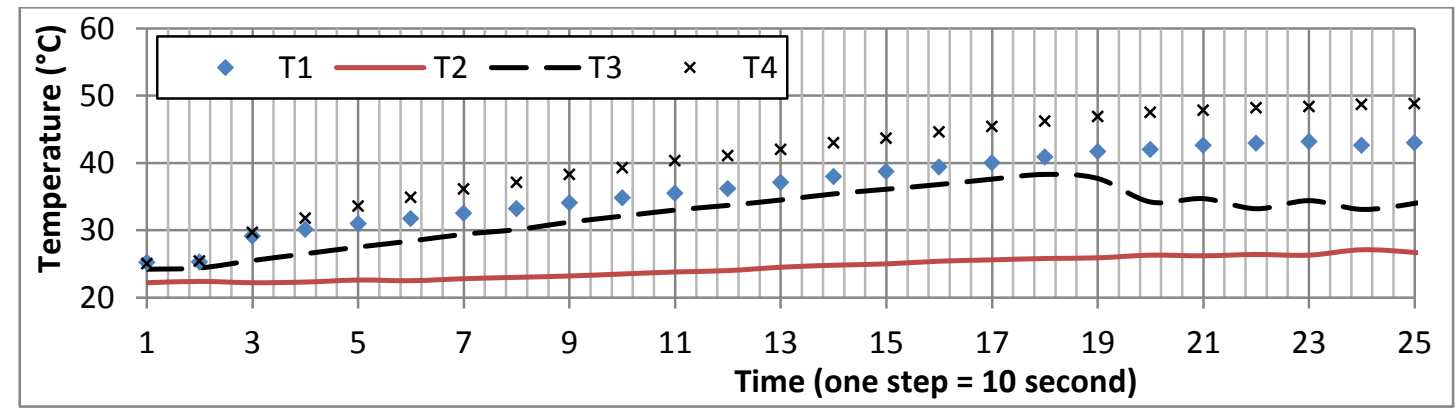

Figure 5-22: Transient temperatures of the points T1 to T4 (run 3, 45 degree) before water flow starts

Temperature of the point T3 is a good indicator of the boiling time inside the evaporator. When T3 point temperature is reduced, water boils and takes heat from the system. Boiling is an endothermic reaction/process; therefore, temperature of the evaporator goes down abruptly during the process. T1 and T3 are points on the evaporator. T1 is attached to the water pool and T3 is located on the point where water vapour (gas) passes the evaporator. Since gas has much lower specific heat capacity than water, a sharp drop in T3 temperature is noticed at the boiling 
point. At the moment that T3 temperature drops (see also Figure 5-23), T1 shows the boiling temperature. In the above case ( 45 degree), water boils at $41.7^{\circ} \mathrm{C}$.

To investigate the effect of angle on boiling process, temperature of the point T3 was monitored at different angles. Figure 5-23 shows the results of monitoring the point T3 temperature without water flow at the condenser container. The start of boiling varies between 160 seconds (in the vertical condition) and 220 seconds (in 30 and 60 degree conditions). The boiling time is 180 and 190 seconds at 35 and 45 degree, respectively. The corresponding boiling temperatures (on point T1) were found to be $43.8^{\circ} \mathrm{C}, 40^{\circ} \mathrm{C}, 41.7^{\circ} \mathrm{C}, 44.2^{\circ} \mathrm{C}$, and $37.9^{\circ} \mathrm{C}$ at $30,35,45,60$, and 90 degree respectively. Recalling calibration records (Table $5-2), 0.5^{\circ} \mathrm{C}$ should be added to above readings to get the accurate boiling temperature at each conditions. Clearly, by increasing the heat flux boiling starts faster/earlier. Different angle positions were tested under $1125 \mathrm{~W} / \mathrm{m}^{2}$ heat flux. The vertical position is found to boil the fastest of all in 120 seconds. The temperature of the 60 degree position reaches as high as $44^{\circ} \mathrm{C}$ before a new boiling occurs. It is not possible to find a constant value for frequency and amplitude of the boiling process in each position.

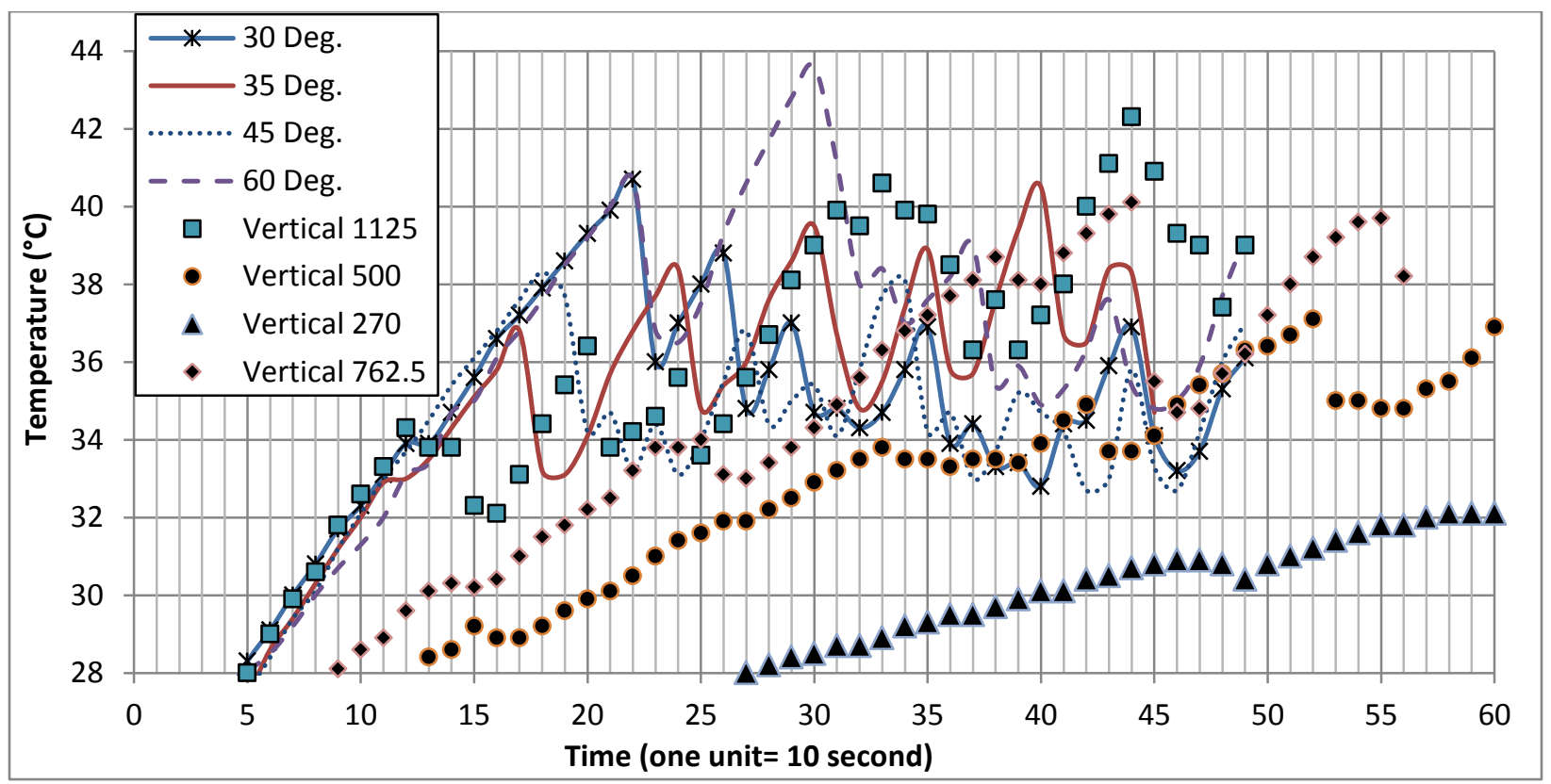

Figure 5-23: Transient temperatures of the point $\mathrm{T} 3$ at different angles and heat fluxes 
The following table summarizes the information at each inclination angle. Maximum temperature across thermosyphon is the difference between T1 and T2.

Table 5-8: The summary of calculated power transferred and maximum temperature difference across

\begin{tabular}{|c|c|c|c|c|}
\multicolumn{5}{|c}{ thermosyphon } \\
\hline Inclination (Deg.) & 35 & 45 & 60 & 90 \\
\hline Power output $(\mathrm{W})$ & $20.43 \pm 6.90$ & $22.72 \pm 3.19$ & $19.48 \pm 5.17$ & $21.27 \pm 3.78$ \\
\hline $\mathrm{T} 1-\mathrm{T} 2\left({ }^{\circ} \mathrm{C}\right)$ & $27.5 \pm 6.90$ & $23.7 \pm 5.45$ & $24.6 \pm 3.45$ & $19.5 \pm 3.52$ \\
\hline
\end{tabular}

The arithmetic average of the values in Table 5-8 is $20.88 \mathrm{~W}$; therefore, about $1.52 \mathrm{~W}$ (22.520.52) was lost. It translates about $6.8 \%$ of input power.

The average maximum temperature of $6^{\circ} \mathrm{C}$ is reported in the literature [76]. This temperature was found to be above $20^{\circ} \mathrm{C}$. This could be partly due to the direct contact of electrical heater on point $\mathrm{T} 1$ (4 to $5^{\circ} \mathrm{C}$ maximum). The other reason goes to the fact that inlet water flow and temperature had been fluctuating during the experiment. The container has 2.7 liters capacity. It takes about 10 minutes (with flow of $4.5 \mathrm{GPH}$ ) for container to get back to steady state each time that inlet water temperature changes. Any measurement in these 10 minutes is not valid. Unfortunately, the data logger could monitor only four channels; therefore, inlet temperature was monitored manually, which might be recorded incorrectly.

Complete plots of all runs are attached in the Appendix B.

\subsection{Conclusions}

Performance of the TDP at different inclination of thermosyphon was investigated under the following conditions:

- Vertically mounted with heat flux range from 270 to $1125 \mathrm{~W} / \mathrm{m}^{2}$.

- Heat flux of $1125 \mathrm{~W} / \mathrm{m}^{2}$ with $30,35,45$, and 60 degree angle.

It takes between 160 and 220 seconds, without flowing water on the condenser, to transfer heat from outdoor to indoor by the TDP. The maximum temperature of $6.4^{\circ} \mathrm{C}$ across the thermosyphon is recorded, while it is transferring heat from evaporator to condenser. It is mentioned in the literature that the maximum temperature difference of $6^{\circ} \mathrm{C}$ can be attained. 


\section{Conclusion and future works}

This chapter includes two separate sections. At first, concluding remarks are stated. As this work is a new start at CSES lab and technology is advanced, in the limited time span, it was not possible to come up with sound and comprehensive results. Therefore, a road map of future works is described for future research on this initiative.

\subsection{Conclusions}

The idea of integrating PCM with TDP was investigated. At first PCM thermal properties and their effects on indoor air temperature and energy demand of the building was analyzed. Then, performance of a thermosyphon experimentally investigated. Moreover, thermal resistance of the TDP was theoretically calculated. Performance of the TDP at different inclination of thermosyphon was assessed under different heat flux, from 270 to $1125 \mathrm{~W} / \mathrm{m}^{2}$. It takes between 160 and 220 seconds, without water flow on the condenser, for the TDP to transfer heat from outdoor to indoor at different angle (from 30 to 90 degree) under $1125 \mathrm{~W} / \mathrm{m}^{2}$ solar radiation. It takes between 120 and 640 seconds, without water flow on the condenser, for the TDP to transfer heat from outdoor to indoor at different solar radiation (from 270 to $1125 \mathrm{~W} / \mathrm{m}^{2}$ ) under vertical condition. Generally, frequency of boiling reduces by reducing the heat flux on the evaporator section. This is due to reduction of power; therefore, it takes time to heat up the evaporator to boil water again.

In summary dissertation contributions are:

- Parametric investigation of the PCM thermal properties on the energy demand and temperature fluctuations of buildings. The best melting range and thermal conductivity of the PCM were sought to make the lowest energy demand and peak power along with less IAT swing.

- The investigation of the effect of free convective heat transfer coefficient $(\mathrm{h})$ on the inside wall surfaces on the energy demands of the ASHRAE Standard 140-2001 (BESTEST), case 600, where two different thicknesses (one and ten millimeters) of PCM are applied on all of the wall and ceiling surfaces.

- The reduction of AHTF by $11 \%$ in mezzanine (SUI house) due to utilization of the PCM. 
- The integration of a typical thermodiode panel (TDP) with PCM to transfer solar energy directly into the indoor air in Toronto. The integration of TDP and PCM can do both, reduce the indoor temperature fluctuations and reduce the energy demand. The latter is due to the fast heat transfer performance of thermosyphon inside the TDP and the former is due to PCM properties. This is another initiative that help NZEB comes true and be affordable.

- The development of a Genetic Algorithm code (in Matlab) to optimize the dimensions of the TDP for Toronto weather conditions to gain maximum solar thermal energy on an annual basis. Matlab code is developed in the way that, by changing input files, the TDP sizes can be optimised for different weather conditions. The TDP sizes were optimized for two different objective functions.

- The reduction of the backward heat transfer (thermal bridging or TB) by 75 times in the current thermosyphon assembly. The TB is one of the main hindrances in using a TDP in cold climates.

- A new definition of thermal comfort indices. These indices represent thermal comfort quantitatively. For example: AHTF, RFI and TSI. The RFI is an indicator of the PCM effectiveness in reducing the temperature fluctuation of a zone. It is between 0 and 1 . The lower value indicates that the PCM reduces more the zone temperature fluctuation. The TSI shows the effect of any new change (e.g., adding PCM) in a zone temperature fluctuation with respect to that of the ambient. It is the ratio of the AHTF of the zone under the change to the AHTF of the ambient at the same time interval.

- The integration of the PCM with thermosyphon makes the TDP to collect and store thermal energy simultaneously. Conveniently, current initiatives either collect or store solar energy.

- Theoretical calculation of the thermal resistance of the TDP. The fin effects of the thermosyphon ends of both sides of the TDP are calculated.

\subsection{Future works}

The concept of using thermosyphon in buildings was investigated in Toronto weather conditions. TDP is now ready to be integrated with PCM. 
Ideally, the experiment should have been conducted on a vibration free table and controlled room. In a controlled room, the walls and external experiment (top of the blanket) surface temperatures can be monitored; therefore, it is not possible to measure loss (due to radiation, convection, and conduction) accurately.

At least two additional works can be done on the TDP: 1) the condenser can have annular fines to transfer heat faster by reducing the thermal resistance or enhancing the convection heat transfer around the condenser and 2) a glass vacuum can cover the evaporator to reduce the surface heat loss due to convection. This is a proven concept in glass sealed solar collectors.

The two main problems that increased the uncertainty of the experiment were related to inlet water temperature fluctuations and calibration of the rotameter. In future, it is suggested to use a constant temperature heat bath to supply water to cool the condenser and buy more accurate devices to measure the water flow. 


\section{Appendices}

Appendices are included Matlab codes and supportive figures.

\section{Appendix A}

\section{A.1 Matlab Codes}

\section{A.1.1 Surface temperature calculation}

\section{resitance.m}

clear $\frac{\circ}{0}$ This codes calculate total resistance of a TDP including PCM and radiation

tic

eps $=0.97$;

zigma $=5.67 e-8$;

Res=zeros;

$\mathrm{R}=$ zeros ;

$\mathrm{G}=0.1 ; \mathrm{H}=0.3 ; \circ$ wedth \& height of the TP $\mathrm{A}=\mathrm{G} * \mathrm{H}$;

\section{SurfaceTemp.m}

clear

tic

$i=0$;

$\mathrm{G}=0.1 ; \mathrm{H}=0.2 ;$ o wedth \& height of the $\mathrm{TP}$ $\mathrm{A}=\mathrm{G} * \mathrm{H}$;

$\mathrm{R}=22.20 ; \%$ When there is no PCM with Le=.17; La=.18; LC =.17; ri $=.007 ;$ ro $=.008$ $\operatorname{Tin}=273.15+10$; 


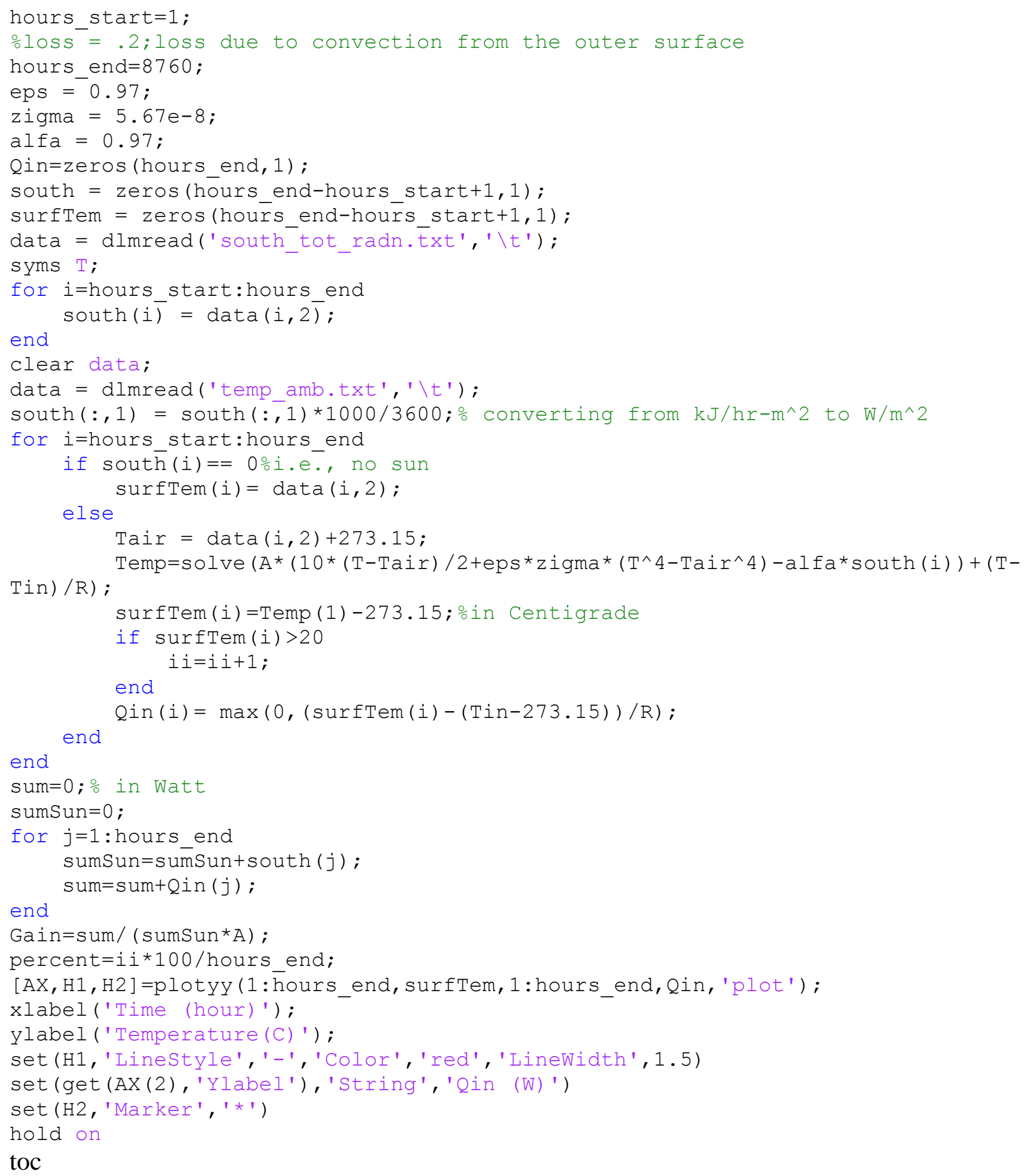

\section{A.1.2 Genetic algorithm codes}

\section{GeneticAlgorithm.m}

tic

clear main function

pop_size=input ('Population of group: (1 to 100, even) \n');

chromo size=5; o ('Number of variables: \n'); pop

generation_size=input ('Iteration number: (1 to 100) \n'); 


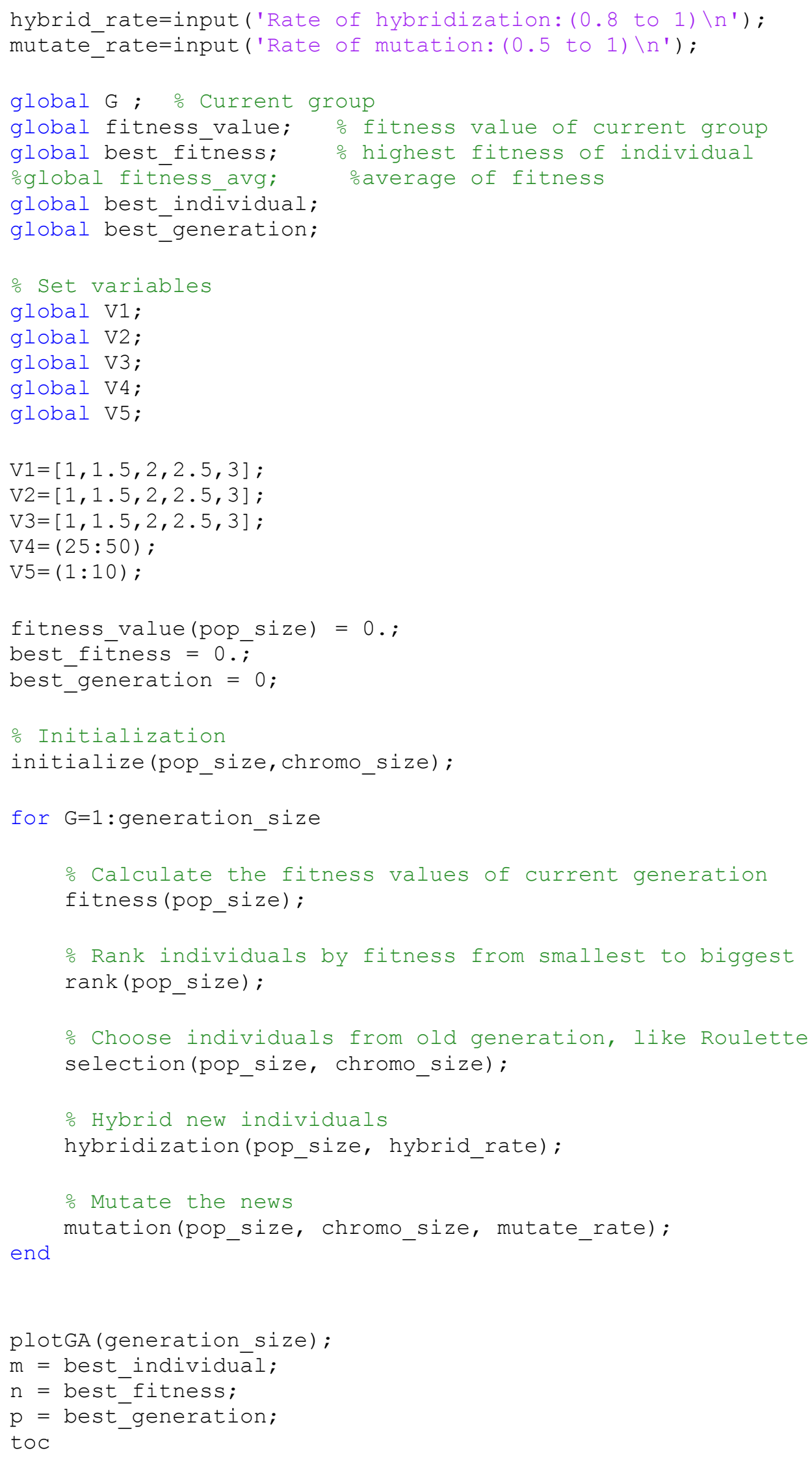




\section{diita_main.m}

function Q_in_avr=diita_main (x)

global q_sōlari;

global T_air;

global T_sky;

global T_in;

global Resistence;

load Tamb

load Qsun

load Tsky

$\mathrm{t} 1=\mathrm{x}(1) / 1000$;

$t 3=x(2) / 1000$;

$t 5=x(3) / 1000$;

$r i=x(4)-x(5)$;

save $x$;

r_o=x (4)/1000;

fíd=fopen ('Best. csv', 'a') ;

fprintf ( fid, ' $\% f \backslash t \% f \backslash t \% f \backslash t \% f \backslash t \% f \backslash t ', x)$;

$r$ i=r_i/1000;

R_o_p $=$ R_o_pos (t $\left.1, t 3, t 5, r \_0, r \_i\right)$;

$\mathrm{R} \circ \mathrm{n}=\mathrm{R} \circ \mathrm{neg}(\mathrm{t} 1, t 3, t 5, \mathrm{r} \circ, \mathrm{r} i)$;

$[\bar{t} \operatorname{pp} 1, \bar{c}]=\bar{s}$ ize (Tamb);

[tmp2, ] =size (Qsun);

[tmp3, ] =size (Tsky);

$\mathrm{M}=\min (\mathrm{tmp} 1, \mathrm{tmp} 2)$;

$\mathrm{N}=\min (\mathrm{M}, \mathrm{tmp} 3)$;

clear tmpl;

clear tmp2;

clear tmp3;

ㅇitialize

T in=293.15;

$\mathrm{R}^{-} \mathrm{i}=\mathrm{Cal} \mathrm{R}$ i

Resistence $=R \_O \_n+R \_i$;

Q_in_S $=0$; $\mathrm{nu}=0$;

$\mathrm{T}=\mathrm{Tamb}(1)$;

for $i i=1: N$

\% Get input value of air temperature and solar radiation

q_solar=Qsun (ii)/3.6;

$\mathrm{T}$ air=Tamb (ii);

T sky=Tsky (ii);

iff $\mathrm{T}>\mathrm{T}$ in

else

$\mathrm{R} \_\overline{\mathrm{O}}=\mathrm{R} \_\mathrm{O}-\mathrm{P}$;

$\mathrm{R} \_\mathrm{O}=\mathrm{R} \_\mathrm{O}_{-} \mathrm{n}$;

end

R i=Cal_R i;

Resistence $\overline{\bar{e}}=\mathrm{R}$ o+R i;

options=optimset ('Display', 'iter','TolFun',10e-15); Ootion to display output

$\mathrm{T} 0=293.15$;

$[\mathrm{T}, \sim]=$ fsolve (@gamma_T, TO, options); $\%$ Call solver

Q_in=(T-T_in)/Resistence;

if $(i i<65 \overline{5} 2$ \&\& ii>2881)

if $Q$ in $>0$ 


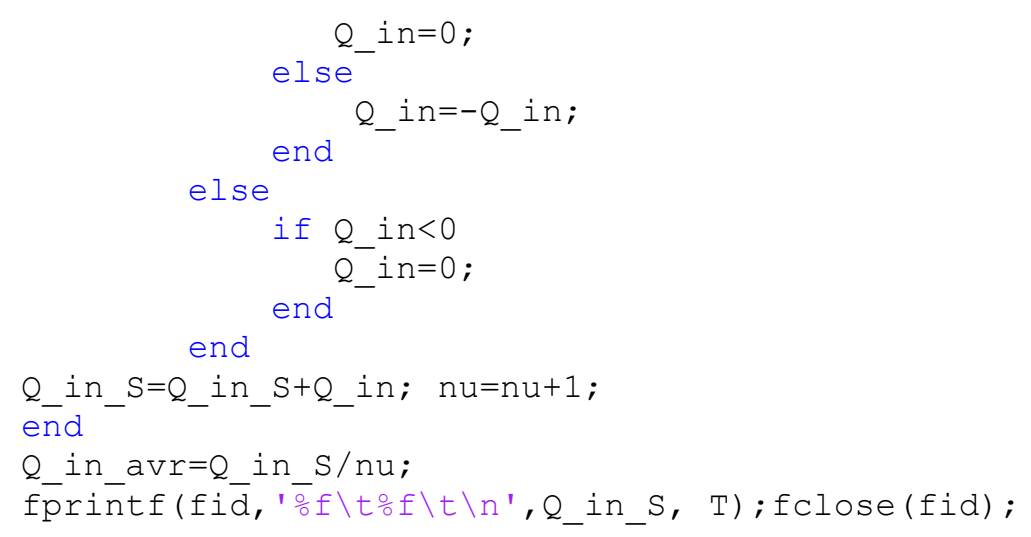

\section{Cal_R_i.m}

function R_i=Cal_R_i

\% The second (of two) resistence dependent on temperature.

global epsilon;

global sigma;

global A;

global T_in;

T_o=T_in-10;

h $i=2$.;

h_ri=epsilon*sigma* (T_o^2+T_in^2)*(T_o+T_in);

$\mathrm{R}^{-} i=1 . /\left(\mathrm{A}^{*}\left(\mathrm{~h} \_r i+\mathrm{h} \_i\right)\right) \bar{i}$

end

\section{fitness.m}

function fitness(pop_size)

global fitness_value;

global pop;

fitness_value=zeros (pop_size,1);

for $i=1: p o p \_s i z e$

fitness_value (i)=diita_main $(\operatorname{pop}(i,:))$;

end save pop;

clear i;

gamma_T.m

function $y=$ gamma_ $T(T) \div y=$ Qin

\%APH $T$ the equations group to get $T$ 


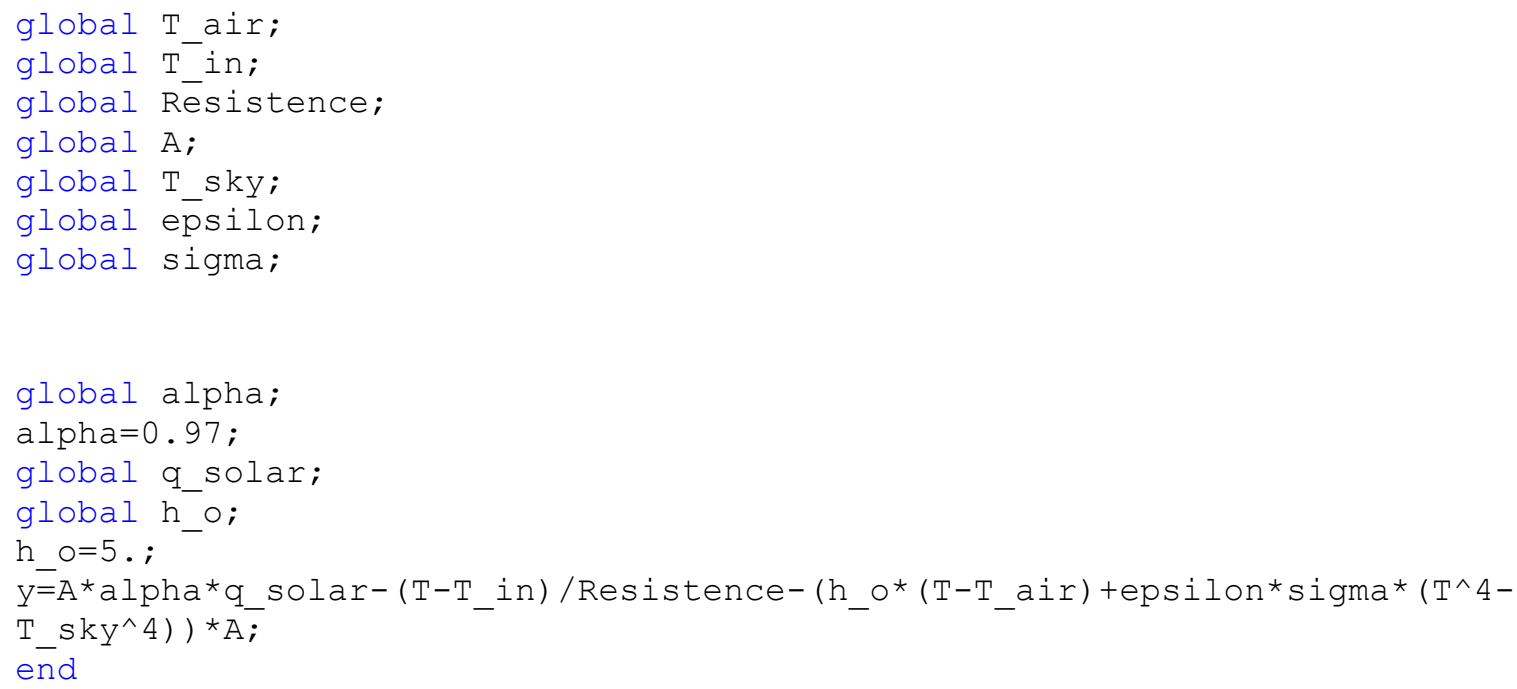

\section{hybridization.m}

function hybridization (pop_size, hybrid_rate)

global pop;

for $i=1: 2:$ pop_size

if (rand < hybrid_rate)

$\operatorname{tmp} 1=\operatorname{pop}(i, 2)$;

$\operatorname{tmp} 2=\operatorname{pop}(i, 4)$;

$\operatorname{pop}(i, 2)=\operatorname{pop}(i+1,2)$;

$\operatorname{pop}(i, 4)=\operatorname{pop}(i+1,4)$;

$\operatorname{pop}(i+1,2)=$ tmp 1 ;

$\operatorname{pop}(i+1,4)=\operatorname{tmp} 2$;

end

end

clear i;

clear tmpl;

clear tmp2;

\section{initialize.m}

function initialize(pop_size, chromo_size)

global V1;

global V2;

global V3;

global V4;

global V5;

for $\mathrm{nl}=1: 5$

$[\mathrm{wW}, \mathrm{mm}]=\operatorname{size}\left(\operatorname{eval}\left(\mathrm{C}^{\prime} \mathrm{V}\right.\right.$ ' $\left.\left.\left.\operatorname{num} 2 \operatorname{str}(\mathrm{n} 1)\right]\right)\right)$;

$\mathrm{V}=$ genvarname $\left(\left[\mathrm{size} \mathrm{V}^{\prime}\right.\right.$ num2str(n1)]);

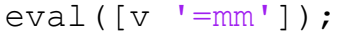

end

clear $\mathrm{n} 1$;

clear $v$;

global pop;

for $i=1:$ pop_size

for $j=1$ : chromo size

choose $=$ round $($ rand*eval (['size V' num2str(j)])); if $\operatorname{choose}==0$ 


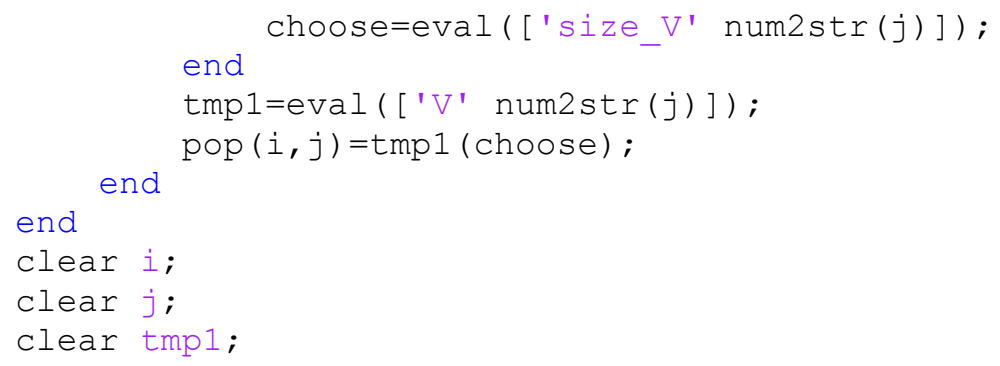

\section{mutation.m}

function mutation( pop_size, chromo_size, mutate_rate) global pop;

\section{plotGA.m}

function plotGA (generation_size)

global fitness_avg;

$\mathrm{x}=1: 1:$ generation_size;

$\mathrm{y}=$ fitness_avg;

plot $(x, y)$

xlabel ('Generation Size');

ylabel ('Average Fitness');

\section{R_o_neg.m}

function R_o=R_o_neg( $t 1, t 3, t 5, r_{-}, r_{-}$i) 


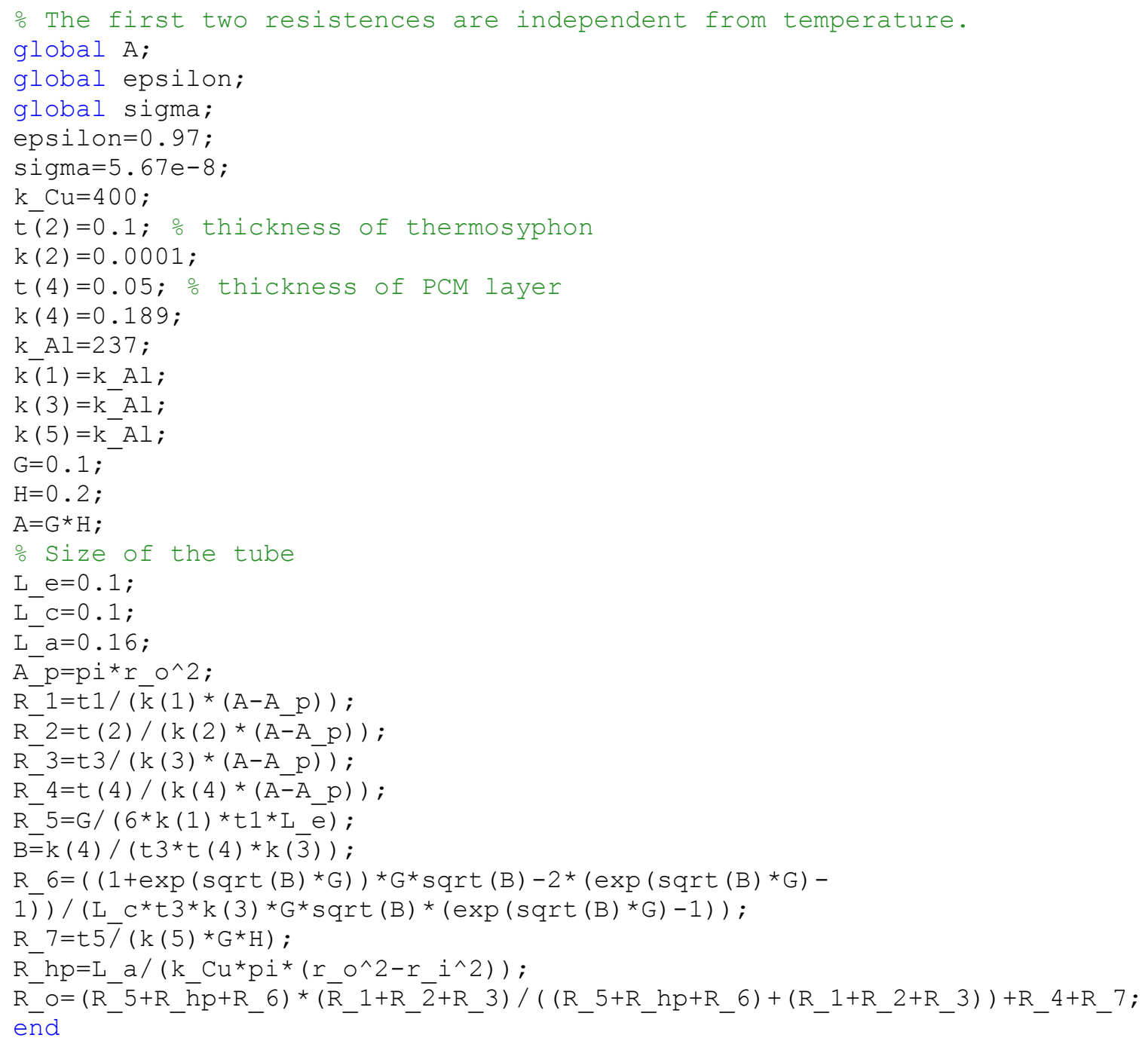

\section{R_o_pos.m}

function R_o=R_o_pos ( $\left.t 1, t 3, t 5, r_{-} o, r \_i\right)$

\% The first (o $\bar{f}$ two) resistence independent from temperature. global A;

global epsilon;

global sigma;

epsilon=0.97;

sigma $=5.67 e-8$;

k_Cu$=400$;

$t \overline{(}(2)=0.1$; $\frac{\circ}{\circ}$ thickness of the foam in the TDP

$\mathrm{k}(2)=0.0001$;

$t(4)=0.05 ;$ \% thickness of PCM layer

$\mathrm{k}(4)=0.189$;

$\mathrm{k} A \mathrm{Al}=237$;

$\mathrm{k}(1)=\mathrm{k} \_\mathrm{Al}$;

$\mathrm{k}(3)=\mathrm{k} A \mathrm{~A}$;

$\mathrm{k}(5)=\mathrm{k} A \mathrm{~A}$;

$\mathrm{G}=0.1$;

$\mathrm{H}=0.2$; 


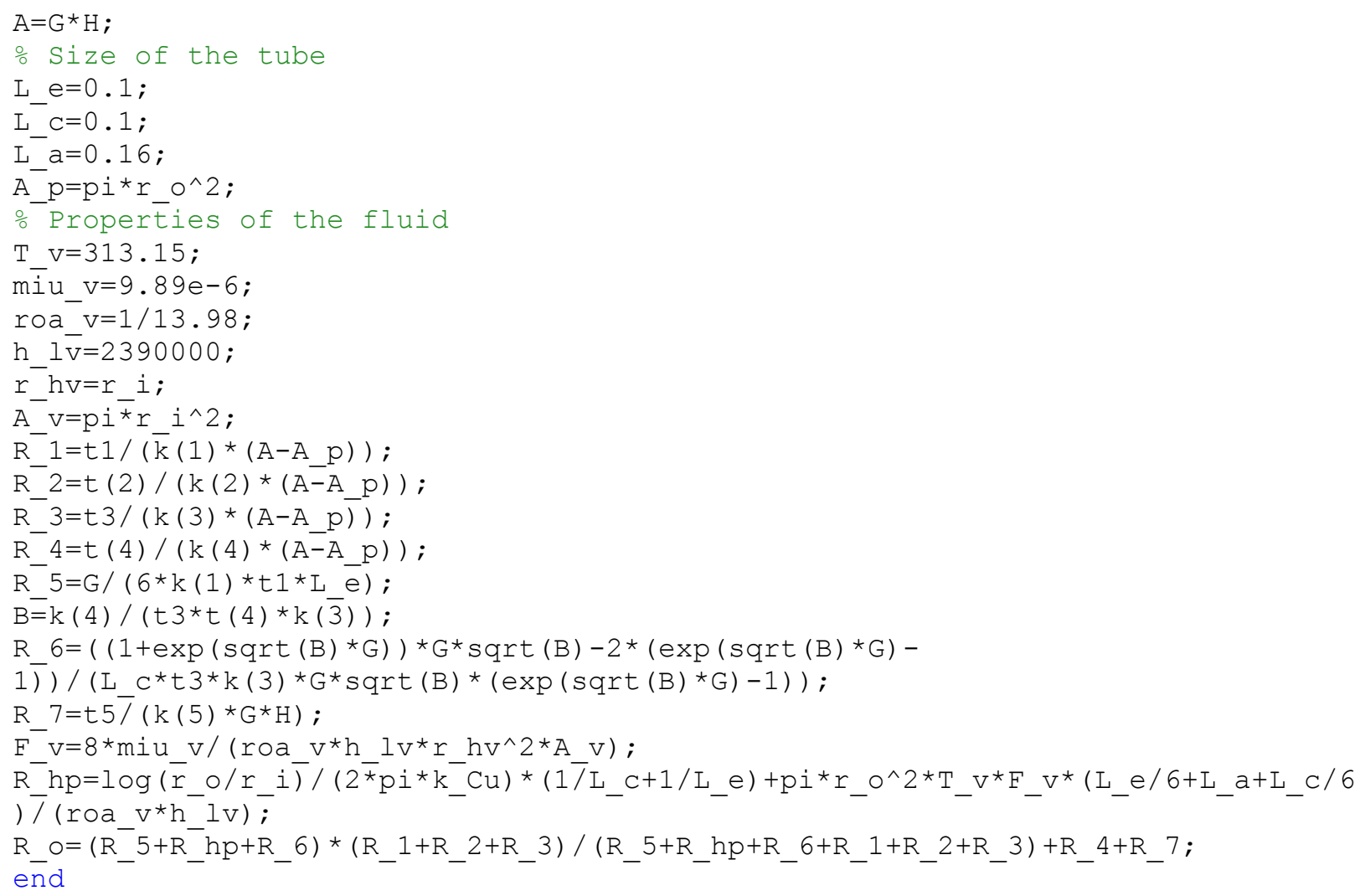

\section{rank.m}

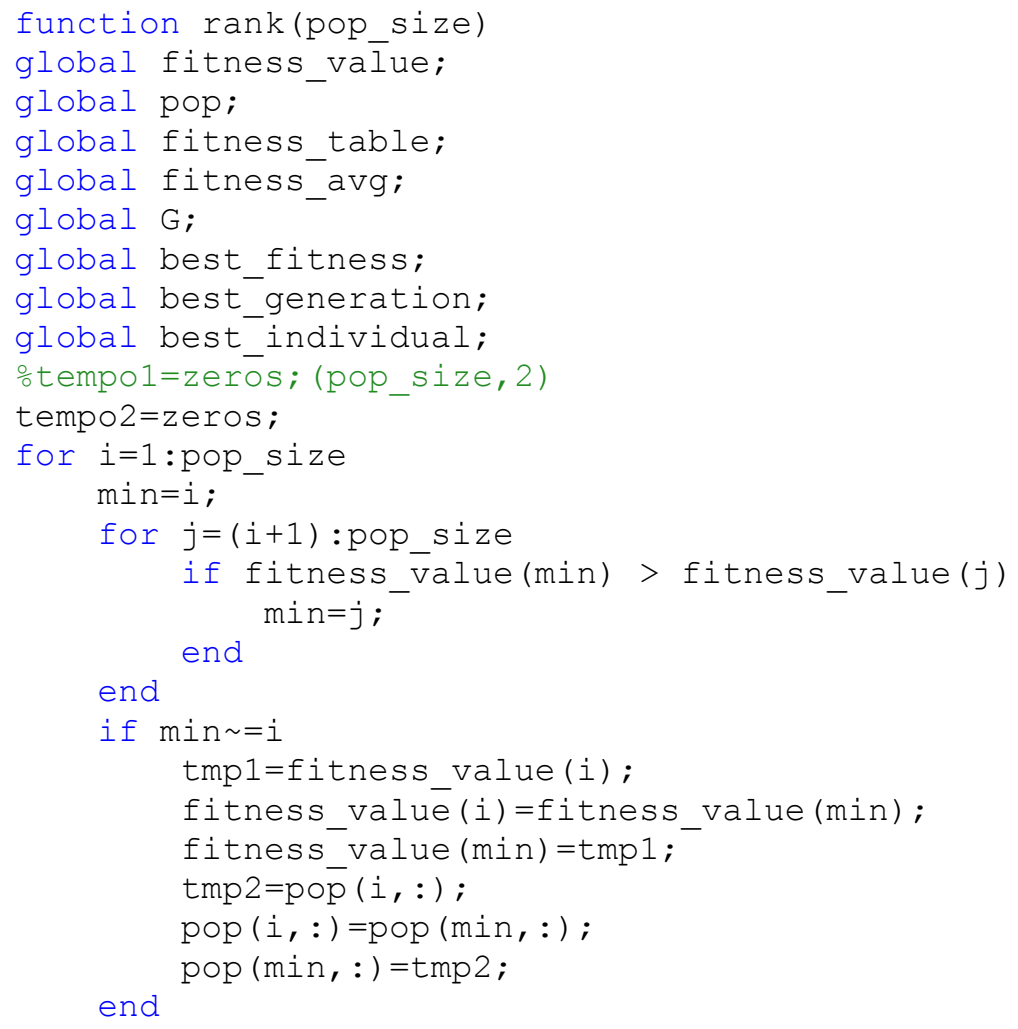




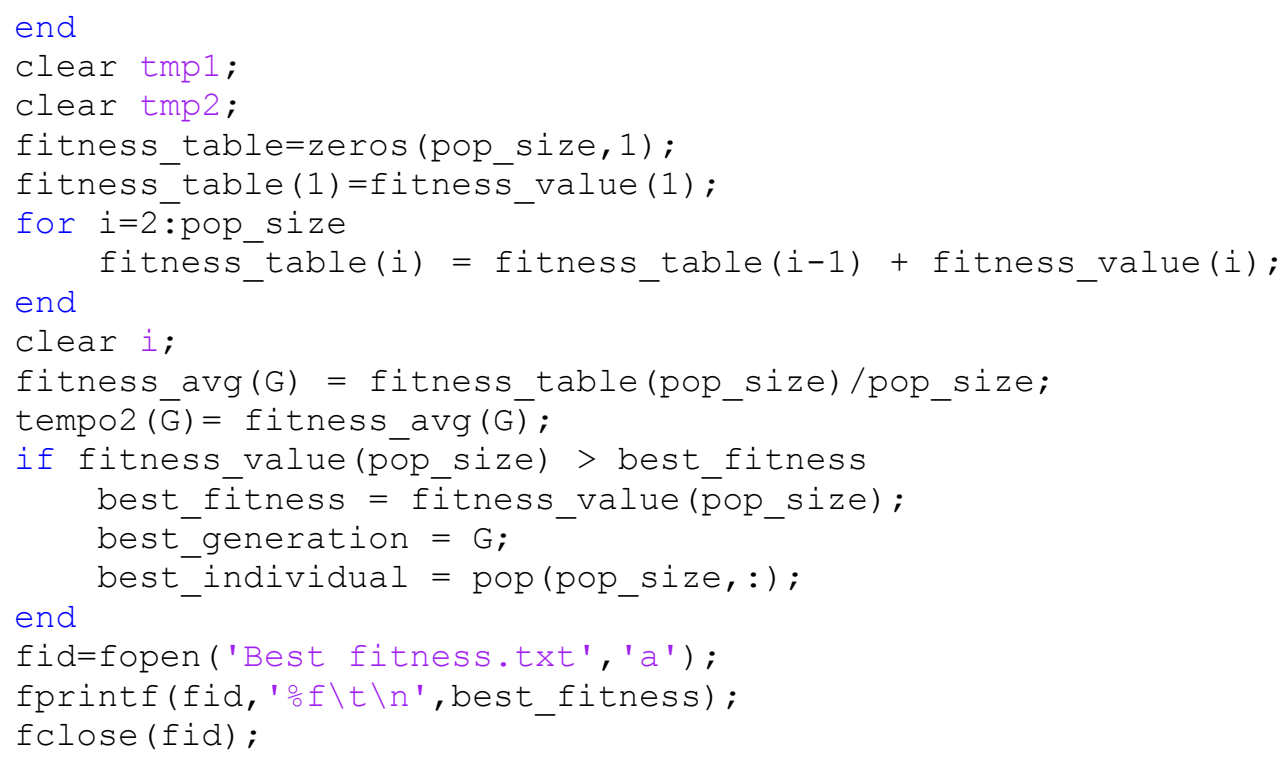

\section{selection.m}

function selection(pop_size, chromo_size) 


\section{Appendix B}

\section{A.1 Supportive figures}

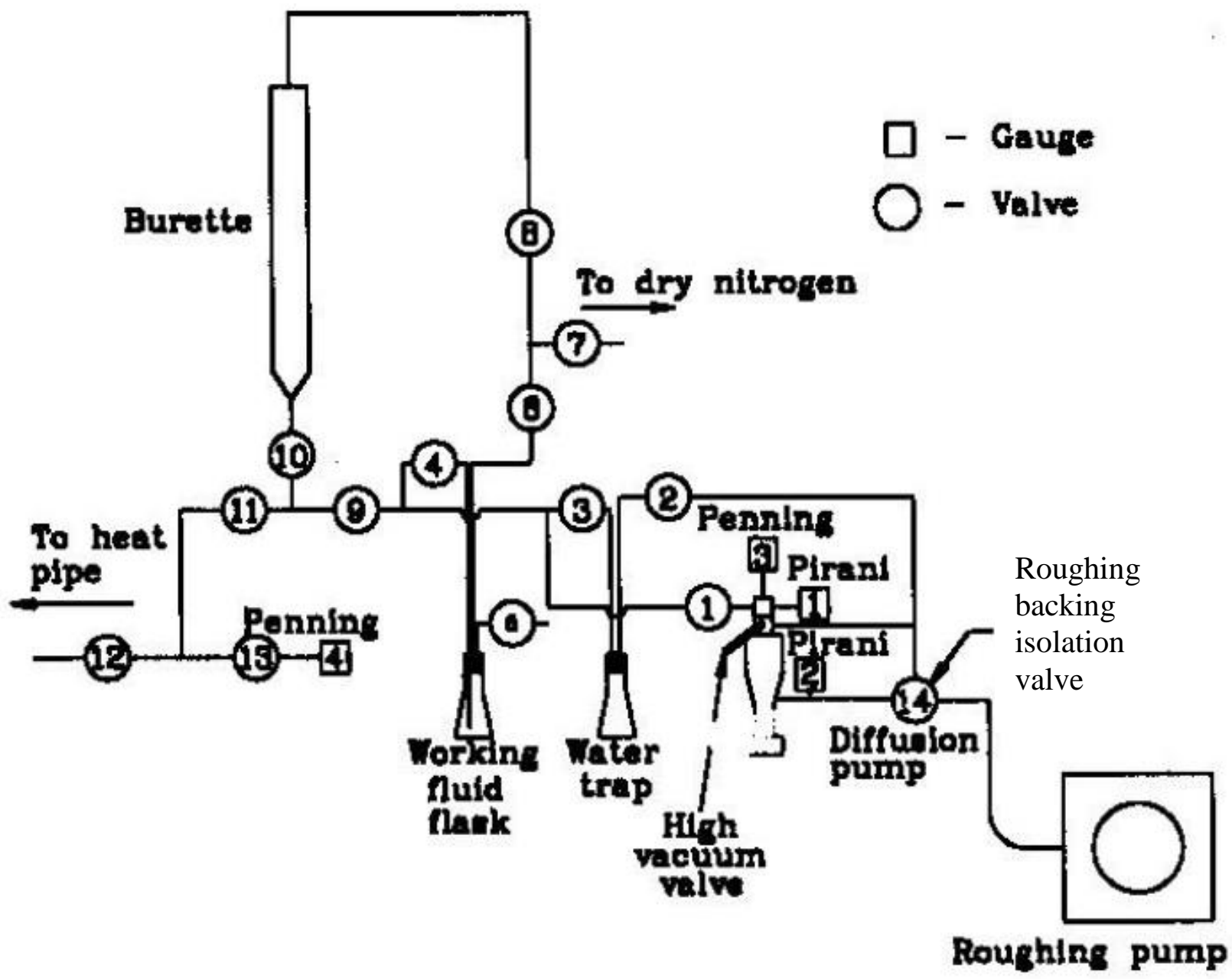

Figure B-1: A low-temperature heat pipe filling rig [28] 


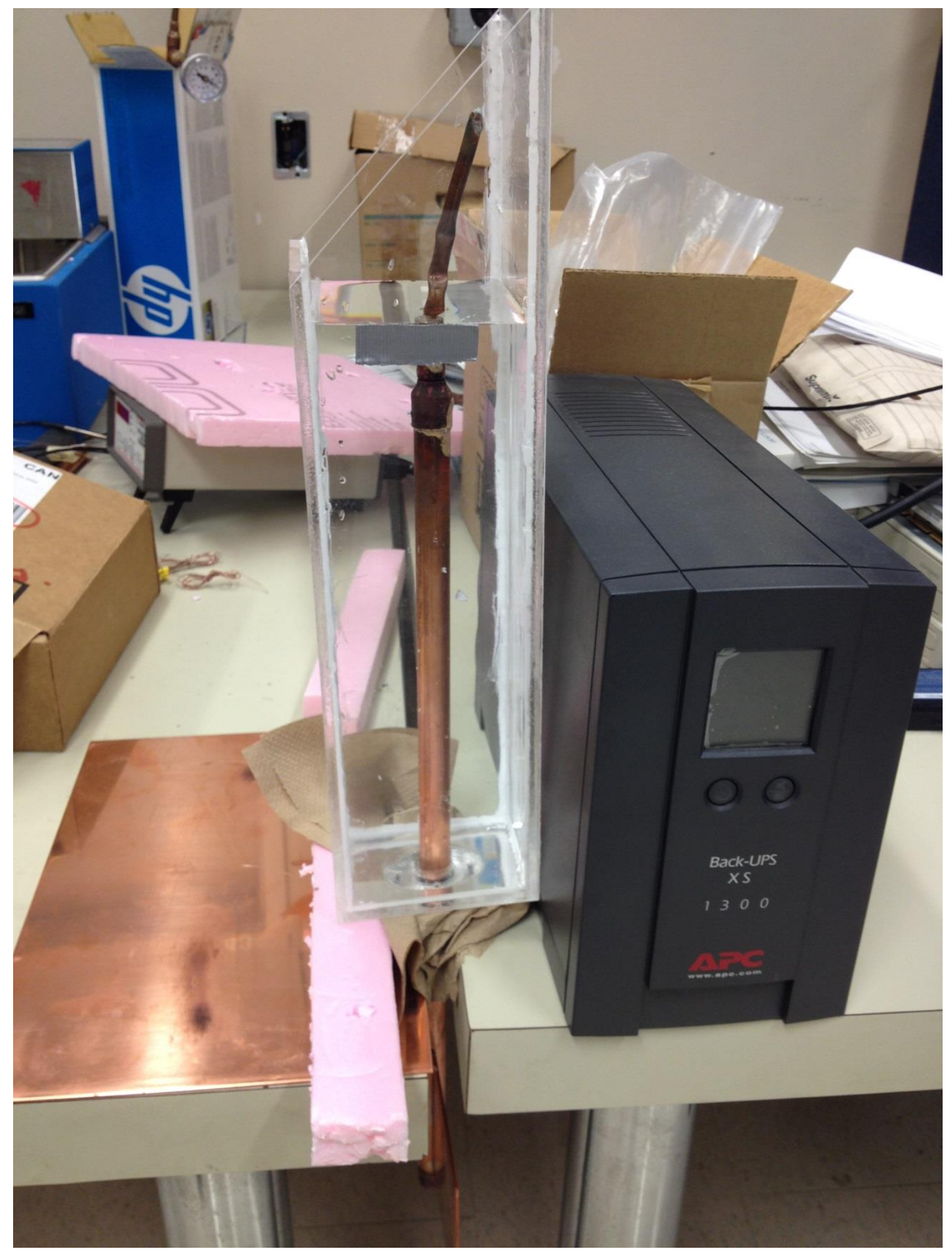

Figure A-2: Leak test of the Plexi glass container 


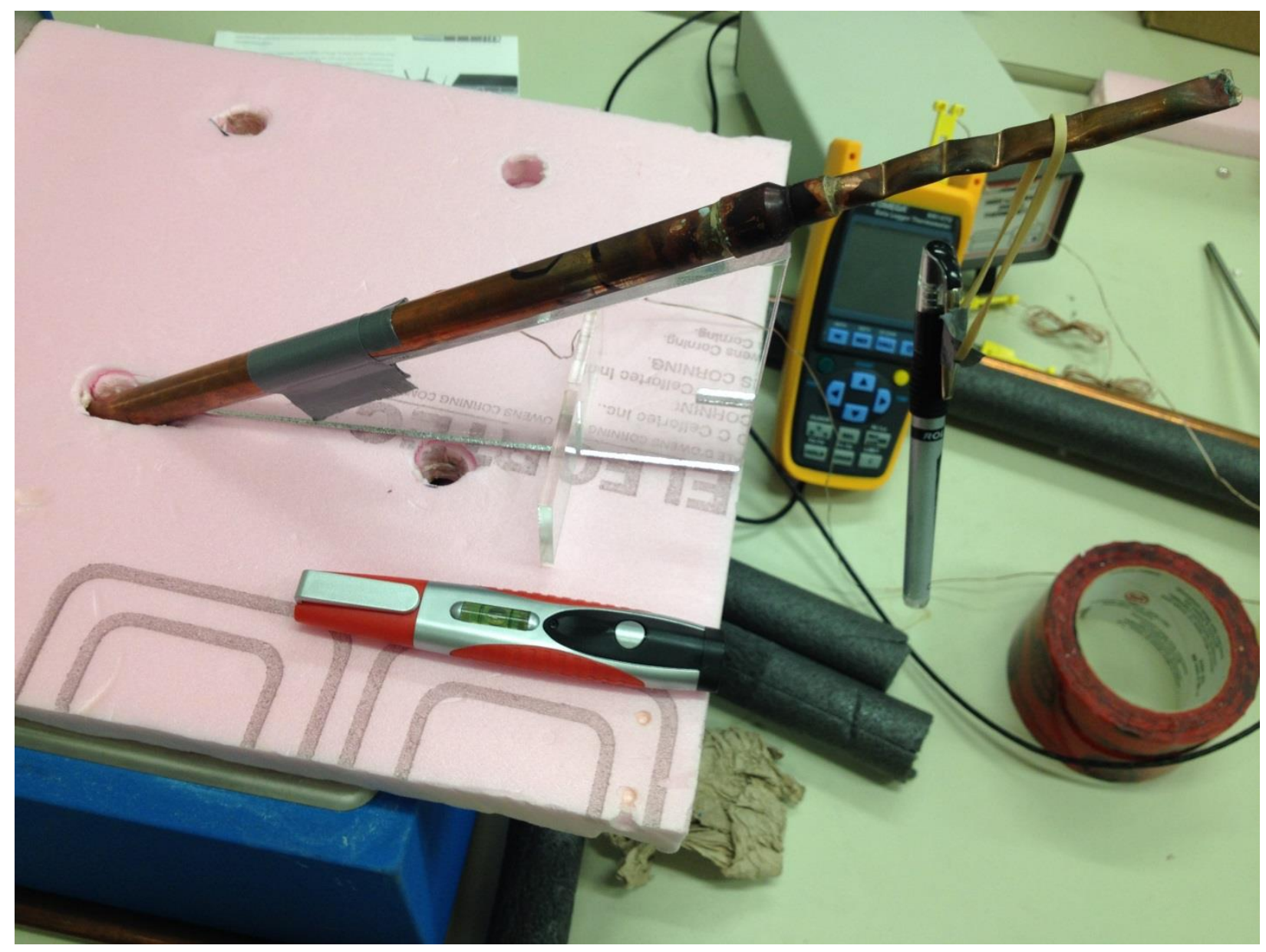

Figure A-3: Testing thermosyphon performance in different angle 

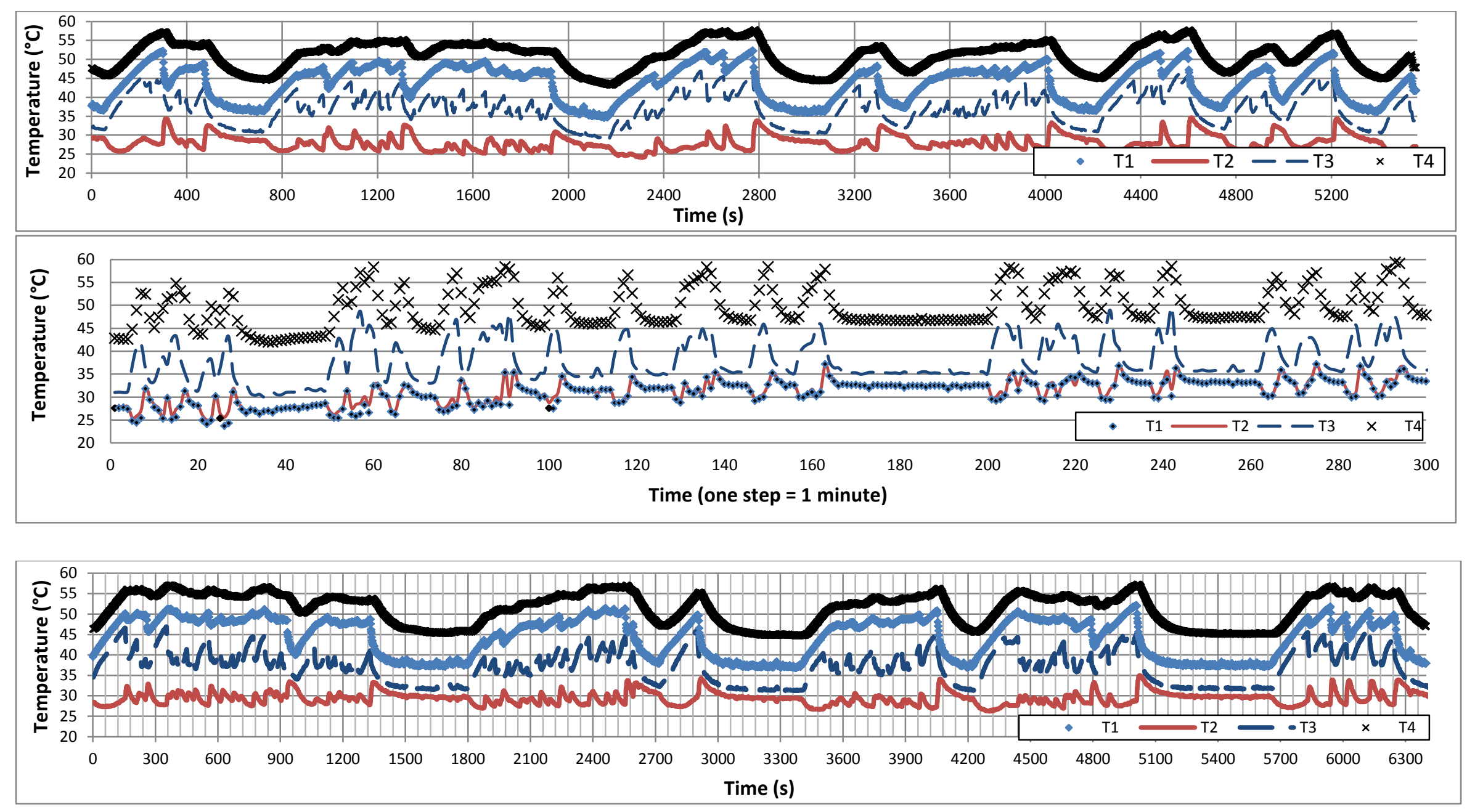

Figure A-4: Testing results at different runs, lower is the $3^{\text {rd }}$ run, middle is the $1^{\text {st }}$ run and upper is the $2^{\text {nd }}$ run $(45$ degree) 

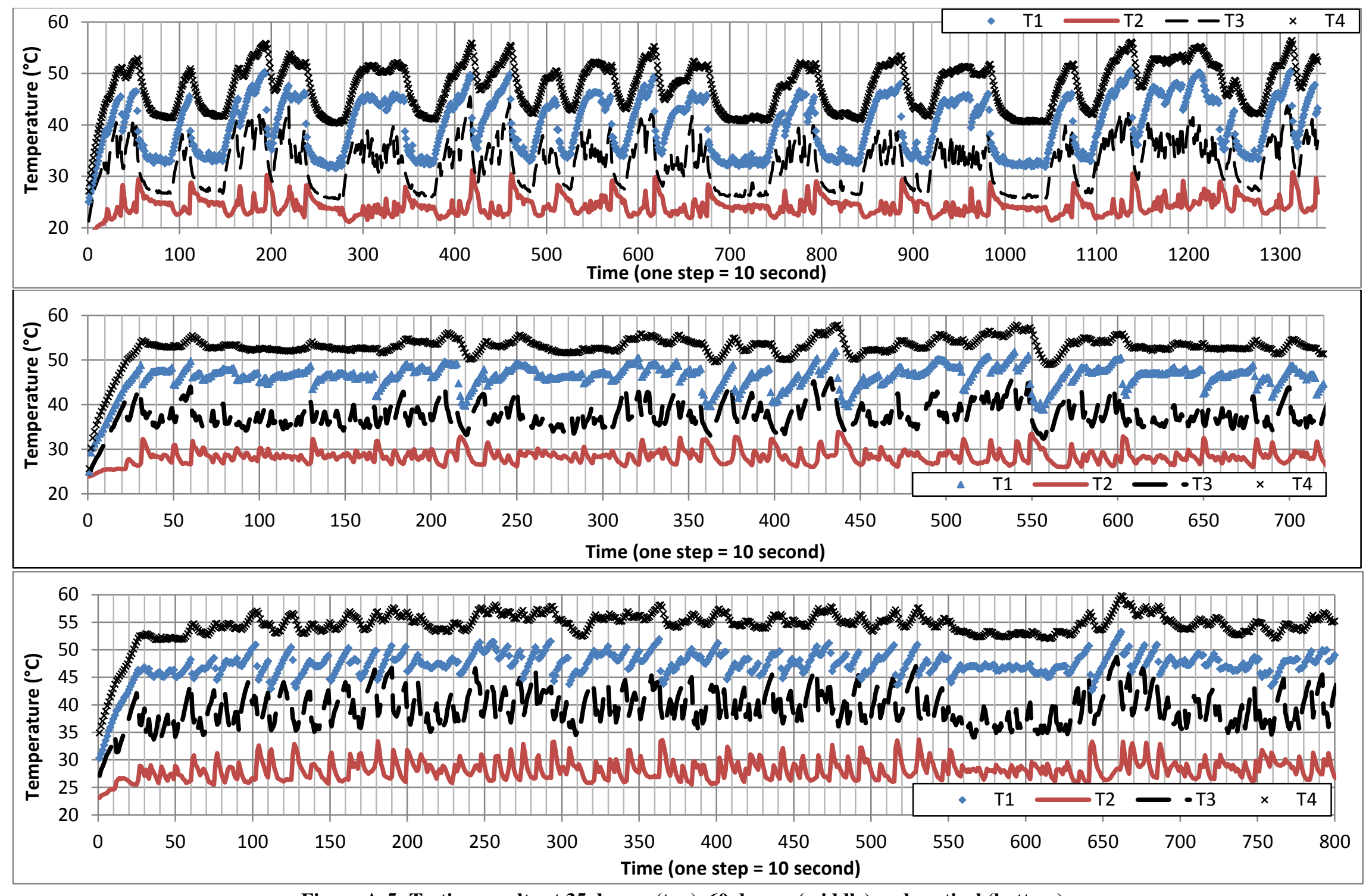

Figure A-5: Testing results at 35 degree (top), 60 degree (middle) and vertical (bottom) 


\section{References}

[1] K. N'Tsoukpoe, H. Liu, N. Le Pierrès and L. Luo, "A review on long-term sorption solar energy storage," Renewable and Sustainable Energy Reviews, p. 13 2385-2396, 2009.

[2] S. Kalogirou and S. Panteliou, "Thermosiphon solar domestic water heating systems: Long temperature performance prediction using Artificial Neural Network," Solar Energy, pp. Vol. 69, No. 2, pp. 163-174, 2000.

[3] A. Athienitis, "Cities in the Sun: The Path Towrds Smart Net-Zero Energy Solar Buildings and Communities," The Partnership Group for Science and Engineering (PAGSE), Montreal, 2012.

[4] M. E. Poulad and A. S. Fung, "Potential benefits from Thermosyphon-PCM (TP) integrated de-sign for buildings applications in Toronto," in eSim Conference, Halifax, NS, 2012.

[5] S. Kalogirou, "Solar thermal collectors and applications," Progress in Energy and Combustion Science, p. 30 231-295, 2004.

[6] L. E. Doman, "Global Energy Use: Status and Trends," in Encyclopedia of Energy, 2004, pp. 3 11-21.

[7] M. Farid, A. Khudhair, A. Razack and S. Al-Hallaj, "A review on phase change energy storage: materials and applications," Energy Conversion and Management, pp. 45 15971615, 2004.

[8] S. Canbazoglu, A. Sahinaslan, A. Ekmekyapar, G. Y. Aksoya and A. F. , "Enhancement of solar thermal energy storage performance using sodium thiosulfate pentahydrate of a conventional solar water-heating system," Energy and Buildings, p. 37 235-242, 2005.

[9] A. Sari, "Thermal reliability test of some fatty acids as PCMs used for solar thermal latent heat storage applications," Energy Conversion and Management, p. 44 2277-2287, 2003.

[10] A. Sharma, V. Tyagi, C. Chen and D. Buddhi, "Review on thermal energy storage with phase change materials and applications," Renewable and Sustainable Energy Reviews , p. 13 318-345, 2009.

[11] P. Oosthuizen and D. Naylor, Introduction to convection heat transfer analysis, McGrawHill, 1999.

[12] S. Sridhar, F. Almeida, D. Zhang and A. Fung, "An Iterative Enthalpy Method to Overcome the Limitations in ESP-r's PCM Solution Algorithm," ASHRAE Transaction, 2011.

[13] A. J. N. Khalifa and R. H. Marshall, "Validation of heat transfer coefficients on interior building surfaces using a real-sized indoor test cell," International Journal of Heat and Mass Transfer, pp. Vol. 33 (10), pp. 2219-2236, 1990.

[14] F. McQuiston, J. Parker and J. Spitler, Heating, Ventilating, and Air Conditioning, Analysis and Design, John Wiley \& Sons, Inc., 2005.

[15] S. Varga, A. O. Oliveira and C. F. Afonso, "Characterization of thermal diode panels for use in the cooling season in buildings," Energy and Buildings, pp. 34, 227-235, 2002.

[16] "Natural Resources Canada," 2009. [Online]. Available: http://oee.nrcan.gc.ca/english/index.cfm. [Accessed 26 July 2011].

[17] W. Chun, Y. Ko, H. Lee, H. Han, J. Kim and K. Chen, "Effects of working fluids on the 
performance of a bi-directional thermodiode for solar energy utilization in buildings," Solar Energy, p. 83 409-419, 2009.

[18] B.-R. Chen, Y.-W. Chang, W.-S. Lee and S.-L. Chen, "Long-term thermal performance of a two-phase thermosyphon solar water heater," Solar Energy, pp. 83 (7), 1048-1055, 1983.

[19] P. Dunn and D. Reay, Heat Pipes, fourth ed., Pergamon, 1994.

[20] M. Esen and H. Esen, "Experimental investigation of a two-phase closed thermosyphon solar water heater," Solar Energy, pp. 79 (5), 459-468, 2005.

[21] S. Tundee, P. Terdtoon, P. Sakulchangsatjatai, R. Singh and A. Akbarzadeh, "Heat extraction from salinity-gradient solar ponds using heat pipe heat exchangers," Solar Energy, pp. 84 (9), 1706-1716, 2010.

[22] H. Imura, Y. Koito, M. Mochizuki and H. Fujimura, " Start-up from the frozen state of twophase thermosyphons," Applied Thermal Engineering , pp. 25 (17-18), 2730-2739, 2005.

[23] N. Roberts and D. Walker, "A Review of Thermal Rectification Observations and Models in Solid Materials," Department of Mechanical Engineering, Vanderbilt University, Nashville, TN, USA, 2013.

[24] D. Sawaki1, W. Kobayashi, Y. Moritomo and I. Terasaki, "Thermal rectification in bulk materials with asymmetric shape," PRESTO, Japan Science and Technology Agency, Saitama, Japan, 2011.

[25] P. Kew, "Investigation into Design and Performance of a Thermal Diode Wall," Europe, 2005.

[26] S. W. Chi, Heat Pipe Theory and Practice, A Sourcebook, Washington: Hemisphere Publishing Co., 1976.

[27] D. Reay and P. Kew, Heat Pipes : Theory, Design and Applications (5th Edition), Jordan Hill, UK: Butterworth-Heinemann, 2006.

[28] A. Faghri, Heat pipe science and technology, Washington: Taylor \& Francis, 1995.

[29] R. Gareta, L. Romeo and A. Gil, "Forecasting of electricity prices with neural networks," Energy Conversion and Management, p. 47:1770-8, 2006.

[30] B. Zohuri, Heat Pipe Design and Technology, Boca Raton, FL: CDC Press, Taylor \& Francis Group, 2011.

[31] M. Bezrodnyi and D. Alekseenko, " Investigation of the critical region of heat and mass transfer in low temperature wickless heat pipes," High Temp., p. 15 309- 313, 1977 .

[32] M. El-Genk and H. Saber, "Determination of operation envelopes for closed two phase thermosyphons," International Journal of Heat and Mass Transfer, pp. 889-903, 1999.

[33] COMSOL, COMSOL Multiphysics User's Guide, Version 4.2 ed., COMSOL AB., 2011.

[34] F. Incropera, D. DeWitt, T. Bergman and A. Lavine, Fundamentals of Heat and Mass transfer, 6th Edition, John Wiley \& Sons, Inc., 2006.

[35] J. D. Bernardin and I. Mudawar, "The Leidenfrost Point: Experimental Study and Assessment of Existing Models," Journal of Heat Transfer, vol. 121, no. Nov., pp. 894-904, 1999.

[36] G. Sarlos and A. Dauriat, "Energy, a challenge for humanity in the 21st century," Shanghai , 2003.

[37] M. Ahmad, A. Bontemps, H. Sallee and D. Quenard, "Thermal testing and numerical 
simulation of a prototype cell using light wallboards coupling vacuum isolation panels and phase change material," Energy and Buildings, vol. 38 , p. 673-681, 2006.

[38] C. A. Whitman, M. Johnson and M. A. White, "Characterization of Thermal Performance of a Solid-Solid Phase Change," Thermochimica Acta, 2011.

[39] D. Zhang, A. Fung and O. Siddiqui, "Numerical Studies of Integrated Concrete with a Solid-Solid Phase Change Material," Calgary, Canada, 2007.

[40] A. M. Borreguero, M. L. Sánchez, J. L. Valverde, M. Carmona and J. F. Rodríguez, "Thermal testing and numerical simulation of gypsum wallboards incorporated with different PCMs content," Applied Energy, 2010.

[41] Y. Konuklu and H. Ö. Paksoy, "Phase Change Material Sandwich Panels for Managing Solar Gain in Buildings," Journal of Solar Energy Engineering, p. 131 (4) 041012 (7 pages), 2009.

[42] T. Kondo, T. Ibamoto and T. Yuuji, Research on thermal storage of PCM wallboard, Japan: Workshop for International Energy Agency, Annex 10, 2000.

[43] A. Athienitis, C. Liu, D. Banu and D. Feldman, " Investigation of the thermal performance of a passive solar test-room with wall latent heat storage," Building and Environment, vol. 32 , p. 405-410, 1997.

[44] N. Zhu, Z. Ma and S. Wang, "Dynamic characteristics and energy performance of buildings using phase change materials: A review," Energy Conversion and Management, pp. 31693181, 2009.

[45] B. Zalba, J. M. Marín, L. F. Cabeza and H. Mehling, "Review on thermal energy storage with phase change: materials, heat transfer analysis and applications," Applied Thermal Engineering, p. 23 251-283, 2003.

[46] R. Panthon, Incompressible Flow, 2nd ed., John Wiley \& Sons, 1996.

[47] M. Ibanez, A. Lazaro, B. Zalba and L. F. Cabeza, "An approach to the simulation of PCMs in building applications using TRNSYS," Applied Thermal Engineering , pp. 25, 1796$1807,2005$.

[48] D. Crawley, J. Hand, M. Kummert and B. Griffith, "Crawley D.B., J.W. Hand, M. Kummert and B.T. Griffith. 2005. Contrasting the capabilities of building energy performance simulation programs," A Joint Report, US DOE,University of Strathelyde UK, University of Wisconsin-Madison USA and National Renewable Eenrgy Laboratory USA, 2005.

[49] K. Peippo, P. Kauranen and P. Lund, "A multicomponent PCM wall optimised for passive solar heating," Energy Buildings, vol. 17, pp. 259-270, 1991.

[50] M. Ibanez and L. Cabeza, "An approach to the simulation of PCMs in building applications using TRNSYS," Barcelona, Spain, 2004.

[51] H. Mehling and L. Cabeza, "Applications for heating and cooling in buildings. D. Mewes and E.H.F. Mayinger," in Heat and cold storage with pcm: an up to date introduction into basics and applications, Berlin, Springer-Verlag Berlin Heidelberg, 2008, p. Chapter 9.

[52] F. Almeida, D. Zhang, A. S. Fung and W. H. Leong, "Investigation of Multilayered PhaseChange-Material Modeling in ESP-R," in International High Performance Buildings Conference, July 12-15, , Purdue, 2010.

[53] M. Moran and H. Shapiro, Fundamentals of Engineering Thermodynamics, 6th ed., John Wiley \& Sons, 2008. 
[54] M. Rahimi, K. Asgary and S. Jesri, "Thermal characteristics of a resurfaced condenser and evaporator closed two-phase thermosyphon," International Communications in Heat and Mass Transfer, p. 37 703-710, 2010.

[55] K. A. Joudi and A. M. Witwit, "Improvements of gravity assisted wickless heat pipes," Energy Conversion \& Management, pp. 41 2041-2061, 2000.

[56] D. Chisholm, J. Goodacre, G. Rattclif, D. Reay and G. Rice, "ESDU No. 81038, Heat pipesperformance of two-phase closed thermosyphons," IHS, 1983.

[57] J. Zhuang, Heat Pipe and Heat Pipe Heat Exchanger, First ed., Shanghai, China: The Press of Jiaotong University, pp. 127-147, 1989.

[58] A. Wright, "Thermosyphons as heat transfer elements in large air pre-heaters," Heat Recovery Systems , pp. Vol. 4, No. 4, pp. 239-245, 1984.

[59] F. P. Incropera and D. P. De Witt, Introduction to Heat Transfer, 4th Ed., New York: John Wiley \& Sons, 2002.

[60] F. Incropera, D. DeWitt, T. Bergman and A. Lavine, Fundamentals of Heat and Mass transfer, 6th ed., Hoboken: John Wiley \& Sons, 2007.

[61] D. Jamet and C. Fouillet, "Direct numerical simulations of nucleat boiling flows of binary mixtures," Avignon, France, 2005.

[62] S. H. Noie, M. R. Sarmasti Emami and M. Khoshnoodi, "Effect of Inclination Angle and Filling Ratio on Thermal Performance of a Two-Phase Closed Thermosyphon under Normal Operating Conditions," Heat Transfer Engineering, vol. 28, no. 4, pp. 365-371, 2007.

[63] S. A. Omar, S. Riffat and M. Xiaoli, "Experimental investigation of a thermoelectric refrigeration system employing a phase change material integrated with thermal diode (thermosyphons)," Applied Thermal Engineering, vol. 21, no. 12, p. 1265-1271, 2001.

[64] S. Riffat, S. Omer and X. Ma, "A novel thermoelectric refrigeration system employing heat pipes and phase change material: an experimental investigation," Renewable Energy, vol. 23, no. 2, p. 313-323, 2001.

[65] X. Ma, Investigation of Novel Thermoelectric Refrigeration Systems, Nottingham: The University of Nottingham, $\mathrm{PhD}$ thesis, 2004.

[66] P. Verma, Varun and S. Singal, "Review of mathematical modeling on latent heat thermal energy storage systems using phase-change material," Renewable and Sustainable Energy Reviews, pp. Vol. 12, pp. 999-1031, 2008.

[67] F. Kuznik, J. Virgone and K. Johannes, "Development and validation of a new TRNSYS type for the simulation of external building walls containing PCM," Energy and Buildings, p. 42 1004-1009, 2010.

[68] O. Siddiqui, A. Fung, H. Tse and D. Zhang, "Modelling of the Net Zero town house in Toronto using TRNSYS, and an analysis of the impact using thermal mass," in Energy Sustainability, Jacksonville, Florida USA, 2008.

[69] P. Lamberg, R. Lehtiniemi and A. Henell, "Numerical and experimental investigation of melting and freezing processes in phase change material storage," Int. J. Thermal Science, pp. Vol 43 , pp. 277-287, 2004.

[70] H. Schranzhofer, P. Puschnig, A. Heinz and W. Streicher, "Validation of a TRNSYS Simulation Model for PCM Energy Storages and PCM Wall Construction Elements," Institute of Thermal Engineering, University of Technology Graz, Graz, Austria, 2006. 
[71] Meteotest, in Global Meteorological Database for Engineers, Planners and Education, Bern, Switzerland., www.meteonorm.com/pages/en/meteonorm.php, 2011.

[72] J. Holland, "Genetic algorithms," Scientific Amarican, p. 66-72, 1992.

[73] L. Gosselin, M. Tye-Gingras and F. Mathieu-Potvin, "Review of utilization of genetic algorithms in heat transfer problems," International Journal of Heat and Mass Transfer, p. 52 2169-2188, 2009.

[74] D. Whitley and T. Starkweather, "Genitor II: a Distributed Genetic Algorithm," Journal of Expt. Theor. Artif. Intell., vol. 2, pp. 198-214, 1990.

[75] H. Hayden, W. Moffatt and J. Wulff, The Structure and Properties of Materials, Volume III, New York: John Wiley \& Sons, 1965, pp. 230-235.

[76] S. Noie, "Heat transfer characteristics of a two-phase closed thermosyphon," Applied Thermal Engineering, vol. 25, p. 495-506, 2005.

[77] Y. Cengel, Heat and Mass Transfer, A Practical Approach, 3rd ed., McGraw-Hill, 2007.

[78] "Comsol," Comsol Multiphysics, 2013. [Online]. Available:

http://www.comsol.fi/model/download/176245/models.cfd.boiling_water.pdf. [Accessed 15 10 2013]. 